University of Louisville

ThinkIR: The University of Louisville's Institutional Repository

Electronic Theses and Dissertations

$12-2014$

\title{
Prompting discussion : writing prompts, habits of mind, and the shape of the writing classroom.
}

\author{
William Matthew Wiles \\ University of Louisville
}

Follow this and additional works at: https://ir.library.louisville.edu/etd

Part of the English Language and Literature Commons

\section{Recommended Citation}

Wiles, William Matthew, "Prompting discussion : writing prompts, habits of mind, and the shape of the writing classroom." (2014). Electronic Theses and Dissertations. Paper 1731.

https://doi.org/10.18297/etd/1731

This Doctoral Dissertation is brought to you for free and open access by ThinkIR: The University of Louisville's Institutional Repository. It has been accepted for inclusion in Electronic Theses and Dissertations by an authorized administrator of ThinkIR: The University of Louisville's Institutional Repository. This title appears here courtesy of the author, who has retained all other copyrights. For more information, please contact thinkir@louisville.edu. 
PROMPTING DISCUSSION: WRITING PROMPTS, HABITS OF MIND, AND THE SHAPE OF THE WRITING CLASSROOM

\author{
By \\ William Matthew Wiles \\ B.A., Murray State University, 2006 \\ M.A., University of Louisville, 2008 \\ A Dissertation \\ Submitted to the Faculty of the \\ College of Arts and Sciences of the University of Louisville \\ In Partial Fulfillment of the Requirements \\ For the Degree of
}

Doctor of Philosophy

Department of English

University of Louisville

Louisville, Kentucky

December 2014 
Copyright 2014 by William Matthew Wiles

All rights reserved 

PROMPTING DISCUSSION: WRITING PROMPTS, HABITS OF MIND, AND THE SHAPE OF THE WRITING CLASSROOM

\section{By}

William Matthew Wiles

B.A., Murray State University, 2006

M.A., University of Louisville, 2008

A Dissertation Approved on

November 5, 2014

by the following Dissertation Committee:

Dr. Bronwyn Williams

Dr. Joanna Wolfe

Dr. Karen Kopelson

Dr. Susan Ryan

Dr. Ann Larson 


\section{DEDICATION}

This thesis is dedicated to my parents, Ruthie and Billy, for their patience, their encouragement, and their love.

"Tell me and I will forget. Show me and I will remember. Involve me and I will understand. Step back and I will act.”

\section{Confucius}




\section{ACKNOWLEDGEMENTS}

I would first like to thank Dr. Joanna Wolfe for helping me push this project from a rough idea to something workable (and even enjoyable). I would also like to thank Dr. Bronwyn Williams for his patience and for his support in helping me see this project through to completion. Thanks are also due to the rest of my committee members-Dr. Karen Kopelson, Dr. Susan Ryan, and Dr. Ann Larson—-for their forbearance and their insights. I must also acknowledge the part that two long-time mentors, Tony Speth and Daniel Hougland, have played in prodding me to complete what they chidingly call "my little term paper." Finally, and most of all, I would like to thank my parents, Ruthie and Billy Wiles, to whom this dissertation is dedicated. They have supported me in more ways I can count, and it means more than I can adequately express here. 


\title{
ABSTRACT \\ PROMPTING DISCUSSION: WRITING PROMPTS, HABITS OF MIND, AND THE SHAPE OF THE WRITING CLASSROOM
}

\author{
William Matthew Wiles
}

November 5, 2014

Much of the important writing students will be tasked with in their college careers calls upon them to approximate the writing styles academics and professionals use to shape and advance their respective fields. Many disciplinary values are encoded within the such texts. Learning these styles can be difficult for students who lack the experience and ingrained habits that their instructors may take for granted. In most cases, college writers are outsiders peeking in from the outskirts of academic and professional discourse. Also, the "Expert Blind Spot" (Ambrose et. al) can make college instructors oblivious to the nuances of the writing styles they take for granted, which can make acquisition of those styles difficult for their students. These factors can lead to students feeling that different courses/disciplines are giving them contradictory lessons in writing, which often leads them to pay more attention to the differences in teachers instead of the differences in disciplinary habits. These conflicts or contradictions in instruction can become "double binds," which are intractable roadblocks caused by the inability to reconcile two contrary commands or signals. 
This project utilizes Genre Theory, Activity Theory, and research in writing across the disciplines to examine conflicts and double binds students face in the disciplinary writing classroom and what role writing prompts play in ameliorating or exacerbating those difficulties. It does so by tracing across four disciplines (philosophy, psychology, nursing, and biology) several common conflicts and double binds encountered at the intersection between ideal academic writing and the realities of the classroom environment (and in the case of one chapter, the complicated boundary between academia, the classroom, and the workplace). This dissertation illuminates common conflicts and double binds inherent in disciplinary writing instruction and makes an argument for effective writing prompt design as an important mediating tool in promoting effective thoughtful student writing. When students know what the rules of the assignment are, they can act more confidently within those boundaries and more easily gain disciplinary awareness and confidence as authors and agents. 


\section{TABLE OF CONTENTS}

PAGE

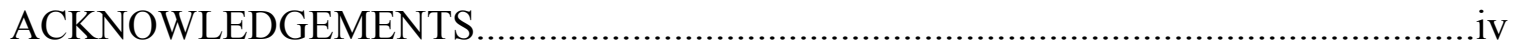

ABSTRACT

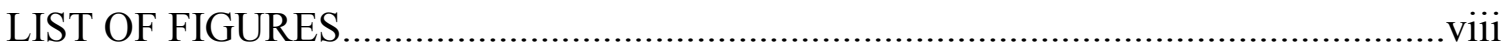

CHAPTER 1: INTRODUCTION ...................................................... 1

CHAPTER 2: DISCOVERING EXPECTATIONS AND DISTRIBUTING

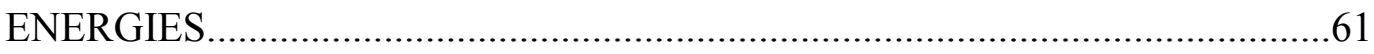

CHAPTER 3: NAVIGATING CONTRADICTIONS AND DOUBLE BINDS..............114

CHAPTER 4: WRITING AT THE BOUNDARY OF SCHOOL AND THE

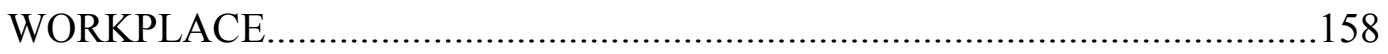

CHAPTER 5: CONCLUSIONS AND IMPLICATIONS FOR PEDAGOGY................201

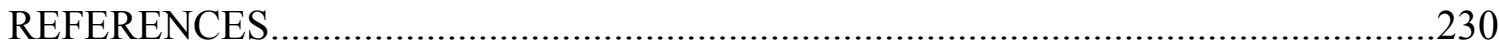

APPENDICES

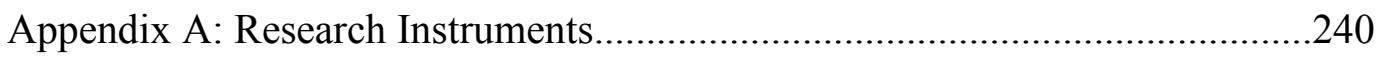

Appendix B: Writing Prompts and Supporting Documents.................................248

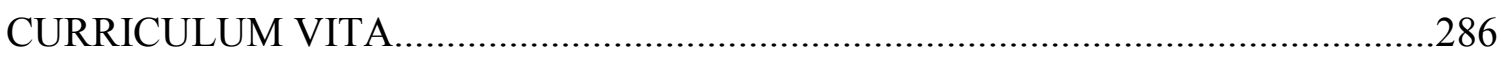




\section{LIST OF FIGURES}

FIGURE $\quad$ PAGE

1. Engeström's Expansion of Vygotsky's Mediational Triangle..........................

2. Two interacting activity systems as minimal model for third generation of Activity

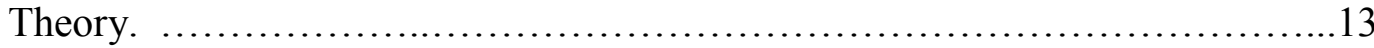

3. Illustration of relation between Activity, Action, and Operation as formulated by

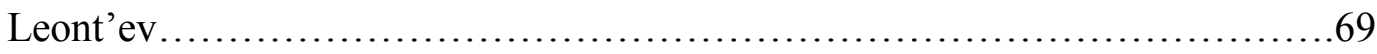

4. Prompt for Final Paper in Biology of the Cell.....................................78

5. Criteria for Evaluating a Scientific Article from Dr. Steiner's Biology of the Cell

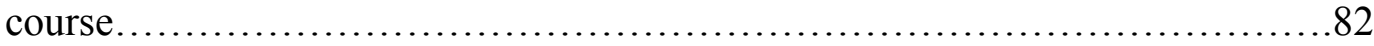

6. Activity System of Dr. Steiner's Biology of the Cell Course.........................83

7. Prescribed Outline provided in Dr. Baker's Multicultural Psychology Assignment

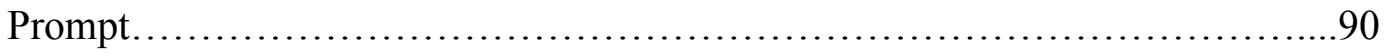

8. Writing Prompts for Dr. Baker's Multicultural Thoughts Assignment......................92

9. Activity System and Double Bind in Psychology........................................................96

10. List of Proscribed Actions and Corresponding Penalties for Dr. Baker's final

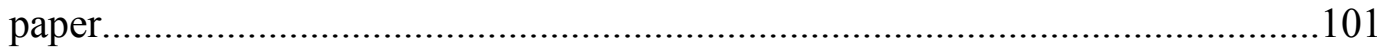

11. Excerpt from Grading Criteria of the EBP Paper.......................................................103

12. Excerpt from Dr. Green's "Tips for Scholarly Writing"............................................104

13. Evaluation Criteria from page 1 of the Term Paper Prompt in Dr. Petersen's Political

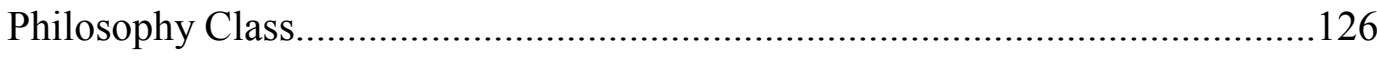


14. Suggested Strategy List from Dr. Petersen's Paper Prompt.

15. Topic Suggestions list from Dr. Petersen's Paper Prompt......................................... 128

16. Sources of Evidence Outline from EBP Paper.......................................................144

17. Diagram of Nursing 471 Activity System...........................................................151

18. Nursing Journal Instructions Condensed by The Researcher...................................171

19. Excerpt on Concision from Nursing Journal guidelines..........................................172

20. Guidelines for EBP Paper Cost-Benefit Analysis.......................................................180

21. Excerpt from a Rhetorical Analysis Prompt created by the Researcher....................212

22. "Strategic Learning Actions and Corresponding Contradictions in the Cycle of

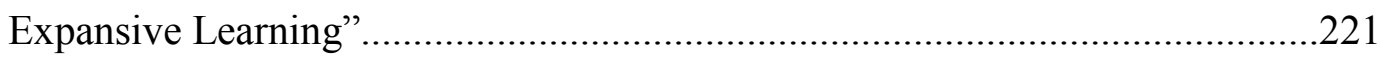




\section{CHAPTER 1 \\ INTRODUCTION}

While grading assignments for a business writing course I taught in the fall of 2012, I came across a student project that I found very puzzling. The assignment was to construct a detailed résumé along with a tightly-written, one-page cover letter targeting a real job that students would be qualified for once they graduated. I knew the particular student in question (a marketing major whom I will refer to here as "James") to be a good student who did not resort to partial efforts on major assignments, and so I was very puzzled as to why his cover letter was immaculately formatted and well-composed while his resume looked almost nothing like what I had expected. The resume did not have many of the parts or details that the prompt prescribed, and in terms of arrangement it looked nothing like the examples we reviewed in class. When I asked James about this, he told me that another teacher of his (a professor in the College of Business, whom I will refer to here as “Dr. B.”) was also assigning a résumé, and Dr. B’s expectations were wildly different from mine.

James explained to me that he was struggling to complete both assignments separately due to time constraints, and since they seemed to have a lot in common he tried to reconcile both résumé philosophies in a single document. Dr. B. and I were, after all, espousing some of the same general principles. One major goal we had in common was composing the resume to maximize quick and efficient readability, although we 
required very different methods of achieving that aim. My assignment required students to include some explanatory detail along with well-proportioned white space to enhance readability. This resulted in a resume of about two pages in length. Dr. B., on the other hand, required James and his classmates to create a very compact and spare resume that could fit well within a single page. James was caught between contradictory instructions that he did not quite know how to reconcile: be detailed but concise, and use white space while simultaneously keeping the resume spare and compact. The result was a product that only sort-of fulfilled the requirements of both instructors.

James' experience reflects an important, but sometimes obscured, reality of the college writing experience: different disciplines have different ways of approaching writing tasks, but many of these differences are masked by deceptive similarities. My general expectations were somewhat compatible with Dr. B's. We wanted our students to produce easily-readable resumes. However, the particular ways in which we wanted to see our students meet those expectations did not mesh well. Since I believed James to be making a good-faith effort in writing this resume, how much could I fault him for trying to assimilate resume-writing knowledge from different classes? One day he would have to make and evaluate a resume on his own as he sought post-college employment. How would he determine which classroom, which lesson, and which example resume was right for him?

There is a certain allure for both students and teachers in the idea of universal standard of "good college writing," which would make the teaching of writing seem more manageable and certain. Students like James could rely on that standard instead of having to ponder which teacher, if either, is correct. This singular standard of writing, 
however, is a mirage that can lead even the best instructors to conflate local conventions with general, universal rules. The diversity of writing in the university makes it simultaneously rich and challenging. Being able to step back and see how and why different disciplines differ in the ways they perceive and practice writing and its instruction can help both students and instructors better navigate the university, but it is easier said than done. For instance, during my meeting with James I endeavored to explain where Dr. B. and I differed in terms of motives and strategies. I explained that I was assigning somewhat of a longer résumé so that students would have a more detailed version to draw from later if they needed to write a shorter, more focused document. Dr. B., meanwhile, was focusing on having students produce a targeted, bare-bones resume that could be read very quickly by busy employers. My attempt to instill some metaawareness in James about how and why Dr. B. and I differed when it came to resume writing felt more like a sheepish apology, since it didn't help to alleviate his position: he was still going to have to produce two different résumés for two different teachers, with both of us espousing similar goals but requiring very different routes to achieve them. It's enough to make a student's head spin.

This was not the first time that I had considered how writing assignments, and in particular the written instructions that accompany them (referred to in this project as "writing prompts," although they can go by other names such as the "instructions," the "assignment handout", "assignment sheet," etc.) play a significant role in how students receive, process, and attempt to meet the expectations of multiple disciplines encountered during the course of a liberal arts education. Writing assignments can provide telling windows into these issues as they can illustrate how teachers are training students to think 
and act as college students and, more particularly, as members of disciplinary and professional communities. However, students engaged in a liberal arts education will find, as James did, that the instructions they receive on seemingly universal writing skills and strategies often won't neatly mesh together. Certain contradictions between writing strategies, as in the case of my résumé assignment and the one assigned by Dr. B., can give students intellectual whiplash as they, like James, try to reconcile instructions that are coming from two different perspectives.

Experts are by definition more experienced in negotiating these conflicts, but students are still learning the rules of the game, as it were. Writing prompts can help coach them through the difficult rhetorical negotiations of a writing assignment, and thus they are important parts of disciplinary writing instruction. However, there can be a tendency to treat them as transparent facilitators of writing assignments, as though they were neutral documents and not highly rhetorical in and of themselves. This buys into the same dangerous myths that can lead local conventions to be posited as universal rules. This dissertation examines the role writing prompts play in mediating the activity of learning to write in different disciplinary genres (like research literature reviews in biology) and in disciplinary classroom settings (i.e., courses within a student's given major). In particular, it uses an Activity Theory and Genre Theory perspectivecontextualized by Writing in the Disciplines research - to identify common conflicts and contradictions encountered by students across disciplines, and it identifies the role that writing prompts play in exacerbating or ameliorating those problems. 


\section{Activity Theory}

Activity Theory examines human activity in terms of systems where subjects' actions are mediated by tools and the influence of a social community. It stems from the work of Russian social psychologist Lev Vygotsky and his efforts to move beyond purely internal (psychological) and purely external (behaviorist) theories of human action (Minick 32-35). The result was the core of a theory that takes into account a variety of internal and external factors such as a subject's internal desires, language and tool use, and external social factors. A basic precept of his theory is that no action is accomplished directly, but rather through the use of an intermediate link in the form of signs and tools like language and writing (Vygotsky 38-54). This mediation, in Vygotsky's view, "transfers the psychological operation to higher and qualitatively new forms and permits humans, by the aid of extrinsic stimuli, to control their behavior from the outside...[it]leads humans to a specific structure of behavior that breaks away from biological development and creates new forms of culturally based psychological process" (Vygotsky 40, emphasis added). These external signs and tools, like speech and writing, embed our activities and the psychological processes underlying them within culture, history, and society. An example pertinent to this dissertation would be how a writing project in a writing classroom is typically mediated by some sort of instructions from the teacher, such as a writing prompt.

Vygotsky's basic model of mediated activity was elaborated further by his colleague A. N. Leontiev, who created a hierarchy of activity and broadened the scope of the theory beyond the actions of an isolated individual. Leontiev drew concrete distinctions between levels of activity. He described an activity as consisting of actions 
(such as writing a paper) and the often-implicit operations (using a pen or keyboard) that underlie those actions (Leontiev 64). In creating this hierarchy of activities, actions, and operations, Leontiev was moving towards establishing activity as "not a reaction or aggregate of reactions, but a system with its own structure, its own internal transformations, and its own development" (46). An activity system, then, is not a haphazard collection of random acts, but rather a hierarchical system that is actively evolving. Finnish social psychologist Yroj Engeström notes that Leontiev's work with Activity Theory (which is often referred to as the second generation of Activity Theory, with Vygotsky representing the first), "brought the focus to collective human action rather than a focus on a single individual, which was a limitation of Vygotsky's initial formulation" ("Expansive Learning at Work" 134). The focus on collective action makes it possible to better analyze an individual's thoughts and actions as part of a social group, with some shared goals and motivations, instead of as an isolated individual.

A helpful illustration of this is Leontiev's example of the hunting party. Vygotsky's initial model of mediated activity helps us understand how an isolated individual might use signs and tools to accomplish a direct goal (such as a person hunting for his or her food), but it does not address how mediation works within an activity system where collective action is needed, such as in a large hunting party. Leontiev's hierarchy of action within a collective system is more apt here, as it can help us understand how the actions of those who serve supporting roles - such as a hunting party's "beaters" who do not kill the game but instead make noise to drive the animals to the hunters - contribute to the collective goal (Leontiev 186-91). In this way, Leontiev made important contributions to our understanding of how collective activities involving 
many people utilize mediated actions: the beater does not directly kill the game, but by using tools such as noisemakers the beater can flush out the animals to support the hunters who pursue and kill the game.

Engeström, in turn, expanded on the work of Leontiev and popularized the use of Activity Theory as a descriptive and analytical model. Engeström defines an activity system as a goal-directed and artifact-mediated system of activity that encompasses many voices and is transformed over the course of time ("Expansive Learnig at Work" 136-7). His attempt to provide a visual reference for the complexity of such a system is represented in Figure 1 below, which is Engeström's expansion of Vygotsky's basic mediational triangle.

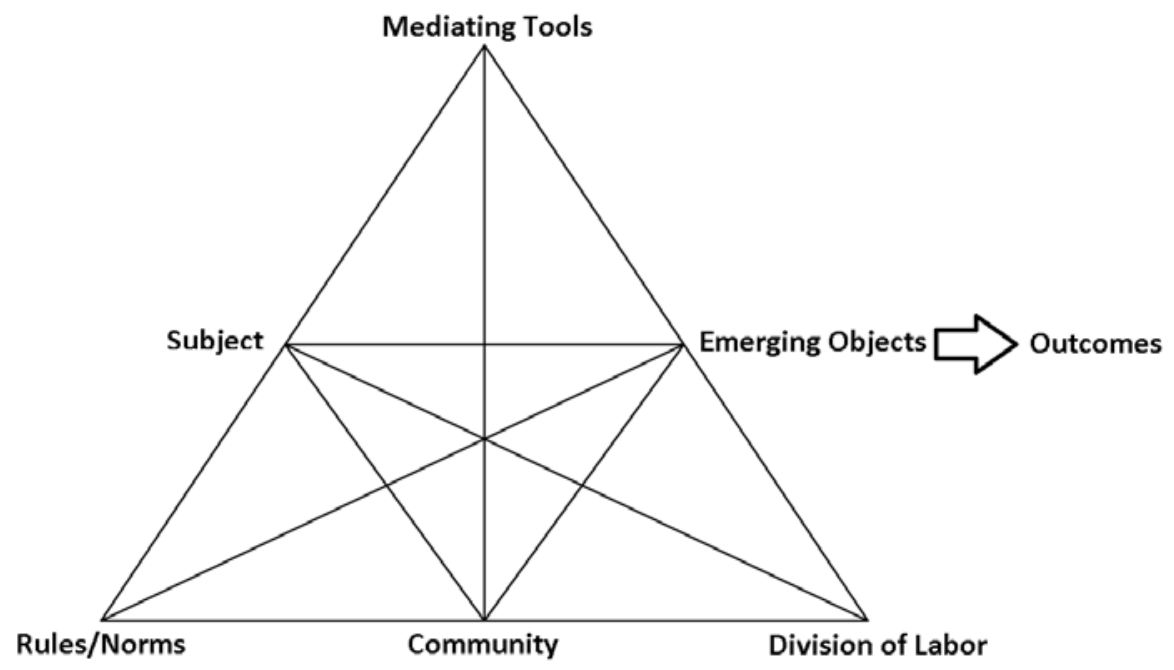

Figure 1. Engeström's Expansion of Vygotsky's mediational triangle; from Engeström, Yrjö. Learning by Expanding: An Activity-Theoretical Approach to Developmental Research. Helsinki: Orienta-Konsultit, 1987. The Laboratory of Comparative Human Cognition, 2012. PDF. 10 February 2014. 
In this formulation, tools refer to both the material and the symbolic cultural artifacts at one's disposal in a particular system. As Cole and Engeström put it, tools "regulate interaction with one's environment and oneself. In this respect they are 'tools' broadly conceived, and the master tool is language" (Cole and Engeström 9). While activity systems are mediated by artifacts, a "tool" within the system can be something as broad as language and our use of it. The lower half of the triangle presented in Figure 1 maps out the social elements affecting the activity system, including social influences such as implicit or explicit community rules, the influence of other community members as actors in the system, and the influence of the division of labor (the social and organizational hierarchy) within that community. Where Vygotsky's basic system only included a subject using a tool to achieve a goal (the upper portion of the triangle), Engeström's attempts to realize in more detail how social conventions play into the mediation of an activity. In this way, Engeström's graphic extension of Vygotsky's and Leontiev's work "provides a conceptual map to the major loci among which human cognition is distributed...[and] it includes other people who must somehow be taken into account simultaneously with the subject as constituents of activity systems" (Cole and Engeström 12). Instead of considering just how an individual goes about an action or an activity, this formulation compels us to consider that person as part of a system involving other people and the social conventions between them.

An important principle of this formulation of an activity system is that it is not intended to create static snapshot of activity. Activity systems are dynamic in that they transform over the course of time, which can make them prone to contradictions, as Engeström explains: 
Contradictions are not the same as problems or conflicts. Contradictions are historically accumulating structural tensions within and between activity systems...Activities are open systems. When an activity system adopts a new element from the outside (for example, a new technology or a new object), it often leads to an aggravated secondary contradiction where some old element (for example, the rules or the division of labor) collides with the new one. Such contradictions generate disturbances and conflicts, but also innovative attempts to change the activity. ("Expansive Learning at Work" 137)

New elements can clash with old ones as a system attempts to adapt and/or expand in reaction to the social influences acting upon it, which often leads to contradictions. What makes Activity Theory dynamic for describing how systems evolve over time is that it does not attempt to gloss over contradictions within the system. They are not anomalies to be disregarded, but they are instead natural and even necessary for growth. According to Cole and Engeström, within every activity system, "equilibrium is an exception and tensions, disturbances, and local innovations are the rule and the engine of change" (Cole and Engeström 8). Conflicts within a system are normal, and indeed they are part of a living system. Contradictions draw attention to conflicts between elements of the system, and attending to these conflicts is necessary for growth. To this end, Engeström and Sannino identify four ways in which contradictions can manifest themselves within an activity system:

(a) as emerging latent primary contradictions within each and any of the nodes of the activity system, (b) as openly manifest secondary contradictions between two or more nodes (e.g., between a new object and an old tool), (c) as tertiary 
contradictions between a newly established mode of activity and remnants of the previous mode of activity, or (d) as external quaternary contradictions between the newly reorganized activity and its neighboring activity systems. (Engeström and Sannino 7)

The "nodes" mentioned in the above quotation refer to any of the labeled points on the triangle presented in Figure 1, and the contradictions enumerated in the passage above refer to conflicts within and between those nodes. Engeström notes that, when contradictions are identified and dealt with, activity systems go through cycles of growth via expansive transformation. He writes that an "expansive transformation is accomplished when the object and motive of the activity are re-conceptualized to embrace a radically wider horizon of possibilities than in the previous mode of the activity ("Learning by Expanding in the Workplace" 137). When internal contradictions are exposed and resolved, then the system can benefit and expand thanks to a revised understanding its capabilities and its limitations. The resolution of internal contradictions is provided by "the appropriation of advanced models and tools" (Cole and Engeström 40) which require a systemic, reflective, and group-centered re-mediation of the system. For example, if computers are introduced in an office environment to streamline filing work, contradictions will occur naturally occur between the old, paper-centered ways of doing things and the radically new, computer-centered approaches to documentation and filing. Resolving these conflicts between nodes in the system requires systemic, group reflection on the uses and limitations of the tools available, and it allows for a better understanding of the system in general and of the role computers can now play in that system in particular. 
Of course, particularly difficult contradictions that stymie development can arise when there is no apparent solution or opportunity to achieve an expanded understanding of what is going on within the system. Appropriating a term from psychologist Gregory Batesman, Engeström identifies a kind of intractable contradiction called a "double bind." Engeström writes that "In double bind situations, the individual, involved in an intense relationship, receives two messages or commands which deny each other-and the individual is unable to comment on the messages, i.e., he cannot make a metacommunicative statement." (Learning by Expanding). A double bind is a kind of psychological no-win scenario. It is a "damned if you do and damned if you don't" situation in which the options apparent to the subject are equally logical and compelling yet are also strongly contradictory.

To return to the example of the business writing student James that opened this chapter, my rationale for the type of resume I was assigning could have seemed just as logical and insightful as the one Dr. B. (the teacher in the school of business) provided for James and his classmates. In attempting to merge the activities, however, James encountered a double bind where he could not reconcile the contradictory instructions or gain the insight necessary to take a step back and develop meta-awareness of the root causes of the problem. Of course, situations like the one James encountered do not happen all at once. Drawing from psychologist Paul F. Dell, Engeström observes that a double bind is something that gradually grows. Dell writes that the double bind "resides in the 'interaction-over-time' by which 'important basic relationships are chronically subjected to invalidation through paradoxical interaction" (Learning by Expanding). In other words, James did not enter an intractable state of confusion all at once. Rather, the 
double bind grew over the course of time as he was given different instructions, different models, and different types of instructional support for what appeared to be the same writing task. The result of these differences created tensions that grew into a seeminglyintractable double bind.

This does not mean that individuals experiencing double binds are caught in a stalemate in which there is no option but to give up. Rather, as in James' case, attempts at innovation are made by the subject to try to muddle through. Sometimes these local innovations flounder and fail, but other times they can have profound effects. As Elizabeth Wardle observes in her Activity-Theory analysis of contradictions experienced by composition instructors, "one individual's inventive resolution may push the activity system toward systemic, group re-mediation" ("Can Cross-Disciplinary Links Help us Teach “Academic Discourse' in FYC?”). However, in a situation like James’ a student may feel that he/she has little enough power to effect change on his/her own. This means, as Wardle contends, that openly identifying contradictions and double binds and pursuing group re-mediation — a re-defining of the use of tools within the community—is a crucial step in alleviating the frustration of subjects within a conflicted system ("CrossDisciplinary Links"). In his 2001 article "Learning by Expanding at Work," Engeström proposes a cyclical model for expansion in which the contradiction is questioned, the system is analyzed, and new models are created, tested, and reflected upon before they are consolidated into new practice (152). In 2010, Engeström and Sannino acknowledged that technological advances and their large-scale use are making the life cycle of objects and systems considerably shorter and more intense, underscoring the need for theories and models that, like Activity Theory, are aimed at expanding our understanding of 
subjects and their tools as part of collective activity systems and not just isolated individuals using technology to supplement or replace isolated tasks.

Activity Theory has been applied to education and workplace settings where new elements (like computers and technology) are incorporated into activity systems and/or where expansive transformation is necessary to address a new problem. Engeström's development of a third generation of Activity Theory has set the theory's trajectory towards further incorporating the heterogeneity of systems as they come into contact with each other. Figure 2 below is one such illustration by Engeström, and it shows two systems that share emerging objects that interact or overlap.

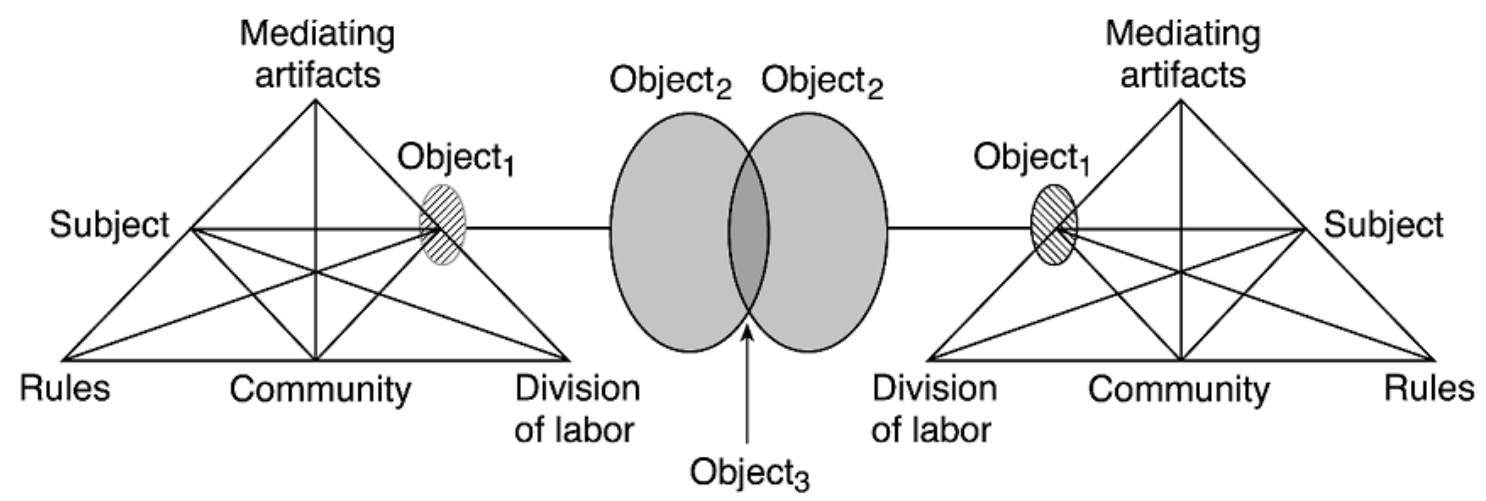

Figure 2. Two interacting activity systems as minimal model for third generation of Activity Theory. From Engeström, Yrjö. "Expansive Learning at Work: Toward an Activity Theoretical Reconceptualization.” Journal of Education and Work 14.1 (2001):

\section{3-156. PDF.}

The third generation of the theory has run into criticism in that the objects (the goals or results) are becoming too large (e.g., observing global warming) to contain within specific cases where they can be qualitatively investigated and out understanding of them appreciably expanded (Spinuzzi, "Losing by Expanding”). This basic model 
(presented in Figure 2), however, is an apt illustration for the situation that James felt he was in: where two classroom activity systems interacted for the production of a similar emerging object, an effective resume. The difficulties James encountered were due to some important differences in the activity systems, namely the departmental and disciplinary differences of the two courses that required him to produce resumes. While Activity Theory helps us contextualize James' case and those of other students within a descriptive framework, it is incomplete without a consideration of the tools that make such activities possible: writing genres. The next section will show how Activity Theory along with Genre Theory can be applied to a Writing in the Disciplines context to better understand how students within liberal arts curriculums are forced to juggle many different (and sometimes contradictory) approaches to writing. As this section will detail, contradictions between elements of a classroom's writing instruction, whether potential or full-blown, can impair student ability to perform to a teacher's expectations. Identifying and discussing ways to ameliorate these hurdles will be a central part of this dissertation.

\section{Activity Theory, Genre Theory, and Writing in the Disciplines}

A synthesis of Activity Theory, Genre Theory, and Writing in the Disciplines (WID) can help us better articulate the struggles experienced by James and other students as the inherent difficulties of trying to write within and between different disciplinary activity systems. Each system has its own sets of operationalized genres, and all are set within an overall university environment that can exacerbate the difficulty of managing multiple activity systems by buying in to powerful myths about the nature of writing and 
disciplinary writing instruction. Many teachers buy into the myth that one or two semesters of college English will be sufficient for preparing students to write in any course and in any discipline. The reality, for students, can be one of frustrations, contradictions, and double binds that from the difficulties that they (like James) face in negotiating a tangle of different writing techniques that vary from department to department and even from class to class. Learning disciplinary writing styles can be a hard thing for students who lack the situated learning experiences that can effectively socialize them into their respective disciplinary activity systems. In most cases, college writers are outsiders peeking in from the outskirts of academic and professional discourse. Additionally, students encounter many disciplinary styles across the curriculum yet delve deeply into only a few, which can cause a kind of intense intellectual whiplash. This incites two related questions: what are some of these problems and how can we help ameliorate the negative effects they may have on the development of student writers? This section will unpack genre theory and research in WID to better articulate these questions and move towards a frame that can help address them. The work of David Russell in particular has been helpful in synthesizing Genre Theory, Activity Theory, and WAC/WID studies to provide a lens through which we can highlight and address these issues.

Genre Theory: Locating genre within an activity system may seem either deceptively simple or frustratingly complex. Does Activity Theory fit within Genre Theory or vice versa? An overly-simplistic way to resolve these two theories would be to locate genre as either the object or as a simple tool within an activity system (see Figures 1 and 2). 
Producing certain genres is indeed often the goal of an activity, particularly within the university, and genres do act as both material and conceptual tools mediating activity. There is a pitfall here, however, in that following this line of thought can lead to buying in to the Aristotelian view of genre as a closed and discrete textual artifact. Carolyn Miller's seminal "Genre as Social Action" is credited with expanding our notion of genre beyond the previous, Aristotelian limits by defining genres as “"'typified rhetorical actions based in recurrent situations" (151). Recurring social situations promote the development of a characteristic response, and instead of being a by-product of that response Miller posits that genre is the response (163). A finished text is not the genre itself but rather a performance of it. In this way, genres, as John Swales describes them, "mediate between social situations and the texts that respond strategically to the exigencies of those situations ("Worlds of Genre" 14). The dialogic exchange between social situations and the texts that respond to them can be understood as genre. This understanding of genre allows us to more productively view genres and the writers that use them as engaged in what Amy Devitt characterizes as a reciprocal relationship between what the situation calls for and what the genre allows/enables us to do (Writing Genres 23). Genre is not an enclosed, isolated "thing," but a performance, a negotiation, and/or mediation between author and audience. Within this more dynamic understanding of genre, writing genres are not stable entities. Catherine Schryer describes them as being at best "stabilized-for-now or stabilized-enough sites of social and ideological action" ("Records as Genre" 204). Genres are always changing in relation to the conditions under which they are being produced. 
This expanded understanding of genre as unbounded from the surface textual features can make synthesizing Genre Theory and Activity Theory difficult since both seem to accomplish similar things: they help us to see activities/genres as ever-shifting dialogues between social exigencies and the objects (texts, social exchanges, etc.) those activities/genres enable or require us to create as responses. Both are also concerned about how history has shaped these responses. Genre, like an activity system, is also always in flux. Charles Bazerman observes that "Each new text produced within a genre reinforces or remolds some aspect of the genre; each reading of a text reshapes the social understanding. The genre does not exist apart from its history, and that history continues with each new text invoking the genre" (Shaping Written Knowledge 8). Each writer of a genre is reinventing or remaking it in big or small ways, because there is no real ideal form (in a Platonic sense) of a writing genre. Genres are always changing and evolving, so how can their workings be resolved with eternally stable definitions or schema? Again we come to the question: is Activity part of Genre or vice versa?

The work of David Russell has been very helpful in resolving Genre Theory with Activity Theory in such a way that one does not subsume the other nor obviate the need for the other. In "Rethinking Genre in School and Society," Russell synthesizes genre with Activity Theory by describing genres as "operationalized social action" (516). Genre provides us a way to talk about the routine and often-implicit ways in which tools, like writing, are used within activity systems. As Russell puts it:

Genres are ways of recognizing and predicting how certain tools..., in certain typified--typical, reoccurring--conditions, may be used to help participants act together purposefully...genres and the activity systems they operationalized 
(temporarily) are regularized or stabilized through routinized tool use within and among (sub) groups. ("Rethinking Genre in School and Society" 513)

If we were to locate genre in the Activity Theory scheme originating from Vygotsky and expanded by Leontiev and Engeström (see Figure 1), we could point to the "tools" node, but it is more than just a simple artifact. Genre encompasses the typified and recurring use of writing as a tool to accomplish a social end. Russell also posits that genre helps us articulate how activity systems are both stable and dynamic as the dialogue between situation and tool use is negotiated and re-negotiated in each instance (516). In this way, Activity Theory can help us understand how writing genres act as mediating tools within a social/cultural system, and genre helps us understand the constant dialectic between action and exigency that drives an activity system.

Genre theorists like Amy Devitt and Anis Bawarshi have stressed the ways in which genre analysis, as a pedagogical tool, can help empower student writers by building awareness of the dynamic and often-subtle interplay between the rhetorical situation and the tools offered by writing genres. For Devitt, "Genre awareness can teach students to seek the rhetorical nature of genre, to understand its context and functions for its user, in order to avoid formulaic copying of a model..." (Writing Genres 201). For Bawarshi, genre analysis can help FYC students prepare for learning how to write in their disciplines, since genres "serve as the 'passports' for accessing, analyzing, navigating, and participating in...disciplinary structures" (155). The empowering nature of genre awareness is demonstrated in genre analyses, which have evidenced deep insight into the social and rhetorical functions of many seemingly-straightforward genres. Such analyses include Devitt's analysis of the genres used by tax accountants (in Writing Genres) and 
jury instructions (in "Materiality and Genre"). In the latter analysis—which forms the first of three analyses in an article co-authored by Deivtt, Anis Bawarshi, and Mary Jo Reiff—Devitt analyzes jury instructions as a genre that mediates interactions between specialists (lawyers and judges) and non-specialists (jurors). She finds in her analysis that such instructions end up working more for members of the legal community than for nonmembers (typical jurors) since "the complexity of the law, the technical nature of its precedents, and, in short, the embeddedness of the genre in its community make it impossible for nonspecialists to understand fully as a specialist would, not matter how well-written, detailed, or rhetorically sophisticated the jury instructions" ("Materiality and Genre" 547). Her analysis of this particular example underscores the universal difficulty of bringing neophytes into a specialist community and expecting them to intelligently and conscientiously utilize the same genres as specialists in the same ways. A similar challenge is faced by university instructors who are charged with ushering students into the genres, and thus the ways of thinking, of the academic disciplines. It is a process fraught with difficulties and subject to complex contradictions of motives. As Devitt observes:

The communal agendas of those who create genres may conflict with the interests of those who use them — users who would ideally reproduce the ideologies and agendas of the legal community, but who do not. To say that the genre of jury instructions — and other similar genres—-simply cross community borders is to simplify the complex interaction of individuals and groups, motives and agendas, and to ignore the conflicting consequences of one genre serving different groups. ("Materiality and Genre" 549) 
Genre theory and genre analysis shows us the dynamism and the messiness of genre; they are not easily bound by pat definitions. To assume that writing genres are transparent texts ignores their rhetorical power, and it discounts the complex interactions of human agents utilizing those genres. Genre analysis can be a powerful tool, but its heuristics are very open and sometimes abstract. Activity Theory, with its hierarchies of activity and the mediational triangle (Figure 1), provides a more concrete analytical frame for genre analysis. This combination provides a helpful tool for analyzing disciplinary writing environments at the college level. In this environment, writing is an important tool with typical, recurring usages and exigencies, although interdisciplinary research on writing and writing instruction has revealed how the differences in how writing is used across disciplines and departments are often obscured by some powerful myths about writing in the university.

WID and the Myths of Transience and Transparency: Writing in the Disciplines (WID) is regarded as a spin-off from Writing Across the Curriculum (WAC). The central mission of the WAC movement is to promote the use of writing as a tool for learning and reflection across the university (not just for English and composition courses). This means incorporating more writing assignments and/or incorporating different types of assignments (such as reflective narratives or other, creative assignments) that can help students integrate subject matter knowledge in new and engaging ways. Consequently, this model of WAC is referred to as "writing to learn." Writing in the Disciplines (WID) grew out of the WAC movement, and it can be broadly defined as having two central objectives: one based on research and the other based on pedagogy. First, WID entails 
the study of specialized academic writing styles, including what defines them and distinguishes them from other styles, how these styles operate as forms of knowledge making, and how they relate to the social practices of "doing" within an academic community. Second, WID promotes the open dissemination of this information to students as they learn to write within their disciplines. Thus, the mission of WID is often characterized as "learning to write," and it is often erroneously set in contrast to WAC's "writing to learn" mission.

Knowledge work in academia depends on writing, and the missions of WAC and WID encourage the teaching of writing across disciplines both to use writing as a form of meaningfully learning disciplinary content and as a way of bringing students in to the central knowledge work of the disciplines. Both of these goals are predicated on the firm belief that academic writing genres are not just the physical end-product of creating new knowledge; they also act as what Michael Carter calls frames for knowing and doing within those disciplines (214-5). Consequently, the process of learning a disciplinary genre is more than just learning the formal features of an academic text. It requires students to learn, internalize, and apply an awareness of the social situation that shapes disciplinary writing. The problem for students is one of the variety of social situations and the genres that respond to them.

In Disciplinary Discourses, Ken Hyland observes that writers within a given disciplinary community do not necessarily have to agree with one another, but they do need to work in agreed-upon ways for the creation of new knowledge to be possible (11). Furthermore, he points out that, despite their similarities, it is the differences between these agreed-upon methods that distinguish one discipline from another: 
While all academic discourse is distinguished by certain common practices, such as acknowledging sources, rigorous testing, intellectual honesty, and so on, there are differences which are more likely to be more significant than such broad similarities. The ways that writers chose to represent themselves, their readers and their world, how they seek to advance knowledge, how they maintain the authority of their discipline and the processes whereby they establish what is to be accepted as substantial truth, a useful contradiction and a valid argument are all culturally influenced practical actions and matters for community agreement. (11, emphasis mine)

There are two important implications of Hyland's statement here. First, the surface features of academic texts are like the tip of the iceberg protruding from the water's surface, but beneath them is a vast body of culturally-influenced conventions that dictate what it is to act and be recognized as a member of a particular disciplinary community. Second, all academic disciplines do share some common practices, but college writing may be more productively defined by how it encompasses a variety of writing styles rather than as a consistent, singular whole. Like the subject in the Burkean parlor, students entering a discipline must do their best to figure out these rules-both explicit and tacit - in a conversation that began long before he/she arrived so that they can make an intelligent and meaningful contribution. The challenge presented by this task is compounded during the course of a liberal arts education in which students find themselves visiting multiple parlors and multiple conversations. They may only encounter the tip of the iceberg in one discipline, and from the water's surface one 
iceberg may look quite like another, while the bulk of the distinguishing features of that disciplinary writing style are obscured beneath the water.

Students are not left to plumb these depths alone. Teachers in the disciplines are guides through these difficult waters, such as when a science teacher coaches students in performing lab experiments and in reporting the results. However, there are some powerful myths at work in many college courses that tend to emphasize similarity over difference when defining "college writing." As a consequence, many students still struggle more than is necessary as they try to acquire and understand the knowledgecreating writing practices in their prospective fields of study.

David Russell defines two of these myths - the myths of transience and transparency—in his comprehensive history, Writing in the Academic Disciplines. He traces the development of the university system from a core grouping of common courses to a highly-developed, branching network of disciplines and specializations. Writing instruction, Russell notes, was left behind as many academics devoted the lion's share of their time to teaching content and to research (3-20). The explicit teaching of writing was then pushed to the margins of college instruction. One consequence of this is the myth of transience, a term that Russell expands from the work of Mike Rose. This myth holds that writing is a generalized skill that can be mastered to a point that it requires little additional honing, and thus it should not occupy much of the time of instructors beyond English and Composition courses (7). This myth can extend beyond general writing skills as students in upper-level courses within their majors are expected to have internalized all of the basics of writing within their discipline. Such thinking about writing as a basic 
college skill, as opposed to a skill that requires consistent practice and support, is one factor in the erroneous characterization of a single, overall standard of "college writing."

Some studies have shown that there are certainly some important broad similarities between writing styles in different disciplines, as Hyland noted. Some general standards (aside from mechanical concerns such as grammar and spelling) and core tasks carry over between disciplines. In Engaged Writers, Dynamic Disciplines, Thaiss and Zawacki identify three basic standards of college writing as a result of their extensive observations and investigations of faculty at George Mason University:

1. Clear evidence in writing that the writer(s) have been persistent, open minded, and disciplined in study,

2. The dominance of reason over emotion or sensual perception.

3. An imagined reader who is coolly rational, reading for information, and intending to formulate a reasoned response. (6-7)

Thaiss and Zawacki point out that while these standards may seem straightforward they are difficult to achieve. They observed that, for the faculty members they interviewed and observed, competence in adhering to these standards was the result of a very gradual process of immersion in their field. This lead them to state that "It's no wonder, given this gradual trajectory of initiation, that newcomers to academia, such as undergraduate students, often feel that teachers' reactions to their writing are mysterious, perhaps motivated by social and personality differences, rather than by factors clearly attributable to academic quality" (7). For students, the variety of writing instruction they receive may seem to be less about foundational, even epistemological differences between disciplines and more about the personality differences between teachers. 
Some core writing tasks shared across disciplines can be defined, but they must be defined broadly. Michael Carter identifies four such tasks in his article "Ways of Knowing, Doing, and Writing in the Disciplines.” Based on his analysis of writing outcome statements created by faculty from fifty-one programs across nine undergraduate colleges at one university, Carter identifies four "metagenres," which he defines as broad "structure[s] of similar ways of doing that point to similar ways of writing and knowing" (219). These metagenres (paraphrased below) include:

1) writing tasks that call for problem solving, (such as writing in engineering)

2) writing task that require empirical inquiry (such as empirical studies in microbiology)

3) writing tasks that require research from sources (such as research papers in history)

4) writing tasks that promote a performance (such as proposals in Design). (219-26). John Bean, in Engaging Ideas, writes that Carter's taxonomy can "help undergraduates make sense of the kinds of work done by scholars in their major field" (258) by pointing out the broad knowledge-making tasks that field tends to emphasize.

Understanding such broad similarities between writing in different disciplines is important and useful as they show the sites of convergence and divergence that illustrate what different disciplines are capable of. However, it can become a problem when local knowledge of writing within one discipline is offered as general knowledge for writing in any and all situations (Linton, Madigan, and Johnson 179). The myth of transience would have us buy into the idea that writing can be generalized into a one-size-fits-all model that can be tackled for the most part in one or two semesters of college composition. The reality is that all writing is situated and contextual, and a broader 
understanding of a particular metagenre (or of the overall hallmarks of college writing that Thaiss and Zawacki note) is only achieved through time and experience with the particulars of different genres and different disciplines. Along this line, Dorothy Winsor, in Writing Like an Engineer (her longitudinal study of the writing of engineering students as they finish school and begin their careers) posits that "Although theorists see genre moving from purpose to form...novices' understanding of genre probably moves in the opposite direction" (27). In other words, students learn how to achieve broad purposes through the particulars of specific genres. They cannot suddenly jump to the kind of larger awareness of writing and genre that experts gain only through time and experience. Understanding of writing moves from the particular to the general, but implying that writing in a new setting can work the other way around (beginning with generally held universals as opposed to paying attention to particulars) stymie a writer's development and cause significant frustrations.

In “Activity Theory and its Implications for Writing Instruction," Russell criticizes the belief in a one-size-fits-all college writing course. He characterizes it as making about as much sense as requiring a course in basic ball handling before an athlete can go on to play a specific ball-related sport (basketball, football, baseball, etc.). He writes that "Like the handling of balls, the writing of genres is 'generalizable" to the extent that written text is handled in similarly ways for similar object(ive)s. A person who can write a footnote in a history paper may find it easier to learn to write a footnote in a chemistry paper than a person who has never written a footnote" ("Activity" 57). To recontextualize this example somewhat, a student who has learned how to write a particular kind of research paper in a composition class will be better off in a future research paper 
than a student who has never had to find, evaluate, quote, and cite a source before. However, seen from an Activity Theory perspective-where all writing genres are historically- and culturally-influenced and always in flux — there is "no autonomous, generalizable skill or set of skills called 'writing' which can be learned and then applied to all genres/activities"(Russell 57, emphasis mine). It is misleading and harmful to assume that writing can be summarily mastered for all contexts and that a generalized writing course, (which is either part of no discipline or part of English and/or the Humanities) can provide all of the writing savvy students will need at the college level. Teaching writing apart from rhetorical exigencies will not build the kind of writing expertise teachers in the disciplines desire. Elizabeth Wardle suggests that some solutions, such as combining academic genres into what she calls a "mutt genre," offer no better solution to preparing students for writing in their disciplines, positing that "they no longer do the same work in the world or accomplish clear purposes in response to meaningful exigencies" ("Mutt Genres" 769). The myth of transience ignores the fact that teaching writing apart from its social situations and exigencies will always be of limited usefulness to student learners.

Russell identifies the second myth, the myth of transparency, as the belief that writing records, rather than shapes, content (Writing in the Academic Disciplines 10). He argues that "As the disciplines became separated form one another and from the wider culture, persuasion became so limited, so bound up with the genres (and activities) of a specific community's discourse, that it could be taken for granted by members of the community" (Writing in the Academic Disciplines 12). As one becomes more adept at a particular mode of communication, certain fundamentals of that communicative process may 
become invisible as they fall beneath the level of conscious attention. In How Learning Works, Ambrose et. al refer to this as an "expert blind spot," which is when teachers operating in a state of unconscious competence in their field of study/research fail to recognize components that students simply lack. Experts who are unconsciously competent may skip steps, make intuitive leaps, or go too fast for learners at lower stages to follow $(97-99 ; 112-13)$. Such blind spots make gauging student instructional needs difficult, since the rhetorical functions of many academic genres may fall within that expert blind spot. As Russell notes, "if professionals are not aware of the role rhetoric plays in their own discipline, then they will see little need to teach it" (Writing in the Academic Disciplines 17). In "Writing Classrooms as Activity Systems," Patrick Dias posits that "Writing in school... and particularly writing within a writing course, is less likely to become operationalized" (19). That is, since writing is the focus of the composition course it is less likely to become so routine that it is not treated reflectively. This may be true for many cases, but for others it will not be the case, such as when certain writing conventions fall within that teacher's expert blind spot.

The sciences have been popular sites within WID studies and analyses since writing within these fields is often seen less as a highly-rhetorical act of meaning making than as a transparent recording process. This is in part because of the influence of positivism on scientific writing, which holds that true knowledge is gained by applying correct methodologies and not in the application of persuasive techniques. WID interest in the sciences is also due to their nature as compact disciplines. Toumlin, as cited by Susan Macdonald as well as by Thaiss and Zawacki, characterized academic disciplines as either being "compact" (with a high level of agreement about shared problems and 
shared methodologies) or "diffuse" (lacking universal agreement regarding shared questions and methods, engendering a wider range of genres and practices). Writing in the sciences is more compact and writing in the humanities tends to be more diffuse (MacDonald 22-5; Thaiss and Zawacki 14-5). The higher level of standardization and the foundation of positivism in the sciences make writing in those disciplines susceptible to the myth of transparency, and consequently writers in those disciplines may be more prone to expert blind spots when it comes to the rhetorical nuances of their academic writing.

Analyses of literature reviews in the sciences demonstrates how even seemingly transparent discussions of previous studies are rich with rhetorical moves that only seem transparent or subtle due to the ways they build agreement with the reader. Bazerman provides a concrete example of this work in his analysis of Watson and Crick's article in which the double-helix shape of DNA was proposed and explored. Although what Watson and Crick were proposing was revolutionary and even controversial, Bazerman observes how the authors position their claim to seem like not only a logical extension of extant knowledge, but also as a claim in agreement with the criteria held by other scholars in the field (Shaping Written Knowledge, 9-10). The compact nature of the sciences mean that the use of rhetoric is often compacted as well, and while it is no less powerful it can seem more transparent due to its regularity. Bazerman observes that "One peculiar aspect of the accomplishment of scientific discourse is that it appears to hide itself...science is commonly thought not to write at all, just simply to record the natural facts...The popular belief of this past century that scientific language is simply a transparent transmitter of natural facts is, of course, wrong..." (14). Lexical analyses of 
scientific writing — such as Susan Peck MacDonald's Professional Academic Writing in the Humanities and Social Sciences and Hyland's Disciplinary Discourses—-have shown how the hard, applied, and social sciences rely on highly rhetorical tropes down to the level of individual word choice.

The belief that writing in the sciences is transparent and rhetoric-free is just a particularly noticeable example of what happens across all disciplines. Winsor, in her study of engineering students, suggests that a belief in the a-rhetorical nature of certain types of disciplinary knowledge and writing may be necessary, to some degree in order to maintain confidence in methods and techniques, particularly in the hard and applied sciences. In her words, "We tend to believe that, in technical practice, objects and data speak for themselves...engineers themselves sometimes hold this belief quite tenaciously" (2) even when they are confronted with experiences that point towards the rhetorical nature of knowledge. This can create a frustration for individuals as it suggests a divide between the purity of the scientific method and what Bazerman chidingly calls the "impure facts of everyday life" ("From Cultural Criticism to Disciplinary Participation," 241). For students, the unaddressed myth of transparency can make writing in the disciplines seem autonomous, mysterious, and alienating.

There are at least three net effects of the myths of transience and transparency. The first is that writing instruction is mistakenly regarded as only for general education and lower-level courses within majors. The second is that a generalized, yet somehow complete, writing course is possible (and preferred). The third is that subtle or implied social/rhetorical realities of disciplinary writing can remain either unaddressed in the classroom or, at best, tacitly taught (the "they'll pick it up as they go" approach). These 
myths perpetuate the idea that there is a single standard of "good college writing" that spans disciplines and departments. In Engaged Writers and Dynamic Disciplines, Chris Thaiss and Terry Zawacki found in their interviews with 14 faculty members across various disciplines at George Mason University that "the common terminology that faculty use often hides basic differences in rhetoric, exigency, epistemology, style, form, and formatting...when very real differences are cloaked in the language of similarity" (89). By comparing rubrics developed over the course of several years in faculty development workshops with faculty across the disciplines, the authors found sets of "standard" writing terms that were common across multiple rubrics:

Argument, clear, engagement, original, balanced, thesis, supporting evidence, logical, sources, development, well-organized, flow, appropriate voice, grammar, spelling, punctuation, format. (Thaiss and Zawacki 86)

The authors found that even when these terms were shared across rubrics and disciplines, they varied in important ways. They concluded that these seemingly-standard writing terms are, in essence, a kind of insider terminology. Outsiders (i.e. students) are often left to fend for themselves when they try to decipher these terms. Furthermore, despite the fact that the authors found major differences in how faculty from various disciplines interpreted supposedly common writing terms, they also found that some of their data from informants still suggested a belief in the transparency and transferability of those terms.

This type of local/general confusion of conventions, caused and/or exacerbated by the myths of transience and transparency, has been observed in studies utilizing activity theory to examine how students negotiate writing in multiple activity systems. David 
Russell and Arturo Yanez’s 2004 article “'Big Picture People Rarely Become Historians" examine the frustrations that students in a general education course (Irish history) experienced when they found that they could not apply writing strategies from different disciplinary activity systems to their work in a history class. They assert that these difficulties were not the fault of the particular students or teachers, but "Rather the causes lie in the constraints under which they carried on their activity, the deep dialectical contradiction in U.S. general education between specialist and non-specialist activity and discourse" (357). General education courses put students in contact with specialists who may often want them to approximate their specialist discourses. Contradictions and double binds within this arrangement can become intractable fairly quickly given that students do not have the time necessary to acquire the subtleties of disciplinary style.

Rebecca Nowacek’s 2009 study “Why is Being Interdisciplinary So Very Hard to Do?" observed a full blown double bind in a team-taught interdisciplinary course led by three instructors from literary studies, history, and religious studies respectively. These instructors encountered confusion and resistance after offering contradictory explanations of the purpose and function of a thesis statement that varied according to the conventions of their respective disciplines. Instead of exploring this contrast as a means of fostering meta-awareness of the nature and function of each discipline, the teachers elided the differences and stressed the similarities, leaving students in the uncomfortable position of having to write to three different sets of expectations for the same assignment simultaneously (505-6). Nowacek concluded that "The challenge for interdisciplinary teaching, understood thus, is to help individuals negotiate the conflicts among motives, mediational tools, and other elements of disciplinary activity systems by identifying and 
naming those double binds, by facilitating opportunities to reflect on and make metacommunicative statements about those conflicts" (513). As mentioned in the section outlining the tenants of Activity Theory, identifying contradictions and double binds is essential in helping a system expand and improve. Without it, teaching writing courses in general and teaching disciplinary writing courses in particular can be horribly alienating experiences for students.

Longitudinal studies following student writers across multiple courses have evidenced this kind of alienating intellectual whiplash as students move across disciplines. A seminal example is Lucille McCarthy’s aptly-titled 1987 study, “A Stranger in Strange Lands." She observed, interviewed, and collected writing from one student, Dave, in three classes (Composition, Poetry, and Cellular Biology) during his freshman and sophomore years. She found that "although the writing tasks in the three classes were in many way similar, Dave interpreted them as being totally different from each other and totally different from anything he had done before" (243). The different formal and social features of each classroom shaped Dave's primary goal, as he put it, as "to figure out what your teachers want. And then you've got to give it to them if you're gonna' get the grade" (233). By and large, Dave focused primarily on the surface features of writing in each class and was unable to abstract any general principles about writing. For McCarthy, this signaled that writing development was very context-dependant, meaning that what is useful depends on what is being asked for in the moment rather than a larger, accumulating body of knowledge or strategies (261).

Anne Beaufort's 2007 College Writing and Beyond offers some corroboration for McCarthy's observation that the immediacy and concreteness of writing in one particular 
class eclipses a larger awareness of disciplinary difference. Her book reports her six-year study of one student, Tim, as he moved through different writing contexts within and beyond college. She considered, among other things, how Tim's composition course, with a teacher named Carla who taught a very expressive form of composition, affected the way Tim approached later writing tasks. Beaufort felt that Tim's knowledge of genre and rhetoric was left implicit and not fully expanded by Carla, which contributed to some confusion he experienced later when he tried to apply strategies from his composition class to his writing later in college. For example, when Tim began writing for his engineering courses, he felt he had "sold out" since he could not write with the personal voice he had developed in his composition class (42).

The frustrations experienced by Dave and Tim demonstrate a familiar pattern in which students tend to focus more on differences between teachers than on differences between disciplines. This difficulty negotiating elements of multiple activity systems causes contradictions and double binds, such as Tim's frustration that he could not employ his personal voice in his engineering writing. The realization that academic writing is social, rhetorical, and highly situated is the result of time and experience. Christina Haas observed this in "Learning to Read Biology" in which she followed a biology student, Eliza, for four years to keep track of how her attitudes and her methods of referring to her work and the work of scholars in her field changed. Haas found that her transition from belief in autonomous text to a belief that writing that acts as a negotiation of meaning by interested agents occurred only through the course of time and through situated learning experiences working in a lab under a faculty member (73-8). The myths of transience and transparency indoctrinate students into a way of thinking 
about writing and disciplinary thinking that takes years to undo (if ever), and students can encounter needless confusion and frustration due to a lack of support for disciplinary awareness.

\section{The Role of Writing Prompts in the Disciplinary Classroom}

Students encounter the effects of the myths of transience and transparency throughout their college careers and beyond. This brings us back to the question of how we can minimize the deleterious effects of these myths on students while also fostering awareness of disciplinary writing conventions and of the salient rhetorical differences between disciplinary writing styles. The "learning to write" mission of WID is one helpful approach, as it is concerned with revealing to students the nuances of writing within their disciplines. The goal of learning to write is not to turn teachers in the disciplines into writing instructors per se, but to encourage instructors to take on the challenge of more fully socializing their students into the writing genres of their profession. The learning to write mission has come under fire by some critics as at best encouraging a limited and rote understanding of writing or as being overly explicit to the point of harmful generalization. Daniel Mahala offers one such critique in that he characterizes WAC in general as promoting an uncomplicated vision of disciplinary communities that effectively robs students of the ability to reflectively make complex rhetorical decisions for themselves and instead reinforces a status quo of blind submission to autonomous rules (775-81). Responding to this, McLeod and Maimon criticize the view of Mahala that by pointing out that WAC in general promotes a shift from teacher-centered classrooms to student-centered ones, which is a subtler but more 
sure method of effecting active engagement and change. They write that "helping students to write in the disciplines is not an exercise in formalism and technical correctness; to the contrary, it is an exercise in epistemology...teaching students to write in a particular discipline...involves having faculty clarify their goals for their classes and thinking explicitly about how to achieve such goals" (580). Such clarification can empower students by making them more aware of what they are doing. Bazerman expresses a similar point to McLeod and Maimon:

When we teach students the rhetoric of the disciplines, thus, we are not necessarily indoctrinating them unreflectively into forms that will oppress them and others. Such oppressions of the self and others are more likely to occur when individuals learn communication patterns implicitly as a matter if getting a long. Explicit teaching of discourse holds up what is taught for inspection, provides the students with means to rethink the ends of discourse, and offers a wider array of means to carry the discourse in new directions. ("From Cultural Criticism to Disciplinary Participation” 241-2).

Speaking from his own experience analyzing writing in the sciences, Bazerman further comments that his experiences working with faculty and students to unpack the "implied baggage of the sciences has freed them to make rhetorical choices with greater clarity" (243). It did not, from his experience, lead to further oppression by the disciplinary status quo, as Mahala implies it would.

Explicit teaching of disciplinary writing conventions can help teachers avoid the effects of the myths of transparency and transience. This is not to say that teachers need to be explicit about every single point, however. Too much explicit teaching can cause a 
cognitive overload for students. Writers in general can only process so much at one time, but expert writers can rely on experience and ingrained habits of mind to carry them the rest of the way. Writing instruction then needs to strike a balance between explicitly teaching certain skills and the intelligent activation of others that students have, or should have, ingrained or have at least been exposed to.

Writing prompts are key mediating tools in a writing classroom in that they can evidence that balance of explicit and implicit invocation of writing conventions. Since writing conventions are tied to knowledge making in a given discipline, writing assignment prompts are often tied to the thinking and writing habits expected not only by the teacher but by the discipline as well. Prompts provide us with a window into the actions and operations of the activity system of a classroom in which disciplinary writing is taught. They not only facilitate the creation of a disciplinary genre, but they also constitute an important genre in that they invoke the operationalized social action of the writing classroom. If genre is a form of social action, then a writing prompt is a form of social action that operates within exigencies at several different levels, including the individual assignment, the class as a whole, the parent discipline, and the institutional setting.

Rhetoric in the Genre of the Writing Prompt: While there has been attention paid to writing prompts in teaching handbooks and research on standardized testing prompts, there has been very little explicit attention paid to the rhetorical nuance of writing prompts as a rhetorical genre, even within composition studies. Anis Bawarshi is one of 
the few scholars who have looked directly at the college writing prompt in using the lens of genre theory (aside from a few empirical researchers discussed in a later section). In Genre and the Invention of the Writer, Bawarshi brings together genre theory and a view of invention as locating one's self in relation to other authors and texts (an approach heavily influenced by Karen Burke LeFerve's Invention as a Social Act). In his chapter on the genres of the composition classroom, Bawarshi considers how writing assignment prompts require the students to locate themselves within particular reader/writer roles: while a prompt is a genre created by the teacher, it is read primarily in terms of how it positions students as writers operating within a set of explicit and implicit expectations (131). Bawarshi notes also that the prompt requires the student to perform mental roleplaying in that they are expected internalize the exigency and purpose of the assignment as their own, whether or not that is truly the case (133). Irene Clark seconds this observation, noting that in some instances:

the genre of the writing prompt requires the student to assume the role of thoughtful novice scholar who is genuinely concerned with the topic in the writing prompt, and that the resulting essay must give the impression that it was generated from the student's own concerns, not because the student was responding to a prompt (and really had no choice about doing so if he or she wanted to pass the course). (8)

A successful student writer in this circumstance is one who internalizes the stated purpose and motivation of the prompt as his or her own. A student may not want to write about Napoleon's defeat at Waterloo, for example, but if that student can give the impression that he/she is genuinely interested in the topic and wanted to write about it 
then the paper is more likely to meet the teacher's expectations. Conversely, a student who makes explicit reference to the prompt, the class, or talks directly to the teacher in his/her paper has committed an error if not a social faux-pas. This is what Bawarshi refers to as "coercion masked as complicity," in that students must demonstrate a certain level of interest and engagement whether or not they truly feel either, and it is a subtle rhetorical move that many successful students probably don't think about as such (133). Many students fail to meet these kinds of unacknowledged expectations, and they lead to what Clark calls the "assign and complain" method of teaching writing (12). On a similar note, Edward White comments in Assigning, Responding, Evaluating that a casual approach to crafting assignments (one that does not sufficiently unpack the teachers' expectations) will promote an casual response from students (5). This includes designing writing assignment prompts. Furthermore, he urges that all instructors consider that: designing writing assignments is a particularly demanding form of writing, calling for the teacher to use the entire writing process. Careful consideration of the needs of the audience and class discussion of the assignment (over the entire period when students are working on it) will help the teacher find out where students are having problems; reflection about these problems will often lead to a revised assignment for future classes. (9)

Writing effective assignment prompts is difficult, and requires at least as much thought and reflection as we expect any given student to put into the project as a whole. While he is not working from an Activity Theory perspective, White's urging here can help to characterize the writing classroom as an activity system with the potential for expansive 
learning: designing an assignment is a form of social action within an activity system that can expand by careful reflection on the efficacy of mediating tools.

The writing prompt, like many other important writing classroom tools such as the syllabus, is "a site of invention in which teacher and student create conditions in which they will eventually interact as reader and writer" (Bawarshi, Genre and the Invention of the Writer 133). Genre theory, therefore, helps us to see the writing prompt as a site of ongoing negotiation between student and teacher as to what kind of writing is appropriate not just for the immediate environment of the classroom, but also by extension the department, the institution, and (in the case of disciplinary classrooms) for a discipline or profession. Like the jury instructions Devitt examined, it is a genre that attempts to bring together members and nonmembers, teachers and students, by establishing the performance expectations held by the former. We should also keep in mind Devitt's observation that genres are nexuses of expectations and agendas that can frequently compete and conflict with one another (Writing Genres 29). Activity Theory provides a concrete frame (the activity system) that can be used to unpack how a writing prompt acts as a mediating tool and how conflicts and contradictions can arise in the activity system of the disciplinary writing classroom.

All of this is not to say that the writing prompt is the only instructional tool that matters or that it is even the most important. Individual writing genres and individual classrooms both utilize what has often been called a "constellation" of resources and influences (Campbell and Jamieson 21; Devitt, Writing Genres 12; Schryer, "Genre and Power" 95). This metaphor is very apt, since a constellation of stars only forms a coherent formation when viewed from a particular point of reference (the Earth). An 
assignment's writing prompt provides a point of reference for understanding the elements of this constellation. The writing prompt is not the ultimate arbiter of the success or failure of a writing assignment, but it is at least a formal declaration of a teacher's expectations. For students, writing prompts also play an important role in what Linda Flower calls "task representation." Flower explores the impact of the way in which students form mental representations of the writing tasks they are charged with. She suggests that we consider task representation "not as a single, simple decision, but as an extended interpretive process that weaves itself throughout composing...[and] that representation is subject to many influences and may evolve in surprising ways during writing" (36). Writing prompts can anchor this process of task interpretation in that they offer a formal articulation of the goals of the assignment, provide some kind of model for how to go about writing the assignment, and are often concentrated codifications of explicit and implicit expectations. Thus, they can play important roles throughout a writing project as students use them to help negotiate and renegotiate their understandings of their writing task. This process can be made more difficult if prompts become victims of the myths of transience and transparency and end up not revealing enough or treating complex and situated writing tasks as simple and obvious ones.

\section{Central Research Questions and Benefits}

The central goal of this dissertation is to explore how teachers and students use writing prompts as mediational tools to negotiate writing appropriate for the disciplinary writing classroom. This project examines how writing prompts, as mediational tools, exacerbate or ameliorate student efforts to acquire and intelligently employ the writing 
and thinking habits of their prospective disciplines. In particular, this project is geared towards addressing the following primary research questions:

1. What strategies do students use to read and interpret prompts and how do those strategies differ from the ways their teachers expect the prompts will/should be read?

2. What contextual clues contribute or detract from student ability to understand a prompt? In particular, what effect do terms for seemingly standard moves—-such as "analyze," "interpret," and "support," which also have distinctive connotations that vary across disciplines—-have on students' understanding of their writing tasks?

3. What additional factors (background in the discipline, previous assignments, instructor discussion, assignment models, assignment sequencing in the class, etc.) contribute to students' abilities to successfully negotiate their instructors' expectations in prompts?

4. What are some common double binds in the instruction of academic writing and what factors exacerbate or ameliorate them for students and instructors?

In terms of the fourth question, I look for any double binds I can identify as I observe students and teachers negotiating writing projects through prompts.

This project can benefit both teachers in the disciplines and composition instructors. In terms of the first group, it can help teachers in the disciplines gain a more nuanced understanding of the role of writing prompts and how they can best support a writing project. In turn, this can help teachers in the disciplines better support their 
students' acquisition of disciplinary thinking and writing habits. Over the past few decades, the WAC and WID movements have helped teachers across the curriculum implement more (and more effective) writing assignments.. This is no small feat, as teachers in the disciplines already have a significant hurdle to overcome in trying to cover all of the material and basic skills. Patrick Bahls in Student Writing in the Quantitative Disciplines, describes the time problem as the biggest obstacle to adding writing to a content-rich class:

It is clear that time spent on writing is time not spent on something else. If over the course of a semester you take two or three hours of class time for writing instruction, peer review, or other writing-related activities, you take two or three hours of class time away from direct treatment of course content. Particularly in highly regimented lower-level courses, this might mean that you will have to consider a few sections of material with less depth than you would have otherwise or you will have to skip one or two sections altogether. (xi)

Given this very real and very considerable obstacle, one important approach in WAC/WID initiatives has been to promote teaching writing more effectively as a way to save time and effort. Teachers featured in this dissertation used different mixes of rough drafts, bibliographies, peer review, and other milestone strategies to help make the writing process easier on students and to ensure for teachers a more consistent batch of student papers. This project can further benefit teachers in the disciplines by providing a better understanding of how a writing prompt is read and used by students and teachers. Also, it will stress how writing prompts are opportunities to activate and reinforce disciplinary habits of mind. Furthermore, it can lead to more effective, more efficient, 
and more instructive writing assignments that avoid the "assign and complain" approach to writing instruction that Irene Clark notes (24).

This project has benefits to teachers in composition as well, and these benefits extend beyond deeper consideration of the craft of designing assignment prompts. Linton, Madigan, and Johnson suggest that the roles of composition instructors and teachers in the disciplines are distinct but complimentary. In particular, they suggest that "English faculty can prepare the ground for acquisition of disciplinary style - which typically takes place throughout the period of undergraduate and graduate study" (171, emphasis mine). While many faculty may play a role in this process of acclimating students to writing in different communities, the authors emphasize that "English faculty are in the best position to introduce students to the concepts of discourse communities and disciplinary style...[which can] illustrate to beginning college students how writing varies with the setting." (171). This act of preparing the ground can be an important step in breaking those myths of transience and transparency (at least for students) as well as bringing down the illusion of a singular standard of "good college writing." English and composition instructors are well placed for this process due to the ubiquity of composition courses and the role they are expected to play in preparing students for writing in various communities. By introducing how different disciplinary communities operate in different ways through writing, composition instructors can help students become more sensitive to differences in disciplinary styles, which can helps students in their socialization efforts within their academic/professional communities as well as alleviate potential double bind situations like that experienced by James, the student discussed at the outset of this chapter. 


\section{The Role of Writing Prompts in Understanding What Writing is Taught Across the Curriculum}

Studies utilizing writing prompts as data were most prominent in the 1980's. The most cited of these is Brent Bridgeman and Sybil Carlson's 1984 study in which over 400 instructors from 34 universities nationwide answered questionnaires about what they were teaching. Also of note is Harris and Hult's 1985 survey of 115 faculty members at Texas Tech. and Charlene Eblen's 1983 study of 266 faculty questionnaires collected at the University of Northern Iowa. Eblen wished to investigate not only what types of writing were being taught, but what faculty valued in student writing as well. The scale of all three of these studies, running from 115 teacher respondents to over 400, illustrates a desire to create an accurate composite view of the writing that teachers across disciplines are assigning. The authors' findings bore significant similarities. They found that there was variation in what counts as good writing (Eblen 246) and they found that the genres of writing most encountered by students were essay exams and short research papers (Harris and Hult 8; Eblen 247).

There were two core problems with the methodologies of these studies, however: reactivity and inconsistent terminology, and these were pointed out by George Braine in a 1988 review article. First, recipients of the questionnaire/survey might respond not with what they do teach, but with what they would like to teach or feel they should teach (Braine 113). Indeed, the reliability of teachers self reporting on their practices has been an ongoing criticism applied to WAC at large (see Ackerman; Oschner and Fowler).

Second, the use of surveys and questionnaires to ascertain this data presupposes that the 
respondents will share the same understanding of writing terminology as the researchers. For example, a faculty respondent may not have the same overt understanding of what separates a "short research paper" (a category form Harris and Hult's study) from an “analytical paper" (a term from Eblen's study) as a teacher from English/Composition does (111). If an analytical paper involves research, then to which category does it belong first and foremost if there is only one choice to be made?

Analyzing writing prompts and instructions directly proved more reliable than questionnaires and surveys when querying what type of assignments teachers were giving students. In 1983, Mike Rose conducted a study of 445 quizzes, examinations, reports, and papers representing 17 academic departments at UCLA in the course of the development of UCLA's Freshman Preparatory Program. However some may discount Roses's study due to the preponderance of short assignments and timed-essays in his sample, which do not represent the kind of thoughtful and deeply engaging assignments that writing teachers and disciplinary teachers value most. The most interesting study within this group, methodologically, is Daniel Horowitz's 1986 study which, like Rose's, looked at prompts directly. Horowitz had a small sample size (prompts from 54 takehome writing assignments from classes at Western Illinois University), but an intriguing methodology as he used genre theory to analyze his sample. Instead of using a prefigured list of writing categories, Horowitz defined the typified writing tasks he observed as they emerged from the data. This was a flexible strategy since he found that even within his relatively small sample that some prompts were more diverse than a restrictive categorization system would allow. His goal in this was to illustrate how "to be useful, a scheme must have enough specificity to capture essential differences among tasks and 
enough generality to place into the same category essentially similar tasks which might appear to be quite different (e.g., two tasks from different subject areas)" (449).

A similar method was used by Dan Melzer in his 2009 article "Writing Assignments Across the Curriculum." The dearth of similar studies in the intervening years between Horowitz and Melzer may be attributed in part to the difficulties of data collection, but Melzer capitalized on the availability of writing prompts online by collecting 2,100 writing assignments from the websites of 100 postsecondary institutions. Like Horowitz, then, Melzer looked at writing prompts to see what they are asking students to do instead of classifying these assignments according to an abstract type. He used a modified version of Britton's Function and Audience taxonomy to categorize the assignment prompts: transactional (subdivided into informative and persuasive), expressive, poetic, and exploratory (the last being Melzer's addition). The majority of assignments in Melzer's sample group were simple transactional assignments $(83 \%$ of his sample) with approximately $66 \%$ of those being informational rather than persuasive, although he credits WAC initiatives with raising the number of more rhetoricallycomplex writing assignments in the past few decades (245-6).

Like others who came before him, Melzer's goal was to use each prompt as part of a large, panoramic snapshot of what types of writing students are encountering. In doing so, however, he did not represent prompts as mere transparent vehicles of data. He is the closest of any empirical researcher thus far in this section to explicitly describing writing prompts as part of the disciplinary writing education students receive instead of just a transparent facilitator of it. For example, his report begins with a close 
consideration of a particular writing prompt for a documentary analysis in a history classroom:

The assignment requires "analysis" and "interpretation," and both of these thinking strategies are defined in ways that are specific to the discipline of history. Although the primary audience for the assignment is the teacher, the implied audience can be seen as fellow historians, since students are asked to play the role of disciplinary insiders ("As a historian, you should always look for what is not said, and ask yourself what the omission signifies"). (241)

Viewed through this lens, the writing assignment prompt is a touchstone for what kind of writing is valued not only in the classroom, but also for the type of thinking valued in the parent discipline of that course as well. This kind of attention to individual prompts, however, is not within the scope of Melzer's study, and so it quickly falls by the wayside.

Studies following Melzer have continued investigating what writing is being taught across the curriculum (like Graves, Hyland, and Samuel's 2010 study and Christopher Wolfe's 2011 study). Although their results are comparable (students are being asked more and more to write complex assignments rather than just simple transactional ones) none of them come as close as researchers like Melzer or theorists like Bawarshi have to explicitly thinking about prompts as complex rhetorical documents in their own right.

As it relates to the goals, scope, and methodology of this dissertation, what should we make of this body of research as a whole? Large-scale surveys can tell us what writing is being taught across the curriculum, but the time has come to consider more deeply how that writing is being taught as well. As data points in a large-scale survey, 
the complexity of writing prompts cannot be deeply delved into, nor can prompts be compared across disciplines to identify common strategies or challenges. This dissertation aims to strike a balance between large-scale surveys and individual case studies by looking at how writing prompts operate in multiple courses across a variety of disciplines. This is to identify cross-disciplinary writing links while also keeping the rhetorical power of individual prompts in view. In short, it may be characterized as an attempt to keep both the forest and the individual trees in focus.

\section{Methods}

The purpose of the data-collection and analysis for this dissertation was to explore how writing prompts mediate student writing in disciplinary classroom settings pursuant to the research questions previously discussed. Of course, prompts are not the sole arbiters of a writing assignment. Consequently, data collection and analysis was structured to help the researcher understand the various, interdependent parts of the classroom activity systems under analysis. This includes identifying conflicting (or potentially conflicting) elements that can lead to contradictions and double binds and identifying practices that help students avoid such obstacles. Research methods consisted of class observations, interviews with the teachers of participating classes, surveys of students from participating classes, and interviews with multiple students from each participating class. The research methods described below (and included in Appendix A) were approved by the Institutional Review Board (IRB) prior to data collection. 
Location: Primary research for this dissertation was conducted at a large southern university. According to its website, it had 22,000 students enrolled around the time the research was collected. Within that total enrollment, almost 16,000 were undergraduates, 6,400 were graduate students, and 126 were Post-Doctoral. Most students, almost 17,000, were full time. At the time of this study, it had 170 fields of study across 12 schools and colleges, including a law school, a thriving medical program, and a growing business program. This was an invaluable site for this type of study due to the rich variety of academic programs available to students.

Participants and Courses: This dissertation involved examining seven classes across five disciplines (philosophy, sociology, psychology, biology, and nursing). Two courses, a sociology course called Race in the US and a philosophy course on Metaphysics, were dropped from the core analysis due to the inability to corroborate findings with more than one student interview. This section will briefly introduce the courses that comprise the core analysis of the chapters yet to come. All student and teacher subjects have been given pseudonyms.

Political Philosophy with Dr. Petersen was a split 500/600-level course for advanced undergraduates and graduate students. It explored ideas of ownership, sovereignty, and suffrage, and the social contract between rulers and the ruled. While it was not designated a writing intensive course (students getting undergraduate degrees from the College of Arts and Sciences at the university had to take two courses at the 300-level or above that were designated as focusing a great deal on writing), Dr. Petersen 
required students to write and present in different genres as a way of helping them process the difficult writings of authors like John Locke. One of Dr. Petersen's reasons for assigning so much writing in this course was to compensate for the lack of overall writing instruction available to Philosophy students. The Philosophy department could not offer students enough writing experience due to the course loads placed on their faculty. Consequently, while the undergraduates in this course were philosophy majors or minors, many of them were still learning the ropes of writing in philosophy, and so Dr. Petersen assigned writing frequently in his course. Three students were interviewed from this class: Beth, Daniel, and Jeremy. Beth was an English major with a Philosophy minor, and she was working for a large, independent bookstore after a successful internship as a secretary and assistant to their marketing director. Daniel was a philosophy major who had minors in math and humanities; his goal after finishing his bachelor's degree was to attend a seminary. Jeremy was an ambitious student, majoring in political science and attempting a second major in psychology with double minors in history and philosophy. At the time of the interview he had been elected to a high position with the university's student government.

Multicultural Psychology was a 300-level, writing intensive psychology course that explored, as it is listed in the course catalog, "The influences of race, gender, class and sexual bias in American society and its impact on individual psychology as well as on economically and socially marginalized groups." This course—which was a mix of psychology majors and minors with a smattering of students from other programsbecame popular under Dr. Davis, who had taught it for several years. Indeed, the course had become so popular that students were required to get approval before they could 
register for it to help keep the class from filling up too fast or filling up with all nonmajors. Dr. Davis was looking for a break from the course, however, and so during the semester in which research was conducted on this course he was mentoring a new faculty member, Dr. Baker, in how to teach the course. Their course content was approximately the same, and I had the opportunity to analyze and interview subjects from both Dr. Davis's section of the course and Dr. Baker's. Five students were interviewed from these two classes. Walter and Jean were students in Dr. Davis' course. Walter was a nontraditional student who began college about seven years after graduating high school. $\mathrm{He}$ was majoring in psychology and sociology, and was considering graduate school at the time of this interview. Jean was a senior with a major in Psychology and a minor in English (focusing on creative writing). After taking a psychology course in high school on a whim, she decided that she liked it so much that she wanted to get her $\mathrm{PhD}$ in the field, and this was still her plan at the time of this interview. Elaine, Maya, and Catherine had Dr. Baker's multicultural psychology course. Elaine was a transfer student from a different institution, and she was playing catch up with her credits to attempt to graduate on time. Her parents were both medical professionals, although she decided after some consideration and shadowing of other medical professionals that she may prefer to pursue a $\mathrm{PhD}$ in psychology rather than a medical degree in that field. Maya was a very softspoken student who was majoring in psychology so that she could become a school counselor. Catherine was a senior who needed just one more semester to graduate. She was looking at becoming a clinical psychologist, and wanted to also see if her skills could be used in overseas mission trips. 
Biology 415, Biology of the Cell, was designated as a writing-intensive course for advanced Biology students. The teacher, Dr. Steiner, wanted his students to start thinking and acting like biologists, which for him means engaging the literature and having intelligent conversations about it in the way that he and his colleagues do. To this end, the class was capped at 24 students, which allowed Steiner to assign multiple smaller writing assignments (reviews and evaluations of current research) and a larger paper with multiple milestone assignments (topic proposal, bibliography, draft, etc.). Since most of his students were more comfortable with large lecture classes where they could excel by staying quiet and taking good notes, Dr. Steiner wanted to bring his students out of their academic shells by engaging them in the conversation on primary research. The three students interviewed in this course (Diane, Robin, and Tiffany) comprised a more homogeneous group than the ones in previous classes discussed: all were traditional college seniors looking at attending medical school once they completed their undergraduate work. Diane desired to work in oncology, and while she was not accepted into medical school for the fall of the year this interview took place, she was making arrangements to intern as a research assistant at a pediatric hospital. She also had the most experience with Dr. Steiner of the group interviewed, since she not only had him for several classes but also acted as a student research assistant for him in an on-campus lab. Robin was a Biology major with an English minor who was starting at the university's medical school in the fall, and she was interested in specializing in dermatology. Tiffany was also starting medical school at the same university in the fall, and she had been working as a research assistant in ophthalmology over the course of a year, which put her in frequent contact with scientific literature and methods. 
Nursing 471 was aptly titled Synthesis of Complex Health Needs (abbreviated as "Synthesis" by students), as it was a capstone course in which nursing students combined knowledge from many previous courses. Students had to draw on the body of knowledge and skills earned in prior courses, like anatomy and pharmacology, to plan and evaluate care procedures for hypothetical patients in the classrooms and real patients in the field. This course coordinated with a semester-long internship program where nursing students began by shadowing active nurses at designated care facilities. After over two hundred hours of interning, nursing students were expected to be able to handle a full shift at their designated facility with minimal guidance from their designated mentors. Writing assignments in the Synthesis class were coordinated with the students internships. Students had to produce periodic journal entries reporting things they observed, things they learned, and methods they would apply in their designated internship site. Their major paper for the course required them to evaluate a practice they observed at their site and determine whether or not it is "best practice" and thus in need of either support or replacement. Five students from the two Synthesis courses were interviewed in the spring and summer semesters: Samantha, Tamera, Carolyn, Sheila, and Mandi. Samantha and Tamera were undergraduates taking the Synthesis course during the spring Semester. Samantha was a traditional undergraduate, attending college directly after high school, and Tamera had come back to school several years after high school. Carolyn, Sheila, and Mandi were students working on second degrees who took the Synthesis course during a long summer term, and all three had considerable work experience that greatly affected the way they approached the course and their clinicals. Carolyn had worked with new mothers as a lactation consultant for many years. After her five 
children had grown up and left home for school or work, she decided to pursue her nursing degree based on her positive experiences with nurses and hospitals in town. Sheila was an interior decorator with experience managing the business side of that profession, and she was coming back to school to pursue a second career after an economic downturn adversely affected her work. Mandi went into the army after high school and later earned a degree in public health. Of all five subjects, Mandi was the only one with graduate-level experience. She was most of the way through a Masters in Public Health and worked as a research assistant for a member of the faculty at the School of Nursing at the time of this study.

The core analysis of this dissertation drew from these six classrooms (two sections of Multicultural Psychology, two of the Nursing synthesis, one from Philosophy, and one from Biology). Data from the Biology and Nursing courses were collected in the Spring and Summer term of 2011. The data from Philosophy (Political Philosophy) and Psychology courses were collected in the Spring term of 2012. Writing was a major component of the students' grades in each of these courses. Three classes within this sample (the Biology class and the two Psychology classes) were designated as Writing Intensive courses (with the designation of "WR" in the course catalogs). These courses had to adhere to the following standards, which are listed on the university's website:

- Written assignments shall reflect the discipline's forms and methods of inquiry.

- Every WR course shall require a minimum of 2400 words of writing in response to several written assignments (papers, essays, tests, reviews, or reports). Faculty assessment shall include recommendations for improvement.

- Course syllabi shall specify all WR requirements for the course. 
- Upper-division WR courses shall include a discipline-based research component as a significant part of at least one of the graded writing assignments.

- Enrollment in WR courses shall be limited to 24 students.

Even though these courses were designated as writing intensive, learning how to write within a discipline was not their raison d'être. Consequently, the writing prompt played a very significant part in communicating the teacher's expectations for writing to the students as there was much content for each of these classes to cover. In a few cases it was the most concentrated explanation of how to craft the written product that the students received in the course. The content and approaches to writing in all of these courses were varied enough to give this project a broad sample of writing tasks across the curriculum. That said, many of the writing experiences shared by students in these courses were also similar enough to draw general conclusions about the struggles of learning how to write within a disciplinary community.

Instrument: Instruments for primary research included surveys for each of the classes involved, an interview with the instructor of each course, and an interview with participating students in each course. All of these instruments received approval from the Institutional Review Board (IRB) prior to being used. The survey was given to each class before they received a grade from their instructor on their final writing project, and it consisted of seven Likert-Scale questions and four short open-response questions. Each of the seven Likert-Scale questions had a 5-point range from Strongly Disagree to Strongly Agree with a neutral option (Undecided) in the center. These questions queried the students' understanding of their teacher's assignment and their confidence in their 
ability to meet their teacher's expectations. The questions asked students about their level of experience with this type of writing and content, their ability to understand the prompt, their confidence that their project would meet their teacher's expectations, etc. (The complete survey can be seen in Appendix A). The open response questions asked students to briefly articulate what they felt was the purpose of the project, what its basic requirements were, and what the most important resource to pay attention to was. These surveys were used to gauge how well students felt they understood their teacher's expectations and whether or not there was a disjunction between students and instructors on what was expected in the writing projects.

The objectives of the interviews of faculty members were threefold: ascertain the instructor's aims, motives, methods and materials (including, but not limited to, the prompt) for teaching and evaluating the writing assignment under scrutiny, delve into his/her history with the particular assignment and its genre, and query his/her approach to writing pedagogy in general as well as the in course being observed in particular. The goal for student interviews was to determine what role the prompt played in their writing, how-between the prompt, the teacher's explanations, and other classroom materialsthe students gained a working knowledge of what the project required, what they understood to be the genre of the project (and its ties to the goals for the course and what kind of skills they may need to learn in their discipline) and how they read and interpreted particular terms in the prompt (which may have a deeper disciplinary connotation that student participants may or may not be aware of). In short, they were asked to detail how their use of classroom materials and their own resources (including their prior experiences) affected their negotiation of the writing project. Semi-structured 
interviews consisting of questions in the categories listed above (along with multiple investigative probes) were used. Again, the complete set of interview questions for both faculty and students can be found in Appendix A.

Interview Analysis: A simple descriptive coding system based on Engeström 's expanded mediational triangle (see Figure 1) was used when coding interviews with faculty and students. Interviews were transcribed using the program Transana, and coding was used with a program called Weft Qualitative Data Analysis (Weft QDA). The coding scheme used different nodes of an activity system identified in Engeström 's expanded mediational triangle to tag different chunks of faculty and staff interviews with primary and secondary descriptive codes. The program Weft QDA was then used to compile and cross reference these codes to aid in comparing instances, for example, when students were discussing tools such as the writing prompt and —as a secondary coding procedure - when they were discussing them in a positive way (as clear and helpful) or a negative way (opaque, difficult to read). This flexible coding method allowed the researcher to easily analyze and interpret interview data through an Activity Theory lens.

\section{Chapter Overviews}

The subsequent chapters of this dissertation explore challenges in assignment prompt design and some common conflicts/contradictions evident in the data. These chapters reveal, explore, and discuss the implications of these challenges in order to better facilitate conversation about them and identify ways of ameliorating them for students and teachers. 
Chapter 2 explores the importance of cues in defining the actions and underlying operations involved in writing at the college level. It identifies challenges faced by students in the Biology and Psychology courses to highlight the importance of cues. In particular, it discusses why unpacking implied expectations with detailed cues is important and how this can be accomplished.

Chapter 3 explores a common conflict in disciplinary writing in the university: balancing the desires for accountability (demonstrating competence in discipline content) and originality (going beyond summary to make an original argument). Students, through anxiety about evaluation or through a lack of knowledge about how to make the transition, can often resort to summary-heavy writing as a default action. This chapter discusses how the faculty in the Philosophy and Nursing courses sampled in this dissertation attempted to provide students with resources in the prompt to deal with this challenge. It suggests that a lack of hierarchical task construction and/or inconsistent student feedback can leave students in a contradiction or double bind in this area.

Chapter 4 further explores the Nursing courses, but it does so by examining them as an attempt to bridge writing for school purposes and writing for professional ("realworld") purposes. In trying to simulate a real-world exigency to prompt student writing and action, the assignment ran against some of the limitations of simulating real-world exigencies in a classroom setting, and inadvertently worked against itself in this regard. This chapter discusses these limitations and highlights why faculty should be aware of them.

Chapter 5 synthesizes lessons from the previous chapters into a series of suggested practices. They are divided according to the different levels of activity in 
which they can be implemented: at the single-assignment level, the level of an entire course and the inter- and intra-departmental levels (to promote efficient and effective writing instruction across the disciplines). These suggestions are not rigid in how they can be adopted, but rather they allow for flexibility based on the goals of the instructor. Diversity in instructional approaches has kept composition a rich and interesting field, and so this chapter avoids prescribing rigid prompt design and implementation strategies as they would create a stifled writing process for both student and teacher. 


\section{CHAPTER 2}

\section{DISCOVERING EXPECATIONS AND DISTRIBUTING ENERGIES}

Students in Dr. Steiner's Biology 416 (Biology of the Cell) class received the prompt for their major term paper for the course on the first page of the class syllabus. The prompt was just over two hundred words in length, it described their project in very scant detail, and it used ambiguous directions such as "the textual format is open." Diane, a pre-med student in this class, reported feeling irritated after seeing the short, vague prompt, because for her it meant that the project was "going to be twice the amount of work that it needs to because he won't just come out and tell me what I need to do." Her concern was that the vague directions and seemingly open format indicated in the prompt belied the very specific expectations Dr. Steiner had for the project, and these were expectations he was not sharing in the prompt. Even though she had Dr. Steiner for classes before, she was still concerned about having to figure out what he wanted from this project. Furthermore, she found it "obnoxious or annoying, because you think to yourself 'oh God, I'm going to have to spend half my time figuring out what I'm supposed to do before I can actually do it,' and that's just, that's just annoying. More work..." Students like Diane are very aware that teachers often have expectations not formally stated in their assignments. They can see their job in the classroom as not only trying to follow the directions on the page, but also as trying to 
decipher the underlying expectations implied in those directions. This is where cues can come into play.

A central idea in this dissertation is that writing prompts should be thought of in terms of rhetorical cues they provide to students. Bawarshi observes that the writing prompt "not only moves the student writer to action; it also cues the student writer to enact a certain kind of action" (Genre and the Invention of the Writer, 127, emphasis original). The writing prompt initiates student writing and signals to them what kind of writing is desired. Irene Clark takes this a step further in discussing writing assignments in terms of a performance like a concert or theater production:

Writing assignments, like stage directions, can be viewed as a performance oriented text genre...From this perspective, writing assignments are similar to stage directions in a number of ways: they contain seemingly explicit cues about format, language, and style that the performer or student is presumed to understand, but which can be understood only by those who are already familiar with the genre...Moreover, both stage directions and writing assignments are based on implicit assumptions about what constitutes an acceptable "performance" and what is necessary to do in order to create that performance. (para. 18, emphasis mine)

Thinking of writing as a performance in need of cues to direct action at different stages can not only help teachers signal what the basic task comprises (e.g., write an analysis of Hamlet), but it can help students with organization and strategies by offering cues for different parts of the writing task (e.g., "In this part, refute what one author has said about...”). These cues can take the form of verbs that act as genre markers (such as 
"evaluate," "analyze," and/or "describe") and can exist as more detailed explanations of the individual moves a writing task required (e.g., "critique the effectiveness of the authors' research methods..."). Providing these sorts of top-down organizational cues can help students who are trying to acclimate themselves to particular disciplinary genres. While some instructors may argue that they can limit the freedom of student writers (which they can, particularly if they are prescriptive to the point that the student is basically filling out a worksheet and calling it a paper), it must be acknowledged that student writers are already limited in their freedom by the teacher's expectations, both explicit and implicit. Writing genres constrain as much as they enable. Therefore, providing cues to guide students in organization and use of conventions can help teachers avoid holding students accountable to vaguely defined constraints, or what Clark calls teaching writing by the "assign and complain" method (para. 19). Students can navigate writing assignments more effectively and with more confidence with a better understanding of where the boundaries are and what tools are available within those genre constraints. The most prominent uses for cues covered in this dissertation are listed below:

1) Cues indicate specific actions and activate/reinforce operational assumptions that underlie those actions: The actions indicated within a writing prompt are always underlined by certain assumed conditions or understandings. For example, while teachers across disciplines may use the term "analysis" to define a student writing project, they will have different ideas about what that action should entail. Some of these differences are idiosyncratic, but many others are the product of the differences in their disciplinary training. Well-constructed cues (in line with the 
rest of the classroom activity system) can help students orient themselves towards the kinds of actions their teachers expect. This chapter will explore these types of cues and their importance.

2) A hierarchical arrangement of cues helps students effectively balance parts of a paper against one another: Disciplinary genres consist of certain moves made within certain orders. At one end of the spectrum is the highly-regimented scientific journal article, and at the other are more open, essayistic writings in parts of the humanities. Even in the latter, however, there are certain expectations as to structure. When students perform these disciplinary writing tasks, they are often required to balance and properly order two types of moves. First, they are required to demonstrate their grasp of content knowledge. Second, they are also evaluated on how well they can employ the rhetorical conventions of certain disciplinary writing styles. Balancing these two goals - the first evaluative, the second other communicative — can sometimes lead to double binds if the cues students are provided with are not arranged in such a way that they facilitate both purposes without getting in each other's way. Chapter 3 will explore this.

3) Well-handled cues can help students locate themselves within the rhetorical purpose of the assignment: Disciplinary writing in the classroom is intended to ease students into the rhetorical roles and habits they will need after they graduate. As such, they can often be a blend of writing for professional purposes and writing for educational/evaluative purposes. These two goals can clash and cause contradictions/double-binds. Chapter 4 will address such a situation. 
In this study, I expected to find that students suffered a kind of intellectual whiplash they attempted to synthesize specialized — and sometimes contradictory— lessons on writing acquired from the variety of disciplines encountered during the course of a liberal arts education (e.g., my history teacher says to write a thesis one way, my political science teacher wants something else, so what do I do?). What I discovered instead was a pattern of contradictions and double binds that existed within disciplinary and classroom activity systems rather than between disciplines/subjects.

One reason for this finding may be that, as this chapter will illustrate through the example of two upper-level courses, the contradictions within elements of an individual class are more immediate and worrying than those between classes. Students are (understandably) more concerned with the grade in the class they are in rather than making lessons from older classes cohere with those from their current classes. Another reason is that students might be habituated to approach each writing course on its own terms as a new experience rather than as part of a longer experience of enculturation, due to (at least) two factors: the habit of mistaking disciplinary difference in writing as the idiosyncrasies of individual teachers, and the way that prompts can position students so that they feel they are writing outside of any authentic writing context.

First, the variety of teachers and subjects that students encounter can tacitly train them to treat each classroom experience as something new and novel, as Lucille McCarthy noted in her aptly-titled longitudinal study from 1987, "A Stranger in Strange Lands.” McCarthy showed a student moving across different courses in different disciplines and treating each one as a new experience, paying little heed to what he might transfer from one to the other (261). A similar observation was made by Russell and 
Yanez in their 2003 study "Big Picture People Rarely Become Historians," in which the authors noticed differences between activity systems (i.e., how writing is taught in journalism classes versus how it is taught in history courses) manifesting in students as a frustration towards the individual teacher's style and expectations (349-51). Consequently, students in this study appeared to be quite habituated to prioritizing the expectations of the instructor as an individual over their prior knowledge and experiences of other courses and, indeed, other disciplines. For students, the teacher is the most immediate representative of the discipline in which they are apprenticing, and it is easier to be concerned with satisfying the teacher's expectations as an individual rather than as a representative of something outside of the classroom context. As Anne Beaufort observed in College Writing and Beyond, each new class and each new teacher brings a new set of concerns and creates a "temporary discourse community within a larger institutional discourse community", and one with more immediate consequences at that (Beaufort 37-8). The immediate concern over a grade in a particular class takes precedence over the larger, more distant requirements of the profession or the discipline. A second and related insight from composition studies that can illuminate why students treat writing courses — particularly those in their disciplines—as novel rather than connected to others is that students may be habituated to look at the writing in such classes as isolated and anti-dialogical. In Genre and the Invention of the Writer, Anis Bawarshi observes that "students are expected to situate their writing within the writing prompt without acknowledging its presence explicitly in their writing so that it appears as though their writing created its own exigency, that somehow their writing is selfprompted" (134). Students are, in other words, expected to pretend they are not writing 
to the teacher as part of a classroom context, and thereby expected to omit references to the social (the assignment) and material (the prompt) elements that situated them to write in the first place. They are to position themselves, instead, to give the impression that the desire to do this work came from within themselves. Of course, this small feat of mental acrobatics is most often a tacit expectation of which many students and teachers are not explicitly aware, although it has significant consequences on student engagement. Kerry Dirk extends Bawarshi's claim through a Bakhtinian lens, suggesting that students in composition may see the papers they produce in their English classes as isolated utterances outside of any kind of authentic dialogue outside of the immediate studentteacher interaction (para. 5). Following Bawarshi's observation that classroom convention tacitly requires students to omit reference to the class or the writing promptthe social and material conditions that helped bring it about—Dirk posits that "the relationship between the assignment prompt and the actual essay may resist dialogue by its very nature" (para. 17). Consequently, students may see each writing assignment as existing in its own discrete bubble, isolated from other aspects of their college experience and from their lives beyond the classroom and to be figured out on its own terms.

Dirk's concern over the composition paper as an isolated utterance can be readily extended to writing assignments in disciplinary classrooms, which are simulations or approximations of what real members of that intellectual community do when they construct and disseminate new knowledge. For students attempting to look at the papers as genuine writing experiences, the experience can be alienating instead of engaging. As Dirk points out, "the conversation within the paper must act as though it is not a part of a conversation between the teacher and the student" (para. 17, emphasis mine), although it 
inescapably is. Since writing in the classroom is, by nature, separated from the context of practice, we might characterize the goal not as writing to communicate but, as Patrick Dias notes, as "writing to produce writing" (19).

Students can, therefore, become habituated towards treating writing classes and each writing assignments as isolated utterances - a collection of experiences with different, idiosyncratic instructors rather than a process of enculturation into a discipline - comprising activity systems all their own and to be figured out and completed primarily (if not entirely) on their own terms (Russell "Rethinking Genre" 539) This is not to say that students cannot and do not use prior writing experiences to inform future tasks; such influences are inevitable and can creep in even when students are actively trying to do something else (as we will see in the example from a philosophy class below). If, however, we accept Carolyn Miller's assertion that genre comprises "typified rhetorical actions based in recurrent situations" (151), then students are more than likely to view writing to the teacher as their primary rhetorical action, as it is the one with the most immediate consequences. Given this, the desires of the teacher, as perceived by students, can be seen as more important than the goals or conventions of the discipline.

The idea of cues and the model set forth by Activity Theory can help us both identify and begin to address this issue by giving us a language to describe the explicit and implied expectations in the writing classroom: actions and operations. During what is described as the second stage of Activity theory, where Vygotsky's initial formulation of tool-mediated action was expanded to include other elements, Leont'ev described an activity as consisting of a subject, an object, actions, and operations. It is the latter two 
terms that are of interest here as they help us distinguish between intentional, goaldirected processes and the more implicit processes that underlie them. Actions are conscious, goal-directed processes undertaken to accomplish the object of the larger activity. Operations are actions that have become so routine that they can become unconscious processes; the term also refers to the conditions under which the action is to be undertaken (Leont'ev 1979; Engeström, Learning While Expanding ); A hierarchy of these terms can be seen in Figure 3 below.

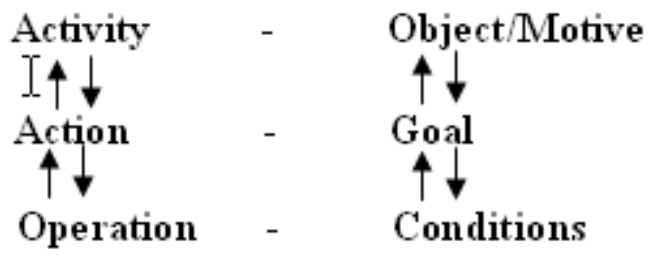

Figure 3. Illustration of relation between Activity, Action, and Operation as formulated by Leont'ev. From Kutti, Kari. "Activity Theory as a Potential Framework for HumanComputer Interaction Research." Context and Consciousness: Activity Theory and Human computer Interaction. Bonnie Nardi ed. Cambridge: MIT Press, 1995: 17-44. PDF.

The bi-directionality indicated by the arrows illustrates how actions can become operations and vice versa. A conscious action can become operationalized when it becomes routine enough that it largely falls below the level of conscious attention. An example of this would be the initial conscious effort spent while learning how to type on a keyboard. The conscious action of typing (which serves larger activities such as typing a paper) can become operationalized when the typist becomes so practiced at it that he/she doesn't have to actively think about where certain keys are or how to hit them in smooth succession. Operations can, however, bubble back up to the level of conscious 
action if the conditions change sufficiently, even when the larger goals and motives remain the same. An example of this might be when our same hypothetical typist moves from using a traditional, rectangular keyboard to an ergonomically-designed one that is split down the middle with key placement meant to reduce hand- and wrist-strain. The typist isn't necessarily re-learning how to type from scratch, but he/she will need to consciously pay attention to how to use the new keyboard before its use can become a routine operation again.

It is in the dynamic between actions and operations that Russell, in synthesizing Activity Theory with Genre Theory, locates the often-tacit workings of genre. In his 1997 article "Rethinking Genre in School and Society,” Russell locates genre within activity systems as “operationalized social action,” (512). Russell synthesizes Miller's focus on genre as typified action with activity theory's concept of operations as more routine, implicit processes:

Genres are ways of recognizing and predicting how certain tools..., in certain typified--typical, reoccurring--conditions, may be used to help participants act together purposefully...genres and the activity systems they operationalized (temporarily) are regularized or stabilized through routinized tool use within and among (sub) groups. (513)

The focus on typical, regularized, routine actions as creating the often-implicit boundaries of genre helps us to locate genre within activity systems as the typified, frequently implicitly-agreed-upon operations that facilitate actions and larger activities. The focus on the temporary nature of genre's regularity is also significant in Russell's articulation of genres place in an activity system. Following Schryer's definition of 
genres as at best "stable for now" (204), genres as operationalized social actions change when the conditions under which they are created change, requiring the genre to be approached as a conscious, goal-directed action. This is particularly true in classroom environments, where students encounter different conditions and expectations as they move from class to class and from instructor to instructor, even if the genres they are required to produce remain the ostensibly same (e.g., writing lab reports in for two different biology instructors).

Patrick Dias, in his article "Writing Classrooms as Activity Systems", notes that "Writing in school...and particularly writing within a writing course, is less likely to become operationalized, that is, flow from goal-directed action to a routine operation as a means of accomplishing an action" (19). Due to its very nature as a class that focuses on writing, Dias contends that the types of writing students perform in class are less likely to become operations as student writers are prompted to devote conscious effort to the complicated, recursive processes of writing. Indeed, the conditions under which students write can change drastically from course to course, causing even familiar genres to be approached differently each time. Of course, the difficulty Dias does not note is that instructors in disciplinary writing courses often have a great deal of tacit, operationalized knowledge that they may not be able to explain students. Students tend to approach new genres (or genres under which the conditions of production have changed) as consisting primarily of conscious, goal-directed actions. In the disciplines, however, many operationalized aspects of disciplinary writing may not be made apparent to students as conscious, goal-directed actions. This is not to say that teachers in the disciplines cannot gain enough distance from their familiar genres to present them as conscious, goal- 
directed actions for students, although that is one hurdle all writing teachers frequently encounter.

Another is a struggle that Russell notes between selection and introduction: should teachers present students with a small, but focused set of genres and activities from the discipline (selection) or provide more of an overview of the variety of genres and activities at work in the discipline (introduction) (542-45)? Further complicating this is the possibility of contradictions between official policies or course descriptions and what teachers as specialized individuals want to highlight for students. In a study of how FYC instructors conceptualize their personal goals for teaching alongside the official goals set by the department, Wardle identified the many ways that the motives and goals of individual FYC teachers clashed with the official motives of the department. These included the desire felt by many teachers to focus on teaching general critical thinking skills and having students write about disciplinary issues as opposed to teaching discipline-specific genres. In part these conflicts were due to the difficulty of ostensibly preparing students to write in any/every discipline via an English class ("Can CrossDisciplinary Links Help us Teach 'Academic Discourse’ in FYC?”). Similar conflicts occur across the curriculum, with various forms and intensities, which increases the variety of experiences students will have writing from course to course and instructor to instructor. This variety isn't a bad thing, but it can make writing challenging for students.

Even if students encounter the same or similar genres across a discipline, then the conditions under which they are producing them in any given class will vary according to the instructor and the class. Two classes may both task students with writing a Literature Review of extant research on a topic, but each teacher will probably have different 
expectations (explicit and tacit) for this seemingly-similar task. The "they should know how to write that by now" approach to teaching writing, then, abdicates responsibility for continuing students enculturation into a mode of disciplinary writing/thinking and overlooks the very real need to clue students in to the particular aspects of that writing that the teacher in question wants students to focus on most. Genres may end up as operationalized social action by seasoned writers, but they are first encountered as constellations of conscious, goal-directed actions by newcomers. Consequently, many tasks that teachers may consider to be rote operations have to be approached by students as conscious actions.

Cueing these actions in writing prompts can help remove student anxiety about what the teacher expects. As detailed earlier, students treat each classroom as a discrete and temporary activity system and may tend to conflate what they perceive to be a teacher's personal preferences with what that teacher's discipline has trained him/her to do. This means that they tend to approach each writing task as one to be figured out on its own terms. Thus, to make the most of a disciplinary writing assignment, teachers need to include support for both the actions students are to expected to take in a paper and the operations that underlie those actions, if only just to mobilize both their explicit and tacit knowledge for the task at hand and sanction their use in that particular class with that particular teacher.

Confusion or conflicts in the process of supporting actions and evoking underlying operations can cause contradictions or double binds for students. This can manifest in conflicts between what students are explicitly told to do and what they are implicitly expected to do. It is important to note these areas where the approximation or 
simulation of disciplinary writing breaks down for students, taking them out of the desired authorial role of disciplinary participants, and causing a kind of tug-of-war between competing motives and conventions. The writing prompt is a representative touchstone for a disciplinary writing assignment and the contradictions that students can encounter within it. They are also sites where students locate themselves in terms of what the project is asking for, what the teacher expects, and in terms of their prior experiences with the genre and with the discipline.

This chapter will explore how the cues (both explicit and implicit) for writing assignments can be spread across the classroom activity system via assignment sequencing and teacher feedback. It will present two classes in which the teachers used feedback on smaller assignments to inform students as to how they were to interpret the actions and operations presented in the assignment prompt's cues. In the first case, that of an upper-level Biology class, students were confident in their understanding of the assignment despite a very spare writing prompt thanks to the teacher's highly personalized feedback and experience with the class. The second case will show students in Psychology struggling to understand a teacher's directions despite feedback and assignment sequencing, due in part to the teacher working with an adaptation of another instructor's course (which caused a collision of two activity systems and some contradictions and double binds for students). What this chapter will show is that students are aware that even familiar conventions used in different classes can take on different forms depending on the operations involved in that particular setting, which observed as the instructor's idiosyncrasies or specific interpretation of common disciplinary actions. Consequently, providing a writing prompt with detailed cues as to 
the actions students are supposed to make and providing support consistent with the operations underlying those actions can lessen student anxiety and help them distribute their energies more effectively in the simulation of academic writing expected by the instructor. The writing prompt instead of just being a starting place can then become an anchor point for teacher and student as they engage in a negotiation of what writing is appropriate for the course.

\section{Learning to “Evaluate” in Biology}

When instructors request a writing action from students, they are working from a set of operationalized assumptions that they may or may not be cognizant of. Dr. Steiner's Biology 416 course is an example of this, as the professor used a very spare writing prompt that masked the operational assumptions made by the term "evaluate." The class utilized assignment sequencing (shorter assignments, project milestones, etc.) to make up for a lack of detailed cues in the prompt. Through personalized feedback on short assignments and a process of initial trial and error, students were able to make sense of the operations underlying the actions that Dr. Steiner's vague prompt was asking for.

Biology 416, Biology of the Cell, comprised mostly of juniors and seniors (with most of those pre-med), and it zoomed in to find "the story at the cellular level," as one student put it. While many of the pre-med students had obvious interests in clinical topics or in research at the level of the entire organism (hospital treatment of cancer, for example), Dr. Steiner (a distinguished faculty member at the school) wanted students to focus in on the advanced and complex functions of life and behavior at the cellular level, including biochemical and molecular functions (such as the more-nuanced aspects of 
cancer cells). Dr. Steiner, a very affable and engaging professor, indicated that the course was different than most of those biology majors encounter in at least three important ways. First, as a WR course the class size was smaller and students were asked to do far more writing than in previous courses. Second, Dr. Steiner made daily participation in the course, in the form of contributing to the class discussion over readings and materials, worth fifty percent of their overall grade. This was different for biology majors used to classes where they could sit, take notes, and do well on the exams to earn their grade. Getting students to participate was a challenge, but Dr. Steiner indicated that it became easier as time went on:

once I get them over the fact that I'm not going to laugh at them if its wrong, or that other at people are going to laugh them because it's wrong, because they're going to have wrong answers some where too, we sort of get past that... and now we have students not just trying to answer, they're asking questions! That's where I want to get, where they're all comfortable to ask questions, because that's what scientists do.

Indeed, his concern over having students in engage in "what scientists do" was a driving force in the class design, and was directly related to the third way this course was different from other biology courses.

The third way in which this course was different from those biology students were used to was in its extensive engagement with primary literature (as opposed to only using a textbook), namely studies and academic articles. Dr. Steiner asserted that to be successful, a biology student needs to "be able to use the language, understand how to read those papers, extract from them the principle points, be able to play one off against 
the other. So I'm really trying to get them to practice and then to do." Doing Biology, according to Dr. Steiner, meant being able to read the primary research, identify its core components, and be able to intelligently discuss that or pose questions for the future with other experts. In his Cellular Biology class, Dr. Steiner was able to do something he was only rarely able to do in his teaching: to focus on creating a discussion-heavy class community that emulated the academic discussion and inquiry that drove the field (as opposed to the lecture format dictated by the large size of the other courses he taught).

Dr. Steiner's class, then, was a very distinct activity system for his students, and one they had to adapt to in a different way than their other courses in their major. Even if many elements seemed familiar, the change in conditions meant that students still had to orient or re-orient themselves to the genres they were asked to produce. Dr. Steiner organized his class assignments so as to further his goal of having students do biology (in the form of interacting with and discussing the primary literature). The final exam in the course was an oral exam consisting of an in-depth, one-on-one conversation with Dr. Steiner regarding a particular scientific article. The major writing project for the course (worth $30 \%$ of the final grade), was a ten-page "library research report" in which students conducted an extensive evaluative review of at least ten peer-reviewed scientific articles related to a topic of their choice (so long as it focused on what was happening at the cellular level). Dr. Steiner gave students the instructions for their final paper along with the syllabus on the first day of class, and they are induced in their entirety in Figure 4:

LIBRARY RESEARCH REPORT: A 10 page (not counting references) fully referenced report is expected from each student in the course. The textual format is open, although references should be included in one of the formats 
commonly utilized in scientific writing. You can use the assigned literature correlation papers as appropriate examples of reference formatting. The report should evaluate some aspect of the recent literature on a specific or general cellular topic. The report may review the field related to a topic, or could involve a comparison/contrast discussion of papers in an area of controversy. The following is the schedule related to this written report:

1) $2 / 24$ - topic (submitted in writing) approved by instructor;

1) $3 / 10$ - outline and initial reference list due;

\section{2) 4/5 - draft of paper due (will be returned with suggestions for revision);}

3) final copy due at oral exam (or earlier) Appropriate and necessary figures, graphs or diagrams may be included in the report. However, if they are not original, you must provide a reference to their source. These non-textual components of the report must account for less than $20 \%$ of the report. Strive to keep to a minimum (or eliminate) the use of web sites as references.

Figure 4. Prompt for Final Paper in Biology of the Cell (all emphasis original).

The prompt is very vague in terms of the assignment's genre, the moves it is intended to make, and its purpose in the course. There is no arrangement of cues or indication of the actions students are to take. It seems to presume a lot in terms of the underlying operations supporting it. There are ambiguous directions, such as "the textual format is open", which seems to indicate a great deal of freedom in the assignment, but the line above that indicates it should be "a fully referenced report" might contravene that suggested freedom as it indicates a particular, but vague, format. Also, the prompt 
indicates that the report "should evaluate some aspect of the recent literature" (emphasis mine) and that "it may review the field related to a topic" (emphasis mine), which at first glance seem like an effort by the teacher to lay out options for the students, but on closer inspection can lead to conflicting understandings of the assignment. Is it about giving background on a topic (reviewing the field related to a topic), or is it about discussing the efforts of the individual studies and their writers as agents in their fields? In terms of the "two way street" of genre in which purpose and form are mutually informing (Williams and Colomb 261), this prompt is vague about both ends of that street. In short, this prompt is vague enough to allow for multiple interpretations of the paper's purpose and genre, which makes performing an appropriate uptake difficult at best. The prompt could lead to contradictions or double binds in the class, as on its own it is not particularly effective as a mediating tool for the activity of the assignment.

Three students interviewed reported confusion and frustration concerning what exactly the prompt was asking for. This chapter opened with an example from the experience of one pre-med student, Diane, who knew that the prompt was the tip of the iceberg in terms of Dr. Steiners' expectations for the project. She was concerned that she would have to really work to find/figure out what Dr. Steiner really wanted from the project. Robin, and Tiffany, two other pre-med students, reported confusion over how Dr. Steiner was defining the core generic functions of the assignment. These two students felt that the statement "the textual format is open" might concern the use of references and citations, although Tiffany speculated that it might also extend to a number of possible shapes the paper could take: 
Tiffany: I guess what he was looking for there was kind of like however you want to do your references. I guess you could do the format exactly like a review, and have like an abstract, and all of that, set it up like a scientific article, or you could do it like I did, just a regular term paper. I guess that's what I understood.

Matt: Ok, what do you mean by "a regular term paper?"

Tiffany: You just start writing and go. I guess you have a thesis statement and what you are planning on doing, but it's not broken down like a scientific review would be in the different categories or anything like that.

While her initial comments suggested she was talking about references and page formatting, Tiffany's speculation also takes in a myriad of signals that the prompt is giving in terms of the paper's overall genre. These signals run the gamut from a paper structured like a review, to a scientific study, to a text that more closely resembles an essay. When looking at the instructions further, Tiffany indicated confusion as to whether or not the central purpose was to compare and contrast specific papers with one another or to just write freely about a topic.

By forgoing the use of more explicit, hierarchical cues while indicating "the textual format is open," the prompt creates a mild contradiction for students. On the one hand, the paper seems to support freedom of choice in its structure while, on the other hand, they are also aware that there are specific expectations being masked by the prompt's ambiguities. The guideline of "evaluate" turned out to be a defining characteristic of what Dr. Steiner considered to be a successful paper, but exactly what was meant by "evaluate" and what kind of action and operational structure that purpose was meant to imply was not made clear in the cues offered by the paper's prompt. The 
prompt appears to assume that students have a particular understanding of what it means to "evaluate" already ingrained and operationalized. While students may have performed evaluations in other classes, the change in instructors (and therefore the chance in conditions) meant that they had to find out what Dr. Steiner meant by "evaluate." Here we have a situation of confusion between the actions indicated in the prompt and the conditions (operations) under which those actions are to be performed.

While the vague assignment prompt seemed like it would herald a double bind between the instructor's and the student's operationalized understandings of what it means to "evaluate," gaps such as these were filled in by the assignment sequencing Dr. Steiner implemented in the class. The course was sequenced so that students could rely on experience and feedback from a sequence of smaller assignments to further establish the generic parameters for the major paper. In particular students were required to write five smaller writing assignments (of roughly 2 pages each) in which they were to evaluate the presentation of data and conclusions reached in articles that they were assigned as a class. The subjects and methods of these articles were coordinated with class readings. For example, at the culmination of a unit based on cellular division, students read and evaluated a 2010 article in the Journal of Cellular Biology on the role a particular protein plays in mitosis (the stage of cellular division leading to the division of a cell's nucleus). This work was supported by a set of guidelines titled "Reading and Evaluating a Scientific Paper." This four-page document details how to effectively read, understand, and evaluate a peer-reviewed, scientific research article. The core of this document for the students was a set of criteria for evaluating a research paper, excerpted Figure 5 below. 


\section{Our Rubric For Evaluating a Paper}

A thorough understanding and evaluation of a paper involves answering several questions:
a. what questions does the paper address?
b. what are the main conclusions of the paper?
c. what evidence supports those conclusions?
d. do the data actually support the conclusions?
e. what is the quality of the evidence?
f. why are the conclusions important?

Figure 5. Criteria for Evaluating a Scientific Article from Dr. Steiner's Biology of the Cell course (full document available in Appendix B)

The full version of this document includes supplementary paragraphs with further explanations of each question (see Appendix B), but this excerpt provided exactly the type of hierarchically organized cues that students lacked in the prompt. Students used this rubric to guide their evaluations in the shorter assignments. Dr. Steiner indicated that he had not always provided a rubric for this sort of assignment, but when he started to he received work much closer to what he was looking for. While the information provided in "Reading and Evaluating a Scientific Paper" did not present anything completely new to the students interviewed, it was crucial for figuring out the actions and underlying operations that Dr. Steiner wanted to see as they evaluated scientific research. This clued students into the operations underlying the action of "evaluation" that they would have to perform in their major paper. Figure 6 illustrates the activity system of Dr. Steiner's class and the problem being discussed. In this adaptation of Engeström's version of the 
mediational triangle, the different loci of activity writing Dr. Steiner's course and their relations to one another are outlined.
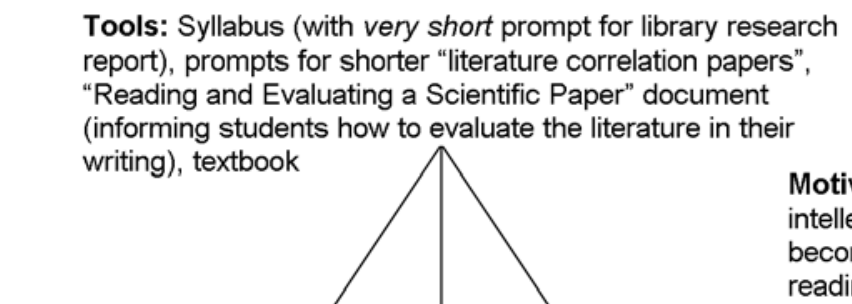

Motives: Have students engage in the intellectual and social work of Biology by becoming familiar and comfortable with reading, unpacking, and discussing the

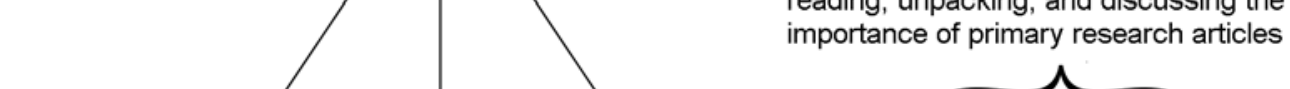

Subject: Student Research Report Paper not know what teacher wanted at first, but through consistency of assignment feedback, supporting materials, and approaches to in-class discussion, they were able to learn what the teacher wanted in the

Rules: "Doing" the work Community: Teacher, of Biology by reading, students (much smaller, summarizing, discussing, more intimate class than and responding to primary literature in class and in writing more intimate class than one another), research paper students in Biology normally milestones (topic approval,

Division of Labor: Assignment paper and were confident in their ability to deliver it. bibliography, draft), personalized feedback from teacher

\section{Figure 6. Activity System of Dr. Steiner's Biology of the Cell Course}

Even with the rubric and the support of the Reading and Evaluating a Scientific Paper document, students had to adjust themselves to the actions and underlying operations required by Dr. Steiner through a process of trial and error. This difficulty was best illustrated in the difficulties that Robin, a pre-med student considering a specialization in dermatology, faced in trying to perform an appropriate uptake od the textual directions. What she found was that the instructions for the paper in the syllabus and in the Reading and Evaluating a Scientific Paper document veiled important operationalized assumptions concerning the term "evaluate":

To me, when I see the word evaluate, that says to me the more, like assess this, this is what they're saying, do I think it's true, do I agree with it? That type of 
stuff, but for [Dr. Steiner] I think he wants us to be able to read it, understand it, and comment on it, not necessarily determine the quality of it, but just to say what's going on.

Robin's initial impression of the project was that they were to evaluate the choices and quality of the methods being used by researchers. Qualitative judgment was a function of evaluation that Robin had operationalized, and which was activated for her by the prompt. She found that she had to re-evaluate those assumptions in terms of the kind of evaluation Dr. Steiner envisioned for the course. Through feedback from her shorter assignments, Robin discovered the differences between her assumptions about evaluation and those of Dr. Steiner. The grades and comments she received from her shorter assignments informed Robin that "evaluating" in this class did not mean critiquing the researchers for any defects or problems with their methodology:

At first...I thought not that [challenging] them was not the main point of the paper, but that it was a significant point you needed to address. Now I'm not even taking that approach with it anymore, I'm just trying to summarize the article and what the main point of it is, rather than how they went about doing it.

Dr. Steiner was looking more for summary-evaluation, unpacking the results of the research articles and evaluating their importance to the state of knowledge, not critiquing their techniques. This was the underlying operation signified by the term "evaluate," and which Robin had to ingrain explicitly in order to perform the actions required by the course's major paper.

Additionally, Robin and Tiffany had difficulties distinguishing between questions in the Reading and Evaluating a Scientific Paper document. Since the criteria excerpted 
in Figure 5 don't indicate which items are worth more or less (it doesn't even explicitly say that this is a grading rubric either), Robin wrote to each question equally in her first short assignment and was counted off for it. It was by a process of trial and error that she figured out which questions to focus on more than others. Tiffany had some difficulties in early short papers distinguishing between two similar items, c and d in Figure 5, which ask what evidence is used to support the researcher's conclusions and whether the data actually support those conclusions respectively. She indicated that she "always felt like that was the same thing....I guess whenever I would explain that part of the research paper I kind of clump it together in my papers.” While the rubric in the Reading and Evaluating a Scientific Paper did provide considerably more cues than the prompt in terms of signaling what types of actions (and what operationalized assumptions might underlie them) was required by writing in the course. Still, it left several important distinctions unspecified.

Dr. Steiner's Biology of the Cell course did several things very well in terms of supporting student writing. He had a sequence of shorter assignments tightly sequenced with course readings and discussions, several milestone assignments (such as topic approvals, bibliographies, and drafts) where students could get feedback from him as they went along, and he provided personalized feedback for each of his students' assignments. The feedback turned out to be the most helpful part for the students, and it compensated greatly for the ambiguity in the prompt and the Reading and Evaluating a Scientific Paper document. When asked whether the prompt and other written guidelines or whether Dr. Steiner's verbal explanations in class helped her more when it came to writing the final paper, Diane said: 
Diane: That's a great question. Can I say neither?

Matt: Sure, as long as you tell me what you mean.

Diane: Yeah, I think the best preparation I could have gotten for this paper was his critique of my writing in the smaller papers. So not necessarily how he was explaining it in class, but, um, putting what he was saying in practice and then having him see if I met those expectations.

Thanks to the small class size and his experience in teaching this course multiple times (improving it a little more each time), Dr. Steiner was able to help his students perform an appropriate uptake of his directions by the time they reached the major paper. The implicit assumptions about writing, and particularly about "evaluating," became clearer to students through his sequencing and feedback.

While the students in Dr. Steiner's class were able to perform appropriate uptakes for the final project thanks to his feedback, it should be reiterated that Biology of the Cell was an unusual course within that major. It was a smaller, discussion-heavy class focused on primary literature and requiring a great deal more writing than students were used to. There were many more opportunities in this class for students to learn more about the operationalized assumptions underlying Dr. Steiner's view of writing in Biology than other students in other courses in the disciplines (even within the same major) might have. Even thought the prompt did not signal its actions in a clear hierarchy, through lower stakes assignments and milestone assignments, students had a lower-stakes learning curve to acclimate themselves to Dr. Steiner's view of "evaluation," for example. That this was a course Dr. Steiner had taught several times before also helped a great deal. The prompt should act as more of a nexus for cues about 
actions, clues about underlying operations, and in general signals for what Dr. Steiner wanted to see in terms of evaluating scientific research. In the next example we will see what happens when a course, and an entire activity system, is inherited from one instructor to another, causing conflicts between two competing systems.

\section{Contradictions in Multicultural Psychology}

Psychology 366, Multicultural Psychology, is a course for psychology majors and minors that focuses on how psychological issues affect different cultures in different ways The course was very popular under Dr. Davis (an Associate Professor in the Psychology department) with a wait list so long that students had to be approved for the course by the department before they could even try to register for it. After many consecutive semesters of teaching this popular course, Dr. Davis desired a break. During the semester in which this data was collected, Dr. Davis collaborated with Dr. Baker (a new Assistant Professor in her second semester at working the university) as the two different sections of this course. Many of the materials for Dr. Baker's course came from Dr. Davis, who planned on taking a break from the course the following semester and letting Dr. Baker take over. The major and minor writing assignments (namely the MCT paper and the Multicultural Thought assignments) were kept essentially the same between courses so that the two instructors could discuss teaching strategies more easily. This section focuses on the course as taught by Dr. Baker (although both teachers were interviewed), since inheriting course designs and swapping writing assignment designs is both common and vulnerable to contradictions and double binds. Students must not only negotiate their immediate instructor's expectations, but those aspects of the previous 
instructor's design (such as certain operationalized assumptions or connections between parts and materials) that may be floating in the activity system beneath the conscious awareness of student or instructor. The result can be confusion and contradiction for both parties and the following section will illustrate why writing prompt with effective, detailed cues is important in such an instance since the vague prompt used in this project acted only as a vague nexus for a set of conflicting expectations.

The semester in which I interviewed Dr. Baker was only her second teaching at that university and her first teaching this particular Multicultural Psychology course. Her primary goal for the course was to put students in touch with the psychologies of different cultures since "almost all of the classes they take in the department are from a Eurocentric perspective, so it's hard to understand and appreciate how other cultures look at things if it is just from one viewpoint" Her second major goal for the course was to strengthen student's research and research writing skills. Like Dr. Steiner's class, Dr. Baker wanted her students to be able to read the empirical literature in the field and effectively summarize, evaluate, and comment on it:

I expect them to be able to describe a research study...to explain the study and then to be able to say 'this is how it's done, this is the sample that was used, this was how many people that were in it.' This is the minimum I expect them to do, you know, and also to say what the basic findings were, like we found that people who were high on stress but low on mindfulness. That would be the minimum, and then beyond that I would hope that they then could compare different articles they've read and then talk about it in a, you know, be able to synthesize it more. 
The goals expressed in the excerpt above are very similar to the kind of summaryevaluation that Dr. Steiner had in mind for his students in Biology of the Cell: she wanted students to be able to understand and comment on the methods and reported results of the primary research and to understand what role they play in the academic conversation. Indeed, comparing a research article to others out there in the field was an important endgoal for Dr. Baker, as she wanted her students to realize that (in her words) "all the studies aren't created equal," and that we can learn what the field still doesn't know by finding what certain studies fail to address completely or what they overlook.

The assignment prompt for the course's major research writing project didn't provide much support on how to accomplish these goals, however. It is a good example of vague actions that could have a myriad of operations underlying them. The prompt was two pages long, and the first page provided due dates and some very basic information about the paper's milestone assignments (topic approval, bibliography, outline, and a draft). The top of the second page provides some basic formatting requirements. It is in the middle of the second page (excerpted below) that students could find cues as to the genre and shape of the project: 


\section{Papers should cover the following areas:}

- History of the issue $(\sim 0.5$ page $)$

- Relevance of the issue ( 1 page)

- Current research on your issue ( 4 pages)

- Cultural Differences ( $\sim 0.5$ page)

- Cultural Similarities ( 0.5 page $)$

- New directions for more research or action ( $\sim 0.5$ page $)$

Figure 7. Prescribed Outline provided in Dr. Baker's Multicultural Psychology Assignment Prompt

The prompt provides more information about the due dates and formatting requirements than it does about the paper's genre. There is no overarching statement about the goal of the paper other than that students are to learn about multicultural psychological research, improve their writing skills, and are free to pick a topic of their choice (from class or on their own, so long as it relates to the class' theme). The cues it does provide (as seen in Figure 7 above) are in a hierarchy, but they only announce very basic actions of the paper, revealing little of the underlying operations that define those actions. Indeed, it presents the actions that comprise the activity of the assignment almost as though they are already operations that students are to implicitly understand and complete. Given the minimal support in this prompt for understanding the paper's genre and the moves to be made within it, and the minimal amount of in-class discussion about the paper, the students were obliged to use the assignment sequencing and their assignment feedback to figure out what was desired from the major paper. The section following the criteria presented above, in which the teacher tells the students "Don't lose 
points by" followed by a list of don'ts, is more detailed than the cues that are intended to clue students in as to the actions and underlying operations of the paper. Like the students in Dr. Steiner's class, Dr. Baker's students needed to use other parts of the activity system than the writing prompt to help them figure out what they needed to do for the final paper.

The problem was that the other parts of the activity system were not as revealing as they could have been, and consequently students were confused about the actions and operations that comprised their paper. There were shorter papers for the course called Multicultural Thoughts, and were intended to be short essays (4.5 pages maximum) on one of a selection of topics. The topic options for these essays could be springboards for discovering a topic for the final paper, but they acted more to familiarize the students with the grading procedures and to get them used to reading the primary literature. Dr. Baker indicated that one of the most important things students could pay attention to was the primary literature so that they could emulate their style in their work for the class (although how they were to emulate it was not clearly signaled in the prompt). The selections for the first MCT paper are provided below in Figure 8. 
Choose 1 (ONE) of the following:

1. Select a movie from the following website [...]: Select a character from the movie and identify a struggle related to the course material that is endured by this individual. What are the psychological components of this struggle? Did the character effectively manage this struggle? What cultural components based upon the individual's background contributed to his or her decision making?

2. The world's highest suicide rates are reported in Sri Lanka (47 per 100,000) and Hungary (39 per 100,000). There are a number of hypotheses as to why these rates are higher than other countries in the world. Investigate internet sources and scholarly journals to explain what psychological explanations may account for these substantially high suicide rates in these two countries. Make sure you correctly cite your sources according to APA format.

3. Different ethnic minority groups have different attitudes about mental-health services. The literature presents conflicting results with regard to ethnic minority groups and mental health service utilization and outcome. Select an ethnic minority group and determine what the literature indicates about this particular group with regard to seeking mental health services, treatment outcome, drop out rates, and other factors. What barriers exist among this group?

Figure 8. Writing Prompts for Dr. Baker's Multicultural Thoughts Assignment. 
Aside from these instructions, a paragraph at the top of the prompt asserted the necessity of citing any sources in APA format. Each topic in the list covers a particular part of multicultural psychology from the readings or class discussions, which included textbook readings and the occasional academic article. The prompt, however, does not provide much in the way of structure for these papers. This is somewhat similar to an example that Bean provides in Engaging Ideas in which a writing prompt (on the subject of the gravedigger scene from Hamlet) overwhelms students with a dense paragraph loaded with far too many questions, one after the other in almost rapid-fire fashion. While the MCT paper prompt is not as overwhelming as the example in Bean's book, it does seem to suffer from a similar problem "because the questions seem parallel rather than hierarchical, students are apt to produce a series of short answers, addressing each in turn, rather than in a unified essay" (105). Which questions or pieces of information do students write more about? Which do they give greater weight? These are very material concerns that are not addressed in the prompt, and acclimating to Dr. Baker's expectations for these assignments was not easy for students.

The students were aware that the course had been adapted from another instructor, and this manifested itself in a series of conflicts and contradictions between written instructions, verbal instructions, and assignment feedback. There was a definite learning curve in the assignments for Elaine, Catherine, and Maya, three psychology majors in Dr. Baker's class. Like any writing course, the learning curve on these assignments not only involves the skills that Dr. Baker wants the students to learn, but the way Dr. Baker reads and assesses the demonstration of those skills on the page. Elaine reported confusion upon receiving her first MCT back with a grade and comments, since she reported that 
they were not told that "we needed to have a title page and all that stuff... we didn't realize we were supposed to have a certain number of sources, but apparently we were supposed to have four." Catherine and Maya reported similar confusion. The prompt for the short MCT papers did indicate that all sources used should be cited in APA format, but did not indicate what or how many were to be used in an MCT paper. In addition, the rubric for the grading of the assignment was not provided until after the grade had been assessed on the first MCT.

Students also reported more glaring contradictions that left them confused about the cues and underlying operations of their writing projects for this class. Catherine pointed out that the second option under the first MCT assignment specifically states that they are to "Investigate internet sources and scholarly journals to explain what psychological explanations may account for these substantially high suicide rates in these two countries," but that the students were told adamantly to never use internet sources for the class. Such contradictions are the result of the inclusion of new elements (Dr. Davis' course) into Dr. Baker's teaching activity system. Despite these problems, however, Elaine indicated that the practice was helpful for her:

I think the thing with the first one too that was the first real formal thing we'd ever written for this class, and so no one really knew how to structure it or, I guess like how formal it was supposed to be, so by the second time around we knew exactly what they expected so everyone did better on the second one. Similarly, Catherine and Maya reported improved grades on the second MCT paper now that they knew what to expect and look for. Still, these types of discrepancies and 
conflicts were symptomatic of the conflicts between Dr. Davis' instantiation of the course and Dr. Baker's adaptation of it, and they carried on in other assignments.

In the outline assignment for the major paper (part of the sequence for the major research paper), Elaine reported that a meeting with the class TA compelled her to rework her outline from the minimum 1.5 pages specified in the prompt to six pages long. There was an example available to student that was eight pages long, but the prompt itself (the official instructions) does not help give an idea of the investment this project required. There were other expectations not outlined or not treated as actions that the students were not made explicitly aware of, such as how they were to tie classroom discussion into their writing. Catherine observed that "I think something that's not on here [indicating prompt] that she expects is the relationship to class stuff, that you have to incorporate what we're doing in class in the paper, and she never told you that, but it's on the rubric." The connections between the actions explicitly signaled in the prompts and the implicit, operationalized assumptions held by the instructor and the TA were largely hidden to students

The division of labor provided by these assignments, the sequencing of smaller, related assignments and milestones towards the major paper, did not help students make connections between the instructions in the assignment prompt and what they were supposed to take from their smaller assignments as much as they could have. In Activity Theory terms, the underlying operations and even the actions themselves were not being clearly signaled, leading students to guess at requirements and tinker towards better grades via a higher-stakes process of trial and error than that experienced by Dr. Steiner's students. The feeling that they were not being told everything they needed to know, 
along with the surprises they encountered when they received grades and comments, prevented students from feeling confident about their work on the final paper. On the subject of the prompt, Catherine indicated that she "thought they had a few holes in them. They kind of led you to ask a bunch of questions." Asking questions, however, produced mixed results.

The students interviewed reported that the class did not feel like an open environment to ask questions. Catherine said that "There's not really directions so you have to assume a lot or you have to ask a lot of questions...[but] It's not very inviting to ask questions. Well, I always go to the TA...and she ends up asking Dr. Baker and eventually she'll get back to her and she'll get back to us." Elaine, Catherine, and Maya reported asking questions of the instructor frequently, and also reported that they felt like they were imposing by asking questions since Dr. Baker would pass the questions on grading and requirements for assignments off to the TA. The TA in turn might often say she could only reply after checking with Dr. Baker. In a similar fashion to the Nursing course discussed in chapter 3 and 4, distributing grading and commenting duties across multiple individuals made the system more vulnerable to conflicts and contradictions. Due to the ineffective nature of getting answers, Elaine reported preferring to not ask questions and figure it out on her own. The community aspect of the activity system, in this case, did not help to give students the support they needed to understand the actions and operations necessary for the assignment. A diagram of the activity system of the course is featured below in Figure 9. The elements in contradiction are connected using dotted lines. 
Tools: MCT Paper Prompts and Research Paper Prompt

(adapted from Dr. Davis' Course, occasionally missing

important instructions and/or containing instructions contradicted by teacher's explanations), APA Manual,

Research Databases

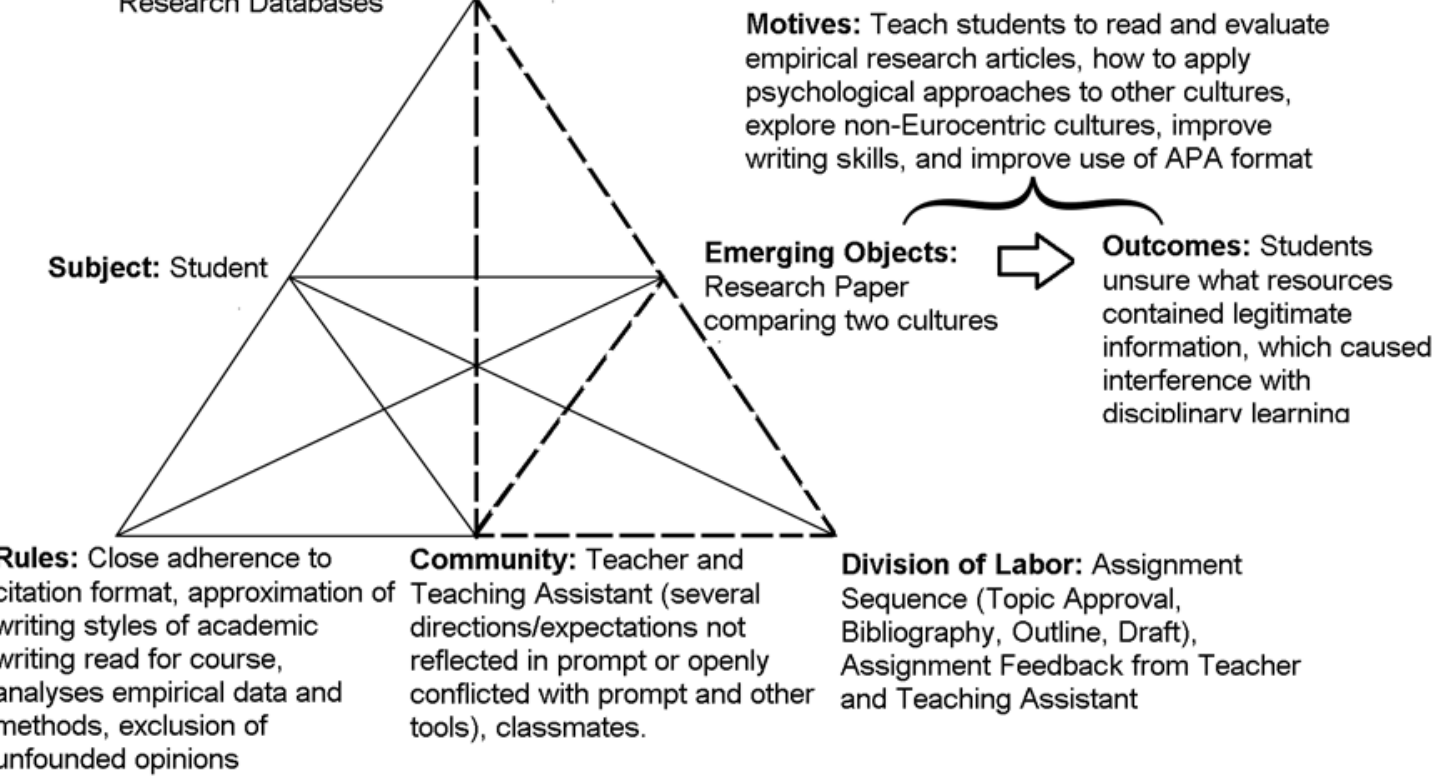

Figure 9. Activity System and Double Bind in Psychology (dotted line between elements in contradiction/conflict with one another)

The students in this class received competing and often contradictory signals regarding the expectations for their writing assignments. As depicted in Figure 9 above, the tools did not quite match the information students received from the community and the division of labor, leaving them confused as to the expected outcomes. This class is illustrative of a stereotypical trail-by-error writing course, where the student expects the "assign and complain" method rather than a more nuanced unpacking of actions and their underlying operations. The students were quite aware of the fact that Dr. Baker's materials were borrowed and that she was new to teaching this specific course, which in combination with the reticence to answer questions about the course prompted the students interviewed to doubt how helpful she could be in revealing her expectations before they submitted their work. Their strategy became the student's version of "assign 
and complain," an approach of "submit and fix" requiring revision. This is not to say that revision is a bad thing, but that students are not actively learning how to write in a discipline if their only way to find out critical elements of the teacher's expectations is to submit and expect to have to make major corrections later.

For both Dr. Steiner's and Dr. Baker's class, a writing prompt that contained more explicit and organized cues would have helped students better orient themselves towards their teachers' expectations. It would have also helped students better understand the lessons about writing in their respective disciplines that the papers were intended to teach. Even though students in Dr. Steiner's course eventually came to an understanding of what he was looking for in terms of what the students thought were familiar actions (e.g., evaluation), a more revealing writing prompt would have alleviated their concerns and given them more experience and guidance in consciously applying the conventions that Dr. Steiner wanted to see in their writing. In Dr. Baker's case, where the teacher was using someone else's assignment and still adjusting her pedagogy to suit her students' needs in that program, a more revealing prompt would have been especially helpful. The prompt could have acted more as a mediating tool, an anchor point, for both students and teacher, since both parties were new to its particular set of actions and operations. Inheriting or appropriating writing assignments from other instructors makes teaching writing possible, so it is not a practice we should discourage. What the case of Dr. Baker's class illustrates, however, is that teachers should be aware that they are adopting more than a set of instructions, but borrowing from a constellation of cues, actions, and operations that are a part of someone else's activity system and someone else's pedagogy. For teachers focusing on promoting the acquisition of disciplinary 
discourse and writing habits, very real differences between seemingly similar cues, actions, and underlying operations can manifest themselves as frustrations as students try to reconcile the instructions in the prompt, the manifest expectations of the instructor, and the built-in expectations of an absent third party (the originator of the assignment). Dr. Steiner's expectations of "evaluation" were different from what some of his students had in mind, but his class was an activity system he had cultivated over the course of several years of practice. He had built in opportunities for students to understand his specific approach to evaluating scientific research, and how it was similar or different from what they had seen before. Dr. Baker's expectations, however, were openly competing with the instructions from the course material, much of which originated from Dr. Davis' design. Students were left to wonder if the teacher knew what she wanted the final product to look like.

What was more than evident, however, was that Dr. Baker had a very firm idea of what she didn't want in the final paper. Assignment sequencing cannot make up for a lack of explicit cues in the writing prompt, since the "assign and complain" method tends to frame actions in terms of negative reinforcement: don't do this or you will lose points. This list of "don'ts" was one of Dr. Baker's personal additions to the prompt, and they are quite substantial. Indeed, the cues concerning what students should not do outnumber the cues regarding what should be in the paper. This gives students boundaries with negative repercussions for writing that fell out of bounds, but little foundation on which to scaffold and build their writing. Most of these cues signaling what not to do were concerned with citation and formatting expectations. 
Instructions for citation and formatting expectations are pervasive in writing prompts across the university. Rules for citation and formatting, like those in the APA

manual, are often presented in writing prompts as skills students should have mastered by the time they start to dig into their major. This particular skill set suffers from the same myths of transparency and transience (the idea that writing is both the unproblematic application of rules and that it can be mastered) as writing in the university in general.

\section{Citation Obsession as Symptom of the Myth of Transience}

As this chapter has argued, providing revealing cues in writing assignment prompts are important as students need to not only clear signals about the conventions they are expected to use, but signals about what their particular teacher is looking for in the use of those conventions. The latter type of signal is important, because while many conventions and approaches to writing will carry over from one class to the next (e.g., the general format of the IMRaD-style report is fairly standard and stable), students are very aware that expectations will vary from teacher to teacher, even within the same discipline. The most explicit and stable cues that students may receive across classes in their discipline may be those concerned with citation format and use. Where other areas of writing assessment may seem open to debate, critiquing proper citation format is seen as relatively cut-and-dried. Consequently, they are also the rules that teachers expect students will have already mastered by the time they are in an upper-level course, and thus do not receive much attention other than to remind students they can lose points if they violate certain rules. In this way, the teaching and reinforcing of citation is emblematic for the tacit instruction in writing across the university: it is seen as 
unproblematic, to be mastered by a certain level, and often (though not entirely) taught in the "assign and complain" mode.

This type of instruction was evident in the prompt for Dr. Baker's class, as seen in the list of pointers presented below in Figure 10.

\section{Don't Lose points on this Assignment by:}

- Turning it in late (10 percent off per day late)

- Leaving out key elements (make sure you include everything listed above)

- Using Internet sources (ask if you have a question about this)

- Forgetting citations for important facts (any fact you didn't already know must have a citation)

- Poor writing style (have someone else proofread it for you if writing is not your strength or visit the writing center)

- Writing more than the maximum amount (extra pages will not be read)〉

- Violating APA format requirements (you will get a zero)

- Handwritten papers are not accepted (you will get a zero)

- Submitting a WordPerfect or.rtf document (these will not be accepted)

- Plagiarizing - any sentence with 5 or more words in a row that are not your own should have quotations around them. (Warning: if you copy 1 sentence or more from another source without citing it, you will get a zero for the whole assignment)

Figure 10. List of Proscribed Actions and Corresponding Penalties for Dr. Baker's final paper. 
It is telling that this assignment prompt provides more detail about how the paper should be formatted (and that said details are presented in the negative, i.e. what not to do). It reflects a concern with formatting, citation, and mechanical correctness that seems almost equal to (if not greater than) the rhetorical concerns of the text. Granted, producing a well-formatted document is an important part of producing a simulation of a professional, academic text. Becoming adept at using APA citation format also helps students in the social sciences across courses in their discipline, as it may be one of the most consistent things they learn and apply across courses in their discipline.

Furthermore, concern over plagiarism reflected in these formatting concerns is not misplaced in this age of near-effortless online access to textual material. As a further check against plagiarism, the teacher in this course even required students to upload copies of their sources to Blackboard (the university's web-based course management software).

Teaching students the necessity of choosing good sources and of being able to back up their claims with relevant evidence is an important skill to build, but what is worrying about this part of the prompt is that it gives both more and more-detailed cues about what the paper should look like (format- and citation-wise) than it does about the substance and genre function of the paper. The students also indicated in interviews that their understanding of how to write the paper came more from feedback and implicit instruction than explicit cues. The preponderance of instruction about format and citation in comparison to the paucity of genre cues can create a contradiction for students in that it can make prioritization difficult: which is more important, that the argument is well written or that it is immaculately formatted? 
The Nursing Synthesis courses examined in this study (discussed in depth in chapters 3 and 4) was on the opposite side of the spectrum from Dr. Baker's course in many ways related to the writing prompt. The instructions in the nursing courses were highly explicit and detailed, and included information about using APA format (as seen in the excerpt in Figure 11 below):

6. WRITING STYLE: Clarity, spelling, grammar, sentence structure, organization, APA formatting, etc. APA formatting includes title page, running head, abstract, text double spaced in 12 font, an introduction, and a conclusion (this is the end of your paper not to be confused with the section on the conclusion based on your evidence). A minimum of 5 points and possibly all 10 points will be lost for any mistake outlined in the "Tips for Scholarly Writing," (10 points)

Figure 11. Excerpt from Grading Criteria of the EBP Paper.

The "Tips for Scholarly Writing" document to which this section alludes provided students with a list of common problems instructors and evaluators had noted from assessing this and similar projects in the past. It included explanations of common problems the importance of writing in complete sentences, using scientific language, avoiding use of 'I', and staying in past tense where appropriate. When it comes to citation and APA format, one particular entry is an apt site for examination for this study (see Figure 12 below): 


\section{Avoid using quotations!!! Let’s repeat that. Avoid using quotations !!!}

Quotations do not tell the reader (in this case your instructor) that the writer (you) understands the material or has the requisite knowledge to express him/herself in his/her own words. Quotations mostly tell the reader the author knows how to copy material from a source. Reserve quotations for those little phrases or bits of material that can only be expressed most effectively by using the referent author's own words. For example: "We have nothing to fear but fear itself" (Roosevelt, 1941) or "Ask not what your country can do for you: Ask what you can do for your country” (Kennedy, 1961). Best word of advice; don't use any quotations!

Figure 12. Excerpt from Dr. Green's “Tips for Scholarly Writing” (emphasis original).

What this piece of textual instruction presents as a general rule is in reality a discipline-specific convention. Quotations are seldom-used in the hard sciences since the author's particular words or phrasings are typically less important than the data, the findings, and the processes used in the research. In the softer disciplines such as the Humanities, the author's choice of words and phrasings are both evidence and part of the method by which knowledge is negotiated. This is not to say that the instructor in the Nursing class, Professor Green, was being insensitive to softer disciplines, but rather that this admonition against quotations should be read as a forceful prohibition against a common faux pas students commit when they use quotations in scientific writing and in 
nursing in particular. That it appears as a general rule rather than one particular to the field of study is symptomatic of a larger issue: how dynamic and defining characteristics of a disciplinary mindset are sublimated into a seemingly unproblematic list of do's and don'ts (with emphasis on the don'ts).

As discussed earlier, teachers across the curriculum (but especially those in the sciences and social sciences) are highly concerned with promoting proper uses of citations. It is not only a check against plagiarism, but a part of the simulation of writing a professional paper as well. For students, however, these may be the most explicit writing instructions they receive in high-level writing courses, since, as Ken Hyland observes, the rules of citation are:

...generally seen as relatively unproblematic due to the highly developed conventions prescribed in the official manuals... But while they provide a relatively stable rhetorical context for communication, these guides also convey the impression that writing is mainly a matter of applying established rules. The fact that different citation choices carry different rhetorical and social meanings complicates this picture. (23)

What genre studies and research in the writing of the disciplines has consistently shown is that even if there are prescriptive conventions and rules, they are not transparent or unproblematic. Teaching citation as a completely routine, transparent operation (or treating it as something students should already have mastered/operationalized by the time they walk into the classroom) is in some degree tabling the discussion with students about their rhetorical nuances and power, although said discussion may never happen within that student's college career. This is another facet of the writing process that 
suffers due to the Myth of Transparency identified by Russell, the idea that writing is the mere act of putting ideas down on paper (Writing 7-10). For students, this transparency can make citation seem like a set of rules made to keep them accountable for performing and documenting their research at best, and at worst it can seem like nigh-arbitrary tedium that creates a minefield of do's and don'ts in which transgressions are swiftly punished.

In an environment like this, the attitude towards citation can be debilitating to students. At the 2014 Conference on College Composition and Communication held in Indianapolis, Stephanie Roach delivered a presentation titled "The Disservice of 'Just Say No' Approaches to Plagiarism." Her contention was that just as the Just Say No to Drugs campaign of decades past oversimplified drug avoidance and de-emphasized societal coping mechanisms for dealing with drugs, so too has its academic equivalent, a kind of "Just Say No" approach to plagiarism, avoided the real difficulties in teaching students how to document sources in favor of a simple absolutism. Telling students to "Just Say No" to plagiarism and avoid it sounds easy, but as we are aware the use of appropriate documentation and citation practices is a skill that has to be honed over time. Roach made the point that good, ethical writing is (and should be) more about doing than about not doing according to Roach, and telling students not to plagiarize in many ways abdicates a large measure of responsibility for the more difficult task of continuing their training in good, ethical citation practices. The negative rhetoric of the "Just Say No" approach paints students who are ignorant of the rules or students who make good-faith mistakes in the exact same light as lazy writers and intentional cheaters. 
Such approaches to plagiarism make grading seem more absolute and unproblematic, but however simple and unproblematic instructors may depict the use of citation for students, for instructors and researchers it is a highly rhetorical process bound up in the very knowledge conventions of their discipline. As Hyland notes, this complicates our picture of citation, and it should complicate our picture of the role it plays in classroom writing assignments and writing assignment prompts.

The comparative differences between citation styles across the disciplines reveals many core values of the respective fields that use them. Diane Dowdy's 1992 article "Citation and Documentation Across the Curriculum" provides an accessible comparison of how different citation methods reflect the ideologies underlying the fields that use them. She compared the citation procedures of the humanities, sciences, and social sciences to highlight how these "rules" for documentation of sources reflected the ideologies and epistemologies of those fields. She observed that the documentation style reveals not only how to cite, but "it also reveals something about the method of research and the traditions of scholarship within the discipline. What counts as knowledge in a particular field is displayed by what is cited and how it is documented." (330). Citation is at the heart of what is counted as valid knowledge and what is not in a discipline. By comparing citation manuals and style sheets, Dowdy concretely observed how, for example, "the humanities uses citations as authoritative places to begin an argument," (332). She also observed how the social sciences focus on citing proof not from quotations but from statistical and experimental data, and how the hard sciences often pare down the use of authors particular words even further than the social sciences by highlighting only the basic summaries of the pieces (341-44). This information may seem 
basic, even rudimentary, to insiders, but recognizing these differences can help teachers in all disciplines better explain to students the logic behind what may otherwise seem like an arbitrary system of citation.

Looking at citation practices alone can clue students and teachers in to large rhetorical differences between disciplines. For example, while discussing the social sciences, Dowdy quotes Bazerman's "Codifying the Social Scientific Style":

The Publication Manual had adopted a reference style wherein the author and date of the cited work appear as facts or landmarks in the course of the article, visibly demonstrating the incrementalism of the literature. As anyone who has worked with this reference system can attest, it is very convenient for listing and summarizing a series of related findings, but it is awkward for extensive quotation or discussion of another text, and even more awkward for contrasting several texts in detail. The format is not designed for the close consideration of competing ideas and subtle formulations. (cited in Dowdy 339)

The sciences and social sciences deemphasize the author's individuality and words to varying degrees, which is visible in how its citation style makes in-depth juxtaposition of quotations or paraphrases from different text awkward for the writer. Looking back at Professor Green's admonition against quotations in the Nursing paper presented in Figure 12 , we can see a concrete example of this difficulty as the teacher tries to explain to students why quotations won't be appropriate in a paper formatted in APA style. Of course, the language of this admonition cloaks disciplinary difference in the language of general, if not absolute, rules. 
The way teachers present citation, formatting, and genre rules to students are important because they play a role in how students perceive their own place and their own agency within those restrictions. Ken Hyland delves more deeply into how the author's agency in scientific and social-scientific research is downplayed even deeper in Disciplinary Discourses by analyzing a large corpus of articles in different disciplines for how citations are instantiated in the texts belonging to various fields. After presenting data showing a significantly lower number of citations in the hard sciences and socials sciences, and a low number of integral citations (citations in which the author is identified in the sentence preceding the parenthetical citation), Hyland addresses these findings in terms of how the hard and social sciences downplay the agency of the writer:

The conventions of impersonality in science articles play an important role in reinforcing this ideology by portraying the legitimacy of hard science knowledge as built on socially invariant criteria. While seeking to establish their own reputations through publication and the recognition bestowed by citation, writers routinely (and often unreflectively) also subscribe to the assumption that the person who publishes a claim is largely immaterial to its accuracy. (32)

Just as Bazerman observed that the citation style used by the social sciences and many of the sciences is not designed for comparing texts in depth, so Hyland observes that this convention stems from a core piece of ideology in disciplines driven by hard-knowledge. There is a dynamic tension here between the authors of scientific articles as individuals seeking to push the field further while also bolstering their own credentials and as being largely irrelevant in the larger scheme of things. Both sides are inevitable and necessary. While the authors behind, say, an article on structural engineering are not automatons 
without feelings or flaws, the positivist belief in the strength of the scientific process and in the hard knowledge underlying it is a necessary one if structural engineers are going to do their work with any confidence that their buildings will stay upright.

When it comes to teaching, however, the absolutism of process and certain rules for writing (like citation) can obscure the ways in which authors work as individual, human agents who make their own decisions. In an article discussing in part on the place of the individual in scientific discourse, Bazerman reflects that "I have found that by analyzing the processes, dynamics, and assumptions of this intstitutionalization of style, I have not at all served to foster the enclosed dominance of this discourse. Rather professionals and students have largely responded that understanding the implied baggage of the discourse has freed them to make rhetorical choices with greater clarity, whether to continue in the traditional forms, whether to modify them, or whether to abandon them altogether for more conducive discourse for other kinds of projects" (243, emphasis mine). Instead of reinforcing a faceless institution of writing, Bazerman feels that his work has made authors more aware of the choices they make in the face of institutionalized genres and discourses. Being made aware of the "implied baggage," as Bazerman calls it, can make authors more alert to the choices they make. Why should this not be so for students as well?

Even if the citation and documentation styles students are to use in courses like the Cultural Psychology, Cellular Biology, and Nursing Synthesis courses discussed in this project downplay the agency of the individual, these students are still aware of themselves as individuals in a course vying to appease another individual, the teacher. They are reading the teacher as much (if not more) than they are reading the discipline, 
and if the instructions they receive in terms of documentation and citation present it as unproblematic (which in a way is necessary for grading) then they may not understand the moves they are making. This extends to all parts of the writing process in a disciplinary classroom. If students are not keyed in to the rhetorical functions behind the work they are producing, then— to use a metaphor employed by David Russell—their efforts would be "as meaningless as learning how pieces move in a chess game without knowing the conditions under which one piece may capture another or knowing that the object is to checkmate the opposing king" (13). In this case, the game is not to capture the king but to negotiate new knowledge.

That students are not aware of all of these nuances when it comes to citation does not mean citation should not be taught. In an acerbic 2011 article for the Chronicle of Higher Education, Kurt Schick, accuses teachers of over-emphasizing citation to the detriment of the teaching of writing in general. He feels that librarians and writing center personnel are made to bear the burden of catching students up in a skill that teachers feel students should have already mastered by the time they arrive in their classrooms. While students should be concerned with documenting their sources, Schick's perspective here seems to align with Roach's in that both feel that the systemic way citation is taught does a disservice to students. In Activity Theory terms, teachers such as those Schick describes expect citation to be a routine if not largely unconscious operation that they should not have to teach as an action or even as a larger activity in their classrooms. For Schick, this is unacceptable. He writes that "Bibliographic citation has apparently eclipsed perfect grammar and the five-paragraph theme as the preoccupation of persnickety professors.” Despite his obvious venom for teachers he feels are treating 
citation as a landmark of mechanical correctness, it is difficult not to draw a direct line between his argument and Robert Connor's historical research on the birth of the focus on grammar in writing classes as an expedient for teachers to have something easy to grade ("Mechanical Correctness as a Focus in Composition Instruction"). Citation can be an easy thing to hold students accountable for and an easy thing to use to dock points. While research examining the prevalence of teaching citation over other forms of writing instruction would have to be proffered to justify Schick's ire, he does bring up at least one very solid point: "We cannot control how much time and effort students invest in a particular writing assignment; we can only influence how they distribute their energies" (para. 2-3).

This is exactly what cues can provide for students, ways they should distribute their energies while working on an assignment. Part of that distribution of energies is being able to apply effort productively to the right actions/conventions utilizing the appropriate underlying operations. Writing prompts that obscure the requisite actions, or focus on time-and-energy consuming actions like citation as an operation as transparent as typing, are being disingenuous to students about the type of commitment the teacher expects the student to bring to bear on the project. Too much time and energy spent to decipher the teacher's expectations or correcting citation can lead to a substantively poorer paper. How much time, effort, and frustration might have been saved if Dr. Steiner and Dr. Baker unpacked the actions they wanted students to perform within the prompt in more detail rather than letting them discover them through trial and error throughout the course? In the case of Dr. Baker's class, the most explicit cues (both in the prompt and in feedback) that students received had to do with proper use of citations 
and sources, creating a minefield of do's and don'ts rather than a more constructive understanding of the conventions required by the assignment and the way they related to and built upon one another. Providing rhetorical cues that determine the overall communicative function of the paper should take precedence over an undue focus on formatting and citation. 


\section{CHAPTER 3}

\section{NAVIGATING CONTRADICTIONS AND DOUBLE BINDS}

For her final paper in her freshman-level sociology course titled "Race in the US," Natalie chose to focus on the portrayal of ethnic/racial minorities in the media. In particular, her paper looked at whether or not Disney films have been racist in their portrayal of minorities (e.g., did Disney intend Whoopi Goldberg and Cheech Marin's voice performances as clownish hyenas in The Lion King to be a caricature of African Americans and Hispanic Americans?). The paper required her to not only make an argument for her side of the issue, but to answer the opposing viewpoint as well. In class, Natalie and her classmates were implored to demonstrate a lack of bias and a sense of fair play by finding research for both sides of their chosen issues. This caused a problem for students like Natalie. She had rejected several options from the list provided due to the difficulty in fairly representing both sides of the issue. For example, she decided against writing a paper on the debate over the continued use of Native American sports mascots due to the scarcity of credible sources supporting the practice. Indeed, much of the research on many of the topics provided on the prompt was overwhelmingly one sided.

Despite picking a topic she thought would be devoid of this problem, Natalie still ran into roadblocks. In her words, Natalie "ran into that problem where everything was this is why [the representation of minorities in Disney movies is] bad, this is why it's 
bad...so even in the paper if you are not supposed to be biased you have to be because that's the only source you have." Like many inexperienced college writers, Natalie felt she was restricted in what she could say by the sources she could find. In other words, if she could not make a particular point unless she found a source to say it for her; consequently if she could not find a source defending Disney movies and their portrayal of minorities, then she felt she could not help but seem biased in her paper.

At least, this is how Natalie saw things. Of course, as a freshman Natalie lacked the kind of rhetorical awareness of conventions that might help, say, an advanced Sociology major use research as a springboard to help her articulate original ideas. Instead, Natalie perceived the extant research as walls that penned her in. It did not help that she was receiving what she perceived to be two contradictory, but equally compelling signals from her instructor: be fair to both sides and use sources as the foundation of your argument, even though the sources you will find will tend to be overwhelmingly one-sided on the issue. She could find no way out from between two competing, and equally compelling messages. The academic ideal of presenting all sides of the issue clashed with the reality that Natalie found in her reading, and her only recourse was to muddle on as best she could.

Experiences like Natalie's are not limited to freshmen in 100-level survey courses. Writing with research is a challenging endeavor for students across the curriculum. Such conflicts, however, are systemic and natural consequences of combining the activity systems of writing within a discipline and writing within a classroom setting. The ideals of a classroom simulation of an academic or disciplinary writing genre can sometimes conflict with the reality of such knowledge work. Some of these conflicts, however, can 
result in intractable double binds. As described in chapter 1, double binds are those "damned if you do, damned if you don't" situations that put the subject in a tight spot between two competing or outright contradictory messages or expectations. In most situations, double binds are not experienced by someone being given two explicit and contradictory messages at the same time (e.g., put up your books, but don't put them up yet). Instead, double binds are experienced over the course of time as expectations gleaned from stated goals, tools, and interactions with agents in the activity system are subject to paradoxical interactions. For example, it was not until Natalie had chosen her topic, performed research, and started writing her paper that she realized the teacher's goal of having students argue both sides of the issue (as a marker of fair-minded intellectual citizenship) was at odds with the reality of the extant literature (in which only one side was substantially represented). Stuck between the proverbial rock and a hard place, Natalie was at a loss since the contradiction was so debilitating that she could not gain any meta-awareness that would allow her to reconcile the contradiction or at least cope with it productively.

This is not to say that students like Natalie or helpless or bear no responsibility for their own work. Rather, the structure of some assignments can unintentionally limit the options of student writers. Thus, it can harm the way students acclimate themselves to the ways of thinking and acting within a disciplinary knowledge community.

Whereas the previous chapter discussed aspects and uses of writing prompts that can facilitate contradictions and double binds if not attended to, this chapter will identify a specific contradiction common in teaching academic writing and how the cues provided in the prompts in two classes exacerbated or ameliorated students' attempts to 
approximate writing in their respective disciplines. In particular, this chapter focuses on assignments in which the contradiction was visible within the prompt itself. The contradiction this chapter will highlight is one between promoting summary for purposes of accountability/evaluation and promoting moves beyond summary for purposes of simulating disciplinary knowledge making. This chapter will describe and unpack this contradiction before illustrating how it manifested in an upper-level philosophy class and an upper-level nursing class. That these courses in very different disciplines struggled with this same contradiction is telling of its pervasiveness in the university. Recognizing difficulties such as this in the classroom approximation of disciplinary writing can help us better attend to them in the future.

\section{Working Through a Contradiction in Two Classrooms: Balancing Accountability and Originality}

Students writing in disciplinary classes are often caught between two competing impulses: writing to demonstrate accountability to course content (often through summaries) and writing for an original argument. Many students—out of concern for their grade, a lack of skill/agency, or just apathy-tend to focus more on summary and less on original argumentation. A common concern among the teachers involved in this study was getting students to move beyond summary and towards writing strategies that will engage them with the textual conversation: analysis, critical response, evaluation, etc. For example, Dr. Petersen (Philosophy) felt that most students in his courses (which required a great deal of textual analysis, critique, and response) did not "know how to construct a paper that has an argument. If it's a 4-page paper, you'll get 3 and a third 
pages of summary, [and that's] from a good paper, a decent paper with 3 pages of pretty good summary and a half a paragraph of opinion." On the other end of the academic spectrum, Dr. Steiner (Biology) has been making an effort to prompt his students to give him more than just tedious step-by-step retellings of what the scientists did in this or that study. He intimated that he tries to impress on his students that he is "not really interested in 'well they did this and this and this', but [you should] pick out the one or two pieces that really had an impact on you and told you 'I think this is right' or 'God, this sucks', you know....look for the big pieces, the big principle rather than all the details that you're probably never going to remember." These instructors were concerned with prompting students to write rhetorically-savvy papers that engage in the knowledge-making work of the discipline instead of just producing writing so preoccupied with summary and demonstrations of knowledge that it ignores the equally-important rhetorical and social concerns of the simulation of disciplinary writing.

Demonstrating subject-matter mastery, however, is an important part of writing and the classroom for both students and teachers, and writing effective summaries is a key part of that skill. Students across the curriculum are constantly being assessed on how well they can demonstrate their grasp of content knowledge (like the science and the data behind a biological research study). This evaluative environment carries over into the disciplinary writing classroom as well, and students are well aware of its presence. Students are very aware that a significant part of their grade most often depends on their ability to show that they understand and are able to relate content knowledge. That said, crafting a writing assignment (and a writing prompt) that effectively balances opportunities for students to demonstrate content knowledge with places where they can 
(or should) move beyond summary into more complex enterprise of shaping new knowledge is a precarious task at best for teachers.

Summary-heavy, argument-light papers of the type that Dr. Petersen was concerned with go by several names, such as the "data dump" paper. In Engaging Ideas, John Bean describes the "data dump" paper as having "no discernible structure. It reveals a student overwhelmed with information and uncertain what to do it...data dump writing patches together quotes, statistics, and other raw information without a thesis or a coherent organizational plan" (23-4). At best, these papers might become what Bean calls "all about papers," which do have an organization, but only "[promise] to be encyclopedic and surpriseless" (22-3). This type of writing is antithetical to the requirements of the WR class as articulated by the university in this study, which include that writing in the course "shall reflect the discipline's forms and methods of inquiry." It is also quite the opposite of what teachers want to see students produce when they are expected to write within a discipline's rhetorical conventions.

Kaufer and Geisler's 1989 study “Novelty in Academic Writing” provides a useful way of framing this issue: a tension between accountability and originality. The authors asserted that making new claims in academic writing doesn't involve creating something from nothing, but rather that new knowledge comes from a deep understanding of existing knowledge and the ability to work with it in complex ways (287-294). As an example, the researchers had two professional philosophers and two students write research papers using the same corpus of sources. As the professional authors tried to stake a new position, Kaufer and Geisler witnessed a predictably more advanced interplay between working with and against the sources to carve out an original 
position. The student texts were predictably less sophisticated in how they worked with sources, and tended towards opposite extremes. One student focused more on relating the information from the research sources than she did on playing them off of one another to craft a new position, while the other student worked more to stake her own separate claim (turning to the sources only late in the text). Both freshmen students, in Kaufer and Geisler's study:

...lacked the concept of novelty as a design strategy for academic writing. What exactly did they lack? They lacked the knowledge or skill to interplay two competing impulses: the impulse to account for the information one inherits from a cultural community (represented in the sources) and the impulse to move beyond these givens by breaking a consensus with them" (297).

The students demonstrated an inability to manage a more complex interplay between the impulses of accountability (demonstrating understanding of the research) and originality (developing a new claim from a reflective exploration of the sources' positions). These impulses are shaped and reinforced in school, but being able to manage them in the way a professional and insider might is not something most students will be able to do on their own until graduate school (Kaufer and Geisler 306).

As disciplinary outsiders, undergraduate students can tend towards struggling to establish accountability via summary to the detriment of originality found in more critical, analytical writing. This is particularly true when they lack agency or familiarity with the discipline. Observing two students with different levels of writing skill and content knowledge, Penrose and Geisler observed that "The traditional response to the problem of lack of authority is to try to increase the domain knowledge upon which authority is 
supposedly founded" (516). In other words, subject matter knowledge becomes a kind of retreat when students feel they do not have the authority to make a more rhetorical argument. John Ackerman, in a 1991 study that compared how students wrote first about a topic they knew little about and then about a topic within their major, found that the students wrote more rhetorically and with more new information when they were writing about a familiar subject matter and fell back on simply summarizing or reporting what they read when tasked with synthesizing information beyond their area of expertise (1512). Summary and description, then, can be an inviting retreat when students feel they lack the agency to make an argument or the familiarity with the material that would allow them to attend to such higher-order concerns. As in the case of two students discussed in the philosophy section below, students may write excessive summary under the impression that they are "establishing a foundation" of knowledge for later analysis, but the later analysis, as noted in the excerpt from an interview with Dr. Petersen at the opening of this section, comes only at the very end. The summary is more comfortable and familiar, and many students have trouble breaking out of it until they realize they need to make at least a token nod to summary-response at the end of their composition.

To this conversation, I would add that these types of papers (the "data dump" or the "all about" paper) have become genres that students fall back on not only because they lack authority for more complex, rhetorical argument, but that they are habituated to them in college if not earlier in high school. High-stakes writing exams, such as exit exams and state-mandated assessment exams, for example, can play a formative role in how students approach certain writing tasks. Research into high-stakes writing exams has shown that grade-school students are often rewarded for overly-descriptive or 
narrative-based writing, even if such strategies are not required. In a 2005 study, Beck and Jeffrey examined 46 "benchmark" papers (i.e., model papers) from standardized tests in the three most populous states (California, Texas, and New York), and found that less than half met the argumentative genre requirements established by the prompts. The rest fell into descriptive or narrative categories. (69-74). This finding is in line with other research into high-stakes testing that shows students being rewarded for providing description or narrative when argument and critical analysis is explicitly required (See Albertson; Amrein and Berliner; Applebee and Langer). Such summary-heavy strategies often used in high-stakes writing do not define all high-school writing, however, and they are not the sole, totalizing influence on student writing, but they can have a significant effect on the default writing strategies that students run to when they encounter new writing situations.

Before college then, influences like standardized testing can condition students to produce overly-descriptive writing, privileging accountability over originality, as a default strategy. This habit can be continued for students at the college level as well. As established by the authors discussed in Chapter 1, research leading back to the 1980 s querying what types of writing that teachers across the curriculum are assigning has consistently shown that longer assignments of the analytical, argumentative types of writing we value most in composition have historically been in the minority of what students are being asked to. Even the writing-intensive courses in this study, (which by mandate incorporate longer, more complex writing assignments) were the exception rather than the rule, and the teachers who participated generally reported being more used to assigning shorter writing tasks such as essay exams. College students can become 
quite acculturated to this type of writing as a part of being a student, and those habits are what composition instructors and teachers in the disciplines have to contend with.

Although, as discussed in Chapter 1, research has shown that the proportion of longer and more rhetorically-complex assignments is improving significantly.

All of this is not to say that students cannot move beyond the strategies of summary for accountability, but that they need to be effectively prompted to do so. The writing prompt is one important tool in that process. In the disciplinary writing classroom, writing prompts act as important mediating tools that help students navigate the writing conventions required by the teacher and the discipline. Looking at the cues writing prompts provide can key researchers in to how teachers envision the way students should approach the writing task and the conventions that comprise it. The following section examines how the general contradiction between prompting accountability and originality manifested itself in an upper-level philosophy classroom, and an upper-level nursing classroom. In the latter, the contradiction resulted in a full-blown double bind. Furthermore, these sections show how cues in the writing prompt affected the students' uptake and how they contributed to a sharpening contradiction between writing for accountability and writing focusing on originality.

\section{Arguing an Issue in Philosophy}

One instance in this study in which students were visibly struggling between the larger tension between summarizing for accountability and using source content to move towards originality occurred in Philosophy 435, a special topics course. This tension was exacerbated by a writing prompt, although it did not result in a full-blown, intractable 
double bind. Philosophy 435 focused on the philosophy of politics and was taught by Dr. Petersen, an Associate Professor who has been making concerted efforts to improve his assignment design. This course was heavily grounded in the philosophy of John Locke in particular and how his ideas have been applied to issues of membership, nationhood, suffrage, and related issues over the centuries since Locke's writing. In recent years, Dr. Petersen has made an effort to be more explicit and guiding in his assignment design. $\mathrm{He}$ reported that he had had enough of "papers that were sort of half baked, so I thought I'd be more intentional about how to build the paper." One aspect of student writing in particular that Dr. Petersen was trying to actively work against was the tendency to use summary of the course readings as an end in itself and not as a means to accomplish something else:

In other classes I've asked them to do summaries. Summaries get old really quickly, and I think doing one summary assignment, maybe two, [for] particularly dense reading, can be useful. But I find it's good to push them to move towards response. And one of the virtues or response papers is that I can emphasize that you don't just summarize and put your opinion at the end, what you do is you construct the paper as a response. What you say in your summary is your evidence for your view.

Dr. Petersen's goal was to prompt students to do more than just summarize. He wanted them to create a structured argument that used targeted summary as a means towards deep response and engagement with the texts. In other words, he wanted students to move beyond accountability and towards an original argument. This was a change for most students in the class. Even though Philosophy 435 was an upper-level course, Dr. 
Petersen explained that the philosophy faculty did not typically have a teaching load that would allow them to assign longer and more complex writing assignments. This class could provide some of that missing instruction, and so Dr. Petersen wanted to be very deliberate in his assignment design to promote that kind of structured analytic writingtypical of good philosophical texts - within his class. Consequently, students in this course were still getting used to what it means to write like a disciplinary insider in philosophy.

Of course, writing in philosophy can encompass a number of genres, and the midterm essay for this course gave students a wide variety of options for composition. The prompt required a complex, non-linear uptake from students, who had to appropriate cues from the prompt and create their own synthesis of them rather than follow a linear, hierarchical set of instructions. While this does reflect both the diffuse nature of writing genres in philosophy and the desire of the instructor to give students options, the complex and diffuse use of cues in the prompt made it difficult for students to use the cues to move from writing for accountability to writing for originality. The main criteria for the assignment — those by which the students will be graded — are shown below in Figure 13. 
Your term paper will be grade on the following criteria:

- Issue Identification: you will identify a significant philosophical problem or locus of significant disagreement among theories.

- Structure: your paper has a coherent structure including setting up the problem, pursuing one or more answers to that problem, giving reasons in favor of or against those answers, and clearly proposing and defending a solution.

- Argumentation: this is linked to structure, but it goes more to the content of what you say in each of those elements of the paper. One thing to focus in is that you use examples only to illustrate arguments - examples themselves, like questions, are not arguments.

- Writing: clarity, grammar, and spelling all count—aim at precision and economy of language.

Due diligence: you must spell the names of our authors and their main arguments correctly, you must spell my name correctly, you must quote and cite accurately. This is a professional paper and it must adhere to professional standards. Figure 13. Evaluation Criteria from page 1 of the Term Paper Prompt in Dr. Petersen's Political Philosophy Class (complete prompt available in Appendix B)

These criteria did helpful rhetorical cues to students. More helpful rhetorical cues were found on the back side of the prompt. The two lists on the back of the prompt (see Figure 14 and 15 below) were much more helpful in cueing the available and/or desired strategies and conventions the students could use. The first list is a set of general strategies often used in philosophical writing. While the grading criteria on the first page 
of the prompt (Figure 13) only announced that a structured argument was needed, this list of strategies (Figure 14) provided students with a sounder starting place

If you're trying to think of a paper idea, one or more of the following strategies may be especially useful:

- compare-and-contrast: take a particularly salient question and try to get to the bottom of a disagreement about that question between two or more authors, with the aim of determining who, if either, is right;

- exegesis: since we have read Locke carefully, use your expertise to try to get to the bottom of Locke's meaning on some issue; you can then apply your understanding to one or more other authors or parts of Locke's text.

- extended critique or extended defense: give reasons for rejecting a thesis that is defended by one or more of our authors, and suggest or defend an alternative; or identify a controversial thesis on which one of our authors depends, and defend it;

- extrapolation/application: take key arguments from one or more authors and apply them to distinct questions, seeing whether they have plausible results there and if not whether the problems there also constitute problems with the original.

- Find the "clearlys": often authors assume something is obvious only because they have not thought carefully about it, and they say "clearly" (or suchlike) because they have no good argument for it; but upon reflection it is not obvious at all. Find a "clearly" and challenge it.

Figure 14. Suggested Strategy List from Dr. Petersen's Paper Prompt. 
The second list, which was directly below the one featured in Figure 14 above, listed a set of strategies and topics directly related to the theme of the course:

1. Try to distinguish among property, territory, and natural resources. Is a Lockean approach helpful here?

2. What is labor, and how, if at all, does it justify title? Does land differ from other property, and if so, why? (On someone else's view, or your own, or both.)

3. What, if any, is the best way to frame one or more provisos on property acquisition? (On someone else's view, or your own, or both.)

4. When, if ever, is "original appropriation required", and why?

5. Compare and contrast two or more libertarian views of property (in land), such as those of Nozick, Schmidtz, Steiner, etc.

6. Explicate and evaluate Locke's theory of the consent of the rising generation (born within the boundaries of an extant state to which their parents consented expressly). What, if any, are the roles of express and tacit consent, inheritance and land, etc. Has Locke smuggled in a parental right to bind children?

7. Carefully distinguish between property, jurisdiction, and meta-jurisdiction. How can a Lockean parse these notions? Is the Lockean account of them successful? What are the implications of this result?

8. What is society? What are some implications of its interposition between individual and state (or government)? Is this a problem for Locke's view? 
9. On a Lockean view, can there be inter-state (international) obligations of distributive justice - with respect to natural resources, say? What is the scope of Lockean distributive justice?

10. What role, if any, does "original appropriation" have in political society and/or in international society? Has it disappeared or is it still ongoing?

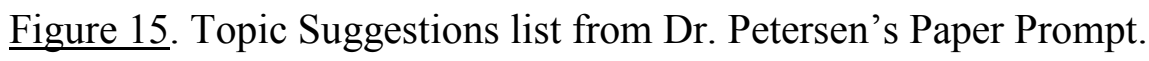

The complete paper prompt can be found in Appendix B of this dissertation. These two lists on the second page of the prompt (in Figure 14 and 15) do a great deal more than the criteria on the first page in defining the parameters of the project. Referencing specific strategies and conventions with directions like "compare and contrast", "evaluate", and "distinguish" provides clearer indications of how to achieve the purposes of the paper than indicating that the paper should "have a coherent structure"(bullet point 2 in Figure 13). Dr. Petersen's goal was to provide students with options for responding to the class texts, and so parsing the signals from these three lists list was somewhat overwhelming and confusing task for students, at least initially.

Beth, a philosophy minor majoring in English, felt that the criteria provided on the first page of the prompt (Figure 13) were helpful, but ultimately they were unrevealing because they were simply, in her words, the "groundwork structure things you just have to have" to write a paper in general. The strategies and topics lists (Figures 14 and 15) were more revealing, but for Beth the problem was that "there were so many options that he gave to us to do the paper that I...[didn't] know what to choose from." Indeed, this prompt required some savvy uptake from students, who needed to pick and match a topic with a general writing strategy and synthesize both into a coherent 
argument. The effect was that they (the students) defined the particulars of their writing genre instead of following a set genre guideline that the entire class was accountable for producing. From the swirl of genre markers available to them in the prompt, they were intended to create a synthesis of a topic, a question, and an organizational frame. Of course, this is a common task of writing in most disciplines, but the way students were cued to do it in this course affected the way the processes they used in approximating the product desired by the instructor.

Of the three students interviewed from this class, Beth was the most successful in reading, interpreting, and adapting the suggestions on the prompt to help her produce a paper that satisfied Dr. Petersen's expectations. Beth wrote a paper adapted from both a topic and a strategy provided by the prompt, and what's more is that she combined the two in such a way that gave her a logical, coherent structure for a full argument instead of a summary-heavy text with argument tacked on at the end. She combined the fifth suggested topic on the numbered list at the bottom of the second page ("Compare and contrast two or more libertarian views of property") with the third bullet point strategy also on that page ("extended defense...identify a controversial thesis on which one of our authors depends, and defend it"). The result was an extended defense Nozik's theory of distribution and ownership of land, based in Lockean theory, and contrasted to a similar theory of Steiner to illustrate that, while both are not practical, Nozik's is more illuminating.

Beth was concerned if she wrote from only one topic or one strategy her paper would lack the requisite depth. Consequently, she adapted a strategy, picked a suggested topic, and then used the used the former as a way of addressing the latter, which 
prevented her from crafting a paper that only narrowly interpreted the prompt. Dr. Petersen, aware that papers he had received in the past using compare and contrast focused solely on the similarities and differences, stated that "I realized that what I wanted out of compare and contrast essays was not this is one way that's another way....compare and contrast as a strategy to achieve something else." This is precisely what Beth's paper was doing, using the strategy as a way of achieving a goal and not as an end in and of itself. Among the three student texts discussed in this section, it also bears the least amount of data dump or summary for summary's sake.

Jeremy (a political science and philosophy double major) and Daniel (a philosophy major) were both students in Dr. Petersen's class along with Beth. Both Jeremy and Daniel submitted what Bean would call an "all about" paper for this assignment: summarizing what has been said on topic yet providing little in the way of argument or analysis. Jeremy used the second question on the enumerated list in Figure 15, which asked the writer to define labor, to guide him in his writing. His goal was to define what labor is in Locke's terms and to illustrate the complexities at hand when Locke's definition of labor in the natural state of man intertwines with money, commerce, and the collective effort of modern, civilized man. Jeremy's paper was preoccupied with establishing Locke's ideas in detail. The following is a representative excerpt of his paper and of "all about" papers in general:

Every man has a right to his own person, furthermore, "the labor of his body and the work of his hands," are solely and justly his (Locke 287). So whenever a person removes something from the state of nature, he has "mixed his labor (something that is exclusively his) with it," which therefore removes the right that 
other men would have to it (Locke 287). The simple fact of picking an apple justifies it as private property because the act of picking it (labor) distinguishes it from the common; in fact, the labor has added something more to it than nature provided, so the apple now belongs to the laborer because he has "fixed his [my] Property in" it (Locke 288).

The rest of the page proceeds in similar fashion, explaining and summarizing Locke with frequent direct quotes and citations and rarely moving beyond description and summary to accomplish his primary goal—illustrating how Locke's ideas apply to modern civilization - until much later. From sections like this, it seems that the application of Locke's ideas to the conditions of modern civilization is almost a secondary concern to explaining Locke. Indeed, Jeremy was very preoccupied with establishing his knowledge of Locke before he felt like he had the agency to move on to providing a more original argument. Jeremy's paper only manages to attempt to flesh out an original argument in the conclusion (and it's one that doesn't quite match the claim established in the beginning of the paper). Jeremy was aware that this was a problem, reporting that his paper "didn't make a unique argument, and an argument that consistently flowed all the way through...I think I demonstrated that I read about the topic, I understood some of the deeper implications of it. It wasn't just the surface level.” Jeremy's paper certainly evidences a familiarity with the text, showing his accountability for the course content, but it doesn't make a concerted move towards originality.

Daniel, a student interested in applying to a seminary after college, also wrote a lengthy summary on Locke's ideas that ended up dominating most of the paper. Daniel developed his topic from the fourth bullet point in the strategies list (see Figure 14) that 
suggested an extrapolation: "take key arguments from one or more authors and apply them to distinct questions, seeing whether they have plausible results there and if not whether the problems there also constitute problems with the original." His goal was to write about Locke's ideas of property, money, and membership as they might apply to Massively Multiplayer Role Playing Games (MMORPGs) like World of Warcraft. In these games, virtual property can be owned and change hands, and real-world money is often exchanged for in-game currency and property. The first half of the paper summarized Locke on the issues of property, money, and related issues before he brought in the MMORPG's in the second half. Daniel acknowledged that "where I fell short was my argumentation... I waited too long to bring in the RPG's, and it wasn't as tightly formed as I wanted it to be and as I thought Petersen wanted it to be...” Like Jeremy, Daniel viewed his summary of Locke as a sort of groundwork that he needed to lay before getting to his main argument. Also like Jeremy, however, Daniel was aware that the groundwork took so much time and space that it drowned out his new analysis and argumentation.

In class and in the writing prompt, Dr. Petersen tried to work against the kinds of accountability and summary-heavy writing that Jeremy and Daniel ended up producing. On the first page of the prompt, he wrote that "You should not think of yourself as writing about a topic. You should think of yourself primarily as answering a question or defending a thesis" (emphasis original). Here, Dr. Petersen makes an important distinction between papers that summarize and describe and papers that argue, critique, defend, and/or in general respond to readings in specific ways. All three of the students 
interviewed readily understood this expectation. Daniel was very articulate about his understanding of the need to make specific arguments when writing on philosophy: what I understood [in my earlier philosophy papers] was that we shouldn't attempt to tackle, like, huge philosophic problems in here, we should find a specific area to write about, and not just an area but a specific question... Because if you, if you try to write about a topic, then you just end up going off on tangents...you end up talking about robot battles in space and you go "how did I get here?" Whereas if you have a more specific question, thesis, whatever, then you're focused and you know here I should end up, I should end up saying I answered this, or I defended this, or I critiqued this...

Daniel understood the difference between arguing from a specific, defensible position and simply describing a topic or issue. It was a difference he had become used to over the course of his college education, but it was one he did not deliver in his paper for Dr. Petersen. Jeremy and Daniel were both strongly influenced by Dr. Petersen's emphasis on making an argument and not merely exploring a topic, a difference that they both readily understood. Given that understanding, why did Jeremy and Daniel, the philosophy majors, have such problems delivering it? Beth spent more time working on her paper than Jeremy or Daniel, which does account for some of why her paper was more successful. However, an operative question for this study is how was their performance of the assignment affected by the ways in which they read and interpreted the assignment prompt. The theory of uptake may help us in this respect.

Anne Freadman's notion of uptake concerns how people process genres and attempt to formulate a response. (“Anyone for Tennis?”; “Uptake”). Bawarshi’s 
definition of Freadman's version of uptake is particulary succinct: it is "[ $[$ the ability to know how to negotiate genres and how to apply and turn genre strategies (rules for play) into textual practices (actual performances)" (83). Uptake is apt for describing the process by which students take up parts of an assignment prompt and use them to negotiate the production of another genre (the paper the prompt facilitates). In this way the prompt is not merely a function of the assignment but an important part of the process by which students negotiate genres in the classroom. In her 2006 article on how uptake in composition writing affects student identity, Melanie Kill notes that "while uptake often works so efficiently as to seem automatic, it is nevertheless a process that always involves selection and representation that open it up to intention and design" (Kill 221). Kill reminds us here that as teachers we can, through careful planning, facilitate certain kinds of uptake and thus improve the way students produce writing genres. The uptake that Dr. Petersen hoped for through his prompt was that the students would be able to negotiate the various parts of the prompt to put together a structured argument. In essence, the students' success was up to their uptake and their ability to plan a structured argument from the prompt. As it turns out, it may not have been enough to coach students out of writing mainly to demonstrate accountability and towards writing more original, argument-driven papers.

Teachers should be conscious of the way in which a considered approach to how writing prompts can enable and limit students. As discussed earlier, producing summaryheavy writing (as a form of demonstrating accountability for learning content knowledge) is a pervasive activity for students in the university. This phenomenon does not just apply to general education courses. Jeremy and Daniel, for instance, intimated in 
interviews that they were primarily used to writing shorter genres for their philosophy courses, including essay tests. Dr. Petersen also indicated that the department was not quite robust enough to support a wider variety of writing in upper-level courses. Consequently, Jeremy and Daniel were habituated to writing short-answer essay tests within their major. Given such situations, merely providing space for students to develop original arguments is not enough; they also need to be cued to how they can balance the need to be accountable to content material and the need to make an argument, lest they fall into a contradiction or double bind between the two. This was a problem with Dr. Petersen's prompt, which was intended to push students towards an original argument and not simply a summary-heavy piece of writing. Taken as individual items, the lists Dr. Petersen provided in his writing prompt might be mistaken for short-essay topics, a summary-heavy mode of writing that Jeremy and Daniel seemed to fall into out of longingrained habit or uptake memory. These two students knew they needed to lean towards writing more original, argument driven writing, but they could not override their habituation towards heavy summary. While they also bear responsibility for the outcome, they were also not adequately equipped by previous writing experience to make the shift towards more complex writing in philosophy, and the prompt did not help them in this area as much as it could have. They experienced a mild contradiction between what they were told to do (write an original argument) and what they had been rewarded for doing in the past (heavy summary).

Beth was probably the best-equipped for this type of paper since her experience as an English major allowed for more classes that used longer, more complex writing assignments. Many of her English classes engaged her in crafting critical interpretations 
of the texts she was reading, and created for her a "space where I can say what I want to say because I have the authority of a reader. " In this way, she described her English major as being very different from philosophy, which she characterized as requiring more technical interpretations of the texts. According to Beth, what helped her most in Dr. Petersen's class was her experience taking a critical theory class within her English major. That course engaged her in reading, unpacking, and applying critical theory such as the works of Saussure and Derrida. Learning how to closely read and unpack these authors transferred to her experience in Dr. Petersen's class. Beth stated that the "texts we were given in Petersen's class were just unfamiliar, and I was really overwhelmed. I think, on the first day I was like 'oh no, what have I gotten myself into,' but then I was able to use the skills that I had learned before to understand Locke." The reading skills she had honed in her critical theory class, and her experience in writing longer, more complex papers than many of her philosophy classmates, aided her uptake in crafting a successful paper in Dr. Petersen's class. She indicated that later she "really used [the lists on the second page] to understand what I was supposed to do and really apply that to the topic." Beth made a structure for herself by appropriating different parts of the prompt, which required somewhat of a non-linear method of reading and implementing the instructions.

Despite the fact that the readings were dense, and that Beth picked them due to her unfamiliarity with them, she was able to uptake a strategy for writing that gave her the cues she needed to move from summary to analysis and argument. Beth's use of her own cues helped her to overcome a lack of authority over the content that might have crippled her writing otherwise. In contrast, Jeremy and Daniel's writing evoke the image of writers who cannot summarize in targeted ways and assume certain positions of agency 
as writers, so instead they try to establish their authority through rote demonstrations of textual knowledge. Their attempt to establish a foundation of written knowledge about their sources encompassed the majority of the time they spent on the paper, and consequently their work did not evolve much beyond summary for summary's sake. The complicated uptake of the prompt made it difficult for them to see a way they could push themselves into going beyond summary until the end of their writing.

Jeremy and Daniel's experiences as philosophy students had not given the much practice in the way of crafting longer, more nuanced writing of the type that Dr. Petersen wanted to see and tried to promote. Considering the level of experience most the students in the class had in writing longer, more complex assignments in philosophy, a more focused and structured assignment design (as opposed to the variable one based on freedom of choice that Dr. Petersen provided) may have helped students more. Limiting the options available and providing a hierarchy of cues (possibly in an enumerated list) for that smaller list (in Figure 14) may have helped students understand both where in their writing they were expected to shift from accountability and originality. It might also have helped given them cues for how to manage that transition. For example, let us consider the sixth topic suggestion from the second list excerpted in Figure 15:

Explicate and evaluate Locke's theory of the consent of the rising generation (born within the boundaries of an extant state to which their parents consented expressly). What, if any, are the roles of express and tacit consent, inheritance and land, etc. Has Locke smuggled in a parental right to bind children?

As this topic suggestion is organized, the portion that requires writing for accountability is the first cue students are given, and consequently they may spend the most time in the 
explication and evaluation and comparatively little time answering the other two questions following the cue to explicate/evaluate. Instead, these cues may be reorganized hierarchically to indicate where and how students might move from accountability to originality. Below is my attempt to reorganize Dr. Petersen's prompt: In his theory of consent of the raising of children, has Locke smuggled in a parental right to bind children? To answer this question, first explicate and evaluate Locke's theory of consent of the raising of children (born within the boundaries of an extant state to which their parents consented expressly). Next, address what role, if any, factors we have discussed such as the difference between express and tacit consent, the inheritance of land, etc. play in complicating Locke's theory. Using this explication and evaluation, prove your thesis as to whether or not Locke has smuggled in a parental right to bind and control their children.

While not a perfect example, it at least illustrates how providing a hierarchy of tasks can help cue students for more structured work that can better balance accountability and originality. The question at the beginning gives students an overall goal that they are to address, and the prompt creates a space in the explication and evaluation portion for summary and accountability to textual material and, in the last sentence, a cue to move on towards originality. Again, it is not a perfect rewrite, but a rewrite along these lines would provide students with more concrete cues for when and how to move beyond summary and towards the core of a larger argument.

As students progress into classes requiring more complicated and advanced forms of disciplinary writing, they need cues to help them navigate potential conflicts and 
double binds inherent in academic writing, like the conflict between accountability and originality in the use of sources. Undergraduates are frequently habituated towards write for accountability, which never stops being an important part of their classroom environment. They often have difficulty transitioning away from summary-heavy writing towards more original, complex, and argument-driven genres. While they know that the latter is valued, their experience conditions them to default to the former, due to a perceived lack of authority (summarizing is easier than taking a stand), a fear of not sounding competent in the course material, and/or a lack of cues/strategies for transitioning from the former to the latter.

In this Philosophy class we see an example of a writing prompt that was intended to promote more original, argument-driven writing, but due to the complex uptake it required, some students interpreted it narrowly and wrote primarily for accountability when originality was explicitly asked for. The example of Dr. Petersen's writing assignment prompt and his student's interaction with it illustrates two major lessons for the use of cues to balance accountability and originality in particular: they can help students see where and how they can accomplish both goals of accountability and originality. Of course, there is such a thing as too much structure. The course discussed in the nexct section used a prompt with a very strict hierarchy of cues that ended up contradicting the messages students received during the evaluation of their writing throughout the course.

\section{Demonstrating Knowledge in Nursing}


While students in the class discussed in the previous section experienced a conflict/contradiction between accountability and originality, the students discussed in this section experienced a full blown double bind caused by these same two competing impulses. Indeed, it is the most prominent system-wide double bind observed in this study. This double bind was the result of a conflict between the communicative ideal of academic writing and the evaluative reality of the classroom environment as it manifest in the term paper of an upper-level Nursing course. The class was a large and complex activity system involving not just a relationship between teacher and students. It also included health care professionals, different health care facilities, and a wide variety of teaching materials beyond just the prompt. As such, there are multiple dimensions to this double bind, and so one aspect of it will be dealt with here and another (the conflict between the classroom and the workplace) will be discussed in Chapter 4 .

Nursing 474, Synthesis of Complex Health Systems, was an upper-division nursing class in which students learned about complex health systems and treatments while they were also engaged in a semester-long clinical internship (the interaction of the activity systems of school and work and how that affected student writing will be dealt with in more detail in Chapter 4). This study looked at two sections (one during the spring semester and one during the following summer) of this course that were taught by the same teacher with the same materials. In both sections, the students were also engaged in a semester-long internship at a health-care facility as part of the capstone of their nursing program. Their experiences in these internships were integrated into the course via the writing assignments discussed $n$ the paragraphs below. The lead instructor for this course, Gail Green, was a nurse working for the university's School of Nursing 
while she was also working on her PhD. Professor Green coordinated with teaching assistants (TAs) as well as the nurses and doctors from the university-affiliated hospitals who worked as graders and respondents for the students. She inherited the course design and the paper from a previous instructor of the course, and modified it to be more amenable to students also devoting a significant chunk of their week to their internships.

The most important writing assignments students completed for this course were their frequent journal assignments and their major term paper. The students completed a sequence of journal assignments in which they were tasked with completing a series of specified writing tasks that showed that the students were carefully observing and contemplating their work sites. The various tasks they were required to complete in these journals included recording a care plan for a patient they observed during one of their shifts, observing and detailing particular practices, and addressing a topic from a list of short writing prompts that covered issues in nursing like Compassion Fatigue. While Professor Green was the head coordinator of the course, the grading of assignments like the journals and the major term paper was broken up between medical professionals affiliated with the School of Nursing (who fall under the Community node of the AT model used in this study). The intent of these journal assignments was to make sure that the students were paying close attention to the variety of things going on in their internship sites.

The term paper was called an Evidence-Based Practice paper (or EBP), and it is the only paper prompt in this study to use a title that helps reveal the rhetorical purpose of the assignment. "Evidence-Based Practice" is a term students in the course were very familiar with from other nursing courses. Nursing in the last twenty years or so has 
become focused on researching and reinforcing "best practice," in which the best of current research (as opposed to habit or tradition) dictate what is best for the patient. Professor Green intended this paper to reinforce the idea of best practice by having her students question what they saw in the workplace during their internships. The title of the paper supported the overall purpose of the assignment and its relation to the students' previous coursework, which is in line with the findings of Lisa Shaver's 2007 study of assignment names in economics classes. Her findings suggest that titles revealing the subject and the genre can help students better understand their task (87-9).

Professor Green was focused on building on her student's prior experiences and pushing them to think linearly as nurses. This meant following the same process in writing that they were trained to follow in their work: observe, plan, prioritize, and act in good order. The EBP paper required students to take a nursing practice they observed in their internship sites (E.G., massage for pain management in a physical therapy office, use of specialized kits to prevent ventilator-related pneumonia in an ICU, etc.). From there, they were required to research extant studies on the practice, and then to either recommend a change or make a plan (complete with a cost-benefit analysis) to posit a way to better support the practice.

The prompt (which can be found, along with the other writing prompts, in Appendix B) for this paper was ten pages long, which included a very detailed outline of the project, formatting requirements, a decision tree, a separate grading rubric, and various supporting materials for finding/evaluating useful sources and writing within APA format. The portion the students reported paying most attention to, in both surveys and interviews was the prescribed outline of the paper itself, which was very directive 
and linear. Students were given a highly structured and specific outline for how the paper should be organized in order to ensure a consistent final product for the graders. The EBP paper was unusual in the nursing department due to its length and complexity, even though students had done similar tasks before (analyzing research, applying critical thinking guides, making plans for patient care, etc.) Having the detailed outline mediated that anxiety by giving students a definite direction.

Below, Figure 16 contains the details of the most important part of the outline for the students (according to the interviewees), the Sources of Evidence section. This chunk of the paper's criteria details how students should evaluate the studies they found within their EBP paper, highlighting factors that would affect the usefulness of the study including the population and the methods. The level of detail in this section of the prompt is representative of the level of detail in the prompt overall:

\section{SOURCES OF EVIDENCE:}

For the selected intervention, you will identify at least 3 sources of evidence about the validity of this practice. The evidence you find will fall into one of three categories; it will support the practice or refute the practice or may be inconclusive as to whether or not the practice is the most effective method of care.

a. Data-based research: One of the 3 sources of evidence must be from a data-based research study. The research study should be less than 5 years but may not be earlier than 2001 (10 years). If important ground-breaking studies have been done that are older, the student must obtain permission from the clinical faculty to use it as a source. Studies done outside the United States may be accepted IF the student can make a rational argument 
of how the findings relate to the population and culture within the USA and in Louisville, KY. Again, the student would be prudent to clear this with the faculty.

The student will thoroughly describe the research study and will include the following in their discussion:

1. purpose of the study,

2. the population (who the participants were, how they were recruited, what were the inclusion/exclusion criteria),

3. a description of the research method (how the researchers conducted the study including any data collection instruments used) and

4. a summary of ALL results. Values and objective date should be given, not just broad statements.

( 5 points may be earned for the appropriateness and applicability of the research and 10 points for the description of the study)

PLEASE NOTE: If a second or third data-based study is used, the same requirements for discussion and the point distribution is the same.

b. It is encouraged that the second and third sources of evidence come from professional practice guidelines and/or evidence summaries. If these sources of evidence cannot be found, the student may use other single databased research studies as evidence. If the student uses other data-based studies, the student must also describe them as above and provide a copy of the study to the clinical faculty.

Figure 16. Sources of Evidence Outline from EBP Paper. 
The students were to go through this prescribed method of examining current research with at least three research sources. Based on what the research found, students were to use the section described in section 2 of the paper as the groundwork to either support current practice or recommend a change. The prompt and the paper were not discussed in class except for when a student would ask a question of Professor Green, making the prompt the defining resource for the assignment, and the Sources of Evidence section was the explanation of how the students should explain the most pivotal portions of their research.

The double bind in this course came from a conflict between the journal assignments and the EBP paper prompt, which reflected a larger, more systemic contradiction within the way students were taught to write for the class and-by extension - in the workplace. The five students interviewed from this class (Samantha, Tamera, Mandi, Carolyn, and Sheila) all experienced this double bind despite their mix of backgrounds and academic experiences. Samantha and Tamera were both first-degree seniors within this interview group, although Samantha was a traditional college student and Tamera was coming back to school after a number of years. Mandi, Carolyn, and Sheila all had considerable work experience prior to this Nursing program. Mandi went into the army after high school and later earned a degree in Public Health, and she was most of the way through a Master's Degree in Public Health at the time of this study. Of all five subjects, Mandi was the only one with graduate-level experience, and she was working as a research assistant for a member of the faculty at the School of Nursing. Carolyn came to nursing as a second-degree and second-career student coming from a career as a pregnancy consultant, and Sheila was a project coordinator for interior 
decoration. Given the varied backgrounds and variety of experience of these five students, it is very telling that they all experienced the same double bind.

The core of this double bind was a conflict between the impulses to write in great detail (to demonstrate subject matter competence and due diligence in research) and to focus on producing an original argument, making it a clear instantiation of the larger conflict between accountability and originality discussed throughout this chapter. The competition between these impulses can be seen in the EBP paper prompt, which asked students to pack a great deal of detail in a relatively small amount of space.

The students found the level of detail and specificity of the EBP prompt to be very intimidating at first, but later very they found it to be helpful as it took the mystery out what the teacher was looking for in the paper. For both Carolyn and Samantha, the length of the prompt seemed much less daunting as they got into the project. Carolyn indicated that the instructions "were lengthy, but once you read these [indicating the outline] it doesn't seem quite so long, because they've gone into a pretty good amount of detail, explaining, you know, what they want," which made the project easier for her. Samantha initially was so intimidated by the prompt that she put it away and had to come back another day, but afterward:

When I came back and then actually saw this [indicating the outline and criteria] and saw how it was numbered and I was like, oh, this is doable. Not so bad. And then when I got started it wasn't bad at all...I don't think that summarizing [the sources] was so hard because once I read through them [I] kind of saw what to pick out and what things that she wanted... 
As represented in the Source of Evidence section, this writing prompt gives students specific cues for how research should be read and explained for a nursing paper. The students are prompted to discuss the purpose, methods (beginning with the population/sample), and results of the study in that order, along with other details.

Giving the students an outline for how to analyze and present the information for each study gave them a clear idea of what the teacher was looking for as an assessor and it also relates to them how Professor Green is trying to teach the students to read studies as nurses. The strict organization of the paper, predictably, did constrain some students. Tamera, a first-degree senior said that "the outline was provided, [and] we weren't allowed to deviate from that." A large amount of the organizational choices of the paper were already made for them. The level of prescription in the project was to create a more consistent written product for the graders to evaluate. While most of the students found the prompt to be helpful once the initial shock of its specificity wore off, all of them began to recognize the contradiction within the project once they became deeply engaged in writing it.

While the EBP paper prompt clearly evidenced what the teachers and graders were looking for, the students encountered a double bind in trying to figure out how to give it to them while retaining the spirit of the assignment: precision and concision. A recurring problem indicated in the student interviews was the difficulty in remaining within the strict page 10-page limit while providing an adequate amount of detail in the Sources of Evidence section (presented in Figure 16 above and worth the most points of any part of the paper). The prompt was not uniform in its cues and directions, making what Engeström would call its "double nature," or how it represents two seemingly- 
contrary objectives on the page (Learning by Expanding, Ch. 3). On the one hand, it states "The body of the paper should not exceed 10 pages. Length does not equate with quality. You must be able to be concise and clear without redundancy. Points will be lost for excessive length." On the other, students were asked to provide a detailed "a description of the research method...including any data collection instruments used" and "a summary of ALL results" (emphasis original, see Figure 16). Two very laudable motives (teaching students to be concise and having them practice unpacking articles completely) conflicted with one another in the activity system of the class and the writing assignment.

This situation would not constitute a double bind if the contradiction was only manifest within the final paper. As noted in the previous chapter, double binds are the result of contradictions exacerbated over time by conflicting sets of signals. This is where the students' journaling experiences come into play. Whereas Professor Green emphasized concision in the EBP paper, the students' graders consistently emphasized wiritng with expansive detail in their journal assignments. As mentioned earlier, the goal of the journals was to make sure that students were paying close attention to the various things going on at their health care internship sites. The graders wanted to make sure students were being accountable to that goal and that they were duly contemplating the issues their journals wanted them to address. Consequently, the graders continually prodded their students to write longer and more detailed entries. . Tamera, became particularly frustrated by this prodding, exclaiming that "Just because you didn't write that you thought about it doesn't mean you didn't think about it." She identified it as a call to demonstrate more knowledge of a type that she had been habituated to in college 
writing, causing her to prefer to "fluff something [rather] than make it smaller" in order to ensure a decent grade.

The constant and consistent reinforcement of the need to write in great detail to satisfy their grader's expectations of accountability carried over into the students' work on the EBP paper, despite the EBP paper's emphasis on concision and its enforcement of that ideal via the strict page limit. In Activity Theory terms, there was a significant primary contradiction within the prompt (which at the same time stressed concision while also prompting students to fully unpack the studies they were using). There was also a secondary contradiction between the prompt as a tool and the influence of the class' community and rules (the graders and their influence on student writing). This conflict is the result of the attempt to balance the evaluative environment of the classroom and the ostensible communicative function of the paper. The contradiction is illustrated in terms of my adaptation of Engeström's expanded mediational triangle (see Chapter 1 for a more detailed description) below in Figure 17. As opposed to the activity systems diagrammed earlier in this chapter and in the previous chapter, the system of the Nursing class had a a more pervasive, system wide conflict. 


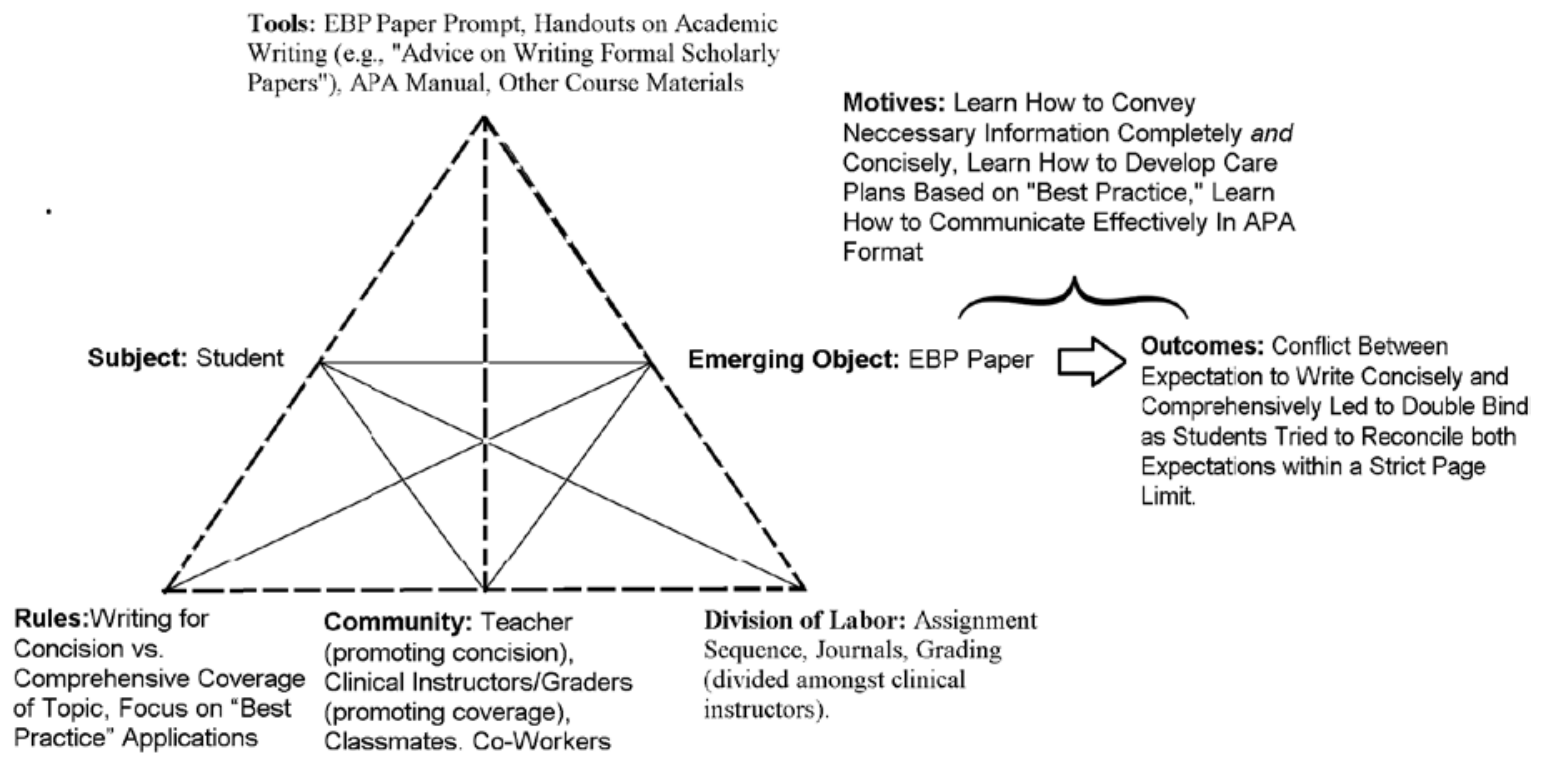

Figure 17. Diagram of Nursing 471 Activity System (elements in conflict and/or contradiction indicated with dotted line)

As a result, the students felt stymied in their efforts to perform for two separate sets of expectations. This aspect of the double bind was keenly felt by Sheila, who stated that she "would prefer to get to the meat and bones [of the issue], but then I'm having this struggle because the person that's grading my paper appears to want more detail than what I feel the guidelines are telling me to do. So it was a struggle because the person grading my paper wasn't the person that wrote these directions." Whether they wrote more or tried their hardest to be concise, the students felt they were in a no-win situation.

The result for these students was an intense editing process that they felt had little chance of success. This feeling was best articulated by Mandi. Even though Mandi had a great deal of college experience and writing experience beyond the Nursing program (including graduate writing experience), she still felt trapped in the double bind as she went through the lengthy process of editing for concision. She knew she could not include all of the detail her grader was expecting to see, but at the same time she felt that 
editing down the content caused her to compromise the effectiveness of multiple parts of the paper. She felt she inevitably had to skimp on later sections of the paper, knowing that the material required in the Sources of Evidence section counted for more points. Mandi had the following to say on this issue:

I felt that the page limit was really my biggest problem. I felt like the amount of information they wanted us to provide, the level of detail I'm assuming they wanted us to provide was difficult to do in ten pages... I wrote, and I edited, I wrote and I edited [small, breathy sigh]. So I tried to think out by points how many pages should be on these things, or, you know, where do I think they are probably going to want me [to go] a little more in depth, and I know I definitely took out, several pages worth of stuff, and that was frustrating for me because I felt like then it hampered my writing style. Where I would have probably wanted to explain something a little more, I felt like, well, I can't explain it any more because I don't have the space to explain it anymore... what they wanted us to talk about I felt like was much bigger than 10 pages allows...

Since the Sources of Evidence section was worth the most points of any portion of the paper, students like Mandi hedged their bets on it by devoting a larger portion of their page allotment to it, forcing them to sacrifice the integrity of other parts of the paper. They felt they were being pushed towards demonstrating accountability when originality (arguing for or against a nursing practice and following through with recommendations) was supposed to be the central focus. This shift led her to take shortcuts of the type Jennie Nelson observed in her 1990 study of how students interpreted teacher instructions Nelson identified these as "shortcuts for producing acceptable responses—-shortcuts that 
allow them to circumvent the thinking and learning processes their teachers hope to promote" (366). Double binds such as these push students towards these kinds of shortcuts. In this case, it meant devoting less space to the parts of the paper requiring an original argument and more to the parts requiring them to demonstrate accountability to their research. Even that, however, did not reassure the students that they would receive a favorable grade, and so they felt trapped in a "damned if I do, damned if I don't situation.

Professor Green was certainly aware of the difficulty students faced in writing about everything their graders wanted within the space constraints. She saw this as creating a learning curve for the journals in which students would have to learn how to say a great deal in a small amount of space, which were lessons that would help them in their final paper and in their professional writings. She also held grade a grade norming session with the graders working for the class to ensure some kind of standardization. However, her teaching materials were at odds with the goals of the graders. The activity system of the class sent students two contradictory messages, and as a result the students were unable to balance accountability and originality. The students here had trouble taking up the role of a health care professional aiming for clear and concise communication due to the overriding concern for their grade. For a student writer, if the writing process becomes a competition between accurately simulating an authorial role and performing for the points, then the latter is going to take precedence.

The primary lesson we can learn from this example is that writing instructions must be in line with the writing instruction (explicit and/or implicit) that students are receiving in class, otherwise students can become victims of double binds and of the 
“assign and complain" method of evaluating writing (Clark 12). The data also suggest that the more spread out a writing assignment is among graders and evaluators, the more prone it may be to contradictory messages and double binds, although grade-norming sessions like those held by Professor Green can help a great deal. Both the cases of the nursing and the philosophy class suggests that the use of textual evidence is one place in the teaching of writing that is prone to double binds, as the teacher doesn't may not want to see a "data dump" paper but at the same time wants to see that the students understand and can relate course material in writing. These examples suggest that balancing of accountability and originality may not an issue of making both equal, but one of establishing clear priorities so as to avoid contradictions and double binds.

\section{The Importance of Cues While Writing Between Accountability and Originality}

In crafting a writing prompt, instructors are providing students with a way of viewing a constellation of classroom resources, disciplinary conventions, and writing strategies. In the examples of these Nursing and Philosophy courses, we have seen teachers trying to use the writing prompt to effect their desired balance between structure and freedom available to students in their writing. While the Nursing class tipped the balance more towards structure to create a more uniform textual artifact for grading, the Philosophy class tipped more towards authorial freedom in subject matter and structure so that students could follow their interests. While both teachers wanted to affect a balance between accountability (via summary of textual materials) and originality (using summary to accomplish another rhetorical purpose), through the writing prompt and its 
cues, conflicts within the system and its tools had significant and sometimes deleterious effects on the student's performance.

Instructors in composition and beyond do not want to see simple regurgitation of information in papers that are intended to be more rhetorically complex. Managing argumentation and subject matter knowledge, however, can be a difficult thing to do for students who are unfamiliar with or still working through understanding the course's content. Summary and description can be come a default or a fall-back strategy when the students are not used to working with the material. Therefore, cues need to be given to students to help them figure out what to do with the information. The following conclusions on the use of cues are drawn from the examples of the classes and assignments discussed in this chapter.

1) Cues should provide a hierarchy of tasks for students: Dr. Petersen's prompt was structured so that students could create their own approach to the topic, but what he had hoped for was a structured approach that resulted from a combination of topics and strategies he provided. Providing a hierarchy of tasks through cues would have limited the options available to students, but might have helped writers like Jeremy and Daniel have an easier time seeing how and where to move from summary to argument. The students in the nursing courses had such a hierarchy of tasks, and while they experienced problems balancing them in terms of content, the prompts hierarchy of cues helped the students understand the overall purpose of the paper and how they should frame their summary.

2) Balance accountability and originality and build opportunities for students to transfer from one to the others: Openly discussing how students are to move from 
summary to originality, and giving them clear cues as to when/how to do so, can ameliorate student anxiety about demonstrating competency for the grade and promote more argumentative writing.

3) The more a prescriptive a prompt's cues are, the less leeway students have to deal with contradictions/double binds: My advocacy for telling cues in a writing assignment prompt does not mean that more is always better. As the nursing students found in the EBP paper, the high level of prescription in the prompt made it difficult for them to deliver on all of the cues they were given within the strict page limit. While a high-level of prescriptive cues may provide teachers with a more consistent textual product form students (making grading easier), it can stymie their development as writers within a discipline if they deny them the latitude to working past/around contradictions or double binds encountered along the way.

4) Writing prompts need to be in line with the writing instruction students receive: Differing expectations can lead to contradictions as students endeavor to reconcile their grader's expectations (if they have been made aware of them through prior feedback) and the intent of the instructor who designed the assignment and structured the division of labor in the course. This necessitates grade norming sessions (which Professor Green did hold with her graders) if not also periodic discussion and reflection among graders.

5) Double binds take students out of desired authorial role: When contradictions between elements of an assignment's activity system become exacerbated, they draw attention away from the authorial role students are supposed to emulate (e.g., 
an academic writing a scholarly article) and place writers firmly in the role of a student struggling to understand the teacher's expectations. Students become very aware of their instructor as their primary audience and as an evaluator, making the simulation of writing to an academic audience a fading illusion. 


\section{CHAPTER 4}

\section{WRITING AT THE BOUNDARY OF SCHOOL AND THE WORKPLACE}

Learning in the university setting cannot always provide authentic contexts for student writers. To remedy this, technical and medical disciplines often offer or require students to apprentice themselves in an authentic community of practice in the form of internships. Such internships are often tied to university classes for course credit which require students to demonstrate or utilize the competencies they have gained during these experiences in the form of a writing assignment. These internships are expected to ease the student's transition from student to professional (Dannels 28; Ward 69). This transitional space is not without its difficulties for the student writer, and researchers in composition have pointed out that these two learning environments - the professional workplace and the classroom - have important differences that, when they are brought together, can cause difficulties for the student. Students receiving inconsistent and/or contradictory signals from these two environments can experience a kind of intellectual whiplash as they try to write to multiple, competing sets of expectations. Do they attempt to write as a professional or as a student vying for a grade? How do the two approaches conflict with each other? This chapter will return to a course already discussed, the capstone nursing course with the Evidence Based Practice Paper (discussed in Chapter 3) and look at it from a different angle: what additional double binds confront students writing in classroom environments integrated with the exigencies of the workplace. 
Using the example of two groups of nursing students engaged in a situated learning environment, this chapter will also indicate what role a writing assignment prompt can play in creating and/or ameliorating the double binds students encounter when trying to juggle the expectations of the classroom and the realities of a profession.

An influential study that illustrates such conflicts between the writing in the classroom and the workplace is Ann Herrington's 1985 study "Writing in Academic Settings: A Study in the Contexts for Writing in Two College Chemical Engineering Courses." Herrington investigated how college writing teachers created relevant contexts for writing in the classroom. She looked at two chemical engineering courses taken by the same group of students: a lab course in which students produced reports on experiments for six different professors, and a design course where students collaborated on a report addressing design problems in chemical products. Utilizing concepts from classical rhetoric, Herrington observed students in the Lab course using more forensic (was this approach the right thing to do?) and epideictic (is the work the student did worthy of praise?) writing strategies, whereas students in the design course used a more deliberative approach (how might this problem be solved?). The design course explicitly attempted to simulate the workplace by having student create a hypothetical company and write memos to their professors using company letterhead (Herrington 342-48).

Herrington found that the expectations, genres, audiences, and purposes of each class differed even though they were both part of the same discipline and taught by the same group of faculty. Furthermore, she found that the newness of the professional element in the design course influenced students to fall back on the more school-centered approaches of audience and purpose than they were using in the lab (340-54). One of the 
most significant findings is the different expectations students and faculty held as to the audience, purpose, and the social role of the writer in the courses' writing assignments. For example, there was disagreement between the faculty as to whether or not the students — who were seniors about to graduate — should be treated more like practicing engineers or more like students. Based on what I have covered so far in Chapter 3 inparticular, we can imagine the dilemma between grading for accountability or originality. In practice, one way this confusion can manifest itself is as the difference between expressing expectations for writing based on demonstrating accountability or writing that is interested in moving beyond accountability to address a question or establish a new/original position. In terms of teachers trying to address student writers as either students or incipient professionals, the difference is between privileging their ability to make and argument and communicate an idea versus demanding writing that demonstrates the students mastery over fundamental engineering concepts.

In her study, Herrington also noted that students had trouble seeing themselves as writing from within a professional role, even in the simulated professionalism of the design course (348-9). This led her to the conclusion that "there is an educational value to the purposes and writer-audience roles of the school community, purposes and roles that may be inconsistent with those of a professional forum...Further, we may be working at cross purposes when we unconsciously try to create both forums in the same classroom, particularly if we give mixed signals to students about our own role" (356). Mixing the discourses, purposes, and exigencies of school and work can confuse students, who are more likely to fall back on the strategies they have cultivated students rather than develop new ones as burgeoning professionals. This habit is exacerbated if 
they are unsure whether they should write to their instructors as teachers or as fellow professionals (a riskier move for most students).

Later researchers have built upon and expanded Herrington's finding of the differences between writing for school and writing for the workplace (even a hypothetical workplace). Rebecca Burnett's 1996 study of students writing a report for the Department of Energy highlights the inconsistencies between school communities and workplace forums that Herrington discussed. Unlike those in Herrington's study, the students in Burnett's were actually writing for a workplace environment as part of their class work. Collaborating on a report for the Department of Energy, the students were tasked with finding ways to lower the cost-per-unit for a mobile laboratory. When they encountered problems or confusion, the students were generally left to fend for themselves as part of their education. Burnett notes that the students' lack of experience in the workplace interfered with their role as professional experts, and so "many of them retreated to a student role of completing their assigned task without regard to the project as a whole; others withdrew from any active participation in the project" (138). Burnett's findings highlighted various factors that differentiate students from professionals, such as different motivations (getting the grade vs. helping the team) and the ability to adapt or reinforce prior knowledge in the face of new contexts. As in Herrington's study, Burnett's findings suggest that when the roles and expectations in a mixed school and work environment come into conflict, students retreat into the more familiar and more insular roles of individual students vying for a favorable grade (138).

Another important finding of Herrington's study that has influenced further research is the ways in which a teacher can shape the classroom writing/learning 
community. While she notes that "the aims of a course might be better realized if we try to create a viable school forum instead of a hypothetical professional one," she also found that there were fewer contradictions between writing and teacher expectations when "writing assignments were consistent with the context that was enacted in the classroom" (356-7). The teachers in the design class had students establish hypothetical companies and their writing furthered that role-playing, and so Herrington found fewer conflicts in the design course than in the lab, where there was more of a disparity between what students understood and what the professors expected. Consistency is the key in this finding as it minimized the chance for double binds. While the teacher plays a pivotal role in establishing a consistent learning environment in the classroom, achieving consistency can be very difficult when students are also involved in a real (and not a simulated) workplace.

Realizing that consistency can be a deceptive ideal in such mixed classes-and building on Herrington's research--Deanna Dannels' 2000 study of mechanical engineering students in a mixed classroom environment suggests that uncritically blending the two environments can be more detrimental than helpful. She found that students have to reconcile ideas about professional identity and audience that are more complex and multi-layered than standardized curricular materials can encompass (14). She argues that:

School will never be the workplace; it will always be school. Yet, many technical disciplines incorporate some form of capstone work-place experience for senior students, the explicit objective being to construct professional experience that eases the transition from student to professional. Therefore, these courses should 
be designed in ways that maximize the potential for integrating the professional context while recognizing the limits of this integration. (28)

As with Herrington, Dannels argues that teachers should understand the inherent problems of incorporating aspects of the workplace in classroom writing, but Dannels explicitly recognizes that these activities can have a useful mediating effect for students about to graduate and enter the profession they have been trained for. Therefore, understanding the uses and the limits and being open about them with students is essential for students and teachers to make the most of the experience. Dannels further indicates that being open about the potential problems with this integration can be an occasion to critique current practices and, perhaps, make an intervention for change (34). This can ease the difficulty students have when trying to write for multiple audiences with conflicting, or even contradictory, expectations.

Uncritically incorporating professional development in the classroom and in writing assignments — either through hypothetical simulations or through schoolfacilitated internships — can have detrimental effects if it is not then implemented critically and consistently. Simply telling students to imagine that they are writing to a CEO is not enough. It is equally insufficient to simply bringing the "real" and the academic together and hoping that the exposure will help to mediate the transition between student and professional. There are potentially many levels of mediation necessary for a learning experience of this type to be beneficial for students. Before I transition into how in particular this chapter adds to the conversation on methods of mediating student difficulty in classes that mix school and the workplace, there are two fundamental aspects of Dannels' argument that I wish to highlight. 
First, she observes that students learn in situated ways that inculcate the social discourse of a community of practice along with content knowledge (6-9). She draws from Situated Learning, an educational theory defined in Jean Lave and Etienne Wegner's influential 1991 monograph Situated Learning: Legitimate Peripheral Participation. In an effort to move away from the simplistic learning model of studentas-passive-receiver, Lave and Wegner posit that newcomers learn the ropes of a community most effectively through active participation instead of through formal, rote instruction. Situated Learning is learning by doing in a real-life community of practice, and Legitimate Peripheral Participation is their model for how a learner moves from being an outsider to being a full member. They define Legitimate Peripheral Participation (hereafter referred to as LPP) as the way in which new-comers acquire knowledge and expertise through growing involvement in direct practice under the guidance of "old-timers" (i.e., experienced members); learners begin with sanctioned activities at the periphery (minor tasks) and move towards the center of full practice and full membership (Lave and Wegner, 1991). Lave and Wegner advocate that "For newcomers then the purpose is not to learn from talk as a substitute for legitimate peripheral participation; it is to learn to talk as a key" (109, emphasis original). In other words, LPP advocates learning by doing instead of learning about doing. In addition to learning content, situated learners are also acclimating themselves to the social rules and expectations of the community, which can be very powerful determinants of success and satisfaction. Dannels argues that teachers incorporating the professional workplace in the classroom should understand how situated learning works and find ways to work with this type of learning in the mixed classroom (31-33). 
Second, given that students learn in situated ways that encompass social dimensions of practice, Dannels argues that "Complicating curricular materials to better reflect social practices may allow students to bridge the distance between design practice in the classroom and in the workplace" (30). The social realities of the workplace can play an important role in whether or not students feel they have the agency to act within the setting being simulated. As we will see in this chapter, the ideals espoused in the classroom can be difficult to realize in the workplace given the social status of a newcomer to a professional work environment. Recognizing the social realities of the workplace, including the opportunities and limitations they afford, can help instructors better support writing assignments that are aimed at bridging the gap between the two environments.

Students writing on the boundary between school and workplace situations can encounter particular difficulties and double binds: they are caught between at least two activity systems that do not neatly intersect with one another. Understanding these difficulties gets us only part of the way towards remedying them. Knowing how instructional materials like writing prompts can helpfully mediate (or in some cases, exacerbate) these difficulties is another important step towards better implementation of the workplace in the classroom. Returning to the example of the nursing classroom first discussed in detail in chapter 2, this chapter will address how students at the end of their disciplinary training utilize writing prompts to navigate the gap between classroom and workplace writing.

Nursing is a rich site for this investigation. A popular view of the nurse is of a worker who mainly follows the orders of doctors, but the field of nursing is intellectually 
rigorous and encourages nurses to be active agents for better health care. Student nurses are plunged into full practice directly after earning their undergraduate degree. The students in this study were prepared for the workplace after graduation via a semesterlong clinical internship, involving them directly in LPP in a community of practice. This placed the subject group for this component of the dissertation study within a similar mixed learning (school and professional) environment discussed by Herrington, Burnett, and Dannels. Nursing is also a profession with an academic and research-based component that often impacts the practical side of the discipline, although tensions exist between the two components. Schryer found that the difference in writing genres used by medical clinicians and those used by academics - indicative of different sets of values, daily activities, and purposes — constitute one of the forces maintaining tension between medical practitioners and researchers ("Genre and Power"106). Such differences can be difficult for full members of a medical profession to negotiate, and even more so for students just starting in the profession. The two groups of nursing students discussed in this chapter were at the end of their nursing major and about to enter the workforce. Ideally, their writing project should allow the students better insight into how to write and act within their discipline. There are inherent difficulties in trying to meld workplace and classroom writing genres, however, and this chapter illuminates some of those difficulties and the role that the writing prompt played in exacerbating or ameliorating them for students on the boundary between school and the professional workplace. In particular, it will focus on three particular challenges/contradictions that appear to be inherent in this kind of mixed writing environments: competition between authority figures, a lack of 
rhetorical and research "savvy," a lack of investment/agency caused by difficulties with new tasks.

\section{The Course and Clinicals as LPP Experience}

LPP and the Clinical Internships: These students were involved in LPP in a situated learning environment, one which brought them closer to being full members of their professional community through gradually growing involvement in nursing practice. They began their 210 clinical hours by shadowing a full-time nurse on his/her rounds, and they progressed towards covering an entire shift on their own towards the end of the semester. In addition to having a practicing nurse mentor, students also periodically checked in with their clinical instructor (the university faculty member or health-care professional who supervised groups of student interns and graded their written work in the Synthesis course) by way of regular journal submissions. This gradual increase in participation in sanctioned activities under the guidance of "old-timers" (established members of the community of practice) fits Lave and Wegner's model of situated learning and LPP in that students are learning by doing and gradually moving towards the center of full practice from the periphery of apprenticeship (56-7). A key criterion for LPP as Lave and Wegner define is learning to talk instead of learning from talk (109). The interview data revealed several instances of students struggling to do just that. The following example from Sheila, the former interior decorator and project manager, is particularly revealing on this point: 
Shelia: A lot of times it's very difficult to translate the classroom to real life because they are such different entities, and, you know, being out there in real life and seeing something happen

Matt: It's different than sitting in a classroom

Sheila: Yeah, and it sticks with you a little more having lived it than learning it? I, I mean, I'm pretty good in the classroom, I've made all A's

Matt: Mm-hmm

Sheila: and, you know, haven't had any problem with that, but when I was out practicing there were a couple of instances where I'm like "Why did I say that or why did I do that? I know better than that that's not what I learned?" But, you know, being out there and working off your instinct or natural reaction you have to train yourself to think appropriately, then, yeah.

Matt: Right, it's different than doing well in one of your lower division classes Sheila: Right, right. I mean, even, even the classroom part, just for instance, I mean nothing bad happened, but I felt like an idiot after I did it. There was a child that had just had a tonsillectomy and we were trying to get him to drink and, [short pause and breathy, embarrassed laugh] I'd stupidly asked him if he wanted to have something with a straw in it and you don't give straws to people who've had tonsillectomies because they might accidentally

Matt: Cut themselves? 
Sheila: Yeah, go too far down their throat, and, you know, they were like "well the doctor doesn't want him to have straws," and I'm like "yeah, I know that," [laughs] but you know, we were just thinking of ways to get him to drink, so.

In this example, Sheila reported a disconnection between what she learned from talk (that tonsillectomy patients shouldn't have straws or anything else that could irritate the incision sites) and how she was learning to talk (trying to figure out how to help alleviate a real patient's discomfort within that patient's particular restrictions). Another seconddegree student, Mandi, who had prior experience in the health care field, also felt intimidated by just how much the clinical revealed to her she had yet to learn, even to the extent of making her doubt the basic skills she already acquired:

Mandi: So, I mean, even when I got there I just felt totally, like, getting back to those simple nursing skills that I should have had, I felt like I didn't have them, and it was fine to learn from the nurse that I followed. I don't know. I mean, I, we're told frequently by nurses and professors that you'll have a lot of time to train, a lot of, um, you know, and you won't, and I've worked in enough different jobs that there will be a lot you won't know until you get into the job

Matt: Right

Mandi: and you learn it if you're just patient with yourself, so I can be realistic about that. I think I am prepared, but, um [very short pause], I don't know, I think there is still so much more to learn. I've thought a lot about 
whether or not it's something we could have learned in nursing school. I don't know, maybe.

The clinical experience made Mandi question even the basic nursing skills as she became more used to applying them in context with real patients instead of on a test or in a paper. These students were becoming acclimated to practice in a more holistic, more inhabited community of practice, which was a very different experience from their time as students in the classroom. All five students reported having to modify their learning habits from the content-based methods that served them well in lecture courses and content-based exams. The clinicals called upon them to use their knowledge in a practical setting with real consequences. The gradual increase of responsibility placed on them during their clinical, and their struggles to learn how to use their knowledge instead of just demonstrating it, brought them closer to the center of full membership through LPP. The writing assignments in the Synthesis course were another method that Professor Green and the clinical instructors used to help students bridge the gulf between abstract medical science and the real applications of medical practice.

The Journal Assignments: The Journal assignments were briefly introduced in the previous chapter. For each week of their clinical internships, students in the Synthesis class were required to submit a structured reflective journal entry to their clinical instructor. A condensed list of the journal's guidelines is provided below in Figure 18, with word-for-word excerpts from the prompt presented in quotations: 
1) An overview of the week's activities (approx $1 / 2$ to 1 page): what kind of procedures, activities, communications between healthcare professionals, and skills were observed. Students were also prompted to "Assess what you learned for the week that was more than just a skill but maybe a realization" (like managing more than one patient or getting paper work done).

2) Write about the Nursing Process (approximately 5-6 pages): "Provide a detailed narrative of the care rendered throughout one shift to one patient (adhering to strict HIPAA requirements).” This includes detailing the patient's background, assessment data (like vitals, test results, etc.), diagnoses, goals for care, interventions taken, medication administered, and evaluation of the effects.

3) Write about one topic form the pre-designated list (approximately $1 / 2$ to 1 page): "In addition to your reflections you will address a topic each week in your journal and explain how you have met that objective. Students are required to address a topic in each journal. If all topics have been covered then repeat a topic." Topics include communication and teaching, case management/community resources, cultural diversity, the role of the nursing profession, identification of researchable topics

4) Time Log: an exact log of time spent in clinical

Figure 18. Nursing Journal Instructions Condensed by The Researcher (emphasis original)

Each item in the requirements has a direct link to the work students were expected to do in their clinicals. The complete prompt for the Journals was five pages long, and covered each item in more detail with itemized lists or outlines and a list of formatting 
requirements at the end, which included APA style (available in Appendix B). At the end of the prompt was a statement (presented in Figure 19 below) explaining the learning goals and the larger purpose and advice:

You can see that if you address each section thoroughly that you must use economy of words and stay focused on what you are writing about or you will have pages and pages of text. This helps your critical thinking skills by helping you prioritize, focus on the task and summarize. As you master this journaling format, you will begin to unconsciously "think" about patient care in terms of the nursing process as you care for them in the clinical setting. This is the primary objective of the journaling assignment. This will take practice and a conscious effort to achieve but you will be surprised at what you learn and how this trains your mind to "think like a nurse" by the end of the semester!

\section{A well-written and concise journal should be about 6 and no more than 8 double-spaced typed pages. You must focus on prioritizes and communicating with economy of words and conciseness. Points will be deducted for journals of excessive length.}

Figure 19. Excerpt on Concision from Nursing Journal guidelines (emphasis original)

This prompt, and in particular this purpose statement, reveals a good deal about the learning goals of both the clinicals and the class. The first and most prominent aspect of this purpose statement is its prescribed "economy of words," the imperative established by the prompt (and thereby, the instructor) to balance detail with concision, particularly when talking to other medical professionals. In both the journal prompt and a personal interview, Professor Green indicated that the journals were geared 
towards inculcating the habits of mind necessary to "think like a nurse." The genre of these journals is not a "pure" academic or professional genre, in that it does not closely mimic specific types of text academic or clinical nurses produce. Still, they are constructed to teach students a great deal about what a nurse needs to pay attention to and consider in his/her daily rounds. The journals are an explicit attempt to mediate the students' transition from students to practicing nurses, thereby helping students to navigate that difficult gap between the classroom and practice that Herrington and the other authors cited above have considered.

The term paper, also introduced in Chapter 2, was called an "Evidence Based Practice Paper." The prompt for the Evidence-Based Practice Paper (hereafter called the EBP paper), described the objective of the project as working "to motivate the student to question everyday practices performed in the clinical setting and to investigate ways to improve patient care and achieve better outcomes based on scientific evidence while containing health care costs." Students were to select a nursing intervention commonly used in the unit where they performed their clinical internships. They were then expected to come to a conclusion as to whether or not that protocol was "best practice" according to current research. From there, students were to propose a plan to either change the practice or to reinforce and improve current operations. In essence, students were prompted to work through a nursing intervention from initial observations all the way through to practical implementation, including budgeting.

The paper itself is very linear: based on what a student determined in his/her review of the research, the path for the rest of the paper fairly predetermined. This linearity seemed to mesh with the writing habits of more scientific-minded students. 
Despite the recursive writing processes they may have been taught in composition courses, advanced students in the sciences observed in this study tended to work through a paper straight from beginning to end. The linear guidelines of the EBP paper, then, appeared to be adapted for this type of student writer. Based on Gail Green's description of the linear, problem-based thought processes she has internalized during her time in the profession, the EBP paper's linearity may be a general reflection of how nurses are taught to think and act: in clearly defined stages straight through from problem to solution. In this way, the observation, planning, and work that students put into this assignment contributed to their LPP experience by requiring them to be observant, inquisitive, and conscientious about what they observed and what they did at their clinical internship sites.

Participants: Five students from the two Synthesis courses were interviewed in the spring and summer semesters: Samantha, Tamera, Carolyn, Sheila, and Mandi. Samantha and Tamera were undergraduates taking the Synthesis course during the spring Semester. Samantha was a traditional undergraduate, attending college directly after high school, and Tamera had come back to school several years after high school. Carolyn, Sheila, and Mandi were students working on second degrees who took the Synthesis course during a long summer term, and all three had considerable work experience that greatly affected the way they approached the course and their clinicals. Carolyn had worked with new mothers as a lactation consultant for many years. After her five children had grown up and left home for school or work, she decided to pursue her nursing degree based on her positive experiences with nurses and hospitals in town. Sheila was an interior decorator with experience managing the business side of that profession, and she 
was coming back to school to pursue a second career after an economic downturn adversely affected her work. Mandi went into the army after high school and later earned a degree in public health. Of all five subjects, Mandi was the only one with graduatelevel experience. She was most of the way through a Masters in Public Health and worked as a research assistant for a member of the faculty at the School of Nursing at the time of this study.

\section{Challenges and Contradictions Encountered in a Classroom Mixed with the Workplace}

Competing Authority Figures: An important learning outcome of the journals and the EBP paper as it was described in the prompt was to learn how to be discriminating and concise in the information provided to the reader. This was covered in Chapter 2 when discussing the contradiction between accountability and originality. It will be revisited briefly here in terms of how that contradiction takes on a different facet when viewed in the context of writing in the workplace, particularly in nursing. In particular, it highlights and confuses the division between writing for school purposes and writing for workplace purposes.

As explained in Chapter 2, concision was a primary goal that Professor Green set for her students' writing. Practicing medical professionals have a lot to do and not a lot of time for lengthy explanations about a patient's condition and history, which is a point that Professor Green frequently communicated to her students. Both the journals and the EBP paper were intended to develop students' ability to prioritize the information they 
reported, making the writing for accountability portion of the students writing as concise as possible. The writing prompts for these projects reflect this imperative in their strict page limit. This makes sense as a form of professional development for students directly involved in LPP in a situated learning environment where the ability to concisely and efficiently report information is of direct use.

As described by the students interviewed, the clinical instructors seemed to be more concerned with having students give lots of detail about their clinical experiences to make sure that they were being attentive in their day-to-day activities. Students were continually prompted to include more and more information about the first part of their journal assignments, the description of observed practices and processes during the past week. Given the page limits for their journals, this meant a difficult editing process for students. Sheila explicitly discussed this problem in her journal writing process:

Sheila: it was just like get more in depth with your writing, which, this [indicating term paper prompt] they give us such a time, you know, page restriction?

Matt: Mm-hmm

Sheila: I was thinking I don't need to give them that in-depth, because, you know, she states in here "these are medical professionals, you don't have to blah blah blah,"

Matt: Right

Sheila: But then I hear this from her, so every one of my journals I was having to edit and edit and crunch and crunch, because it was really hard, and in here we're supposed to do a topic every week, well I would up having a paragraph space left to address the topic, so, I basically addressed one or two topics 
when I did my big giant journals, and then, I just, I'm like, these will be addressed when I do the smaller journals, because I don't have room. According to Sheila and the other interview subjects, this was a common experience. The "topic" portion she described is third on the guidelines for the journals (see Figure 18). The first and second parts of the journal entries were to consist of a detailed overview of what the nurses observed and learned and a detailed narrative of the care provided to one patient during their shift respectively. The clinical instructors prompted students to provide detailed accounts of what they observed during the week as a way of making sure the nursing interns were paying close attention and making the most of their clinical internships. This, of course, invalidated the lessons that Professor Green was trying to instill about concision, and it limited the amount of space that students had to develop the other portions of their journal assignments. It is a phenomenon that would create great difficulty for students in the EBP paper

These contradictory instructions, when viewed from an Activity Theory and LPP perspective, caused a confusion of authority figures and rules for students. Attempting to follow Professor Green's imperative to be concise when writing for the clinical instructors - the very medical professionals they are supposed to be concise for-resulted in frustration as the instructors continually asked for more and more detail. This was particularly frustrating to Tamera, who at first tried to be concise to fulfill the rhetorical imperative of the prompt. She found herself penalized for leaving out information, prompting her to note in interview that "Just because you didn't write that you thought about it doesn't mean you didn't think about it." Prioritizing important information by leaving out what the students deemed less important information was punished. 
Essentially, Professor Green and the Clinical instructors were working at cross purposes in this aspect of the assignment. Professor Green was stressing the communicative purposes of professional writing in nursing: it needs to be concise and tothe-point without losing a certain degree of comprehensiveness and detail. The clinical instructors seemed to be stressing the evaluative goals of school-related writing: students need to give lots of detail to prove that they have been paying close attention. In a way, they reversed their roles as readers somewhat, with the professionals reading more like teachers and the teacher reading more like a professional. Who were students to believe? Whose lessons were they to take with them into the "real world" of nursing practice? It is telling that the sections in which they desired more detail were the sections in which they, the clinical instructors, had the most agency: the sites where these nursing students were working as part of their clinical internships.

One difficult aspect of classes and assignments that bridge the gap between school and the workplace is the handling of the roles of faculty and graders. Do they read more as professionals or more as teachers? How does that translate into the instructions they give to students? The contradictions experienced by students in this project were compounded by a degree of role confusion for students. Who were their readers and who were they as writers? Were they students writing to professionals, professionals writing to professionals, professionals writing to a teacher-evaluator, or some mix of all of these?

This course certainly did help students in many ways, and Professor Green and her clinical instructors were not unconsciously or uncritically mixing academic and workplace writing. Indeed, they discussed these issues and even held grade norming sessions to heighten their internal consistency and reliability when it came to grading. 
The precarious nexus that is the workplace-integrated classroom, however, opened the class and the assignments to contradictions and double binds that did not become apparent until students were struggling with them. The most immediate effect of this double bind was that students were caught between competing expectations for the same paper: their clinical instructors had been given Professor Green's prompt and rubric and trained in how to use them, but were assessing student writing in a way inconsistent with the goals of concision that Professor Green had built into the assignment. In the interest of saving their grade, the students had to perform a kind of writing triage (if I can be forgiven the pun) in that they had to sacrifice other parts of the paper to prioritize the portion worth the most points. The larger effect of the double bind was that students were left to ponder what message they should take away from the experience and what authority figures to believe or trust when it came to the imperative to write either concisely or to provide all of the details required.

\section{A Lack of Familiar Resources Leads to a Lack of Investment and Shortcuts: Another} frustrating double bind students faced in this paper resulted from their struggles with the cost-benefit analysis portion of the assignment. In this section, the students interviewed had problems fulfilling the requirements to their (and their instructor's) satisfaction, and were willing to settle for lost points in the interest of focusing on what they deemed more important parts of the assignment. The cost-benefit analysis portion was a common area that these students sacrificed, and this was not because of its unimportance but rather due to its difficulty and the paucity of reliable resources presented to them. Following their discussion of peer-reviewed research on their topic and their decision to support or alter 
the medical practice in question, the students were expected to perform a detailed and accurate cost-benefit analysis to help persuade their hypothetical readers (hospital administrators) to adopt the writer's recommendations. The instructions for the costbenefit analysis section are presented uncondensed in Figure 19 below.

\section{COST-BENEFIT ANALYSIS:}

For each of the three approaches described in \#4 above, you will have to justify costs versus benefits. You MUST obtain real cost estimations and give references for the source of your costs. Failure to provide details regarding costs or details regarding benefits will cause you to lose the majority of points for this section. Vague broad statements will not suffice in meeting this requirement. (10 points)

\section{For REINFORCING CURRENT PRACTICE:}

a. Describe in detail the costs of teaching strategy you chose. Think in terms of the cost of man-power hours, materials and/or equipment needed to achieve the initial and on-going teaching and monitoring.

b. Justify the costs in quantifiable benefits: better patient outcomes, increased nurse/staff productivity or supplies and equipment reconfiguration can be translated to cost-savings in health care.

\section{For IMPLEMENTATION OF THE MOST CURRENT BEST PRACTICE:}

a. Describe in detail the costs of eliminating the current intervention and/or implementing the most current practice. Think in terms of the cost of man-power 
hours, materials and/or equipment needed to achieve the initial and on-going training and monitoring to effect this change.

b. Justify the costs in quantifiable benefits: better patient outcomes, increased nurse/staff productivity or supplies and equipment reconfiguration can be translated to cost-savings in health care.

\section{For FURTHER INVESTIGATION OF THE CURRENT PRACTICE:}

a. Describe in detail the costs associated with the research study you will conduct. Think in terms of the cost of man-power hours (training data collectors, time for data collection, writing the proposal and the resulting reports), materials and/or equipment you will need to conduct the study, and any compensation to the investigators.

b. Justify the costs for conducting the research in quantifiable benefits: knowledge that will lead to better patient outcomes, increased nurse/staff productivity or supplies and equipment reconfiguration can be translated to real cost-savings that can justify the money needed for the research.

Figure 20. Guidelines for EBP Paper Cost-Benefit Analysis

This section continues the prompt's pattern of providing a set of specific instructions that branch out from certain decisions made earlier in the paper. The instructions emphasize finding real and quantifiable costs, warning students that being vague will cost them points. This section seems to call for an in-depth financial analysis using several different types of data (material cost, staff training costs, productivity increases, better patient outcomes, etc.). It also asks a great deal of parallel questions: the 
students are presumably expected to prioritize and pick the most relevant aspects of the costs to discuss, although this section of the prompt asks a broad spectrum of questions and can be construed as indicating that students are to answer all of them equally. With all of the research, analysis, and detailed discussion this section seems to call for, it appears to be a task almost equal to the use of peer-reviewed research in the Sources of Evidence section. However, this section was only worth a third of the points of the Sources of Evidence section.

The relative point value of the Cost-Benefit section compared to the Sources of Evidence section certainly implies that students were expected to spend more time and effort on the latter than the former. However, the relative difficulty of these tasks was not on par with their point values. The students reported that the cost-benefit analysis seemed to demand just as much (if not more) effort due to a lack of resources for costs and difficulty with the "reality" of said costs. The students were used to finding, evaluating, and discussing peer-reviewed research; it was a task that they had performed for most of their classes in the School of Nursing (leading Samantha to declare that the teachers "love for us to find adequate sources"). Additionally, the Sources of Evidence section had the most support of any portion of the assignment in the form of textual cues, tips on finding and evaluating research sources, and formatting directions. The costbenefit analysis, on the other hand, seemed to demand as much time and effort as the Sources of Evidence section, but the students neither had the experience, instruction, or resources to perform this task to what they felt were their instructors' expectations. In short, they were receiving mixed signals regarding this portion of the project: this section will need to be as detailed and verifiably accurate as the Sources of Evidence section- 
and it will be more difficult given the novelty of the task - but you should spend only a third of the time and space on it. Considering how rhetorically important such a costbenefit analysis would be to the ultimate persuasive purpose of the paper, the mixed signals students received regarding this section added to their overall difficulties with the project.

Carolyn, who had prior experience as a health-care consultant, described having problems even approaching it:

Carolyn: The, um, cost-benefit analysis required me to be able to go in and talk to the nurse manager, and, um, maybe look at, you know, past, um, actual files of those things, um, the better understanding of the financial aspect of how the floor is run and the scheduling and all that. I don't feel that I had enough information, um you know, to really do that justice.

Matt: Ok

Carolyn: That was, um, there just wasn't enough time [laughs]

Matt: Mm-hmm, yeah, it sounds like a big

Carolyn: Yeah, and I'm somebody that likes to, you know, I want to do a good job with that but I didn't get it... I didn't do very well on my paper, you know that was the one thing that I really kind of blanked out on

Carolyn's frustration with this section of the paper stemmed from the fact that costs and scheduling was a facet of the job she had not had to consider before, let alone write about in a formal paper. For Carolyn, adequately addressing the cost-benefit analysis would mean spending almost as much time on that portion alone as she had on the rest of the paper up to that point, particularly since she had yet to discover the resources necessary 
to find the information she needed. Students like Carolyn were trained and experienced in how to use the school's resources to efficiently locate the research that they needed, but they seemed to feel adrift in the cost-benefit portion of the assignment as they tried to puzzle out what resources to use and how to use them. Both Carolyn and Samantha discussed meeting with their clinical advisor for information about costs, but still found acquiring the requisite information difficult. Sheila was more detailed about her trouble in this section:

Sheila: Mrs. Green said to a student, you know "basically this assignment is so I will know that you all know how to read research articles and how to interpret them," and, you know, I get that as far as us having to come up with the three different sources of evidence for a topic. But then the second part of it goes into, having to [pause while she looks at the prompt] like you make a decision based on your articles, whether or not this particular practice is recommended, not recommended, or inconclusive. That all I get, I understand that part fine. The second part was, ok now that you've got your conclusion you have to pretend like you work at the hospital and what are you going to do to reinforce the practice, change the practice, or do another study to figure out what the practice should be. So that's all well and good, [tone rises] except [tone falls] we don't really have clear cut sources to find pricing [trails off, short pause]. In my previous life I did tons of budgets, I mean I did budgets for renovation projects, so I know how to do a budget

Matt: Mm-hmm 
Sheila: And part of that is to do a budget, but in doing a budget you've got to be able to have sources to get accurate financial information.

Matt: Ok, how much did they charge, you know, for the use of the bed, or the IVs?

Sheila: Exactly!

Matt: and you didn't have that?

Sheila: No. In the hospitals [short pause] don't publish what they pay for things and, you know, I searched online to try to find some things and I found, of all places, Amazon I found prices for syringes and [laughing] stuff like that!

Two things are significant in this excerpt from Sheila. First, the cost-benefit analysis required a shift to an unfamiliar writing role for her and her classmates. Second, finding prices was one thing, but finding accurate prices was another.

Tamera's experience helps illustrate the problem of finding accurate prices. She worked straight through each portion of the paper but became stuck on the cost-benefit analysis when she had difficulty finding sources. Her topic was pain management through massage therapy, and given that few materials were needed in this intervention, she thought that the costs would be fairly easy to calculate. However, the costs of training and certifying medical professionals in this type of pain-management therapy varied across institutions. Consequently, she was uncertain about what sources to rely upon. She considered changing her topic, but decided against it given the amount of effort she had already invested in the project. Sheila was also frustrated by the variety of prices she encountered: 
Sheila: It was difficult to find sources to give me prices [taps table with her hand in the rhythm of her speech "give-me-prices"], and it was, it was kind of like [pause]. To me, I just felt like, I was like, this isn't really applicable. I mean, yeah, the budget framework and realizing the components that go into it

Matt: Right

Sheila: but for me to give you actual prices? They're not going to be accurate, they're not going to be really real-life prices, so this is just going to be an exercise in futility in my mind.

While she understood the necessity of budgeting and understanding the financial side of the medical profession, Sheila felt that any prices she gave were going to be guesses at best, since each hospital's costs are different based on their suppliers, location, staff, training, hospital policies, etc. The cost-benefit analysis was difficult for students like Sheila and Tamera (whose difficulties in this regard were mentioned earlier in this section) not only because of a lack of resources, but of the difficulty in negotiating the uncertainty of a multiplicity of costs; the idea of a "real" cost is undermined by the reality of cost variations in different locations and an uncertainty of what to rely upon.

The students' lack of resources required them to take novel routes presumably unanticipated by the instructor (Sheila relying on medical equipment prices from Amazon, for example) and varying degrees of guesswork. The two students who seemed least bothered by the cost-benefit analysis were Mandi and Samantha. Mandi's choice of topic was predicated on her access to price information: 
Mandi: I really spent a lot of time thinking 'how am I going to find these numbers?'...I ended up doing mine on technology solutions. Initially really I wanted to do something else, but I have a brother who is in health care information technology, and if I didn't have him I didn't know where I would have found numbers.

Even for Mandi, with her experience and resources as a research assistant in the School of Nursing, finding these resources was difficult, and it forced her to rely on a family connection. Her decision of paper topic was determined by what resources were readily available to use, and not by what practice needed the most attention in her clinical site. The student who seemed to have the least amount of difficulty with this section was Samantha, but that was because she resigned herself to relying more on guesswork early on. She was quoted different prices when she spoke with her clinical instructor and with her floor manager at her internship site. In the end, she averaged the different prices she was quoted and hoped for the best.

The common difficulties experienced by these students underline both the difficulty of the task and the paucity of their preparation for such a task. It is a good example of a double bind no only due to what seemed like an intractable contradiction (this section requires a lot more time and effort and it will be graded stringently, but you are rewarded less for it so don't spend that much time on it) but also due to the local innovations students had to attempt to work through the problem. Some of the approaches made by these students led to a kind of short-circuiting of the intended lessons of the project as students endeavored to find away around their seemingly intractable difficulties with the cost-benefit analysis. In this aspect, they resemble 
findings in Jennie Nelson's 1990 study "This is an Easy Assignment" investigating how the 13 college freshmen interpreted their writing assignments differently than their professors. Nelson observed students taking shortcuts in the interest of a favorable product despite how said short cuts conflicted with the learning goals of the paper. She writes that:

In many cases, students focus on the products they are required to produce instead of on the processes they are being asked to engage in. This limited focus can lead students to take short cuts to produce acceptable papersshort cuts that may allow them to circumvent the writing and learning processes that assignments are intended to promote. (392)

Such shortcuts are not always taken because of laziness, but can also be taken as ways to ameliorate contradictions or doublebinds present in the writing prompt or its extended activity system. Mandi's choice of topic is a good example here, since she essentially began at the end of the project by selecting a practice she could find accurate prices for rather than beginning with a practice she knew little about and wanted to investigate and contemplate further. From a student's standpoint, this may not seem crucially problematic, but when the pedagogy is intended to reinforce the problem-solving habits students are developing in a situated learning environment, it represents a potentially harmful shortcut around the intended learning model. The journals required students to react to their direct experiences in their clinicals, and the EBP paper similarly required students to choose a nursing intervention commonly used in their clinical setting. The intent behind these assignments is to teach nursing students to be inquisitive about the 
medical practices being employed around them, and reinforce the importance of evidence to either support a practice or to indicate a need for change. If students consider abandoning a change because they cannot find costs, or if they consider the availability of costs before delving into whether or not the practice is in the best interests of the patient, then can we still say that the civic-mindedness of the project is still being adhered to?

Burnett wrote that "Workplace professionals may not know everything they need to in order to complete a task or to participate productively on a collaborative team. What they have, though, is the ability and access to obtain the needed information and the awareness that such information is essential to the successful completion of their task" (149). The ability to negotiate uncertainty separates professionals from students; this is referred to as "savvy" by Schryer et. al in their 2005 study of case presentations in optometry. In their study they differentiated between two types of knowledge to describe the different competencies being demonstrated in case presentations and medical rounds: "certain knowledge" and what they called "savvy" knowledge, which is the ability to adapt knowledge for specific situations (236). The authors observed both being used and trained in the case presentations, and concluded both as being necessary for the practice of medicine: the certainty of scientific knowledge is only useful if it can be adapted to a particular patient's situation. In this study, the nursing students lacked the degree of "savvy" knowledge necessary to both find prices and confidently discriminate between relevant and irrelevant prices for their rhetorical purpose.

The double bind students faced in the cost-benefit analysis was one of being rewarded fewer points for - and hence being told to spend less time on - a task that 
required proportionally more work due to their lack of resources and the newness of the requirement. The primary focus of the paper was on the Sources of Evidence section and the use of peer-reviewed research. This section was evaluated as a culmination of the students' ability to find, evaluate, read, and discuss the medical research that made their field possible. They all had varying degrees of savvy in this domain, honed over the course of their time at the School of Nursing. The cost-benefit analysis, however, plunged students into a task in which there were specific expectations but no training, resources, or experience available to them for the most part. In short, it required them to do more with less assistance or experience, and its point value on the prompt indicated that they should spend less time and effort on it despite its difficulty. The students did not have the savvy to make this section work in the way they desired, and hence felt stymied by it with no option but to put something down, hope for the best, and focus their efforts on other parts of the assignment that were worth more points. Considering the intent of this project as helping bridge the gap between school and workplace writing, the heavy shift towards product over rhetorical effectiveness that this double bind caused had significant, negative effects on the students overall perception of the usefulness of the assignment.

Lack of Resources and a New Writing Role Leads to a Realization of a Lack of Agency: There comes a point in a student's work where their frustration with the task undermines the learning goals (144). In this case, the students understood that they were calling into question a common activity in their clinical learning environments, and that a guiding educational philosophy of the School of Nursing was to develop nurses who can 
recognize and move for change where and when it is warranted. The EBP paper has a very kairotic quality in this aspect, but kairos depends on more than just good timing. As Dannels noted, students learn in situated ways, and so the social dimension of what they learn in the real or simulated workplace needs to be recognized and represented if the incorporation of it in the classroom is to have the intended effect (26). One goal of the university is to engender habits of good citizenship in students, and a goal of the School of Nursing observed here is to train good citizenship habits in nurses in order to ensure the best care and that change, if warranted, will take place. These goals, however, must contend with the fact that learners involved in apprenticeships and LPP are very aware of their status on the periphery, making it socially difficult for them to envision their own agency and to effect change.

The cost-benefit analysis was a local problem that may have led to a more global confusion since it requires students to think and posit an action outside their purview and LPP experience. In the idealized scenario of the classroom, the EBP paper has a very strong civic purpose: when a nurse sees a practice in the workplace that is not best practice or not in the interests of the patient, then he or she needs to make a case for change. The difficulties students encountered in the cost-benefit analysis revealed how difficult that would truly be. Making administration-level decisions (even hypothetical ones to serve the purposes of the paper) served to remind the students of their low status as new nurses without the clout to affect significant, top-down changes. Students experienced this phenomenon in other ways. As Sheila commented just after the previous excerpt: 
Sheila: One of the parts about it, and I'm sure it was probably intended as part of the learning, it's not spelled out in here, but is the fact that there are a lot of interventions that are being done that are not based in evidence and are being done even though there's evidence saying you should not be doing it or doing it another way and its a little frustrating knowing that, you know, here I am a student and I've found this information out, but

Matt: Right

Sheila: it's not going to hold any weight with anyone.

Matt: Mm-hmm

Sheila: and, you know, I didn't try to tell anyone how to do anything... There were several nurses sitting around doing charting and I asked them, you know, "what is your policy for doing this," or "how do you do it" or "do you have any suggestions on something you're doing routinely and you're kind of like "why do we do this?" And, they didn't really have any more suggestions and I asked them about the particular thing, how do you do that, and they were like "well this is all we do," and I was like "oh, ok, so you don't test this part," and they were like "no, we don't do that," and I'm like "ok," you know, I could just tell that it wouldn't be appropriate for me to say [in a sarcastically haughty voice] "well you know evidence shows you should be doing it this way" [laughs]

These experiences revealed to Sheila the very real differences between the idealized scenarios posited in the classroom and the social realities of the workplace. Both Sheila and Tamera explicitly recognized the difficulty of not only going against 
hospital policy, but of challenging the practice of other nurses within their community of practice. This is not to say that they should simply stay quiet when they notice something potentially harmful going on, but rather that debating or challenging hospital policy can threaten relationships that new nurses need to thrive in their workplace (particularly if they have not been given the rhetorical means to affect meaningful change). Some research in nursing studies has shown how on-the-job socialization and cultivating positive relationships with colleagues are important factors in nurse retention (Thyrose et al. 2011; Price 2009). Challenging established practices, be they formal or informal, can further marginalize new nurses (who are already trying to make their way from the periphery to the center of full membership), which can adversely affect a nurse's sense of identity and fulfillment within the field (Thyrose et al. 28). Furthermore, asking the nurses to challenge hospital policy in a written exercise establishes an ideal of research and agency that can create dissonance for nurses on the ward. Cheri Price's 2009 report for the Journal of Advanced Nursing was a meta-study incorporating the results of studies in nursing from the previous two decades. The studies were chosen for their focus on career choice in nursing, and Price found that early socialization experiences have a profound impact on a nurse's professional identity. In particular, Price reported that "Early experiences which give an idealistic perspective of nursing can cause dissonance and distress for new nurses because of the incongruence between previously held assumptions and the actual practice setting" (18). Early lessons, therefore, can establish expectations that put students in a double bind once they are on the job. We are left to wonder, then, how the dissonance between classroom lessons (in both content matter and in civic duty) will affect the career choices made by students like Sheila and Tamera, who 
noted how adhering to best-practices seemed easier to talk about in the classroom than it does in the workplace.

While the EBP paper has a good deal of kairos about it, the prompt did not provide any particular audience for the project and did not tie in with how the nurses might actually lobby for change if warranted. Who would they write to? What channels would they use? What were the appropriate tropes and genres for proposing such a change? How can a nurse on the floor be heard by hospital administrators? The journals had a communicative purpose implied in them in that they were used to keep the clinical instructors updated as to what the nurses were doing with their mentors and to keep them accountable for paying attention and learning from the appropriate aspects of their daily tasks. One reason Sheila described parts of the EBP paper as "an exercise in futility" may be because the paper had no direct communicative purpose beyond evaluating their knowledge. If they did find that an intervention in the health care facility where they fulfilled their clinicals was not best practice, what could they do with it as new nurses with minimal on-the-job experience? The interview data suggested that this put them in a social double bind of sorts: if they were willing to suggest a major change in policy/procedure, it would endanger the social and professional relationships they needed to begin their new careers. This double bind may have been more clearly triggered by the Cost-Benefit Analysis than the Sources of Evidence Section. Students had practice in searching and critiquing evidence, making it a more familiar academic, school-centric genre. The Cost-Benefit Analysis was a newer genre convention that required the students to challenge hospital policy in a more practical, detailed way than the more abstract genre of the research critique in the Cost-Benefit Analysis section. Giving 
students the rhetorical means to effect change while also acknowledging the social realities of the professional workplace can help students avoid debilitating disillusionment, the more immediate consequence of which may be difficulties buying in to the rhetorical importance of a writing assignment intended to bridge the classroom and the workplace.

\section{Conclusions and Implications}

Using classes and internships to bridge the gap between school and the workplace is certainly a very valuable enterprise, and it is the contention of this chapter that stakeholders in such enterprises recognize and address common difficulties in combining two different environments. The struggles of these nursing students highlight a few of

the double binds and limitations inherent in combining classroom discourse with LPP in a work environment:

1. Competing Authority Figures: Students will inevitably encounter discrepancies in how different instructors/mentors describe tasks or responsibilities, but for a mixed classroom like the nursing course it is important that these groups not be working at cross purposes. The nursing instructor emphasized concision in professional writing in nursing, while the clinical instructors (the ostensible professionals students were to practice writing for) continually demanded more detail for evaluative purposes. Addressing contradictions like this can make writing easier for students and assessment more consistent among instructors. It can also lessen the chance 
of students becoming double bound via two sets of equally compelling instructions from two equally competent authority figures.

\section{Double Binds and Lack of Resources Led to Shortcuts and a Lack of}

Investment in the Project: The double bind between accountability and originality noted in Chapter 3 and revisited in this chapter led students to take shortcuts that sacrificed the greater goal of the paper for achieving as many points as possible in what the students deemed crucial areas. The lack of resources in the cost-benefit analysis also affected student perception in the overall relevance of the assignment, as it confronted them with a new and very difficult task that they had minimal preparation for, and yet even though it required just as much work and just as much rigor as the Sources of Evidence section (more due to its newness) it was worth fewer points. Contradictory instructions and insufficient resources (both research resources and rhetorical resources) can lead students to take shortcuts that short circuit the learning process that teachers envisioned for the project.

3. A Lack of Explanation for New Tasks and Imbalances of Tasks Can Cause Students Affect Students' Sense of Agency: Student writers are pretty used to writing for informative and argumentative purposes, but they still need coaching in the particular exigency of each project, particularly when it is one that touches so closely on their expected professional roles. The newness of the cost-benefit analysis, the student's scramble for resources they were unused to using, and the way that the task's difficulty was out of balance with its relative weight in the paper all caused students frustration, and that 
frustration affected both their investment in the paper and their larger sense of agency in the workplace as it highlighted the difficulties they would have in realizing the civic idealism represented in the EBP paper.

Based on the research reported on in these chapters, the following is a list of suggestions to address these common difficulties in combining the classroom and the workplace for students:

1. Be open about Limitations: Students in these mixed classes may be asked to write from a role they are uncomfortable with or do not feel they have earned. Being open in the prompt about important conflicts/contradictions between classroom writing and workplace writing (in terms of role, audience, and context as well as audience) can ease student anxiety and proactively counteract concerns about the futility of the assignment.

2. Utilize Role-Playing: In her study of engineering classes utilizing workplacediscourses, Herrington found that in one course role-playing in writing assignments was effective because it created an internally consistent rhetorical scenario: the students worked as engineers in a fictitious company with their professors as the section chiefs (357). The fictitious roles guided students and helped them feel that the work they did on their project was not confined to their imagination alone; it was part of the classroom discourse. In a course that mixes a traditional classroom and a real-life workplace environment, role playing can take on a more realistic element. Real people in real positions of power and authority can be appealed to as the audience and referred to in the prompt, even if they will never read the resulting paper. Clearly establishing the context, format, and 
channels of communication such writing projects would take in a real workplace can bolster the role playing in classroom writing, making it feel more consistent with the workplace students are experiencing. A writing prompt can easily provide these small, but important details.

3. Provide Resources for New Challenges: Students need research resources, genre resources (examples for formatting and overall structure), and rhetorical resources for addressing certain audiences. While students in this study could use research resources they were familiar with to find peer-reviewed medical research, they lacked savvy for finding prices for nursing interventions and had to start from scratch. They also lacked the resources for how to format the cost-benefit analysis, as they were given many parallel questions in the prompt and little guidance as to how to prioritize and structure their response. Additionally, the students were not used to taking on the role of someone addressing hospital administrators to lobby for a change, and so they lacked the kinds of rhetorical resources necessary for doing so tactfully and effectively. In a writing prompt, a list of potentially-useful resources is a simple way to signal to students not only what resources they can tap, but what kind of resources are acceptable. Many teachers already do this, but it is doubly important when confronting students with new types of research tasks. Providing examples for students to analyze and refer to can ameliorate their difficulty in figuring out the assignment greatly.

Textbooks like They Say/I Say offer great sentence-level rhetorical resources for students to use when writing about research, and the templates provided in these kinds of textbooks can easily be adapted for writing in courses like the nursing 
class. The purpose is not to turn the paper into a fill-in-the-blanks worksheet, but to provide a helping hand for students trying on a new writing role and addressing a new audience. The prompt can provide many of these things and/or it can also refer to resources where students can find them.

4. Importance Should be Weighed with Difficulty in Prompts and Rubrics: The EBP paper prompt provided more support for the Sources of Evidence section, and students spent the most time on that section as it was also worth the most points of any section in the paper's prescribed outline. The Cost-Benefit Analysis, however, proved to be more difficult and potentially more time-consuming in several pertinent ways, even though it was worth fewer points. Since this section was weighted significantly less in terms of points than the Sources of Evidence section, the students spent less time on it and were willing to take shortcuts and concede points in this section due to its difficulty. Students in mixed classes are encountering many new challenges that they may have to apply to their writing, and the relative point value of different requirements of their writing assignments should not only reflect importance but difficulty as well if the overall goals of the assignment are going to be adequately realized.

5. Discrepancies between Graders or Authority Figures Should be Addressed:

Students bring with them expectations and habits from a class' previous writing assignments to a term paper, particularly if those previous assignments were intended to help students build towards the larger project. An acknowledgement of how said projects are similar and different can help to put everyone on the same page about what students were intended to learn in their smaller writing 
assignments. Also, any discrepancies between how writing is assessed in one project (particularly if the grader is not the designer of the assignment) should be addressed to avoid contradictory expectations.

Even if they are also working in internships paired with the course, when students are in a classroom they are still working as students. This means that they are primarily concerned with demonstrating competence for a grade, whereas they are mobilizing their knowledge for more practical, communicative purposes in the workplace. While the ultimate goal of the mixed classroom may be the latter purpose, it must recognize how both can clash with one another and cause contradictions or double binds. There is no reason to gloss over these difficulties or talk around them. As Dannels suggested, being open about limitations and complicating our curricular materials to take the everyday, social aspects of situated learning into account can help teachers to better implement writing projects in courses that mix school and the workplace (28). 


\section{CHAPTER 5}

\section{CONCLUSIONS AND SUGGESTIONS FOR PEDAGOGY}

As teachers, we are information architects who create channels for our students to navigate on their path to knowledge and expertise within their chosen fields. A writing assignment prompt is one such important channel that can guide students through the challenges of writing in the disciplinary classroom. Consequently they must be considered less as transparent instructions and more as spaces that "conceptually locate students within a situation and provide them with the rhetorical means for acting within it" (Bawarshi 128). Within these conceptual realms, students mentally construct and reconstruct the writing task presented to them to approximate something appropriate for the situation. To ensure that students are able to realize more closely the kind of written product envisioned by the instructor, the amount of thought put into crafting a writing prompt for an assignment should be commensurate with the amount of effort teachers expect the average student to put into the assignment.

Chapters 2 and 3 of this dissertation explored how writing prompts can be seen as hierarchies of cues that help students manage writing both on the local and global level. Instructions in writing prompts cue the actions that students are meant to explicitly demonstrate as well as the underlying operations that they are supposed to have ingrained. New conventions as well as older, familiar ones should be explained in terms of how the prompt cues them. Students need support for writing tasks that are still new to them, but 
they also need to tune their understanding of supposedly-universal writing tasks (analysis, evaluation, summary, compare and contrast, etc.) to their instructor's specific expectations for those tasks. Cues should be organized hierarchically to help students perceive the place of each writing task and thus can move between local and global considerations.

Cues are also important to help students own the social and epistemic goals of the text as well. As seen in Chapter 4, students who feel they do not have the standing and know-how to address a social purpose implicit in a writing assignment (such as suggesting a change to a hospital administrator while the student is still just an intern) are more likely to feel that they have less agency as a writer and as a new professional, and consequently they will have less investment in the project. This is one of several places in which the simulation of real-world writing can break down or make things more difficult for students if such limitations are not acknowledged and dealt with.

As I write this, I also want to emphasize that there is not a need to produce gigantic, unwieldy writing prompts that outline every minute action in painstaking detail. As demonstrated in the analysis of the Nursing paper, a high level of prescription can limit the amount of freedom students have to adjust their writing when they are faced with contradictions or double binds. To save time and stress for both the student and the teacher, the writing prompt should be treated as part of the activity system of a writing assignment and of the classroom in general. Consequently, it should be detailed enough that it supports - and in turn be supported by — other elements of the activity system. If tasks accomplished and practiced in class help students understand how better to approach a task described in a writing prompt (and vice versa), then students are less 
likely to be victims of contradictions between elements of the classroom activity system. The writing prompt is not the end-all-be-all of a writing assignment, and teachers who treat it as such (i.e., expecting that students will learn everything they need to now from the prompt as a way of freeing themselves from having to explicitly teach writing) are abdicating some of their responsibility as an instructor.

Encouraging a close consideration of writing prompts and their rhetorical place in the classroom is not a problematic obstacle when working within composition. There, the central focus is on promoting better writing practices. It is a more demanding challenge when working with disciplines such as those discussed in the preceding chapters of this dissertation, where the focus may be on helping students to master content knowledge with writing as a secondary or even tertiary concern at best. Most teachers in the disciplines who do not take time to teach writing explicitly cite very real and very practical concerns in their explanations. As Patrick Bahls, a math professor who struggles to incorporate meaningful writing assignments into his college courses, notes in Student Writing in the Quantitative Disciplines, time taken to teach writing most often means sacrificing something in an already-crowded syllabus:

It is clear that time spent on writing is time not spent on something else. If over the course of a semester you take two or three hours of class time for writing instruction, peer review, or other writing-related activates, you take two or three hours of class time away from direct treatment of course content. Particularly in highly-regimented lower-level courses, this might mean you have to consider few sections of material with less depth than you would have otherwise or that you will have to skip one or two sections altogether. (xi) 
Teachers in content-rich disciplines already have to make difficult choices regarding coverage versus depth. Adding time for explicit writing instruction only compounds this difficult balancing act.

Further compounding the problems caused by these practical obstacles are the myths of transparency and transience, which can lead instructors to abdicate their responsibility to teach writing explicitly due to the popularized misconception that writing is more about mastering basic mechanics than it is about being engaged in a craft. The myth of transparency is often exacerbated by the positivist underpinnings that make many of the hard-knowledge disciplines possible. Civil engineers are not overly concerned with the social constructed-ness of disciplinary knowledge when they are designing a bridge; they are more concerned with the best employment for their knowledge rather than questioning its transparency. Belief that certain ideas and precepts of their profession are right is part of what makes their work possible. In the classroom, this positivist belief in transparent, rhetoric-free knowledge can also extend to the communication of that knowledge from one party to another, which leads to the myth of transparency that can veil very real rhetorical techniques used in disciplinary writing. The myth of transience is exacerbated by the aforementioned practical concerns of covering a great deal of content in a relatively limited amount of time. Consequently, writing instruction is pushed to the margins of the curriculum. These myths can perpetuate sentiments such as "teaching writing is not my job" or "they should know how to write that way by now," which causes a kind of passing the buck that leaves composition instructors alone with the tasks of preparing students to write appropriate, error-free writing for all classes and majors after one or two semesters of instruction. 
Despite these obstacles, many positive strides have been made by programs such as WAC and WID in getting teachers on board with using more and better writing instruction in their classroom. In addition, they make composition studies more visible and vital. A complete top-down change of how writing is taught across the curriculum, however, is not only impracticable at the moment but is also likely to meet with heavy resistance. Instead, these initiatives have shown that key to effecting change is, as Babara Walvoord notes, to work with instructors who are already willing to use more writing in their pedagogy and/or to make better and more effective use of it, since aggressively encouraging unconvinced teachers to change their practices in a kind of missionary model of writing instruction reform will also meet with heavy resistance (13).

The time and effort put into assigning, teaching, and grading writing assignments are the two biggest concerns for incorporating more writing. Therefore, the rest of this chapter delivers a series of flexible strategies for designing and implementing writing prompts in such a way that saves teachers time, effort, and undue frustration. These strategies also help minimize the possibility for contradictions and double binds. Additionally, this chapter will provide strategies for identifying and dealing with contradictions and double binds as they appear. They are divided according to the different levels of activity in which they can be implemented: at the single-assignment level, the level of an entire course, and the inter- and intra-departmental levels. Note that these suggestions are not rigid in how they can be adopted, but rather they allow for flexibility based on the goals of the instructor. Diversity in instructional approaches has kept composition a rich and interesting field, and so this chapter avoids prescribing rigid prompt design and implementation strategies as they would create a stifled writing 
process for both student and teacher. These strategies stem from the findings of the previous chapters, and they are designed to help clarify the expectations outlined in a writing prompt and to make the prompt work more organically with the activity system of the classroom and the teacher's goals for the course.

\section{Prompt and Assignment Level Recommendations}

Surprisingly few writing instructor handbooks and articles provide detailed information for constructing assignment prompts themselves, just as very few works in rhetoric and composition consider them closely as highly rhetorical documents. This section presents a four-part process for writing and supporting writing prompts based on the findings of this dissertation: establish the purpose, clarify the task, define grading criteria, and support the task.

Establish the Purpose: Establishing the purpose has three basic parts: define an intriguing problem/question, identify an audience and a role, and establish learning goals. First, defining an interesting, addressable problem or question can be the difference between a paper with focused purpose and what Bean calls a "data dump" or "all about" paper, which lacks clear organizational structure (24-26). Students most often need help in crafting a question that is appropriate in terms of scope and context. A writing prompt can provide assistance in this by either giving examples and/or by establishing the rhetorical situation that the students are simulating in their writing. The questions that drive writing in disciplinary settings are situated in complex social and historical relationships. Directing students simply to "choose a topic you are interested in" 
misrepresents these relationships to students, and it makes a "data dump" or "all about" paper more likely by blurring the lines between a topic, a question, and a thesis/central claim. This is not to say that students should not have a choice as to what they write about, but rather that guiding students towards appropriate writing questions/problems earlier rather than later can save students and teachers a great deal of time, effort, and needless frustration.

The second part of establishing the purpose is identifying the audience and the writer's relation to that audience. This step helps students navigate tricky rhetorical situations, and it is also vital in helping students realize the purpose of the project. Traci Gardiner, in her book Designing Writing Assignments, writes that:

Without knowledge of their audience and purpose, students cannot position themselves as experts. In fact, depending upon the audience and purpose, students may not actually be experts. A student may consider herself an expert on soccer, but if the audience is soccer coaches, she may not be as confident about her knowledge. The assignment needs to provide more support and detail before students are able to choose their focus. (39)

Such a situation is exactly what happened in the Nursing class examined in this dissertation. The nursing students did not have the rhetorical resources to make them confident that they could persuade or even approach their target audience. While they were simulating a proposal to hospital administrators; they were very aware that as interns they lacked the ethos necessary to demand changes in hospital policy. Providing some resources or guidance in how to handle this author/reader relationship may have helped students feel like they had greater ownership over the paper and the position they 
staked out in it. The student writer's audience may always be a fiction (since we all know that the teacher is most often the only audience that will read their work), but it can be a guiding fiction that can help students negotiate writing roadblocks.

The third part of establishing the purpose, establishing clear learning goals, helps students understand both what they are supposed to learn and why it is important. According to Ann Penrose (as quoted by Ochsner and Fowler), "Writing will be useful as a means of learning only if teachers discuss the types of learning [our emphasis] students are to engage in, not just the type of paper they are to produce" (Ochsner and Fowler 124). Students are quite used to writing as busy work or as a medium through which they can regurgitate rote content knowledge, and they are more likely to engage and take ownership over a project that in which it is clear that what they will learn will be of use to them in future classes and/or in their careers. Establishing core learning goals in the writing prompt can communicate to students how a writing assignment fulfills learning goals established in the course syllabus. In an age of growing accountability and oversight for teachers, this can also allow administrators to more clearly see how individual teachers are pursuing learning goals established by the department, but the school as a whole, and/or by an accreditation organization.

It should be noted that all of the teachers observed in this study established the purpose in their prompts to varying degrees. While these teachers sometimes presented the writing tasks they expected students to perform in unclear or conflicting ways, they were very clear about why students needed to learn these genres and how they would help them in their future studies. 
Clarify The Task: The moves of academic and professional writing are often governed by many expectations that easily fall beneath the attention of expert writers. They are comparable to an iceberg: what is on the surface is only a small portion of the entire object. Beneath the surface features of an example of disciplinary or professional writing is a whole host of practices and habits of mind that neophytes will not have access to. Expert writes often fall into a mode of what Ambrose et. al call Unconscious Mastery in their book How Learning Works; these writers are not always aware of the complicated acts they are performing as they work. It can be easy, therefore, for experts to omit or overlook key steps in producing the desired final product, since they take for granted the steps that students are still struggling to understand. Newcomers often work in a mode that Ambrose et. al call "Unconscious Incompetence," which does not mean that they lack intelligence but rather that they do not have access to the skills and knowledge of experts and furthermore are not quite aware of what it is they lack access to (96-121). Student writers most often can only see the tip of the disciplinary iceberg, and it is up to instructors to reveal the remaining portions of it. Clarifying the writing task means unpacking expectations by describing writing in terms of actions and cues.

One of the first steps in this process is to divide complicated tasks into more manageable ones, and for this I would like to juxtapose two sets of cues from two of the prompts utilized in this study. The Multicultural Psychology prompt provided vague cues that essentially only announced the basic idea of the major sections. In order, it prescribed that students write about the relevance of their issue, the current research on the issue, contrast cultural differences, compare cultural similarities, and indicate new directions for action or research (see Figure 7 in Chapter 2 for this excerpted section of 
the prompt and/or the complete prompt in Appendix B). These cues are vague and unhelpful to a student trying to figure out the nuances of the project from the prompt alone (the entire prompt can be found in Appendix B). Take the item "Current research on your issue" (the exact wording from the prompt) as an example of a task in need of unpacking. There are many hidden assumptions there that are not expressed in the prompt. How much research is enough? What am I to cover regarding these studies? How much detail should I devote to describing methodology and contextualizing results? This prompt leaves so many questions unanswered that students may be at a loss as to where to start.

We can see just how much there can be to unpack when we juxtapose the Multicultural Psychology prompt to the Sources of Evidence section in the EBP paper prompt. This section had structured cues for students to follow as they discussed the research on their topic: describe the purposes of the study, describe the population used, describe the research method used for data collection and analysis, and summarize all results. While the nursing prompt was intimidating to students at first, they were comforted by the level of prescriptive detail because it gave them a clear direction for putting the paper together (it was only later that the amount of detail became a problem). This prompt tends to describe tasks in terms of the product (what the paper should look like) and not in terms of actions and cues, but it does a far better job of breaking down a complicated task into more manageable chunks than the Psychology paper does. These two examples underscore the importance of describing cues in complete sentences with explanatory details. Simply naming the sections that a paper is supposed to have forces 
students to engage in guess work, and it leaves them in a frustrated hope that the teacher will fill in the blanks.

As discussed in Chapters 2 and 3, providing a hierarchy of cues can help students prioritize their efforts. Knowing what sections will require the most amount of work and/or which sections are the most important to the overall rhetorical effectiveness of the paper can help direct student efforts in a productive direction. Teachers should avoid providing too many of what Bean calls parallel questions. Take this example of a prompt he provides as an example in his book Engaging Ideas:

In the graveyard scene of Hamlet, Shakespeare calls to mind the medieval memento mori ("remember thy death") philosophic tradition by having Hamlet contemplate the meaning of a human skull. But Shakespeare alters his sources by adding the clownish gravediggers. How does the presence of the gravediggers influence the way you read this scene and perhaps the play itself? Why did Shakespeare add the gravediggers? Do you think "comic relief" is an adequate explanation? Do you think the gravediggers are funny? Absurd? Blasphemous? How does Hamlet's attitude toward the gravediggers affect the scene? Do you think it is appropriate to sing while digging a grave? You might also want to think about the jokes they tell. Do these jokes comment on themes in the play? Do you think that Yorick was more like the gravediggers or more like Hamlet? Does Hamlet seem like a Christian in this scene or something else? You may want to do some research to help you with this topic, but you don't need to. If you do use research be sure to cite your sources. (105) 
Where does a student start with a prompt such as this? From an instructor's perspective, we can surmise that this teacher wants to provide his/her students with several ways to approach the writing task. However, there are so many questions and so little indication as to which ones are more important than others that students can't help but be overwhelmed and confused. Are students supposed to answer all of these questions? Are they supposed to be answered in equal length and depth? Prompts like this may cue students to address interesting problems, but with no central question or organizing scheme students will only produce roughly stitched-together data dump and all about papers. Providing hierarchies of cues and questions (and avoiding too many parallel questions) saves students time and undue frustration.

Unpacking cues as hierarchies of actions and questions rather than just lists of sections in general helps clarify the writing task students are supposed to complete. While we might say that all writing is part of a recursive trial-and-error process, there is an important difference between struggling with the nuances of writing task and struggling to understand the teacher's fundamental expectations for the assignment. The following is an example of this approach from a Rhetorical Ad Analysis paper that I often assign for freshman composition courses:

\section{1) Describe the advertisements you have chosen to analyze and identify their} target audience(s) (15 Points): Offer just enough description so that a reader unfamiliar with the ad can understand its basic elements and so that you have covered the ground you will discuss in your analysis. You can (but are not required to) use the following questions to get you going:

- How is the ad arranged visually? 
- What is your eye drawn to first? Why?

- Is there anything repeated, intensified, exaggerated?

Figure 21. Excerpt from a Rhetorical Analysis Prompt created by the Researcher.

While it is certainly not a perfect example, the task description above endeavors to do three things. First, it describes the task in general detail in the bolded section; when I use this prompt I tell my students that the bold indicates the required move I need to see them make. Second, the text next to the bolded text explains the move in some additional detail. Finally, the bullet questions outline some questions that students have the option of answering, and not questions they are required to answer. Like in the example Hamlet prompt provided by Bean above, the prompt does provide some parallel questions that students can choose from, but there are important differences: there are not too many of them and the prompt makes it clear that they are optional. The goal is to provide students with some detailed explanations of the moves they are required to make and questions that they can address to help them generate material. This helps give structure to the assignment while allowing room for variety, which keeps the assignment from seeming like a fill-in-the-blanks worksheet.

Define Grading Criteria: Bean writes that "the more clearly you define your criteria at the outset, the better the final products you will receive" (292). He suggests that students who better understand how they will be evaluated can more effectively meet the teacher's expectations. The writing prompt is one key place where assessment criteria can be explained. This can be as simple as indicating what number of points each section is 
worth and as in-depth as providing a grading rubric along with the prompt. Grading rubrics can be one of the most effective ways to clarify grading criteria. There are two basic types of grading rubrics: task specific rubrics, and general rubrics. Task-specific rubrics are custom built for an individual assignment. The advantage of these rubrics is that they can clarify an individual writing task better than a general rubric can. The advantage of the general rubric is that it can be used for multiple assignments in a class, cutting down on the prep time for the teacher and creating a rubric that students can become more familiar with in a class with multiple writing assignments (Bean 267-90). Either way, rubrics can help students better understand how they are being assessed and they can help teachers more clearly align their assessment practices with course goals and required learning outcomes. As Patrick Bahls notes, "a well designed rubric will make it easy for you to convert qualitative feedback into a quantitative score" (58). Rubrics can demystify the grading process and aide in the difficult task of assigning a number to what is largely a qualitative assessment process.

Rubrics can also help students to prioritize their efforts with a writing assignment. Students will pay more attention to sections of a paper that are worth proportionally more than others. For instance, in the Nursing paper prompt, the Sources of Evidence section was worth the most out of any section of the paper (close to a third of their grade), and so students prioritized their efforts in this section. The Cost Benefit analysis section, however, was worth considerably less, even though it was a more difficult task for students since they had little experience with that kind of task and lacked the resources to address it well. This portion of the paper would have caused students as much stress if at the very least the point values were more commensurate to the difficulty of the task. If it 
had been worth more points, then students would have known to put more time and effort into it. If the task was simpler and made more familiar, then students would have had less difficulty giving it the amount of time it deserved in comparison to the other parts of the project. Balancing point values with task difficulty is important because it show students how to direct their attention in a project, and the rubric is one place where this can be accomplished.

Of course, rubrics sometimes lead to an overly-restrictive interpretation of the writing and learning process. There is an important distinction to be made between promoting high standards and promoting a very narrow approach to the writing process. An instructor who uses a rubric as a simple checklist can inhibit student writing in that such a project is more akin to filling in the blanks of a worksheet than it is to a process involving craft. A checklist-oriented approach to rubrics can also promote "data-dump" and "all about" papers, even if the instructor desires something more complex. Based on my work in this dissertation, I believe that the best use of rubrics (to support complex writing assignments) is to establish the parameters of acceptable writing — however broad or narrow they may be - so as to reinforce the key features of an assignment while also allowing students some latitude in how they define their approach to the task. An overly prescriptive rubric, like an overly-prescriptive prompt, can lead to a project that is not only frustrating, but also ineffective where their long-term learning outcomes are concerned; its lessons are quickly applied and just as quickly forgotten.

Support the Task: Supporting a writing assignment does not require Herculean efforts, but rather a repetition of smaller efforts to give students practice, feedback, and examples 
that they can work with. Milestone assignments such as topic proposals, annotated bibliographies, outlines, drafts, and student-teacher conferences do create additional work for the teacher and student during the writing assignment, but they can save a great deal of time and effort during the composition and grading of the final draft. The writing prompt is one place where these milestones can be announced and even described in some detail. Students who gain a sharper idea of what is required of them through milestone assignments are more likely to create a final written product that aligns closely with what the teacher expects. Also, such milestones allow teachers to assess their student's progress and understanding along the way. Other ways to support a writing assignment will be discussed in the next major section, which describes how writing assignments (and the assignment prompt) can be supported and promoted beyond the prompt itself.

\section{Classroom Level Recommendations}

Discussing writing prompts in class is a simple, but highly effective, way to ensure that students have the opportunity to better understand the task assigned to them. This means more than simply reading through the prompt on the day it is distributed, although that is important as well. The writing prompt can be most effective if it is a familiar presence in the classroom discourse, so that students do not see it and the writing assignment as separate or isolated from what they are learning and doing in class. This can mean bringing the prompt into class discussion, demonstrating how grading criteria can be applied to course readings or sample papers, discussing the purpose or cues as they apply to classroom tasks, etc. Making the writing prompt a familiar presence in the 
classroom discourse and fostering an environment that invites questions about the project can help students gain a firmer grasp of the writing assignment and what they are supposed to learn from it.

Some of the onus of unpacking the assignment can be taken off of the teacher alone by creating opportunities where students need to ask questions about the prompt or probe deeper into the implied requirements of the assignment. I return to one of Bean's observations, that "No matter how clearly you think you have explained the assignment, students will ferret out ambiguities" (105). However, we should not see this as a drawback but as a resource. If teachers have a top-down view of the project, then students will see different potential problems or ambiguities from their perspective on the bottom, i.e. as the ones completing the task set for them. Using students as a resource to help unpack a project can help students gain a firmer grasp of what is expected of them and it can help the teacher discover any contradictions or double binds floating around in the system. Additionally, it can make implicit assumptions about the writing task and/or the professional genre it mimics more explicit for students.

Creating an environment where students are invited to ask questions and feel confident in doing so is central to using students to help unpack an assignment. Several teachers in this study—including the psychology, nursing, and biology teacher-declined to discuss the assignment much at first. The nursing teacher felt that the students should take the bulk of the responsibility for reading and understanding the prompt. Professor Green was available for questions when students had them, but she was not going to hold students' hands through the process of the assignment. It is difficult to say whether or not more open discussion of the assignment and its difficulties would have alleviated the 
double binds experienced by students working on that project, but it may well have helped. Students in Multicultural Psychology reported that they felt uncomfortable asking questions in class, primarily because the teacher either did not create an environment where students felt comfortable asking questions or because the buffer the teacher but between her and her students, the teaching assistant, made finding answers to even basic questions difficult. The biology teacher, Dr. Steiner, had the least detailed prompt of any teacher observed in this study, but he fostered a teaching environment that dealt promptly and enthusiastically with questions about the project. As a result, his students were highly confident about their understanding of his expectations.

Another useful way to support the writing prompt in class is through formative assessment and carefully-considered assignment sequencing, which is another aspect that Dr. Steiner did well. When students read peer-reviewed papers that introduced them to new research methods or to new approaches to analyzing cellular life, the class analyzed them using the same criteria that Dr. Steiner wanted them to apply to the analysis of peerreviewed sources for their own papers. This helped build student confidence in their required writing tasks, and it helped Dr. Steiner gauge where students were in terms of their abilities to write the paper. Formative assessment in the form of topic proposals, bibliographies, drafts, and even informal classroom writing can play important and useful roles in acclimating students to a teacher's expectations. Providing sample writings for students to read and analyze - whether they be professional examples of the genres they are attempting to produce or sample student writing — can also help reinforce the prompt by making the requirements listed in the prompt more concrete and understandable. 
Annotating these example writings to highlight important points can also help students be better able to align their expectations with that of the instructor.

\section{Inter- and Intra-Departmental Recommendations}

The recommendation I have for inter- and intra-departmental levels of supporting writing prompts is simple to state but difficult in execution. It is of a kind with the primary missions of WAC and WID: share and promote dialogue among college instructors. This project began with a desire to know what other teachers were assigning both within and beyond the discipline of composition. If one of the ostensible goals of composition is to prepare students for writing in the university, then I wanted to know what kind of tasks and processes I was expected to prepare them for. Seeing how other teachers assign writing, both within and beyond the composition department, has informed my research and my pedagogy greatly. I have also seen such opportunities engage faculty in the discussion of what the college's overall learning goals are for the average student. Creating opportunities for sharing writing assignments and engaging in a dialogue about them can make a profound impact on how teachers of all disciplines consider their writing prompts and how those prompts support their assignments.

Such dialogue can also help save students from suffering contradictions or double binds. Also, sharing prompts can provide a better, clearer, fairer representation of what other disciplines do. Other disciplines can become convenient straw men for explaining what is not acceptable in a particular classroom writing. For example, a common misconception about writing in English and composition is that it is writing based on 
feeling and opinion rather than fact and logic. This makes writing in English in particular a convenient straw man for teachers who want to steer students away from arguments based solely on personal opinion, but it creates a false representation of writing in English and composition that can ultimately harm both fields. The focus on logical, structured writing is exactly why composition, a child of English departments, has been tapped to prepare students for writing across the curriculum. Denying or obscuring this aspect of writing in the humanities can cause contradictions and double binds for students, as can misrepresenting the kinds of writing students do beyond composition. Imagine a student who feels she can voice her opinion in English, but cannot in an evaluative article for her biology class. Such a double bind was felt by Tim the primary subject in Anne Beaufort's College Writing and Beyond, who felt he had "sold out" in later classes in his college career because he could not write with the kind of personal voice he had been taught to cultivate in his composition courses (42). Encouraging dialogue between disciplines about writing can help teachers minimize the difficulties students encounter as they try to write within the varied landscape of a liberal arts education.

\section{Identifying and Resolving Double Binds}

Engeström has prescribed a cycle in which subjects can identify and deal with systemic contradictions and double binds. The seven-step cycle begins with open questioning and dialogue about the issue causing problems. The second step involves more rigorous, methodical analysis, the end result of which is the positing of a new 
model (step three). The fourth step and fifth steps involve examining and implementing a new model of the system. Steps six and seven involve reflecting on the model (making sure it does not conflict with neighboring systems) and consolidating the new practice ("Expansive Learning at Work," 150-2). The model is illustrated below in Figure 22.

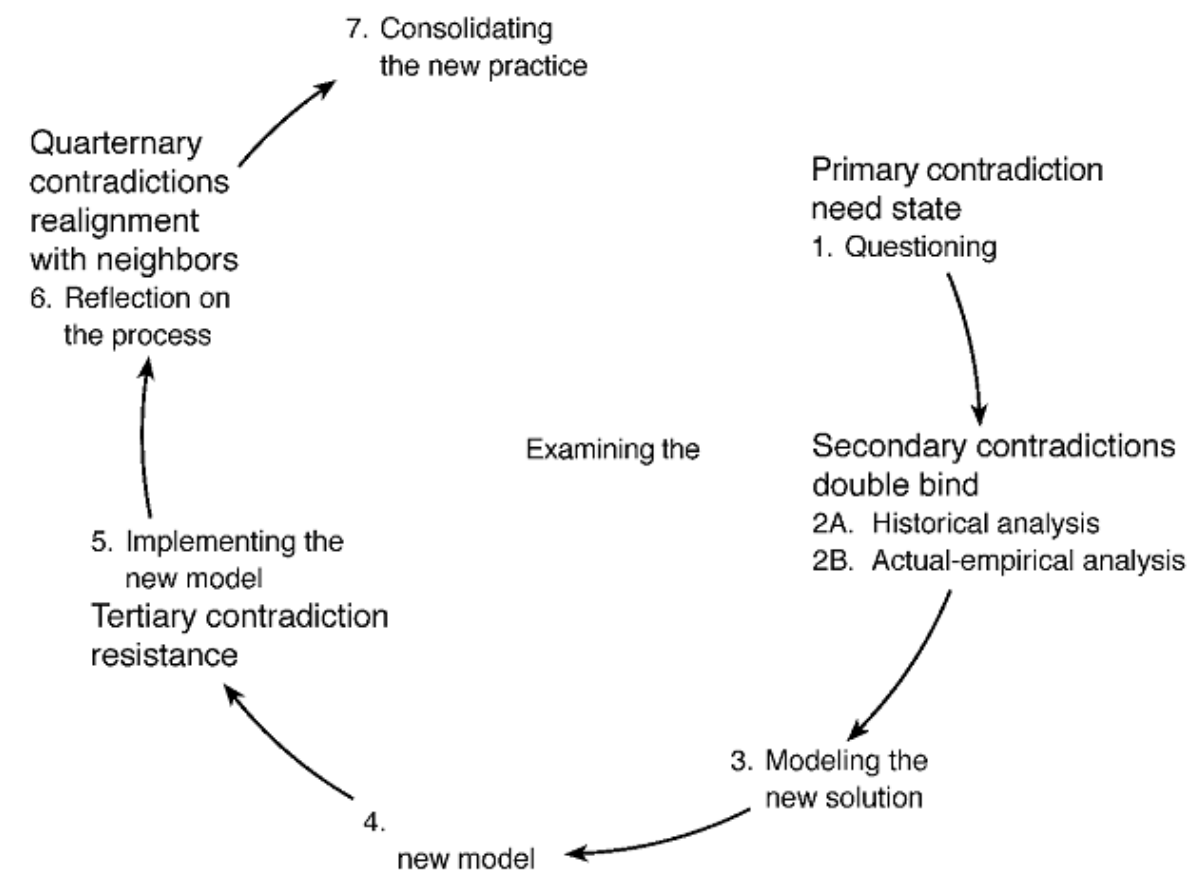

Figure 22. "Strategic Learning actions and corresponding contradictions in the cycle of expansive learning," from Engeström, Yrjö. "Expansive Learning at Work:

Toward an Activity Theoretical Reconceptualization." Journal of Education and Work 14.1 (2001): 133-156. PDF.

Essentially, it is a simple, iterative process of identifying problems and testing solutions. I posit that what really matters in applying this cycle to writing assignment prompts is not the individual steps but the idea that assignment design is a cyclical process involving constant revision and improvement. This very basic model offers a 
direction towards a more reflective and expansive system. It is also a solution that can include many members of the system in its carrying out. This is necessary because, as Wardle point out, individuals cannot resolve systemic contradictions on their own:

Although people must (and do) find ways to resolve their own psychological double binds, in doing so they can only create their own individual solutions. What activity theory calls re-mediation (resolving systemic contradictions) requires more than individual innovation. Individuals cannot re-mediate the contradictions in the activity system by themselves because contradictions are in social/material relations among groups of people and the tools they use. Thus, contradictions must be resolved by groups of people. Until such group remediation occurs, individuals must find individual ways to cope with their psychological double binds. (“Cross Disciplinary Links”)

Genres and activity systems operate not by some static formula, but by an evolving dialectic between available tools and the social demands of the situation. An individual caught in a systemic double bind can only create a temporary fix for himself/herself. He or she can only modify or adapt the way he or she uses tools to address the situation. A lasting solution to a systemic problem, per Activity Theory's theory of "re-mediation," requires group attention and consensus. The type of change this posits comes from the middle, where the central users are concentrated, rather than just from the top down (which correlates with Activity Theories roots in Soviet Psychology). A simpler way to put this would be to put it in terms of genre and genre theory: if genre is social action, then it takes social action to meaningfully change a genre. 
Applying this model to classrooms in general and composition classrooms in particular is difficult, however. Activity Theory has proven to be an effective descriptive tool for analyzing workplaces that deal heavily with information-based activities (such as computer information systems). In such professional environments, groups of peers work within various hierarchies to accomplish common objectives. These groups typically work together over extended periods of time, and so changes can be tested and implemented gradually with time to reflect on each stage. Within the classroom, however, a somewhat different environment exists that can make Engeström's cycle of expansion difficult to realize.

The classroom has a steeper hierarchy than most workplaces with, typically, one person on top (the teacher) and everyone else on the bottom. This makes change from the middle or from the bottom up more difficult. Additionally, students work solely for their grade as individuals; the fate of the class as a whole is largely beyond their concern. Even when group work is assigned, the typical student is most concerned with his or her grade as opposed to the overall success of the group. Finally, students may only be in a particular class with a particular teacher once. Therefore, they are present for only one cycle of the class' full activity system and play only a limited role in altering the activity system for the benefit of future users. Their investment in improving that system for the future (i.e., for future students of that class) may consequently be somewhat low. Teachers can question, examine, and change their teaching mid-term based on student reaction, of course, but doing so too often can cause confusion and a general lack of confidence in the teacher. Activity Theory does not yet provide a solution for addressing these concerns in classrooms. Studies using Activity Theory to analyze teaching 
practices have typically focused on what those classrooms evidence about t he need for broader, programmatic change rather than how an individual teacher can identify and attempt to resolve double binds on the classroom level.

Given these difficulties, the way to identify and resolve double binds on the level of an individual classroom is to engage students throughout a writing project. As discussed earlier, contradictions and double binds become apparent only over the course of time, as participants in the system begin to feel their presence interfering with their work. For a writing assignment, contradictions and double binds, then, will only become apparent while students are engaged in the writing process. This means that teachers need to be vigilant for difficulties students encounter beyond the normal, and healthy, struggles of learning how to engage a writing assignment.

How can teachers identify growing contradictions or double binds? Here I would reiterate the importance of the strategies described earlier, particularly the use of the writing prompt in the classroom. Creating opportunities and incentives for students to ask questions, get assistance, and see examples of appropriate writing for the classroom brings them into the process of checking for contradictions and double binds. Obviously, when students get low grades on formative assessment opportunities like bibliographies and outlines, some misunderstanding may be present. The Biology course is a great example of this. Students initially received scores on their homework and shorter papers that they were dissatisfied with, but these small, low-stake assignments helped them align their understanding with Dr. Steiner's expectations. By the time the major assignment rolled around, students already had a firm understanding of what kind of writing Dr. Steiner valued. Providing solid assignment sequencing, individual feedback, and an 
environment that welcomed and rewarded the asking of questions helped students work through what might have been some debilitating contradictions between the ways Dr. Steiner evaluated writing and the ways their other Biology teachers assessed writing. While the psychology and nursing classes did have formative assessment, they did not have the same level of interaction with the teacher over the project, nor did they have an environment that promoted the easy asking (and answering) of questions.

How can teachers deal with contradictions and double binds? As seen in this project, students were more affected by contradictions and double binds within the activity system of an individual classroom. They were less affected by contradictions and double binds experienced between different courses and different disciplines. Consequently, the ways in which an individual teacher establishes his/her expectations through the writing prompt and related materials were key factors in how students negotiated potential contradictions. The following is a short list of strategies for dealing with contradictions and double binds should the assignment need to change in order to ameliorate their effects:

- Make small adjustments before big adjustments: Making smaller adjustments to the prompt is less likely to confuse students or to project a sense of indecisiveness on the part of the teacher (which will worry students when the time for grades rolls around). Small adjustments include tightening wording in a prompt, illustrating with an example, posing a sample research question, etc. Major changes include changing the requirements for entire sections. 
- Whenever possible, work with an example text: Abstract discussion about a paper that has not yet come into existence can only go so far. Working with an example text (such as a sample student paper from a previous term) gives students something concrete to work with and can promote more specific questions and more useful answers. Teachers may also consider annotating a sample student text to highlight successful aspects of that text and draw attention to defects that students should avoid.

- Discriminate between symptoms and causes: In the Nursing paper, students had difficulty achieving a balance between concision and detail. While their struggle with the page limit was certainly an important factor, the root cause was that Professor Green and her graders were working at cross purposes: the former wanted students to write with great concision, and the latter wanted students to expand and demonstrate their deep understanding of their subject.

- Explain, don't explain away: In Nowacek's study "Why is Being Interdisciplinary So Very Hard to Do?" the three teachers of the interdisciplinary humanities course tended to elide the differences between their disciplines in an effort to present a unified set of expectations to students. This explaining away of student concerns only exacerbated the students' challenges as they tried to write one paper that would satisfy three different (and conflicting) sets of expectations. They may have been trying to maintain an authoritative position over the class by explaining away possible problems with the assignment.

The research performed for this dissertation went a long way in addressing the project's primary research questions, but its scope and design did limit what it could 
show in some respects. This study attempted to strike a balance between broad surveys and in-depth case studies by taking a close look at writing in multiple classrooms across the curriculum. As such, it sacrifices a degree of the depth of case studies for a broader view of multiple classrooms, and it trades the breadth of a survey for a closer view of each site. This was not a serious impediment to the project, but I have often wondered what the project might have revealed if I had chosen one format or the other: to do a more empirical survey of multiple classes across the disciplines or to go more in-depth on only one or two sites.

The type and number of courses used in this study created some challenges that I would address differently in future work of this type. By design, this study focused on courses at the 300 level and above, as those courses are primarily for students majoring in that course's discipline. As such, they are sites where students are (ostensibly) invested in learning how to work within that field, since they are parts of their chosen major. There was significant difficulty in finding courses at this level that would use enough writing meet the criteria of this study. Furthermore, finding willing instructors and willing student subjects provided an extra layer of difficulty. Some courses examined had to be disregarded due to a lack of participation from student subjects (namely a midlevel Philosophy course, an entry-level Sociology course, and a 200-level Sociology course). It took three semesters of research to gather the data from the courses that are featured in this dissertation, and part of that unintentionally lengthy time frame was due to the difficulty in finding appropriate classes with enough willing student participants. The courses used here provided good coverage of the academic spectrum - from the humanities to the hard sciences - although the data collection took more time than 
initially intended. Planning for this type of study in the future would require more advance preparation in terms of examining future course schedules and making contact with instructors of qualified courses before an academic term begins.

There are many aspects of this project that contain avenues for future research. More research of this type — using Activity Theory to look at student writing across the disciplines - could identify more common contradictions/double binds and the ways students cope with them. Focusing more on the ways that students cope with these common challenges can benefit both composition studies, programs like WAC/WID, and teachers in the disciplines directly. The use of writing at the intersection of school and the workplace (the subject of Chapter 4) provides intriguing applications for the use of an Activity Theory framework and a WAC/WID lens. There is also great potential for furthering the study of genre in how it pertains to WAC/WID, namely how students acquire disciplinary genres, how they are/can be trained to think within certain generic frameworks that comprise their discipline(s), and how genres are signaled and processed by students and general readers.

This project's goals have been to identify common issues that students face as they learn how to write within their disciplines, and to investigate what role the writing prompt plays (and can play) in that process. As composition instructors, our job is to prepare students to write well in a college (and later in a professional) setting. This is more of a Herculean task than many people realize, as many instructors in disciplines outside of composition still hold to the belief that "good writing" at the college level is singular thing that can and should be mastered within two semesters of college writing courses. As we are aware, the field of writing in the university and beyond is too varied 
for there to be a single panacea to all student writing ailments. If nothing else, this project helps to disprove the myths of transparency and transience by showing the variability of college writing and how documents like writing prompts are far from being transparent facilitators of information. They are highly rhetorical documents situating students within highly rhetorical writing situations. In general, opening ourselves (and, hopefully, opening others as well) to how writing prompts play a role in not only faciliting writing but in a student's overall writing education and disciplinary acculturation can take us one step closer to dispelling the myths of transparency and transience. In particular, this project offers specific ideas and solutions to some common problems that many teachers encounter in writing assignment design. 


\section{REFERENCES}

Ackerman, John. "Reading, Writing, and Knowing: The Role of Disciplinary Knowledge in Comprehension and Composing." Research in the Teaching of English 25.2 (1991): 133-178. PDF.

Albertson, Bonnie. "Organization and Development Features of Grade 8 and Grade 10 Writers: A Descriptive Study of Delaware Student Testing Program (DTSP) Essays." Research in the Teaching of English 41.4 (2007): 435-464. Print.

Ambrose, Susan, Michael Bridges, Michele DiPietro, Marsha Lovett, and Marie Norman. How Learning Works: Seven Research-Based Principles for Smart Teaching. San Francisco: John Wiley \& Sons, 2010. Print.

Bahls, Patrick. Student Writing in the Quantitative Disciplines: A Guide for College Faculty. San Francisco: Jossey-Bass, 2012. Print.

Bawarshi, Anis. Genre and the Invention of the Writer: Reconsidering the Place of Invention in Composition. Logan, Utah: Utah State University Press, 2003. Print.

Bazerman, Charles. "From Cultural Criticism to Disciplinary Participation: Living with Powerful Words." Writing Across the Curriculum: A Critical Sourcebook. Ed. Terry Myers Zawacki and Paul M. Rogers. Boston: Bedford St. Martins, 2012. 238-45. Print. 
---. Shaping Written Knowledge: The Genre and Activity of the Experimental Article in

Science. Madison, WI: University of Wisconsin Press, 1988. Print.

Bean, John. Engaging Ideas: The Professor's Guide to Integrating Writing, Critical Thinking, and Active Learning in the Classroom. $2^{\text {nd }}$ ed. San Francisco: JosseyBass, 2011. Print.

Beaufort, Anne. College Writing and Beyond: A New Framework for University Writing Instruction.. Logan UT: Utah State University Press, 2007. Print.

Beck, Sarah W. and Jill V. Jeffrey. "Genres of High-Stakes Writing Assessments and The Construct of Writing Competence." Assessing Writing 12 (2007): 60-79. PDF. Braine, George. "Academic Writing Task Surveys: The Need for a Fresh Approach." Texas Papers in Foreign Language Education 1.2 (1988): 101-118. PDF.

Burnett, Rebecca E. “'Some People Weren't Able to Contribute Anything but Their Technical Knowledge': The Anatomy of a Dysfunctional Team.” Nonacademic Writing: Social Theory and Technology. Ed. Ann Hill Duin and Craig J. Hansen. Mahwah, NJ: Lawrence Erlbaum Associates Incorporated: 123-56. Print.

Bridgeman, Brent, and Sybil Carson. "Survey of Academic Writing Tasks." Written Communication 1.2 (1984): 247-280. Print.

Campbell, Karlyn Kohrs, and Kathleen Hall Jamieson. "Form and Genre in Rhetorical Criticism: An Introduction." Form and Genre: Shaping Rhetorical Action. Falls Church, VA: Speech Communication Association, 1978. 9-32. PDF.

Carter, Michael. "Ways of Knowing, Doing, and Writing in the Disciplines." Writing Across the Curriculum: A Critical Sourcebook. Ed. Terry Myers Zawacki and Paul M. Rogers. Boston: Bedford St. Martins, 2012. 212-38. Print. 
Clark, Irene. "A Genre Approach to Writing Assignments." Composition Forum 14.2 (2005): n. pag. Web. 17 October 2011.

Cole, Mike, and Yrjö Engeström. "A Cultural-Historical Approach to Distributed Cognition.” Distributed Cognition. Ed. Gavriel Salomon. Cambridge: Cambridge University Press, 1993. 1-46. PDF.

Dannels, Deanna P. "Learning to Be Professional: Technical Classroom Discourse, Practice, and Professional Identity Construction.” Journal of Business and Technical Communication 14.5 (2000): 5-37. PDF.

Devitt, Amy, Anis, Bawarshi, and Mary Jo Reiff. "Materiality and Genre in the Study of Discourse Communities." College English 65.5 (2003): 541-448. PDF.

Devitt, Amy. Writing Genres. Carbondale: Southern Illinois University Press, 2004. Print. Dias, Patrick. "Writing Classrooms as Activity Systems" Transitions: Writing in Academic and Workplace Settings. Ed. Patrick Dias and Anthony Paré. Cresskill: Hampton Press: 11-29. Print.

Dirk, Kerry. "The 'Research Paper' Prompt" Composition Forum: A Journal of Pedagogical Theory in Rhetoric and Composition 25.1 (2012). Web. 1 Oct. 2014.

Dowdey, Diane. "Citation and Documentation Across the Curriculum." Constructing Rhetorical Education. Ed. Marie Secor and Davida Charney. Carbondale: Southern Illinois University Press, 1992. 330-351. Print.

Eblen, Charlene. "Writing Across the Curriculum: A Survey of University Faculty's Views and Classroom Practices." Research in the Teaching of English 17.4 (1983): 343-348. Print. 
Engeström, Yrjö, and Annalisa Sannino. "Studies of Expansive Learning: Foundations, Findings, and Future Challenges." Educational Research Review 5.1 (2010): 1-24. PDF.

Engeström, Yrjö. "Expansive Learning at Work: Toward an Activity Theoretical Reconceptualization.” Journal of Education and Work 14.1 (2001): 133-156. PDF.

---. Learning by Expanding: An Activity-Theoretical Approach to Developmental Research. Helsinki: Orienta-Konsultit, 1987. The Laboratory of Comparative Human Cognition, 2012. Web. 10 February 2014.

Freadman, Anne. "Anyone for Tennis?" Genre and the New Rhetoric. Ed Aviva Freedman and Peter Medway. London: Taylor \& Francis, 1994. 43-66. Print.

---. "Uptake." The Rhetoric and Ideology of Genre: Strategies for Stability and Change. Ed. Richard Coe, Lorelei Lingard, and Tatiana Telsenko. Cresskill, NJ: Hampton, 2002. 39-53. Print.

Gardner, Traci. Designing Writing Assignments. Urbana, Ill.: NCTE, 2008. Print.

Graves, Roger, Theresa Hyland, and Boba Samuels. "Undergraduate Writing Assignments: An Analysis of Syllabi at One Canadian College." Written Communication 27.3 (2010): 293-317. PDF.

Haas, Christina. “Learning to Read Biology: One Student's Rhetorical Development in College.” Written Communication 11.1 (1994): 43-84. PDF.

Harris, Jeanette, and Christine Hult. "Using a Survey of Writing Assignments to Make Informed Curricular Decisions." Writing program Administration 8.3 (1983): 714. PDF. 
Herrington, Anne. "Writing in Academic Settings: A Study of the Contexts for Writing in Two College Chemical Engineering Courses." Research in the Teaching of English 19 (1985): 331-61. PDF.

Hilgers, Thomas, Edna Lardizabal Hussey, and Monica Stitt-Bergh. ““As You're Writing, You Have These Epiphanies': What College Students Say About Writing and Learning in their Majors." Written Communication 16.3 (1999): 317-53. PDF.

Horowitz, Daniel M. "What Professors Really Require: Academic Tasks for the ESL Classroom." TESOL Quarterly 20.3 (1986): 445-462. PDF.

Hyland, Ken. Disciplinary Discourses: Social Interactions in Academic Writing. Harlow, England: Longman, 2000. Print.

Kaufer, David, and Cheryl Geisler. "Novelty in Academic Writing." Written Communication 6.3 (1989): 286-311. Print.

Kill, Melanie. "Acknowledging the Rough Edges of Resistance: Negotiation of Identities for First-Year Composition." College Composition and Communication 58.2 (Dec. 2006): 213-235. PDF.

LeFevre, Karen B. Invention As a Social Act. Carbondale: Southern Illinois University Press, 1987. Print.

Flower, Linda. The Role of Task Representation in Reading to Write. Berkeley, CA: Center for the Study of Writing, 1987. Print.

Kutti, Kari. "Activity Theory as a Potential Framework for Human-Computer Interaction Research." Context and Consciousness: Activity Theory and Human computer Interaction. Ed. Bonnie Nardi. Cambridge: MIT Press, 1995. 17-44. PDF. 
Lave, Jean and Etienne Wegner. Situated Learning: Legitimate Peripheral Participation. Cambridge: Cambridge University Press, 1991. Print.

Leontiev, Aleksei Nikolaevich. The Development of the Mind: Selected works of Aleksei Nikolaevich Leoniev. Pacifica, CA: Marxist Internet Archive, 2009. PDF.

Linton, Patricia, Robert Madigan, and Susan Johnson. "Introducing Students to Disciplinary Genres: The Role of the General Composition Course.” Writing Across the Curriculum: A Critical Sourcebook. Ed Terry Myers Zawacki and Paul M. Rogers. Boston: Bedford St. Martins, 2012. 158-67. Print.

Mahala, Daniel. "Writing Utopias: Writing Across the Curriculum and the Promise of Reform." College English 53.7 (1991): 773-789. PDF.

MacDonald, Susan Peck. Professional Academic Writing in the Humanities and Social Sciences. Carbondale and Edwardsville: Southern Illinois University Press, 1994. Print.

McCarthy, Lucille. “A Stranger in Strange Lands: A College Student Writing Across the Curriculum." Research in the Teaching of English 21.3 (1987): 233-265. Print.

McLeod, Susan, and Elaine Maimon. "Clearing the Air: WAC Myths and Realities." College English 62.5 (2000): 573-83. PDF.

Melzer, Dan. "Writing Assignments Across the Curriculum: A National Study of College Writing." College Composition and Communication 61.2 (2009): 240-261. PDF. Miller, Carolyn. “Genre as Social Action.” Quarterly Journal of Speech 70.2 (1984): 151-167. Print. 
Minick, Norris. "The Development of Vygotsky's thought: An Introduction to Thinking and Speech." An Introduction to Vygotsky. Ed. Harry Daniels. London: Routledge, 2005. 32-56. Print.

Nelson, Jennie. ““This Was an Easy Assignment’: Examining How Students Interpret Academic Writing Tasks." Research in the Teaching of English 24.4 (1990): 36296. PDF.

Nowacek, Rebecca S. "Why is Being Interdisciplinary So Very Hard to Do? Thoughts on the Perils and Promise of Interdisciplinary Pedagogy." College Composition and Communication 60.3 (2009): 493-515. PDF.

Ochsner, Robert, and Judy Fowler. "Playing Devil's Advocate: Evaluating the Literature of the WAC/WID Movement." Review of Educational Research 74.2 (2004): 117140. PDF.

Price, Sheri. "Becoming a Nurse: A Meta-Study of Early Professional Socialization and Career Choice in Nursing.” Journal of Advanced Nursing 65.1 (2009): 11-19. PDF.

Rose, Mike. "Remedial Writing Courses: A Critique and a Proposal." College English 45.2 (1983): 109-126. PDF.

Russell, David R. "Activity Theory and its Implications for Writing Instruction.” Reconceiving Writing, Rethinking Writing Instruction. Ed. Joseph Petraglia. Malway, NJ: Lawrence Erlbaum, 1995. 51-77. Print.

Russell, David R., and Arturo Yanez. "'Big Picture People Rarely Become Historians': Genre Systems and the Contradictions of General Education." Writing Selves/Writing Societies. Ed. Charles Bazerman and David R. Russell. Fort 
Collins: The WAC Clearinghouse and Mind, Culture, and Activity, 2002. 331-62. PDF.

Russell, David. "Rethinking Genre in School and Society: An Activity Theory Analysis." Written Communication 14.4 (1997): 504-554. PDF.

Russell, David. Writing in the Academic Disciplines: A Curricular History. 2nd ed. Carbondale, IL: Southern Illinois University Press, 2002. Print.

Shaver, Lisa. "Eliminating The Shell Game: Using Writing-Assignment Names to Integrate Disciplinary Learning.” Journal of Business and Technical Writing 21.1 (2007): 74-90. PDF.

Schick, Kurt. "Citation Obsession? Get Over It!" The Chronicle of Higher Education. N.p., 30 Oct. 2011. Web. 02 Oct. 2014.

Schryer, Catherine, Lorelei Lingard, and Marlee M. Spafford. "Techne or Artful Science and the Genre of Case Presentations in Healthcare Settings.” Communication Monographs 72.2 (2005): 234-260. PDF.

Schryer, Catherine F. “The Lab vs. the Clinic: Sites of Competing Genres.” Genre and the New Rhetoric. Ed. Aviva Freedman and Peter Medway. Bristol, PA: Taylor \& Francis Inc., 1994. 105-124. Print.

---. "Records as Genre." Written Communication 10.2 (1993): 200-234. PDF.

---. "Genre and Power: A Chronotopic Analysis." The Rhetoric and Ideology of Genre: Strategies for Stability and Change. Ed. Richard Coe, Lorelei Lingard, and Tatiana Telsenko. Cresskill, NJ: Hampton, 2002. 73-102. Print. Spinuuzi, Clay. "Losing by Expanding: Corralling the Runaway Object." Journal of Business and Technical Communication 25 (2011): 449-86. PDF. 
Swales, John M. "Worlds of Genre-Metaphors of Genre." Genre in a Changing World. Ed. Charles Bazerman, Adair Bonini, and Debora Figueiredo. Fort Collins: WAC Clearinghouse, 2009. 3-16. Print.

Thaiss, Christopher and Terry Myers Zawacki. Engaged Writers and Dynamic Disciplines: Research on the Academic Writing Life. Portsmouth NH: Boynton/Cook, 2006. Print.

Thyrose, Lars, Lise Hounsgaard, Nina Bonderup Dohn, and Lis Wagner. "Newly Qualified Nurses-Experiences of Interaction With Members of a Community of Practice." Nurse Education Today 32.5 (2012): 551-55. PDF.

Vygotsky, Lev. Mind in Society: The Development of Higher Psychological Processes. Ed. Michael Cole, Vera John-Steiner, Sylvia Scribner, and Ellen Souberman. Cambridge: Harvard University Press, 1978. Print.

Walvoord, Barbara. "Getting Started." Writing Across the Curriculum: A Guide to Developing Programs. Ed. Susan H. McLeod and Margaret Soven. Newbury Park, CA: Sage Publications, 1992. 9-22. Print.

Ward, Mark Sr. "Squaring the Learning Circle: Cross-Classroom Collaborations and the Impact of Audience on Student Outcomes in Professional Writing." Journal of Business and Technical Communication 23.61 (2008): 61-82. PDF.

Wardle, Elizabeth. "Can Cross-Disciplinary Links Help Us Teach 'Academic Discourse' in FYC?" Across the Disciplines 1 (2004). Web. 10 February 2014.

---. "'Mutt Genres' and the Goal of FYC: Can We Help Students Write the Genres of the University?" College Composition and Communication 60.4 (2009): 765-789. PDF. 
White, Edward. Assigning, Responding, Evaluating: A Writing Teacher's Guide. 4th ed. Boston: Bedford/St. Martin's Press, 2007. Print.

Winsor, Dorothy. Writing Like an Engineer: A Rhetorical Education. Mahwah, N.J.: Lawrence Erlbaum Associates, 1996. Print.

Wolfe, Christopher. "Argumentation Across the Curriculum." Written Communication 28.2 (2011): 193-214. Print. 


\section{APPENDIX A \\ RESEARCH INSTRUMENTS}

This appendix contains one survey and two sets of interview questions (for semistructured interviews) used in the data collection for this dissertation. They are ordered according to how they were used in the course of data collection. Teachers were interviewed first so that the researcher could gain an understanding of the class and its challenges. Students were then given a copy of the survey included in this appendix, the purpose of which was to help orient the researcher in terms of the students' understanding of their instructor's assignment and their confidence in submitting a satisfactory product. During the administration of the survey, the researcher collected the contact information for students who volunteered for an interview on their writing in that course. Institutional Review Board (IRB) approval was obtained for these instruments before they were used in data collection, and all subject (teachers and students) signed informed consent forms before participating in surveys and/or interviews (per IRB guidelines). All subjects were given pseudonyms in the text of this dissertation to protect their anonymity. 


\section{Questions for First Interview with Course Instructor}

Background, Warm Ups, and Questions about the Course:

1) What are your research interests or area(s) of specialization

2) What kinds of courses do you typically teach?

3) How many years have you been teaching courses at this level?

4) What typical assignments might a student at the 200 or 300 course level encounter in your department?

a. What typical assignments would students encounter in your classes, in particular?

5) What are some examples of good writing models in your classes that you can think of?

a. What makes them good examples?

6) What tips do you usually give to students to help them learn how to write successfully in your field?

a. What do students need to know to write successfully in your class?

7) In your own words, that are your goals for this course?

a. What kind of students generally take this course (freshman, majors only, students with specific academic interests, etc.)?

8) What instructional methods work best for you to get material across to students?

\section{The Assignment:}

1) How would you describe this assignment and what are your goals for students writing it? 
a. How is it important that students learn the conventions of this type of writing?

2) Have you taught this assignment in the past?

a. Where did you learn this type of writing?

b. How did you initially approach teaching it?

c. What resources did you use to assist you in teaching this type of writing?

d. What were the results?

e. How has that experienced influenced the way you teach this type of writing now?

f. What conventions do you feel to be the most important for this type of assignment?

g. Were there any particular points in the assignment that students tended to find difficult or get confused?

h. What are some popular topics or approaches to this project among students (ones that you might use as examples when explaining the assignment)?

3) What are your criteria for a successful paper within this assignment?

a. How have you developed those criteria?

b. What are the central terms or ideas you want students to engage?

4) In your own words, what do you mean by [insert particular term or genre-signal word here]?

5) Walk me through your schedule for teaching this assignment.

a. When do they get the prompt? 
b. What other materials do they receive or have at their disposal?

c. What in class activities do they do, if any?

d. How do students pick topics?

\section{Drawing Conclusions}

9) If you had to give a quick summary of your approach to teaching writing in your courses or in your discipline, the kind of thing that you might put in an abstract or in a short description about yourself, what would you say? 


\section{Date: Student Classification: Major:}

Open Response: Write your response to the following questions in the space provided:

1) What would you say the project is asking you to do?

2) What, in your view, are some of your teacher's primary expectations for this paper?

3) How might the skills needed for this assignment be useful beyond this class, if at all?

4) For you, what is the single most important thing to pay attention to in the instructions for this project?

5) Do you have any relevant professional or advanced academic experience in your discipline (internship, lab assistantship, relevant real-world experience)? If so, please explain briefly:

Please circle the reply that matches your level of agreement the following statements:

1) I have experience writing this kind of project:

Strongly Disagree Disagree Undecided Agree Strongly Agree

2) Coming into this course, I had a lot of knowledge of the content being taught:

Strongly Disagree Disagree Undecided Agree Strongly Agree

3) I understand what my teacher wants from this assignment:

Strongly Disagree Disagree Undecided Agree Strongly Agree

4) I feel the prompt has enough information to get me started:

Strongly Disagree Disagree Undecided Agree Strongly Agree

5) I feel the prompt has been explained to my satisfaction:

Strongly Disagree Disagree Undecided Agree Strongly Agree

6) I am confident at the moment that my final draft will be satisfactory to my instructor:

Strongly Disagree Disagree Undecided Agree Strongly Agree

7) Good writing is the same, no matter the subject:

Strongly Disagree Disagree Undecided Agree Strongly Agree 


\section{Interview Questions for Student Subjects}

\section{Background and Warm Up Questions}

1) What is your major?

a. What interested you in pursuing that field?

b. How many courses have you had so far in your major?

i. What were the more memorable/effective ones?

c. What do you think about your major so far?

d. What differences do you see between where you are now in your education/training and where you want to be or need to be when you graduate?

2) Tell me about what you are doing right now in your class.

a. What's your opinion about this current work?

b. How do you see this work relating to the overall purpose of the class?

c. How does the writing you are doing for this class compare to the kinds of writing you have done in the past?

i. How is it similar or different from other writing you have done in your major?

3) In what ways has your instructor explained the purpose of the work you have been doing?

4) What does he/she generally expect from your work in general?

5) What does he/she expect from your writing for this class?

6) What has been your opinion of the course so far?

\section{Writing Process Questions}

1) If I were watching you work on this project as you were finishing it, what would I see?

a. What materials from the class did you use?

b. What materials outside of the class did you use?

c. How much time did you put into this project and how was that distributed?

d. Do you feel you were allotted enough time by your instructor?

2) How did you go about researching and writing the paper? 
a. Is this process of research/writing typical for you?

3) Did you discuss the paper with other classmates?

a. What did your classmates have to say about your writing?

4) Do you feel you were prepared for this writing project?

\section{The Assignment's Instructions}

1) Let's look at the prompt for this project. Could you tell me your impressions of how it was written?

a. What are your impressions of how it was explained orally by your instructor?

2) Besides written and oral instructions, what materials did your instructor provide to you to help with this project?

3) Indicate on the prompt what you felt was the most important part of the project.

a. What were you most worried about when you saw it for the first time?

4) Do you feel you met your instructor's expectations for the project?

a. Point to a place in your paper where you see yourself fulfilling what the project was asking for.

b. What part of the project gave you the most difficulty?

i. Did anything in particular help you work through it?

5) [The rest of this section will pose questions based on specific wording in the prompt, asking student participants to consider how these terms or moves were explained and how they connect to the larger idea of the project]

\section{Assignment Genre}

1) What kind of experience do you have in writing this type of paper, if any?

a. How is this writing project similar or different from what you've done in the past?

b. How does the format of the written instructions compare to writing instructions you've received in the past?

i. How do these writing instructions compare to other instructions you have received from classes in your major?

2) How would you describe the purpose of this type of paper? 
3) Were there any key words or phrases your teacher used or that were included in the course materials that helped you understand what to do?

4) What is your evaluation of how the prompt was written and organized?

5) What is your evaluation of how the project was explained orally?

a. What do you remember your teacher stressing the most?

7) Which do you feel gave you the better understanding of the project: the written instructions or your instructor's oral comments?

a. Why do you feel the (written or oral) instructions help you more?

b. Do you generally work better with written or oral instructions?

8) Did the prompt or the verbal instructions prepare you for the work you would have to put in?

9) If you had another week to work on it, what might you do with your project?

10) What did you have to learn to complete this project?

a. How did the prompt prepare you to learn this material or these methods?

b. In what ways, if any, did the teacher's verbal explanations and other course materials attempt help you to learn how to write this project?

11) What have you learned from this project that might help you in future projects for this class, if anything?

a. For future classes of this type?

12) When a teacher passes out a set of writing instructions, what do you expect or want from them to help you understand what you need to do?

a. What do you feel writing instructions should look like?

b. Describe, if you can, what previous experiences may have led you to that expectation. 


\section{APPENDIX B WRITING PROMPTS AND SUPPORTING DOCUMENTS}

This section includes writing prompts for the major assignments featured in this dissertation as well as supporting documents that played a major role in the writing assignment. Names have been redacted. A guide to the documents presented in this appendix is included below.

PAGE

\section{BIOLOGY}

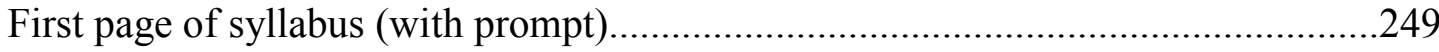

“Reading and Evaluating a Scientific Paper" Handout............................................250

\section{NURSING}

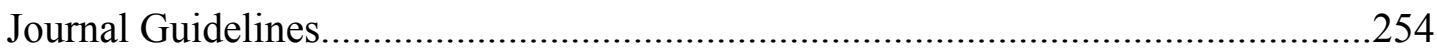

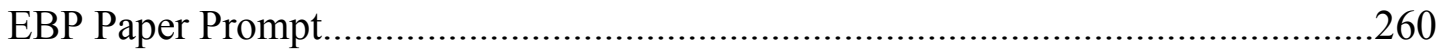

EBP Paper Decision Tree...............................................265

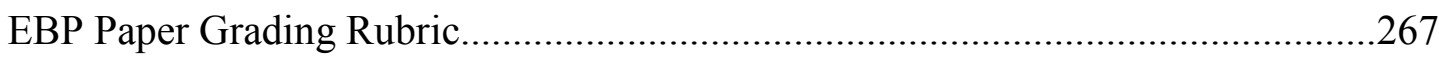

“Advice on Writing Formal Scholarly Papers” Handout.........................................277

PHILOSOPHY

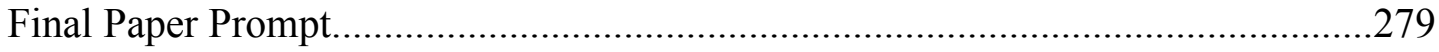

\section{PSYCHOLOGY}

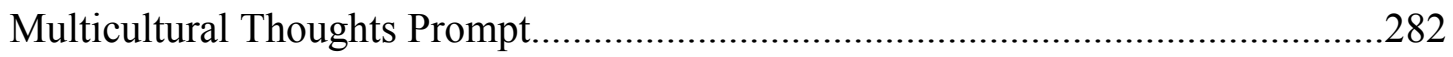

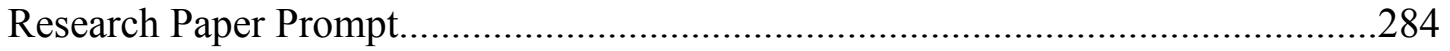


Instructor:

Office:

E-mail:

Meeting Time: Tuesdays and Thursdays 1:00-2:15 PM 123 Humanities

Text: $\quad$ Molecular Biology of the Cell, $5^{\text {th }}$ edition, Alberts et al

The course will be divided into five sections, each of which will include discussion of assigned text material and papers from the current literature which correlate with the topic under discussion. Grades will be assigned based upon the following: class participation (50\%), a library research report (30\%), and a final oral exam (20\%). February 28 is the last day to withdraw from this course without academic penalty. The $+/$ - grading scale will not be employed. It is anticipated that grades will be given on the $90 \%$ or above (A), $80 \%$ or above (B), $70 \%$ or above (C) and $60 \%$ or above (D) scale, although the instructor reserves the right to make adjustments.

PARTICIPATION: attendance per se will not be utilized in determining your grade, but there is an expectation of student preparedness and active involvement. Every student should strive to be involved in discussion during each class period, whether it is offering explanations for questions posed by the instructor other students or in posing questions themselves. You can earn a maximum of one point each day for involvement in class discussions (a total of 25 points). Also included in the participation portion of the evaluation will be the submission of five typewritten reviews (3 pages each) of the literature papers discussed during each section of the course. These reviews should address the questions identified in the accompanying document "Reading and Evaluating a Scientific Paper". These written reviews will be worth 5 points each ( 25 points possible) and will be due on the day of discussion.

LIBRARY RESEARCH REPORT: A 10 page (not counting references) fully referenced report is expected from each student in the course. The textual format is open, although references should be included in one of the formats commonly utilized in scientific writing. You can use the assigned literature correlation papers as appropriate examples of reference formatting. The report should evaluate some aspect of the recent literature on a specific or general cellular topic. The report may review the field related to a topic, or could involve a comparison/contrast discussion of papers in an area of controversy. The following is the schedule related to this written report:

4) $2 / 24$ - topic (submitted in writing) approved by instructor;

5) $3 / 10$ - outline and initial reference list due;

6) $4 / 5$ - draft of paper due (will be returned with suggestions for revision);

7) final copy due at oral exam (or earlier)

Appropriate and necessary figures, graphs or diagrams may be included in the report. However, if they are not original, you must provide a reference to their source. These non-textual components of the report must account for less than $20 \%$ of the report. Strive to keep to a minimum (or eliminate) the use of web sites as references.

FINAL ORAL EXAM: Students will meet individually with the instructor to discuss a research paper. The discussions will last 20-30 minutes and will be arranged to fit the schedules of the students and instructor during the period of April 25-29, 2011. 


\section{Reading and Evaluating a Scientific Paper}

\section{Organization of a paper}

In most scientific journals, scientific papers follow a standard format. They are divided into several sections, and each section serves a specific purpose.

Standard Format

A paper begins with a short Summary or Abstract. Generally it gives a brief background to the topic; describes concisely the major findings of the paper; and relates these findings to the field of study. This is the logical order that the paper will follow as a whole.

The next section of the paper is the Introduction. In many journals this section is not given a title. This section presents the background knowledge necessary for the reader to understand why the findings of the paper are an advance on the knowledge in the field. Typically, the introduction describes first the accepted state of knowledge in a specialized filed; then it focuses more specifically on a particular aspect, usually describing a finding or a set of findings that led directly to the work described in the paper. If the authors are testing a hypothesis, the source of that hypothesis is spelled out, findings are given with which it is consistent, and one or more predictions are given. In many papers, one or several major conclusions of the paper are presented at the end of this section, so that the reader knows the major answers to the questions just posed. Papers more descriptive or comparative in nature may begin with an introduction to an area which interests the authors, or the need for a broader database.

The next section of most papers in the Materials and Methods. In some journals this section is the last one. Its purpose is to describe the materials used in the experiments and the methods by which the experiments were carried out. In principle, this description should be detailed enough to allow other researchers to replicate the work. In practice, these descriptions are often highly compressed, and they often refer back to previous papers by the authors or others.

The third section is usually Results. This section describes the experiments and the reasons they were done. Generally, the logic of the results section follows directly from that of the introduction. That is, the introduction poses the questions addressed in the early part of the results. Beyond this point, the organization of results differs from one paper to another. In some papers, the results are presented without extensive discussion, which is reserved for the following section. This is appropriate when the data in the early parts do not need to be interpreted extensively to understand why the later experiments were done. In other papers, results are given, and then they are interpreted, perhaps taken together with other findings not in the paper, so as to give the logical basis for the later experiments.

The fourth section is the Discussion. This section serves several purposes. First the data in the paper are interpreted; that is, they are analyzed to show what the authors believe the data show. Any limitations to the interpretations should be acknowledged, and fact should be clearly separated from speculation. Second, the findings of the paper are related to other findings in the field. This serves to show how the findings contribute to knowledge, or correct the errors of previous work. As stated, some of these logical arguments are often found in the results when it is necessary to clarify why later experiments were carried out. Although you might argue that in this case the discussion material should be presented in the introduction, more often you cannot grasp its significance until the first part of the results is given. 
Finally, papers usually have a short Acknowledgements section, in which various contributions of other workers are recognized, followed by a Reference list giving references to papers and other works cited in the text.

Papers also contain several Figures and Tables. These contain data described in the paper. The figures and tables also have legends, whose purpose is to give details of the particular experiment or experiments shown there. Typically, if a procedure is used only once in a paper, these details are described in the materials and methods, and the figure or table legend refers back to that description. If a procedure is used repeatedly, however, a general description is given in the materials and methods, and the details for a particular experiment are given in the table or figure legend.

Variations on the organization of a paper

In most scientific journals the above format is followed. Occasionally the results and discussion are combined, in cases in which the data need extensive discussion to allow the reader to follow the train of logic developed in the course of the research. As stated above, in some journals materials and methods follows the discussion. In certain older papers the summary was given at the end of the paper.

The formats for two widely read journals, Science and Nature, differ markedly from the above outline. These journals reach a wide audience and many authors wish to publish in them; accordingly, the space limitations on the papers are severe and the prose is usually highly compressed. In both journals there are no discrete sections except for a short abstract and a reference list. In Science the abstract is self-contained; in Nature the abstract also serves as a brief introduction to the paper. Experimental details are usually given either in endnotes or figure and table legends or a short methods section. Authors often try to circumvent length limitations by putting as much material as possible in these locations. In addition, an increasingly common practice is to put a substantial fraction of the less important material, and much of the methodology, into supplemental data that can be accessed online.

In response to the pressure to edit and make the paper concise, many authors choose to condense, or more typically, omit the logical connections that would make the flow of the paper easier. In addition, much of the background that would make the paper accessible to a wider audience is condensed or omitted so that the less informed reader has to consult a review article or previous papers to make sense of what the issues are and why they are important.

\section{Reading a scientific paper}

Although it is tempting to read a paper straight through as you would do with a text, it is more efficient to organize the way your read a paper differently. First read the title and abstract and review in your mind what you know about the topic. This clarifies whether you know enough background to appreciate the paper. If not, you might choose to the background in a review paper or textbook. The abstract also identifies the major points of the work.

If you are familiar with a field the introduction can be skimmed or even skipped. As stated above, the logical flow of most papers goes straight from the introduction to the results; accordingly the paper should be read in that way as well, skipping materials and methods and referring back to this section as need to clarify what was actually done. A reader familiar with the field who is interested in a particular point given in the abstract often skips directly to the relevant section of the results and from there to the discussion for interpretation of the findings.

Many papers contain shorthand phrases that we might term "codewords" since they have connotations that are generally not explicit. In many papers not all experimental data are shown but referred to by "(data not shown)". This is often for reasons of space. The practice is accepted when authors have documented their competence to do the experiments properly (usually in previous papers). Two other codewords are "unpublished data" and "preliminary data". The former can mean either that the data are not of publishable quality or that the work is part of a 
larger story that will one day be published. The latter means different things to different people, but one connotation is that the experiment was done only once.

\section{Difficulties in reading}

Several difficulties confront a reader, especially if the reader is unfamiliar with the field. One major problem is that many papers are just poorly written. While some scientists write poorly, others do not enjoy writing. Sometimes the author is so familiar with the material that it is difficult to step back and see it from the point of view of a reader. Bad writing has several consequences: the logical connections are often left out, papers are often cluttered with jargon, and there is not a clear road map of the paper (side issues and fine points are given equal time with the main logical thread) and the reader loses sight of the main issues.

Another major difficulty arises can't understand just what the experiment was. Authors refer to previous papers; these in turn refer to previous papers in a long chain. Often the chain ends in a paper describing several methods, or the description is so compressed as to be unclear. Often descriptions are badly written so that it becomes ambiguous what was really done.

Other difficulties arise when authors are uncritical about their experiments or results. Authors may not be open to other possibilities for explaining their results which were not tested or perhaps even mentioned. In addition, many authors do not clearly distinguish between fact and speculation. This makes it difficult for a reader, especially a novice, to know how well established are the "facts" under discussion and to know what is settled and what is not. Many authors are ambitious and overstate the importance of their findings or put a speculation into the title in a way that makes it sound like a well-established finding (assertive sentence title). This trend is becoming very prevalent.

\section{Our Rubric For Evaluating a Paper}

A thorough understanding and evaluation of a paper involves answering several questions:

g. what questions does the paper address?

$\mathrm{h}$. what are the main conclusions of the paper?

i. what evidence supports those conclusions?

j. do the data actually support the conclusions?

$\mathrm{k}$. what is the quality of the evidence?

1. why are the conclusions important?

What questions does the paper address?

Research can be of several different types: descriptive, comparative or analytical. Descriptive research often takes place in the early stages of our understanding of a system. Typical descriptive approaches are DNA sequencing or microarray approaches. Comparative research often takes place when we are asking how general a finding is. Is it specific to my particular organism or is it more broadly applicable. A typical comparative approach would be comparing the sequence of a gene from one organism with that from other organisms in which that gene is found. Analytical research generally takes place when we know enough to begin formulating hypotheses about how a system works, how the parts are interconnected, and what the causal connections are. A typical analytical approach would be to devise two or more alternative hypotheses with the goal of the experiments to distinguish between the hypotheses. Of course many papers will be a combination of these approaches. In a well-written paper the introduction generally frames a question or set of questions. The results of experiments can raise additional questions, the answers to which might become evident only in the results and discussion sections of the paper.

What are the main conclusions of the paper? 
This can often be answered in a preliminary way by examining the abstract. Here the authors highlight what they think are the key points of the work. Because abstracts have severe space constraints, looking here is often not enough. You still need to read the paper with this question in mind.

\section{What evidence supports those conclusions?}

You should look initially to the results section. The description of the findings points to the relevant tables and figures. This is straightforward when there is one primary experiment to support a point. However, it is often the case that several different experiments or approaches combine to support a particular conclusion.

Do the data actually support the conclusions?

Even if you assume that the data are believable, it still might be the case that the data do not actually support the conclusion the authors wish to reach. This may be because the logical connection between the data and the interpretation is not sound, or there might be other interpretations consistent with the data. Note whether the authors take multiple approaches to answering a question. Do they have multiple lines of evidence, from different directions or using different approaches supporting the conclusion?

What is the quality of the evidence?

This is the hardest question to answer. However, it is also one of the most important skills to learn. It involves changing from being a passive consumer of information and ideas (which one often learns by only reading textbooks) to an active producer and critical evaluator. This is one aspect of the critical thinking that is the value added in the process of education. Developing the ability to evaluate evidence is one of the most difficult and most important aspects of learning to be a critical scientist and reader.

First, you need to understand thoroughly the methods utilized in the experiments. Authors generally assume that the reader has a general knowledge of common methods in the field. If you lack this knowledge, you must make an extra effort to be informed about the basic methodology. Secondly, you need to know the limitations of the methodology. Every method or technique has limitations, and if the experiments are not done correctly they can't be interpreted. Thirdly, you need to distinguish between what the data show and what the authors say they show. This is really an interpretation on the authors' part. Do you interpret the information the same way? Fourthly, it is often helpful to look at the original journal (or the electronic version). This particularly true in cell biology where there are photos of gels, autoradiograms, or cells themselves. Fifth, are the proper controls present?

Why are the conclusions important?

Do the conclusions make a significant advance in our knowledge? Do they lead to new insights, new questions, or even new research directions? You may have to understand the field relatively well to provide an informed answer to this question. 


\section{N474 JOURNALING GUIDELINES}

(please use APA $6^{\text {th }}$ edition to format your journals and title each subheading in your journal for clarification):

The reflective journal has $\mathbf{4}$ distinct components. Please identify each section with the appropriate heading. The sections are as follows:

1. Overview of the week's activities: (approx $1 / 2$ to 1 page)

2. Nursing Process: (approximately 5-6 pages)

3. Topic: (approximately $1 / 2$ to 1 page)

4. Time Log

\section{Journal Component \#1) Overview of Week’s Experiences;}

\section{OVERVIEW:}

- List all the psychomotor skills you were able to attempt or observe for the week.

- Include observations like procedures or tests you were able to witness.

- Think about the communication between healthcare professionals and comment on the things you see and hear.

- Assess what you learned for the week that was more than just a skill but maybe a realization (like managing more than one patient or getting paper work done).

- Report on any misc or professional activities for which you accrued hours the previous week.

\section{Journal Component \#2) Nursing Process:}

Provide a detailed narrative of the care rendered throughout one shift to one patient (adhering to strict HIPAA requirements).

The student's description of patient care must follow the format of the nursing process as follows

\section{BACKGROUND:}

- Provide a brief description of the patient. Include age, ethnicity, gender, admitting diagnosis, comorbidities, allergies, and developmental stage.

- Give a brief explanation of the patient's course of events during the hospitalization up to the day you cared for him.

- List the acute diagnosis and the patient's chronic co-morbidities.

- State which day of hospitalization it was on the day you cared for the patient (i.e. hospital day \#5) and/or what post-op day it might have been (POD 1 is the day after surgery).

\section{ASSESSMENT DATA:}

- You must include vital signs for assessments. (give a range unless they vary greatly over the shift, then report them individually)

- Assessment data should include only “abnormal” physical and psycho-social findings. Include problems that may have developed during the time you cared for the patient.

- Give possible explanations (rationale) for the abnormal physical and psycho-social findings

- Include recent lab results and other diagnostic tests which are important in understanding the patient's condition. You may write that X, Y, and Z were WNL but always give the values of abnormal results.

- Give possible explanations for why studies are abnormal that are specifically related to this particular patient and not copied from textbooks. Application of knowledge is the key here.

\section{NURSING DIAGNOSES:}

- Limit your Nursing Diagnoses to the Priority Top 2 for the shift in which you cared for the patient.

- These must be based on your abnormal physical/psycho-social assessment findings, abnormal diagnostics and/or significant "risks" for this patient. "Risks" must be actual risks for this particular patient that were a priority concern for that shift. Risk for infection might be a 
pertinent risk factor for most patients in the hospital but not always a main concern during the shift in which you cared for the patient.

- Think about the main focus of your care for the patient that day. The way you spent your time reveals the priority issues that had to be addressed. This is a true exercise in critical thinking. You may have had a lot of NDs but what were the main problems you had to address to achieve the results you wanted to achieve for this patient during your shift?

\section{GOALS:}

- For each nursing diagnosis you should have a goal that you tried to achieve during your shift with the patient. Specifically identify which ND the goal is for. Goals must be clearly measurable and timed for your shift.

- Keep your goals realistic. You are most likely not going to "cure" the patient in one day. What patient outcomes did you expect to reasonably achieve during the shift for which you provided care?

- Include one-long term goal that addresses case management and community resources timed for discharge or beyond discharge.

\section{INTERVENTIONS:}

- Interventions are written in a narrative form telling the reader how you cared for the patient. Tell the reader a story describing the care you gave (or what your preceptor may have done) and specify how the care was related to a particular ND.

- Remember to give (in your own words, not quoting Ackley), the rationales for performing the care. Why did you perform those interventions? As a senior approaching graduation, you should know rationales.

- You may include a brief description of other care that was important but did not relate to a particular ND, but keep it brief.

- Don't describe every detail of everything that was done if it was common basic nursing care. For example, oral care is common basic care. It isn't necessary to include that in your interventions unless the patient had a particular ND to which this intervention is directly linked and important; like "risk for infection related to mechanical ventilation".

- If you write that you "monitored" or "observed for" this or that as your intervention, then you MUST give the findings / values of that which you monitored or assessed for. For example, "I monitored the patient's respirations after giving morphine" is not enough. Add something like this, "the respiratory rate 1 hour following morphine administration was 20 bpm."

- You can briefly state that a certain med was given in your interventions. For example, if one of your patient's ND is "fluid volume excess" and you may write "I gave the patient Lasix 60mg IV" in the "Interventions" section. You will describe this drug in more detail in the medications section.

- Additionally, think about what could have or should have been done as you reflect on the care rendered. This should include collaborative care as well as nursing care. This is important as it is an opportunity for you to critique your care.

\section{MEDICATIONS:}

- Because instructors are not there with you to quiz you about medications, it is essential that you explain medication administration thoroughly so we know that you are passing medications with knowledge and safety.

- List ALL of the meds your patient received during your shift and any meds given the preceding shift that were not given on your shift. You may use a table to report these. Include dosage, route and frequency. Be sure to include any PRN or ONE-TIME meds the patient received on your shift.

- Briefly describe the action/class of med.

- For meds you actually gave during your shift, describe what you assessed your patient for before giving each med and give a detailed account of how the med was safely administered. This is especially crucial for IV meds (see special instructions below).

- Describe what you monitored and assessed the patient for after giving any the medication. You should be thinking about effectiveness and/or possible side effects. Be specific about your 
findings. REMEMBER to use values of what you found not just vague statements like "I monitored his blood pressure".

- If the patient receive meds that were administered by another HCP (preceptor, respiratory therapist, resident etc.) report how you monitored and assess the patient for effectiveness and side effects of those drugs.

- Be specific giving values and specific findings rather than broad statements. Were there other precautions taken such as checking labs before giving the med and if so what was the value of the lab? (K+ levels, PT/INR, BUN \& Creatinine, etc.) For example: Don't just write that you "checked the patient's potassium level prior to giving the Lasix". Instead write "the patient's K+ level prior to giving the Lasix was 4.5. This was important to know because this drug can deplete $\mathrm{K}+$ levels. Low $\mathrm{K}+$ levels can place the pt at risk for dysrhythmias".

- If a med is given IV, then you MUST describe in detail the following:

o Rate of administration (whether IV push or on the pump)

o Describe what IV site was used

o If you checked the site for patency and infiltration

o If you checked compatibility of other meds going through the line

o For IV infusions (drips), you must give the concentration of the solution, the number of $\mathrm{ml} / \mathrm{hr}$ the pump was set on and the dose of the drug delivered each hour.

- For example, if a patient is on an insulin drip, you might write "the patient was on a continuous infusion of 100 units of Regular Insulin in $100 \mathrm{~mL}$ of NS at $3 \mathrm{~mL} / \mathrm{hr}$ on the pump to deliver 3 units of insulin per hour".

- Do not write verbatim what the textbook says you are supposed to do, but what you (or your preceptor) actually did!

\section{EVALUATION:}

- Compare your patient outcomes to the goals. Since the goals are measurable, you can easily identify whether or not the goals were met. This is what every nurse does at the end of the day and is usually embedded in the shift report.

- You may not always meet your goal but you need to assess in measurable terms the progress made. If you did not meet your goals, what other interventions might have been tried to meet those goals?

- AVOID USING WORDS IN YOUR GOALS AND EVALUATIONS SUCH AS:

Sufficient

Adequate

Increased

Decreased

Appropriate

These words are subjective and not measurable!

\section{Journal Component \#3) Topics:}

In addition to your reflections you will address a topic each week in your journal and explain how you have met that objective. Students are required to address a topic in each journal. If all topics have been covered then repeat atopic.

Topic: PRECEPTOR'S ORGANIZATIONAL SKILLS (report in the first journal after your shadow day with your preceptor):

A. Address how your preceptor organized her/his workload, set priorities, re-prioritized.

B. How might you function similarly or differently?

C. How did your preceptor interact with other health care providers, including nursing assistants?

D. How is the role of the nurse different and/or similar to your current perception of what a nurse does/should do?

Topic: INTERVIEW WITH THE NURSE MANAGER (ASAP after your shadow experience, ideally by second or third journal) 
A. Set up an appointment to meet with the nurse manager for about 15 minutes. You will do this as a professional courtesy to introduce yourself to the manager and let him/her know a little about yourself. If there is more than one student on the unit, this may be done as a group. Try to ask for a meeting in which all students can attend together to be respectful of the manager's busy schedule.

B. In your interview, ask the manager the following:

1. What qualifications are required for his/her position?

2. What responsibilities does the manager's position hold that are completely different than that of a staff nurse?

3. Is there a management training program or how does one go about obtaining the skills needed to effectively manage a nursing unit?

4. What is the manager's fiscal responsibility for the unit?

5. Review the job descriptions for the RN, LPN, and NA (even if those personnel are not used in your particular clinical unit).

6. Find out what the quality improvement plan is for the unit.

7. Report how the QI plan is measured and how often data are collected. What is done with the data?

Choose from the following Topics each week as they are appropriate to a clinical experience. ALL topics must be addressed by the end of the clinical experience.

Topic: IDENTIFICATION OF RESEARCHABLE TOPICS

A. Describe examples of practice issues you have observed in the clinical area that might lend themselves to further scrutiny through a research project. Examples of some issues that might warrant further examination could be patient responses to a variety of nursing interventions regarding therapeutic communication, teaching, hygiene, activity progression, and certain infection control practices.

B. Do not choose topics for which there is already an existing body of literature (i.e. pt. teaching).

\section{Topic: COMMUNICATION and TEACHING}

A. Describe, in detail, a situation in which you communicated effectively with a patient and/or family member. Communication in this context is more than teaching or talking (i.e., not about ways a pt on a ventilator or with a tracheostomy can communicate). Communication in this context is making contact with the patient in more than a superficial way; it is connecting with and learning intimate personal details about the patient that influences the relationship with the patient.

B. How did this communication change the way you care for the patient based on what you found out about him?

C. Discuss an example of when you provided patient/family teaching. Describe what you taught and how you taught it.

D. Evaluate yourself on how well you think you taught

E. Evaluate if patient/family learning took place.

F. Explain how you could improve your patient/family teaching next time. Discuss opportunities that you missed for patient teaching and indicate how you could be more successful next time in providing appropriate patient education.

\section{Topic: CASE MANAGEMENT / COMMUNITY RESOURCES}

A. Describe what community resources would be available for your patient after discharge from acute care. Be specific in naming agencies or resources. You must demonstrate some knowledge of the resources not just list an abstract resource.

B. What financial resources does your patient have?

C. How will the patient be able to carry out discharge instructions? Do they need durable medical equipment? How will they get transportation for follow-up care.

You must PLEASE pick a patient that has challenges in this regard, not a patient for whom these issues will not be a challenge.

\section{Topic: CULTURAL DIVERSITY}


A. Describe a patient with a particular culture for whom you have cared for. Remember that culture extends beyond race, religion and ethnicity. Culture encompasses social and gender roles within the family and societal group. Practices of day-to-day life are based on culture. For example, people from Appalachia have a distinct culture. People from urban areas have cultural difference from people from rural areas. Be specific about the cultural differences as you observed them in your patient/family.

B. Discuss how your observations of how of this patient's culture practices impacted (or should have) the care required and the care you provided.

Topic: PERCEPTION OF THE ROLE OF NURSING and MY METAMORPHASIS (this last topic must addressed in your final journal)

A. Describe how your perception of the role of the nurse and nursing as a profession has changed throughout this clinical rotation.

B. Describe how you think you have changed over the clinical experience. How do you feel with regards to your beginning your new career as a Registered Nurse?

\section{Journal Component \#4) Log of Clinical Time:}

Each week in your journal you will list your clinical days and hours for the week. This is in addition to your written and signed log you keep in your clinical area. If you have not accrued the minimum 12 or 24hrs for the week, you must supply an explanation of why this was not done.

Please keep your "Patient Care" hours (these are all the hours spent with your preceptor in your clinical facility) and the "Miscellaneous" hours recorded separately.

\section{HOURS:}

- Always list the date of each day and your attendance in "hours and minutes"

- Always list the total the number of "patient care hours for the week".

- Always list your grand total of "patient care hours" (cumulative)

- List the date of any day that week you participated in a professional or misc/activity and your attendance in "hours and minutes" (if any)

- Always list the total the number of "Prof/Misc" hours for the week (it will usually be "0")

- Always list the grand total of "Prof/Misc"

Example: PATIENT CARE HOURS

Weds 10/4: Pt Care 12hrs 45min

Fri 10/6: Pt. Care $12 \mathrm{hrs} 50 \mathrm{~min}$

Tot hrs for week: $25 \mathrm{hrs} 35 \mathrm{~min}$

Cumulative pt care hrs: $125 \mathrm{hrs} 20 \mathrm{~min}$
MISCELLANEOUS/PROFESSIONAL HOURS

Mon. 10/3: 1 hr. Attended KANS/NSC meeting Weds. 10/5: 2.5 hours. Assisted Mrs. Adams in HPS

Sat 10/7: $1 \mathrm{hr}$ 30min. Attended Oncology Nursing

Tot hrs for week: 5 hours

$$
\text { Society Meeting }
$$

Cumulative hrs: 16 hrs $15 \mathrm{~min}$

\section{ADDITIONAL TIPS:}

Keep MDs' and nurses' (including preceptors') names anonymous.

Follow basic APA and good writing rules:

- double-spaced throughout and use "Times New Roman" with 12 point font

- use formal language without slang

- narrative form (OK to list labs or make a table)

- stay in the past tense

- use correct spelling and grammar.

- Watch out for unclear or unacceptable abbreviations.

- If you cite authors, then you must have a "reference page". Remember, textbooks editors are not usually authors. Lewis et al. are not the authors of your med-surg text. Each chapter has an author who is the person you must cite.

You can see that if you address each section thoroughly that you must use economy of words and stay focused on what you are writing about or you will have pages and pages of text. This helps your critical thinking skills by helping you prioritize, focus on the task and summarize. As you master this journaling format, you will begin to unconsciously "think" about patient care in terms of the nursing process as you 
care for them in the clinical setting. This is the primary objective of the journaling assignment. This will take practice and a conscious effort to achieve but you will be surprised at what you learn and how this trains your mind to "think like a nurse" by the end of the semester!

A well-written and concise journal should be about 6 and no more than 8 double-spaced typed pages. You must focus on prioritizes and communicating with economy of words and conciseness. Points will be deducted for journals of excessive length. 


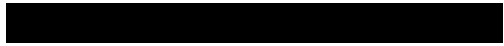 \\ SCHOOL OF NURSING \\ N471 \\ EVIDENCE-BASED PRACTICE PAPER INFORMATION}

The purpose of the focus paper is to assist you in synthesizing knowledge and information about and developing skills for investigating the scientific rationale for nursing practice that yields quality patient outcomes. Research strongly demonstrates that writing improves one's critical thinking skills. As a Baccalaureate prepared professional nurse, you should be able to clearly articulate your thoughts in a clear and concise manner. Not unlike the ability to assess and prioritize in the clinical setting, students should be able to demonstrate critical thinking using their knowledge to discriminate between what is essential and important to sufficiently inform the reader from what is extraneous material that does not clarify one's thoughts or objectives.

There is a 10-page limit on this paper exclusive of the Title Page, Abstract and Reference Page(s). Content exceeding 10 pages (from page 12 forward to the references) will not be graded. You will lose points accordingly for the content not reviewed. If you are having difficulty meeting this limit, PLEASE talk with your instructor for advisement on how to meet this requirement.

This paper is an in-depth investigation of scientific rationale supporting a nursing practice (intervention) or protocol that the student sees commonly utilized in his/her $\mathbf{N 4 7 4}$ clinical setting.

(Students may elect to choose an intervention that is not currently used in the student's clinical setting but is currently being discussed in the literature. If the student is interested in choosing this approach, he/she should thoroughly discuss this with the clinical faculty for clarification and guidance on how to proceed further.)

The student will determine, based on different sources of reliable evidence, whether or not the intervention is the most current practice that yields the highest quality patient outcomes. The students will develop a plan for continuing or implementing the best practice and monitoring patient outcomes or developing further research needed to determine best practice.

The student will develop awareness that strategies are always associated with costs and will understand the need to justify costs by illustrating the monetary and humane benefits produces.

It is an objective of this exercise to motivate the student to question everyday practices performed in the clinical setting and to investigate ways to improve patient care and achieve better outcomes based on scientific evidence while containing health care costs.

This paper will be submitted via Blackboard. The paper must be submitted by the date and time specified on the syllabus calendar. Papers turned in later the deadline will be considered late. Ten points will be deducted for every day the paper is late. Papers more than $\mathbf{2}$ days late will not be accepted and the earned graded for this assignment will be " 0 ".

\section{POINTS TO REMEMBER}

1. This paper is a formal scholarly paper written in APA style ( $\left.\mathbf{6}^{\text {th }} \mathbf{e d .}\right)$. This includes an abstract, introduction, conclusion and reference list.

2. Grammar, sentence structure, spelling, clarity, organization, etc., will be evaluated. Be sure to use complete sentences.

3. Write the paper in the order the sections are presented. Use subheadings for each section to make the content clear for the reader (your instructor).

4. Do not use jargon and slang. Your language is directed at a scientific audience and therefore you should use professional and scientific language. 
5. Read the “Tips for Scholarly Writing” posted on Blackboard under “Course Documents". These are common mistakes student make writing papers. You will be held accountable and will lose points for these types of mistakes.

6. The body of the paper should not exceed 10 pages. Length does not equate with quality. You must be able to be concise and clear without redundancy. Points will be lost for excessive length.

7. Students are urged to utilize the services of the University's Writing Center on Belknap Campus or the Virtual Writing Center located through Blackboard to assist them in their writing skills. All students registered for classes at U of L have access the "Virtual Writing Center" on Blackboard under "Courses You Are Enrolled In". Early submission of drafts is necessary to have time to use feedback for re-writing and re-submitting. Students do better with multiple submissions rather than using the center just once.

8. If the student is not clear on the instructions for each section or the paper overall, the student should contact the instructor for clarification. Do not get your information from a classmate. The student will be held accountable if their writing does not address the section(s) as it was intended.

9. Have your research article approved well in advance of your paper. Finding your research is the first thing you should do when you decide on a topic. Failure to find adequate research may force you to pick another topic. You want to do this early. Provide your clinical instructor with an electronic or "hard copy" of the article(s) once approved. Failure to provide your instructor with your research article(s) by the paper deadline date and time will result in a late penalty for the paper.

10. SAVE OFTEN!! You do not want to re-create this paper should you have a technology failure. So SAVE your work often and in more than one place. No allowance will be made for your failures to safeguard your work. Likewise you are responsible for ensuring that you have submitted the correct document.

11. See the course calendar for the paper due date. Papers must be submitted by 5:00 PM on the date they are due. Papers received after this time (5:01) will be considered late (note: The G-Wise system and Blackboard are down and non-operational between the hours of $10 \mathrm{pm}$ and $2 \mathrm{am}$ every Friday). Consider sending your paper before the final hour. Power outages, computer glitches etc. do happen: waiting until the last minute increases your risk that you may not be able to send your paper on time should a problem occur.

This assignment meets the following Nursing Program Objectives:

\#2. Communicates effectively in writing with peers, clients and other professionals.

\#3. Consistently demonstrates critical thinking, cognitive skills, and affective disposition.

\#5. Selects, uses, and evaluates interventions for the client.

This assignment meets Course Objectives \#1, \#2, \#3, \#4, \#5, and \#6.

\section{LEARNING OBJECTIVES}

At the completion of this activity, the student will:

1. Identify and apply current research findings and other levels of evidence to validate or refute nursing care interventions as "best-practice".

2. Develop a detailed plan to continue or implement the identified "best-practice" or develop a detailed research study to further investigate the current practice.

3. Understand and determine costs related to staff education, implementation of practice changes, and research.

4. Communicate effectively through consistent demonstration of quality writing and critical thinking cognitive skills.

5. Communicate effectively in writing using proper APA format. 


\section{SCHOOL OF NURSING}

N471

\section{Evidence-Based Practice Paper Writing Requirements}

1. NURSING INTERVENTION OR NURSING PROTOCOL (hereto forward referred to as the "intervention"): Select a nursing intervention or protocol commonly used in the care of the patients on the unit to which you are assigned for your clinical experience. The intervention should be something you find all nurses commonly doing and is generally accepted as the appropriate method of care. Think about how this intervention impacts patients/families and whether or not patients/families perceive them as "best practice". Are we questioning practices that patients/families question or find intolerable? (Discuss the chosen intervention with your clinical faculty to make sure you are on the right track.)

Once you have decided on the intervention you are going to investigate, explain the intervention in detail, why it used and what patient/family outcomes are expected from this practice.

(10 points)

\section{SOURCES OF EVIDENCE:}

For the selected intervention, you will identify at least 3 sources of evidence about the validity of this practice. The evidence you find will fall into one of three categories; it will support the practice or refute the practice or may be inconclusive as to whether or not the practice is the most effective method of care.

a. Data-based research: One of the 3 sources of evidence must be from a data-based research study. The research study should be less than 5 years but may not be earlier than 2001 (10 years). If important groundbreaking studies have been done that are older, the student must obtain permission from the clinical faculty to use it as a source.

Studies done outside the United States may be accepted IF the student can make a rational argument of how the findings relate to the population and culture within the USA and in Louisville, KY. Again, the student would be prudent to clear this with the faculty.

The student will thoroughly describe the research study and will include the following in their discussion:

1) purpose of the study,

2) the population (who the participants were, how they were recruited, what were the inclusion/exclusion criteria),

3) a description of the research method (how the researchers conducted the study including any data collection instruments used) and

4) a summary of ALL results. Values and objective date should be given, not just broad statements. ( 5 points may earned for the appropriateness and applicability of the research and 10 points for the description of the study.

PLEASE NOTE: If a second or third data-based study is used, the same requirements for discussion and the point distribution is the same.

b. It is encouraged that the second and third sources of evidences come from professional practice guidelines and/or evidence summaries. If these sources of evidence cannot be found, the student may use other single data-based research studies as evidence. If the student uses other data-based studies, the student must also describe them as above and provide a copy of the study to the clinical faculty.

\section{CONCLUSION BASED ON THE EVIDENCE:}

At the end of your description of each of the 3 sources of evidence (research study, evidence summaries and practice guidelines) with a paragraph discussing your own conclusion of whether or not the findings of the evidence overall support, refute or are inconclusive about your identified nursing intervention as "best practice". Your conclusion will fall into one of three categories;

a) you believe the evidence supports the intervention as best-practice, b) you believe the evidence does not support or even refutes the intervention as best-practice or c) you believe the overall evidence is inconclusive that this intervention is best-practice. Make a clear strong statement of your conclusion and 
the rationale for your stand. Consider the "level" of each of the $\mathbf{3}$ sources of evidence as you make your conclusion

$(10 \mathrm{pts})$

4. The next section (titled by all capital letters as listed below) is determined by your conclusion above. You will take the viewpoint of a nurse on the unit (not a student) in determining the how best-practice will be supported on the unit where you are assigned for N474 clinical

(15 points)

If the evidence supports the current practice: REINFORCING CURRENT PRACTICE:

The intervention currently in place has been determined to be the best-practice therefore you want to ensure that the staff is informed and using this practice consistently.

a. You will develop a detailed teaching strategy of how you would disseminate your findings to the nursing staff of your unit to ensure that everyone knows that this intervention is best-practice. Include other disciplines that this may involved in this intervention.

b. Describe how you will continuously monitor the use of the intervention to ensure that the nursing staff is performing this best practice consistently and correctly.

c. Describe what quality patient outcomes you expect from using this practice and how you will monitor those patient outcomes.

d. Describe how your teaching strategy will be on-going and will capture newly hired nursing personnel and/or other disciplines involved.

If the evidence refutes or suggests this intervention / protocol is no longer "best practice": IMPLEMENTATION OF CHANGE IN PRACTICE TO THE MOST CURRENT BEST PRACTICE.

The identified intervention is not supported as best practice therefore you must make a change on your unit.

a. You will develop a detailed plan of how you will implement the change in practice and utilize the

"best practice" recommended in the 3 sources to replace the current outdated intervention currently used on your unit. Think in terms of steps you would have to take if this requires changes in current policy and procedure. This step may require eliminating the current intervention as well as implementing a new one. Be sure to describe the intervention that is currently in place if you are introducing a new intervention or concept.

b. How will you collaborate with other disciplines that may be affected by this change and discuss how you would include them in your implementation strategy.

c. Describe how you will continuously monitor the use of the newly implemented intervention (or the elimination of the old intervention) to ensure that the nursing staff is performing this best practice consistently and correctly.

d. Describe what quality patient outcomes you expect from using this practice and how you will monitor those patient outcomes.

e. Describe how you will ensure that newly hired nursing personnel and/or other disciplines are oriented to this best practice.

If the evidence is inconclusive in either refuting or supporting the current intervention/protocol and no "best-practice" is identified: FURTHER INVESTIGATION OF THE CURRENT PRACTICE The evidence has not clearly supported or refuted the intervention. Further research is needed to determine if this intervention is the best practice for yielding quality patient outcomes.

a. You will develop a detailed proposal for a research study. Your study should be clearly described in enough detail that the reader would know essentially how to conduct the research. You must include the following points:

- A statement of the problem: the current practice and the lack of scientific evidence to support it.

- A clearly stated research question (be precise in stating what you are investigating?)

- Where the research will take place (you want to restrict this to your clinical facility)

- The number of participants you will recruit

- How you will recruit the participants 
- How you will protect the participants' privacy

- Inclusion/exclusion criteria for participants

- What data you will collect (patient outcomes for example)

- How will you collect the data (interviews, questionnaires, pt data etc.)

- Who will collect the data and how will they be trained

- How long will it take to perform the study

\section{COST-BENEFIT ANALYSIS:}

For each of the three approaches described in \#4 above, you will have to justify costs versus benefits. You MUST obtain real cost estimations and give references for the source of your costs. Failure to provide details regarding costs or details regarding benefits will cause you to lose the majority of points for this section. Vague broad statements will not suffice in meeting this requirement. (10 points)

\section{For REINFORCING CURRENT PRACTICE:}

a. Describe in detail the costs of teaching strategy you chose. Think in terms of the cost of man-power hours, materials and/or equipment needed to achieve the initial and on-going teaching and monitoring. b. Justify the costs in quantifiable benefits: better patient outcomes, increased nurse/staff productivity or supplies and equipment reconfiguration can be translated to cost-savings in health care.

For IMPLEMENTATION OF THE MOST CURRENT BEST PRACTICE:

a. Describe in detail the costs of eliminating the current intervention and/or implementing the most current practice. Think in terms of the cost of man-power hours, materials and/or equipment needed to achieve the initial and on-going training and monitoring to effect this change.

b. Justify the costs in quantifiable benefits: better patient outcomes, increased nurse/staff productivity or supplies and equipment reconfiguration can be translated to cost-savings in health care.

\section{For FURTHER INVESTIGATION OF THE CURRENT PRACTICE:}

a. Describe in detail the costs associated with the research study you will conduct. Think in terms of the cost of man-power hours (training data collectors, time for data collection, writing the proposal and the resulting reports), materials and/or equipment you will need to conduct the study, and any compensation to the investigators.

b. Justify the costs for conducting the research in quantifiable benefits: knowledge that will lead to better patient outcomes, increased nurse/staff productivity or supplies and equipment reconfiguration can be translated to real cost-savings that can justify the money needed for the research.

6. WRITING STYLE: Clarity, spelling, grammar, sentence structure, organization, APA formatting, etc. APA formatting includes title page, running head, abstract, text double spaced in 12 font, an introduction, and a conclusion (this is the end of your paper not to be confused with the section on the conclusion based on your evidence). A minimum of 5 points and possibly all 10 points will be lost for any mistake outlined in the "Tips for Scholarly Writing". (10 points) 

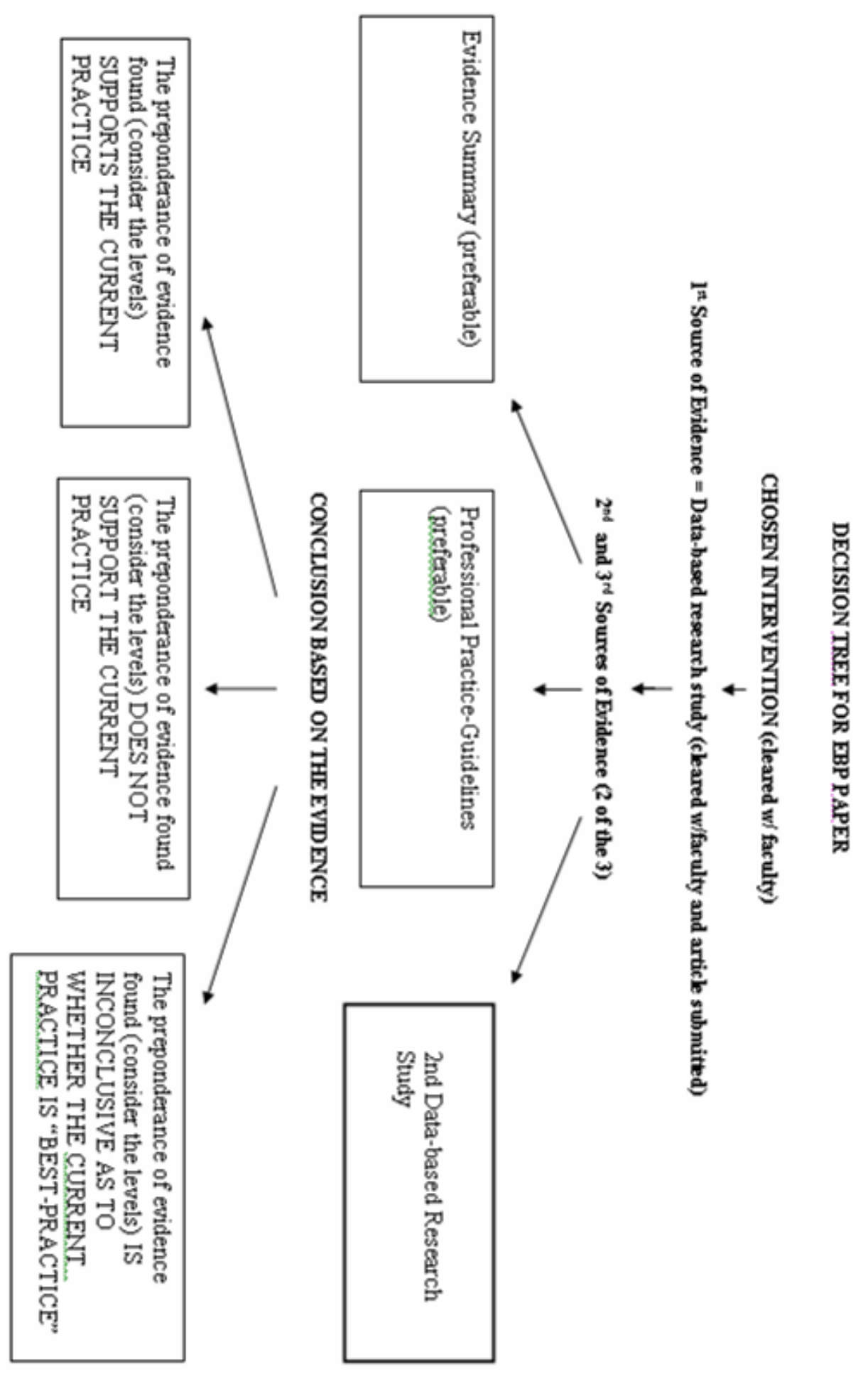

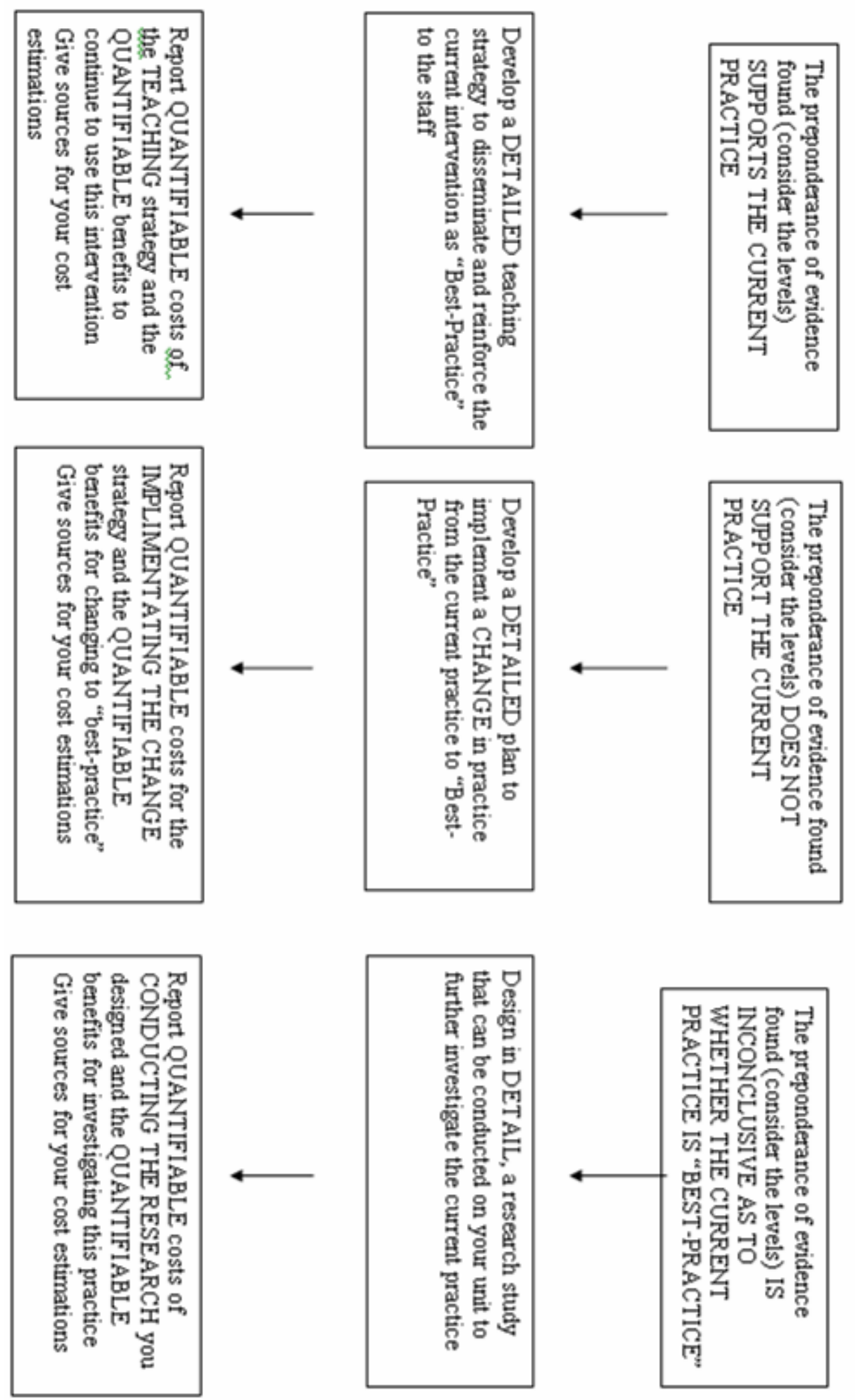
Each section of the paper is graded individually. Points given for the section reflect the quality of work for that section only. Points for each section are totaled for the final grade.

EXCEEDS OR MEETS STANDARD WITH NO EXCEPTIONS: The student meeting these criteria must show work that is beyond the minimum expected for that section. The student demonstrates mastery of the concept and display knowledge above the minimal required. There is absence of flaws or mistakes or only minor flaws exist. This is “ $A$ ” work.

MEETS STANDARD WITH FEW EXCEPTIONS: The student adequately describes the minimal required components for the section. A broad range of points may be awarded depending on the depth and mastery of the content. Content may be flawed in some aspects or unclear. This is " $B$ " to " $C$ " work.

CRITICAL COMPONENTS ABSENT: The student has major flaws in the description of the components or one or more critical components is absent. Content is unclear and does not demonstrate mastery of the content. 


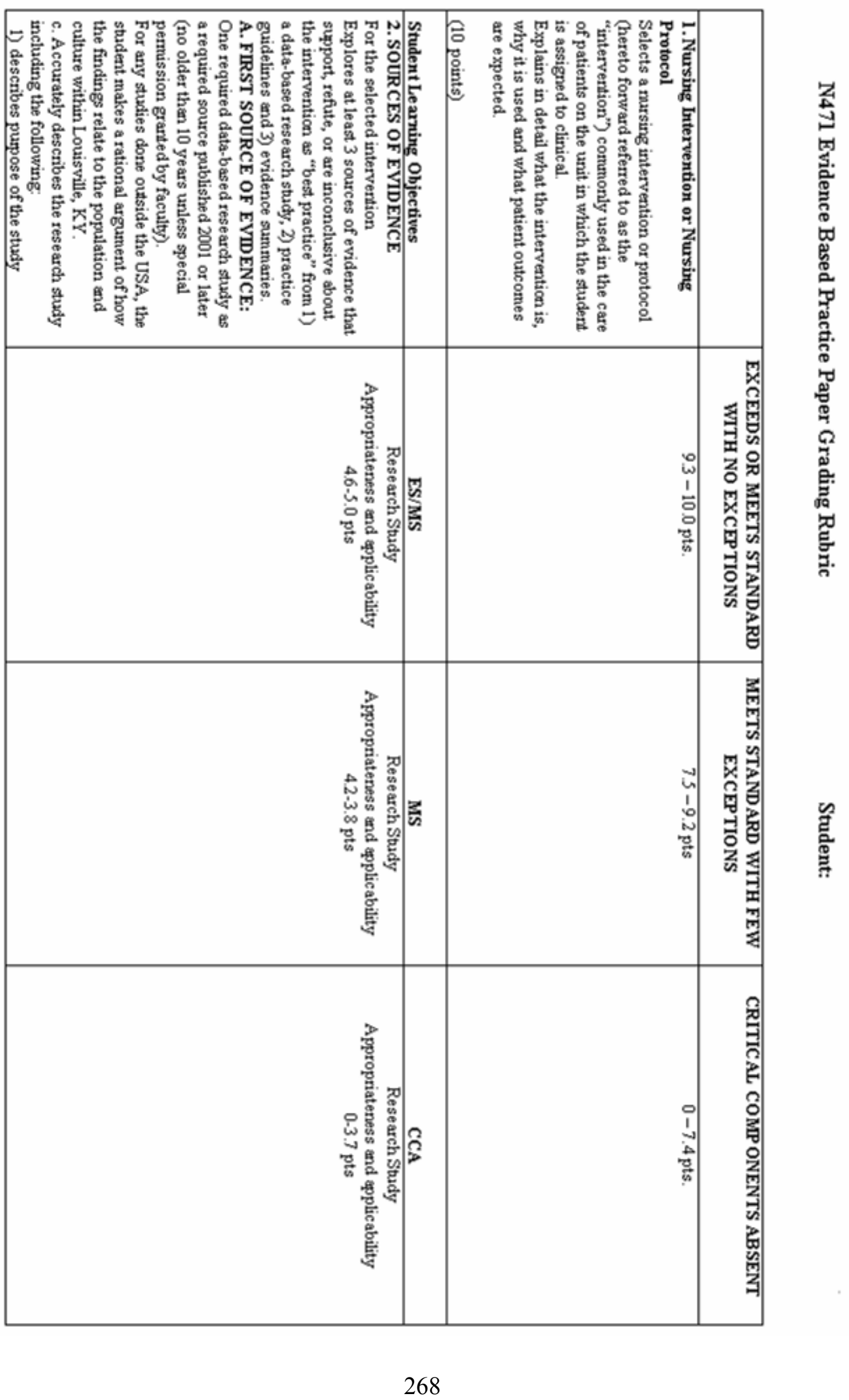




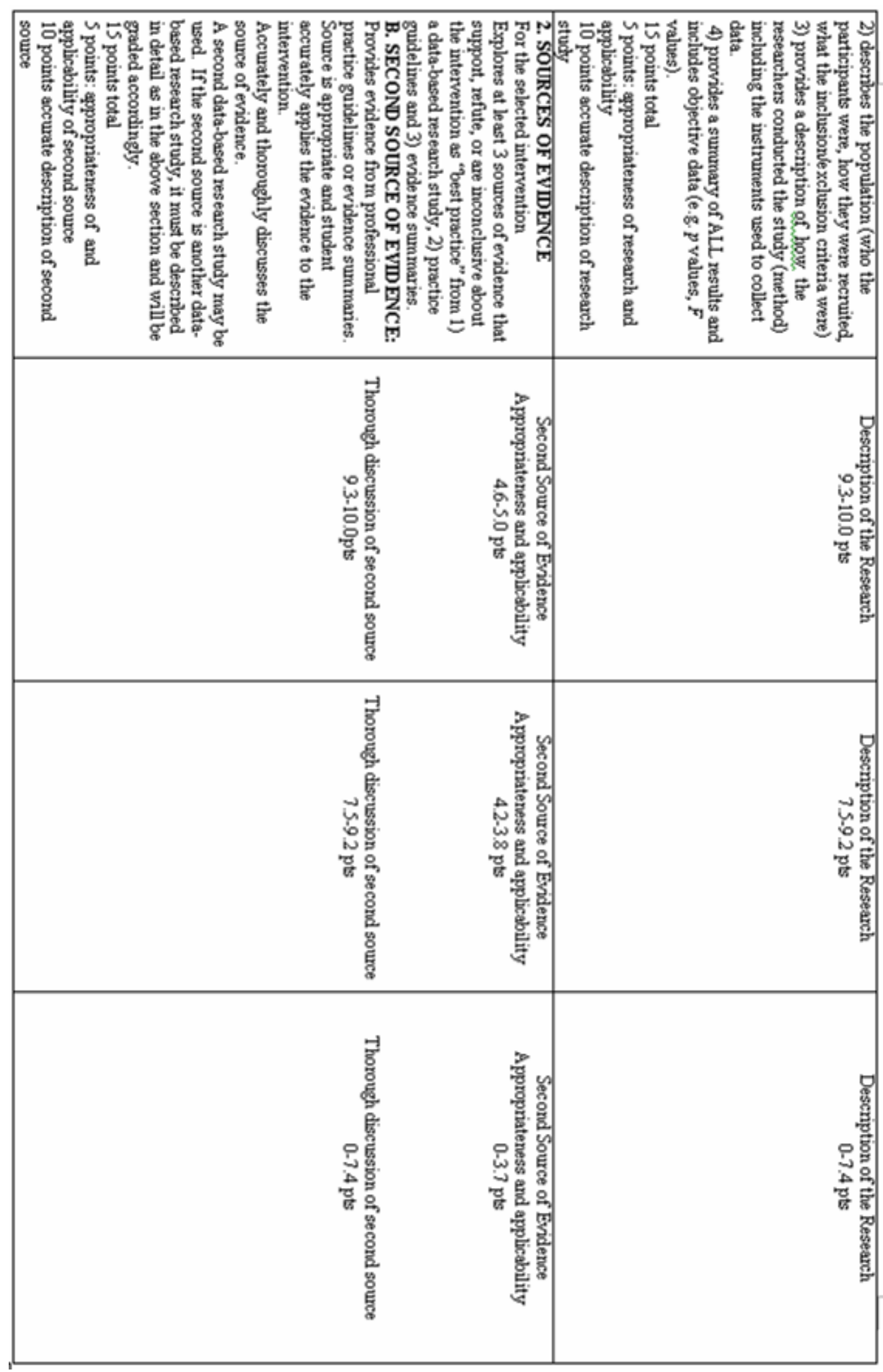




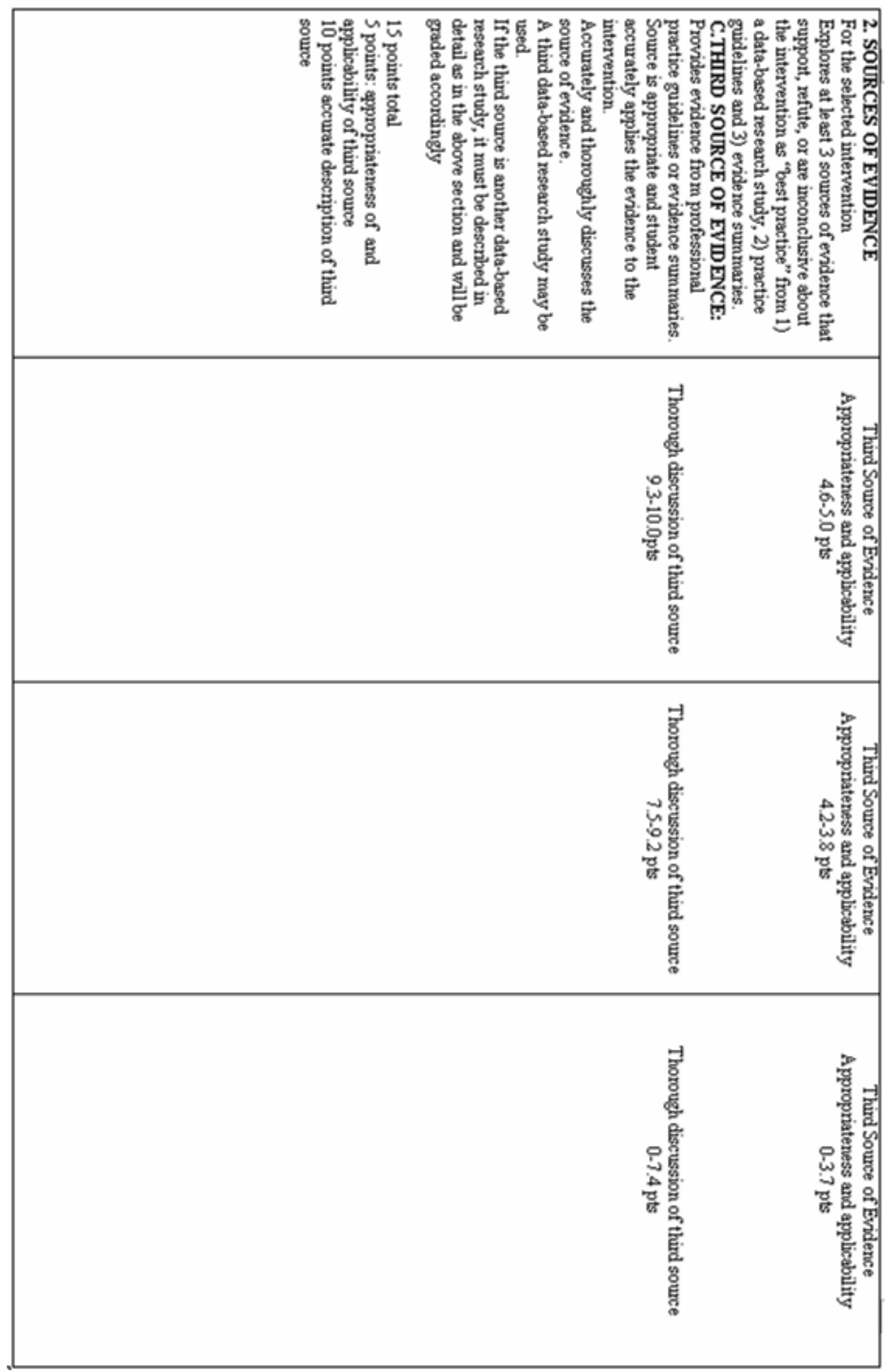




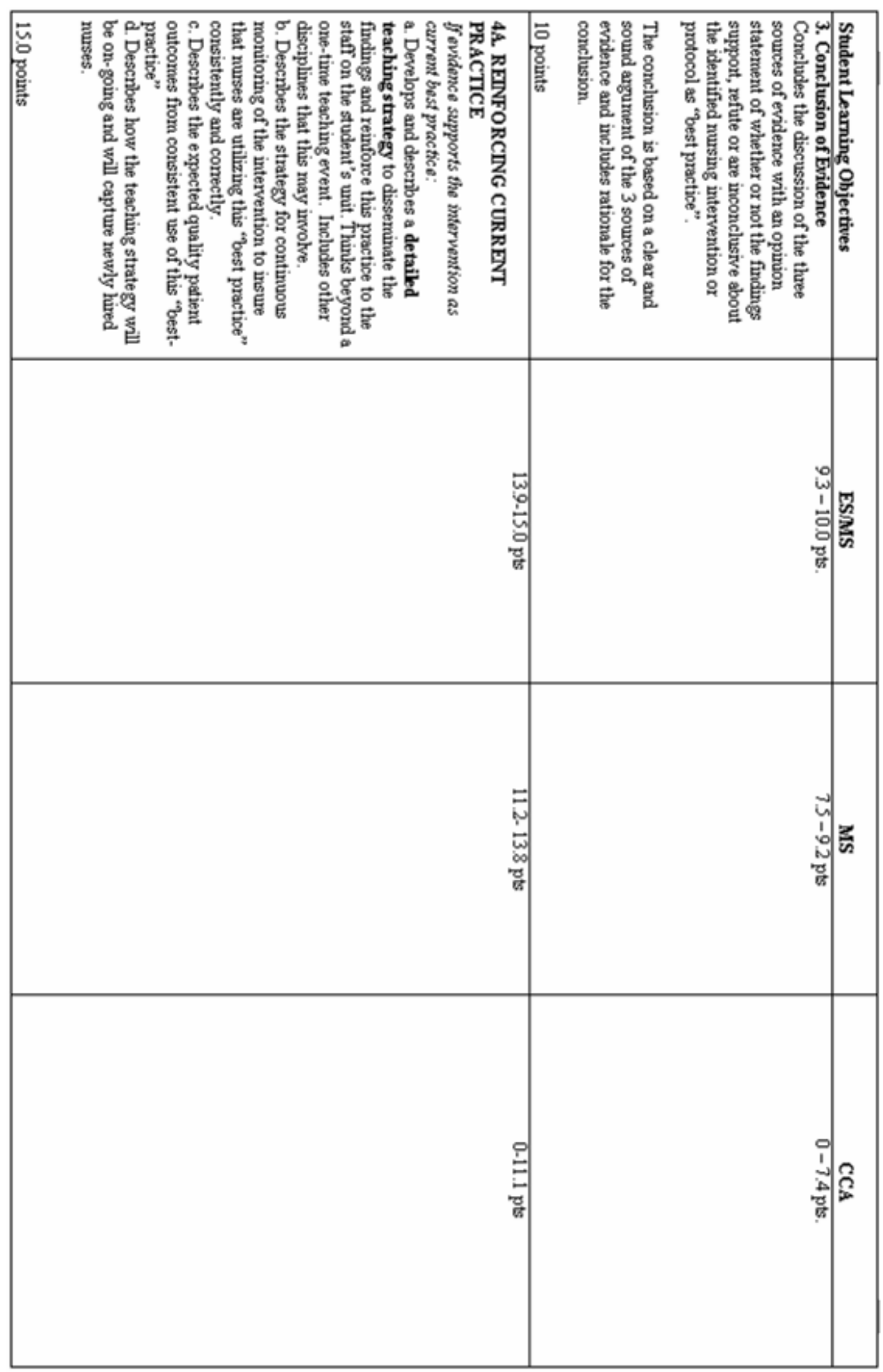




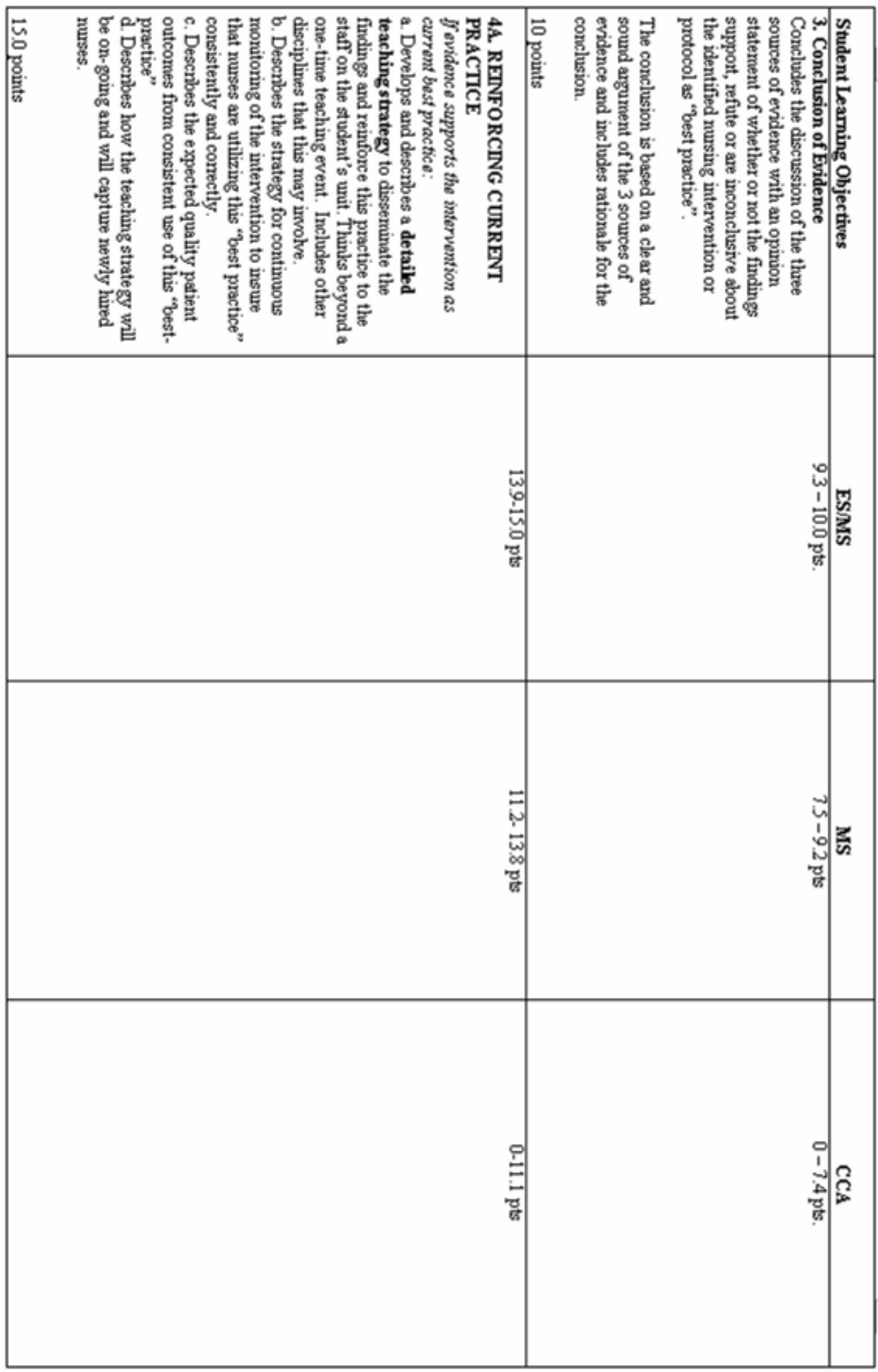




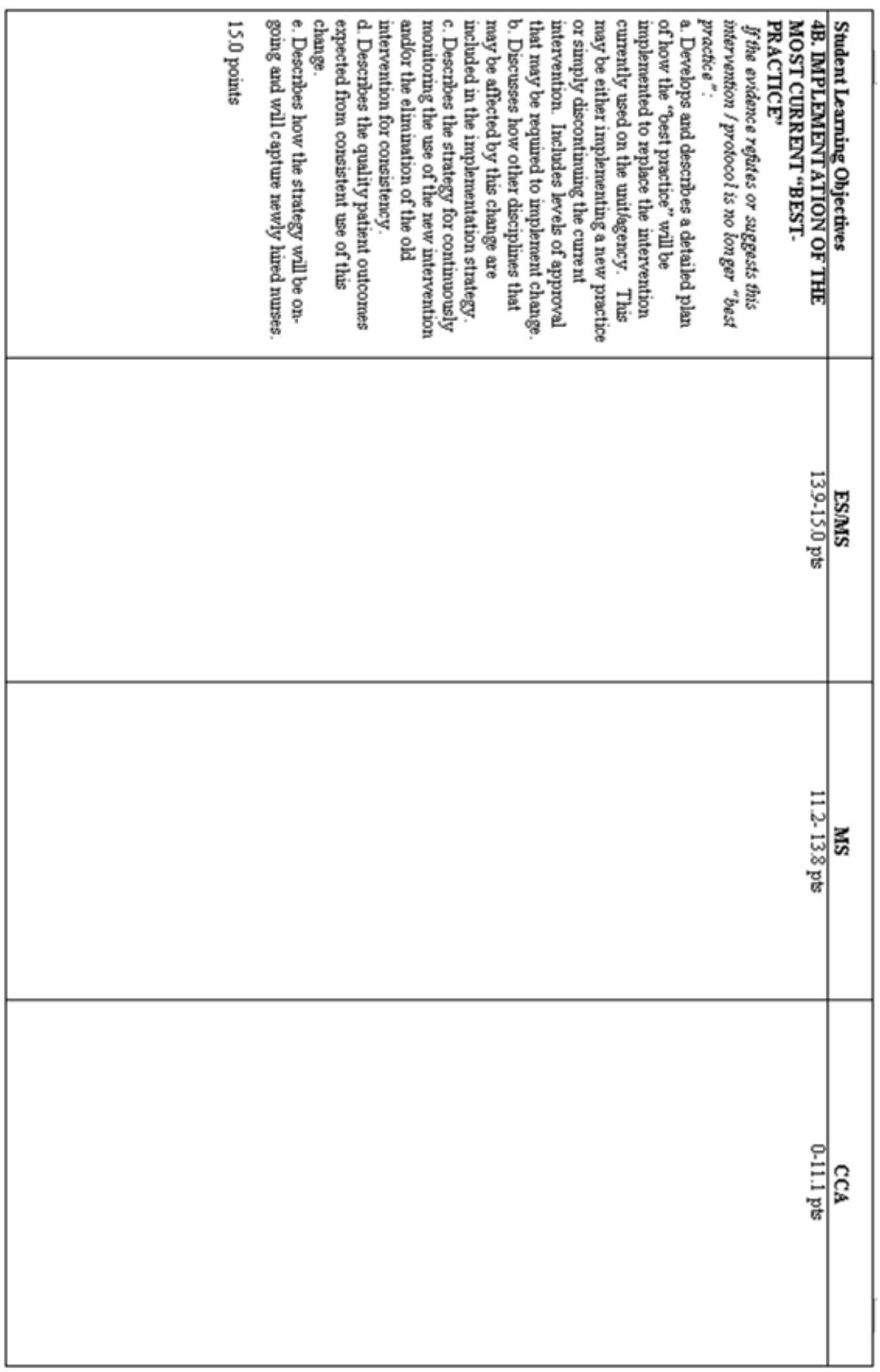




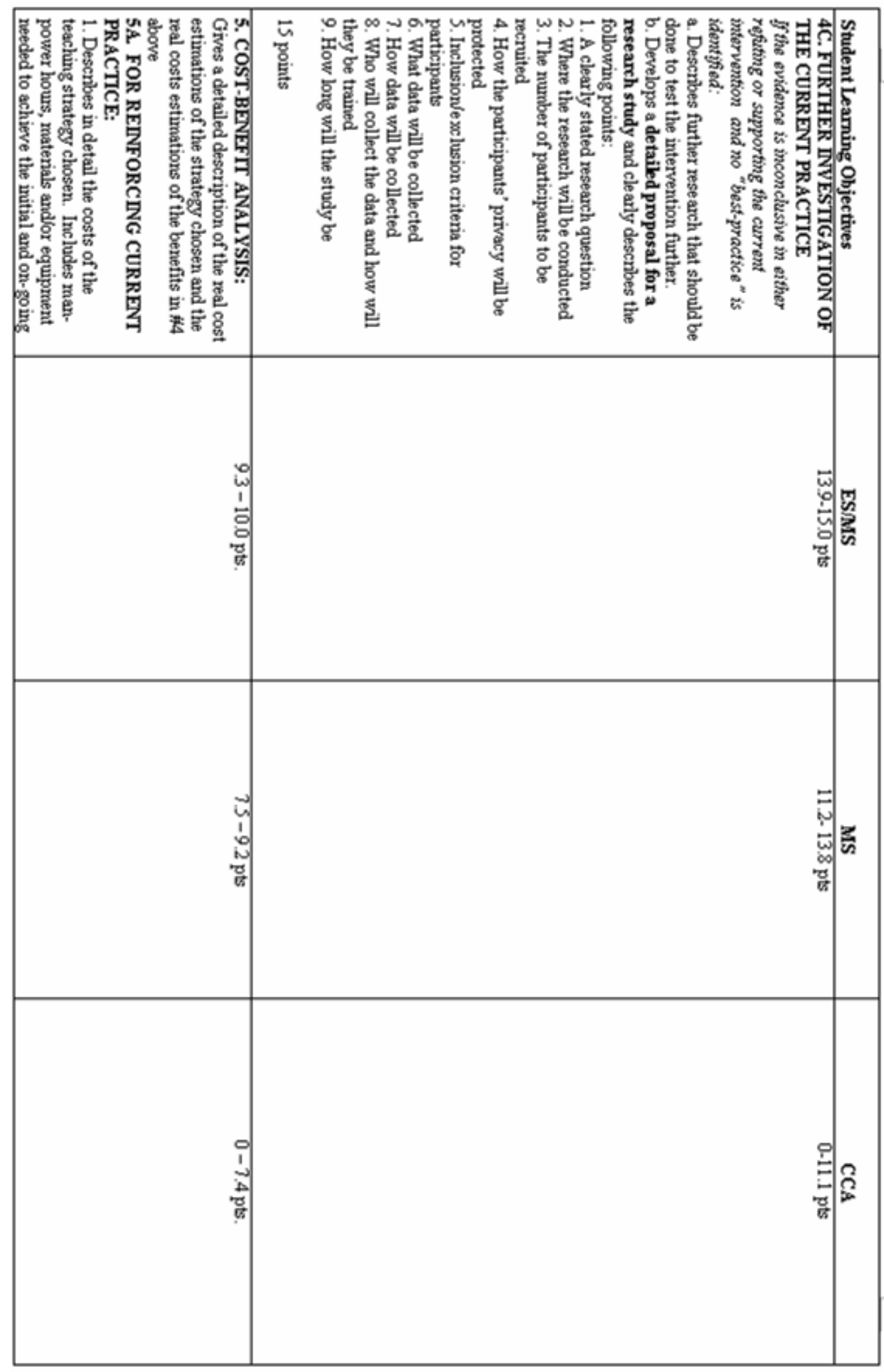




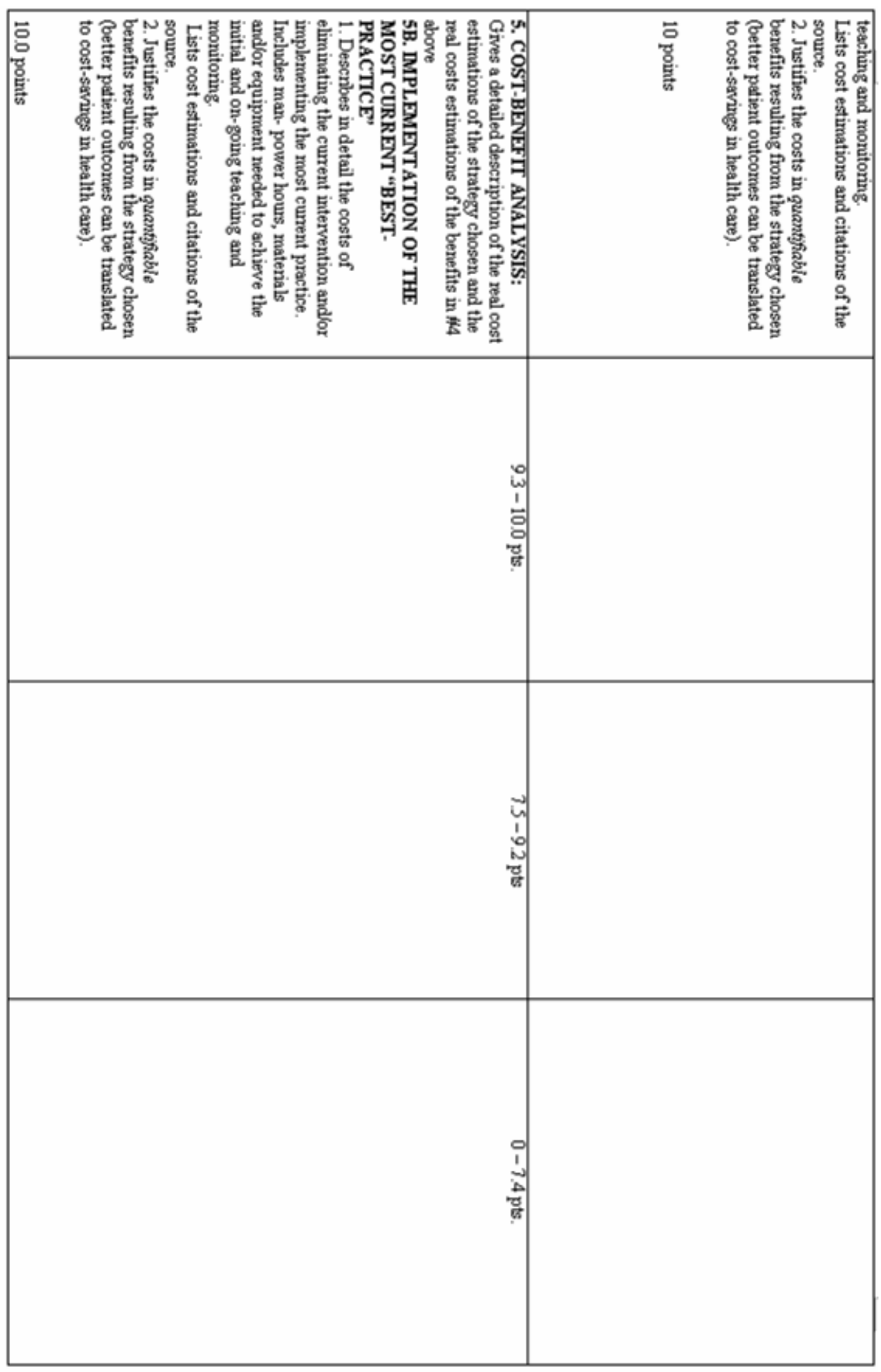




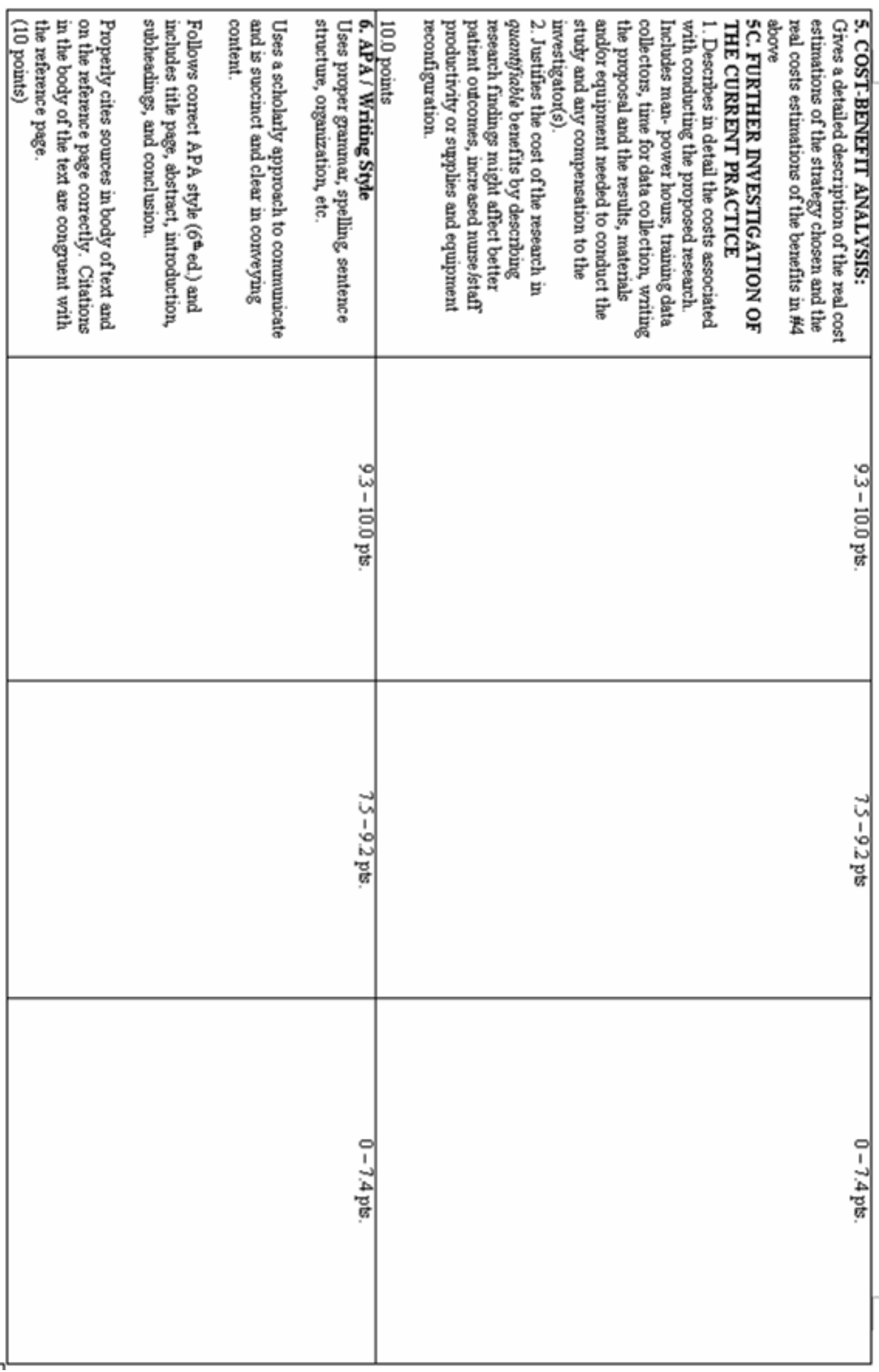




\section{ADVICE ON WRITING FORMAL SCHOLARLY PAPERS}

In response to common mistakes in written assignments reported by faculty, I have compiled a few tips to assist you in writing. You are advised to review these as you are writing your Synthesis Paper. Errors of the nature listed below will result in loss of points.

1. Formal papers (including those is APA format) require a Title page, Abstract page, an introduction (though you do not title it as such) and a conclusion. These are basic writing skills with which you should all be familiar.

2. Remember to use complete sentences. Do not write in the language that is used in charting. Do not use slang or colloquialisms.

3. Stay in the past tense as you refer to events regarding patient care. Present tense is appropriate when writing about timeless material such medications, pathophysiology but not when writing about the patient. Your experiences with the patient occurred in the past.

4. This is a nursing paper and therefore scientific language should be used for explanations. You can assume that your audience are health-care/nursing professionals. Example of what NOT to do: "the lungs can't get enough oxygen into the body". Correct: "Oxygenation is impaired".

5. Avoid the use of "I". Papers are written in a formal third person approach. You should not write in detail about superfluous interactions between the author and the subject.

6. Avoid using quotations!!! Let's repeat that. Avoid using quotations !!! Quotations do not tell the reader (in this case your instructor) that the writer (you) understands the material or has the requisite knowledge to express him/herself in his/her own words.

Quotations mostly tell the reader the author knows how to copy material from a source.

Reserve quotations for those little phrases or bits of material that can only be expressed most effectively by using the referent author's own words. For example: "We have nothing to fear but fear itself" (Roosevelt, 1941) or "Ask not what your country can do for you: Ask what you can do for your country" (Kennedy, 1961).

Best word of advice; don’t use any quotations!

7. Avoid using Websites for your references. Most Web-based sites are written for lay people. You should use medical /nursing textbooks or scholarly journals as the source of your information! National health organization websites (American Cancer Society, American Lung Association, American Heart Association), professional organization websites (ANA, KNA, American Association of Critical Care Nurses) or government-based websites are acceptable for quoting facts and figures. Web$\mathrm{MD}$ and Wikapedia are examples of unacceptable sites.

8. Examine your writing style. Clarity equates with understanding. Long sentences begin to lose meaning ("breath pauses"). Appropriate paragraph breaks allow the reader to know you are moving into a new area of thought.

9. ANTHROPOMORPHISM: This is giving "human characteristics" to inanimate objects. Example: "The heart trys to work harder" "The lungs have issues with other body parts". Read the APA manual, pgs 38-39. Again, using scientific language is the key to avoiding this pitfall.

10. When critiquing research, you do not use the article title in the body of your text. You are critiquing a "study" not an article and you r are referring to the "researchers" not the authors. The complete citation is on your reference page. Once you've introduced the study (i.e. "A study by

(2005) found that elderly patients underreport pain") you do not have to cite the authors after every passage; your reader knows that you are critiquing this study. 
11. Please review how to reference "chapters in an edited book" (most textbooks). This can be found on pg. 252 of the APA manual. Book editors are not the authors. Give credit to the chapter author for his/her intellectual property.

12. Please review page 12 in the APA manual on Abstracts. Abstracts and Introductions are very different.

13. Don't just list things; explain them! 


\section{Final Papers \\ Phil 535/635, spring 2012}

\section{Undergrads (and grads with 3 or fewer $300+$ PHIL courses who talk to me about this and prefer to do two papers instead of one):}

The midterm paper is worth $25 \%$ of your course grade. This is a major paper of between 7 and 10 pages (typed in something like 12-point Times New Roman - i.e., about this size - with default margins and double-spaced). The paper is due February 23 by 4:15 p.m.

You may, but need not, do outside research. The most important thing is for you to be critically engaging the material and defending a significant philosophical thesis. You should not think of yourself primarily as writing about a topic. You should think of yourself primarily as answering a question or defending a thesis. Obviously, the thesis is about something, and you have to make that clear. But it is not a philosophical paper unless you are defending a thesis about that topic.

Any subject covered in any of the texts in the first half of the course is fair game, with the caveat that you should not go too far out on a limb (e.g. in esoteric Lockean studies), since you'll be out on your own perhaps more than you'd like.

Your term paper will be graded on the following criteria:

- Issue identification: you identify a significant philosophical problem or locus of significant disagreement among theories.

- Structure: your paper has a coherent structure including setting up the problem, pursuing one or more answers to that problem, giving reasons in favor of or against those answers, and clearly proposing and defending a solution.

- Argumentation: this is linked to structure but it goes more to the content of what you say in each of those elements of the paper. One thing to focus on is that you use examples only to illustrate arguments - examples themselves, like questions, are not arguments.

- Writing: clarity, grammar, and spelling all count - aim at precision and economy in language.

- Due diligence: you must spell the names of our authors and their main arguments correctly, you must spell my name correctly, you must quote and cite accurately. This is a professional paper and it must adhere to professional standards.

Outside research is not required. It may help. But please bear in mind that the quality of a philosophy paper is typically unrelated to the sheer amount of stuff you know. It's not what you know, it's how you argue for the thesis; it's how resourceful you are in thinking of reasons or implications, and applying them judiciously to the case; it's how insightfully you can glean relevant considerations from examples; it's whether you can raise and reply to criticisms of your arguments. Insofar as outside research helps with these things, then go for it. But don't substitute outside research for these things. 


\section{Topic suggestions}

You can write on a topic other than one of these but you might want to discuss it with me before you get started in earnest.

If you're trying to think of paper idea, one or more of the following strategies may be especially useful:

- compare-and-contrast: take a particularly salient question and try to get to the bottom of a disagreement about that question between two or more authors, with the aim of determining who, if either, is right;

- exegesis: since we have read Locke carefully, use your expertise to try to get to the bottom of Locke's meaning on some issue; you can then apply your understanding to one or more other authors or parts of Locke's text.

- extended critique or extended defense: give reasons for rejecting a thesis that is defended by one or more of our authors, and suggest or defend an alternative; or identify a controversial thesis on which one of our authors depends, and defend it;

- extrapolation/application: take key arguments from one or more authors and apply them to distinct questions, seeing whether they have plausible results there and if not whether the problems there also constitute problems with the original.

- Find the "clearlys": often authors assume something is obvious only because they have not thought carefully about it, and they say "clearly" (or suchlike) because they have no good argument for it; but upon reflection it is not obvious at all. Find a "clearly" and challenge it.

11. Try to distinguish among property, territory, and natural resources. Is a Lockean approach helpful here?

12. What is labor, and how, if at all, does it justify title? Does land differ from other property, and if so, why? (On someone else's view, or your own, or both.)

13. What, if any, is the best way to frame one or more provisos on property acquisition? (On someone else's view, or your own, or both.)

14. When, if ever, is "original appropriation required", and why?

15. Compare and contrast two or more libertarian views of property (in land), such as those of Nozick, Schmidtz, Steiner, etc.

16. Explicate and evaluate Locke's theory of the consent of the rising generation (born within the boundaries of an extant state to which their parents consented expressly). What, if any, are the roles of express and tacit consent, inheritance and land, etc. Has Locke smuggled in a parental right to bind children?

17. Carefully distinguish between property, jurisdiction, and meta-jurisdiction. How can a Lockean parse these notions? Is the Lockean account of them successful? What are the implications of this result?

18. What is society? What are some implications of its interposition between individual and state (or government)? Is this a problem for Locke's view?

19. On a Lockean view, can there be inter-state (international) obligations of distributive justice - with respect to natural resources, say? What is the scope of Lockean distributive justice?

20. What role, if any, does "original appropriation" have in political society and/or in international society? Has it disappeared, or is it still ongoing? 
Grad Students: Your term paper may be built around any of these questions as well as questions from the second half of the course, though I would also encourage you to think synoptically about questions touching on, say, land, membership, indigenous peoples, and Locke exegesis. You must do outside research (though the same caveats apply as above). 


\section{Multicultural Critical Thoughts (MCTs)}

NOTE: MCTs should be coherent, organized, typewritten essays of at least four pages and not more than 4.5 pages in length. These assignments must be typed. Hand-written papers are unacceptable. It is expected that the assignment will be your own work, and will not paraphrase or quote other sources, including web pages, without proper citation. If you do not know how to cite sources properly, please consult the professor or TA. Failure to cite sources properly is considered academic dishonesty and will result in an $F$ grade for the assignment and the possibility of disciplinary sanction or dismissal. A critical aspect of good scholarship is knowing how to gather information and use this information to bolster your own arguments. Arguments without sources are less than compelling. It is further recommended that you consult the APA Publication Manual.

When you complete these assignments, please make sure to address all the elements listed within each assignment with sufficient detail. Remember, these assignments are your opportunity to demonstrate that you understand the course concepts. Each MCT is worth 20 points (20\% of your final grade), with the lowest MCT being dropped.

\section{MCT \#1, Due February 7th}

Choose 1 (ONE) of the following:

1. Select a movie from the following website: http://www.louis-hoffmanvirtualclassroom.com/Psychology\%20Resources/Diversity_Issues/Diversity_Mov ies.htm Select a character from the movie and identify a struggle related to the course material that is endured by this individual. What are the psychological components of this struggle? Did the character effectively manage this struggle? What cultural components based upon the individual's background contributed to his or her decision making?

2. The world's highest suicide rates are reported in Sri Lanka (47 per 100,000) and Hungary (39 per 100,000). There are a number of hypotheses as to why these rates are higher than other countries in the world. Investigate internet sources and scholarly journals to explain what psychological explanations may account for these substantially high suicide rates in these two countries. Make sure you correctly cite your sources according to APA format.

3. Different ethnic minority groups have different attitudes about mental-health services. The literature presents conflicting results with regard to ethnic minority groups and mental health service utilization and outcome. Select an ethnic minority group and determine what the literature indicates about this particular group with regard to seeking mental health services, treatment outcome, drop out rates, and other factors. What barriers exist among this group? 


\section{MCT \#2, Due March 20th}

Choose 1 (ONE) of the following:

4. Chapter 7 and 8 delineate several theories that describe human motivation, behavior, and development. Select 2 theories described in the text and evaluate how well (or poorly) these theories consider the cultural backgrounds of the specified group. For example, how well does Maslow's hierarchy of needs account for Asian American culture as compared to psychoanalytic theory? Alternatively, how well does Erickson's psychosocial stages of psychosocial development apply to African American culture compared to Piaget's developmental theory?

5. Exercise 8.1 in the text (pg. 242) outlines a study addressing verbal communication between children and adults in several Asian countries and the United States. Answer the questions in exercise 8.1. The article can be found on Blackboard under course documents in the articles folder.

6. Read the article titled "Clinical Problems That Initiate Professional Help-Seeking Behaviors from Asian Americans.” This article can be found on Blackboard. Summarize the findings from this article and find an additional article that supports the findings from this article. What role does acculturation play in the reported findings? How are these findings similar or different from your own cultural background?

7. Select a culture-specific syndrome that was covered during the course. Write a description of this syndrome including history, symptom presentation, as well as what ethnic group typically endorses this phenomenon. What disorder(s) in the official classification of mental disorders (i.e. DSM-IV, ICD-10) share (s) similarities to this culture-specific syndrome? Should they be considered the same manifestations of similar problems? Why or why not? Use internet and scholarly sources to support your argument. 


\section{PSYC 366: Multicultural Psychology - WR \\ Spring 2012 - Professor}

\section{Research Paper Requirements}

\section{Purpose of this Assignment}

This assignment is intended to teach you about multicultural psychological research and to improve your writing skills.

\section{Timeline}

Pick a topic you would like to learn more about. This can be a subject we cover in class or something else. You will need to have your topic approved in advance to ensure that it is not too broad or too narrow. Your choice of topic must be submitted to Blackboard no later than $\mathbf{2} / \mathbf{9}$.

Gather your research sources. You will need to use 10 or more scholarly sources, and at least 6 sources should be empirical, peer-reviewed journal articles found in the PsychInfo or MedLine database. These articles should be specifically about multicultural issues. Internet sources are not permitted. You will submit a proposed bibliography via Blackboard in APA format no later than 2/21.

Develop a detailed outline of your paper that is at least 1.5 pages long. It should indicate where you plan to use your sources. The more details, the better. The outline is due $\mathbf{3 / \mathbf { 8 }}$ uploaded to Blackboard.

Your paper will be reviewed by a classmate on $4 / 3$. You are required to be present on that day with a reasonably complete draft of your paper. You can also use that time to ask the professor questions about your paper.

A first draft of your paper is due on $\mathbf{4 / 1 0}$ submitted to Blackboard. You must also submit a copy of the empirical articles you used to Blackboard as well. This means the whole article and not just the abstract. It is expected that you have read all articles you cite. Your paper will be reviewed and you will receive feedback via Blackboard. You will be given a grade on your paper as if it was your final draft.

Missing any of the above milestones will result in a 10\% deduction off your final paper grade, per milestone.

A final draft of your paper is due on $\mathbf{4 / 1 9}$. If you are satisfied with the grade you got on $4 / 10$ then you do not need to submit a revision. 


\section{Formatting Your Paper}

Final papers should be 6-7 pages, double-spaced, with one-inch margins and references in APA format. The page of references, title page, and abstract are not included in the page count. All pages must be numbered. All papers must be submitted to Blackboard as MS Word documents with a .doc or .docx extension Email submissions are not accepted.

\section{Papers should cover the following areas:}

- History of the issue ( $\sim 0.5$ page)

- Relevance of the issue ( 1 page)

- Current research on your issue ( 4 pages)

- Cultural differences $(\sim 0.5$ page $)$

- Cultural similarities $(\sim 0.5$ page $)$

- New directions for more research or action $(\sim 0.5$ page $)$

\section{Don't lose points on this assignment by:}

- Turning it in late (10 percent off per day late)

- Leaving out key elements (make sure you include everything listed above)

- Using internet sources (ask if you have questions about this)

- Forgetting citations for important facts (any fact you that you didn't already know must have a citation)

- Poor writing style (have someone else proofread it for you if writing is not your strength or visit the writing center)

- Writing more than the maximum amount (extra pages will not be read)

- Violating APA format requirements (you will get a zero)

- Handwritten papers are not accepted (you will get a zero)

- Submitting a WordPerfect or .rtf document (these will not be accepted)

- Plagiarizing - any sentence with 5 or more words in a row that are not your own should have quotations around them. (Warning: if you copy 1 sentence or more from another source without citing it, you will get a zero for the whole assignment)

Due Date: April 19 $9^{\text {th }}$ by 11:59 pm 


\title{
CURRICULUM VITA
}

\author{
W. Matthew Wiles \\ 150A Idlewood Ct. \\ Elizabethtown, Ky. 42701 \\ (270) 331-0191 \\ matthew.wiles2@gmail.com \\ Skype: matt.wiles11
}

\section{Education}

Ph.D. in Rhetoric and Composition: University of Louisville, Louisville, Ky. (Expected 2014)

Dissertation: "Prompting Discussion: Writing Prompts, Habits of Mind, and the Shape of the Writing Classroom." Committee: Dr. Bronwyn Williams, Dr. Joanna Wolfe, Dr. Karen Kopelson, Dr. Susan Ryan, Dr. Anne Larson

M.A. in English Studies: University of Louisville, Louisville, Ky. (2008)

Culminating Project: "Repetition of Trauma and the Mechanics of Memory in Memento and Eternal Sunshine of the Spotless Mind." Director: Dr. Aaron Jaffe

B.A. English (Creative Writing Focus): Murray State University, Murray, Ky. (2006) Summa Cum Laude

\section{Academic Employment and Teaching Experience}

Instructor of English, Elizabethtown Community and Technical College (2013-Present)

ENC 90/91: Foundations of College Writing

English 101: Writing I

English 102: Writing II

Graduate Teaching Assistant, University of Louisville (2008-2013)

English 101: Introduciton to College Composition

English 102: Intermediate College Composition

English 105: Advanced Composition for Freshmen

English 301: Introduction to English Studies

English 306: Business Writing

\section{Administrative Experience}

Assistant Director of Composition (2011-12): Mentored new composition instructors on a 
weekly basis, including observing their courses, assisting them in building course materials, and writing observation reports for the director of composition. Assisted the director of composition in the orientation and semester-long practicum course for new instructors. Planned and facilitated pedagogy workshops for part-time instructors on assignment design, sequencing, commenting, and assessment. Assessed portfolios for course credit, mediated student grievances, assisted in course scheduling, and helped to manage departmental materials (including electronic document databases, program guidelines, etc.).

\section{Writing Center Experience}

Writing Center Consultant, University of Louisville Writing Center (2007-2008): Consulted students from many disciplines on writing in a variety of genres in face-to-face tutoring sessions.

Virtual Writing Center Consultant (2007-2008): Consulted students from many disciplines, including distance-learning students, on writing using digital mediums. Students submitted and received commented drafts via email and/or live, chat-based consultations using whiteboard software.

\section{Selected Course Descriptions}

"Compocalypse." Writing I and II (Fall 2014): This course design used the theory of gamification paired with the pop-culture phenomenon of the zombie apocalypse to create a classroom that used the rhetorical situations provided by zombie film and television shows to engage students in crafting structured, effective arguments.

Business Writing (Summer, Fall 2012): Introduced students to common business writing genres (memos, business letters, proposals, etc.) by having them respond to various role-playing scenarios that evoke common workplace situations and/or problems (responding to complaints, giving good and bad news, persuading via an investment proposal, etc.). Worked with students on document design, editing for concision and clarity, and writing from within a reader-friendly ethos.

"Education, Media, and Us." Advanced Composition for Freshmen (Fall 2011; Spring 2012): Instructed students in the university's Honors program in both the writing process and genre concerns of English 101 and the research writing goals of English 102.

Introduction to English Studies (Summer 2011): Prepared students entering the English major and minor. Introduced relevant forms (fiction, poetry, drama, criticism) and sub-disciplines (Rhetoric and Composition, Cultural Studies, etc.) as well as provided a primer for learning and applying literary theory. 


\section{Service and Professional Development}

"Prompting Discussion" Presentation: A presentation based on my dissertation was given at both the 2014 ECTC Faculty Convoctation and the 2014 ECTC Adjunct Faculty Night. The presentation focused on how writing prompts can be effectively used to both facilitate classroom writing and stimulate overall student learning. August 2014.

"Capturing Student Attention with Screen Capture Software" Presentation for ECTC Technology Day 2014: This presentation informed instructors on how they can use screen-capture software like Snagit and Camtasia to enhance their pedagogy, open up new possibilities for evaluation, and create new tools for students.

General Education Assessment Committee: Worked with English Department Coordinator and with members of General Education assessment Committee at the University of Louisville to ensure that ECTC's English and Composition courses are being held to standards that allow for transfer credit and an easier transition from ECTC to a four-year institution like the University of Louisville.

"User-Friendly Collaborative Studying" Workshop for School of Interdisciplinary and Graduate Studies' (SIGS) PLAN Initiative for graduate students: Addressed how graduate students can use accessible, web-based software like Google Docs to facilitate collaborative writing and studying among graduate students who are doing everything from studying for comprehensive exams to collaborating on conference abstracts and presentations. October 2011 and August 2012

Assessor, General Education Assessment Project for the General Education Curriculum Committee (GECC): Evaluated effectiveness of selected student papers from across the university in meeting institutional critical thinking and cultural diversity goals for required and elective courses in the general education curriculum. September 2011, and May 2012

Executive Committee, English Graduate Student Organization. 2011-12: facilitated elections for graduate student representatives to various departmental and institutional committees, mediated in communications between professors and graduate students, oversaw EGO budget for special events. 2011-12

Graduate Student Mentor: Served as peer mentor for new PhD students entering the Rhetoric and Composition Program at the University of Louisville. 2011-12.

Tech Committee, Thomas R. Watson Conference on Rhetoric and Composition: Met technical needs for presenters at the Thomas R. Watson Conference. Assisted in set-up and take-down of equipment for special exhibits and workshops. 2008 \& 2010 .

Panel Chair, Thomas R. Watson Conference. 2008. 


\section{Conference Presentations}

"Compocalypse Now: Risk and Reward in Teaching the Art of Rhetoric through Gamification" (co-presentation with Maggie Brown, ECTC). The $66^{\text {th }}$ Conference on College Composition and Communication. Tampa, FL, March 2015.

"Outsiders, Insiders, and the Double Binds Between Them: An Analysis of UpperDivision Nursing Students Writing Between The University and the Workplace." The $64^{\text {th }}$ Conference on College Composition and Communication. Las Vegas, NV: March 2013.

"Blogging Across the Disciplines: A Consideration of Scholarly Blogs and the Teaching of Composition." Thomas R. Watson Conference on Rhetoric and Composition, Louisville, Ky: October 2012.

"Prompting Discussion: Using Written Assignment Instructions to Teach Disciplinary Difference." The 63rd Conference on College Composition and Communication. St. Louis, MO: March 21-24, 2012.

"Breaking History: Science Fiction as Social/Mental Intervention" The 40h Annual Louisville Conference on Literature and Culture since 1900, Louisville, Ky: February 2012.

"Posthumous Futures and Cultural Criticism in Science Fiction" The 39th Annual Louisville Conference on Literature and Culture since 1900, Louisville, Ky: February 2011.

"Mythbusting in the Composition Classroom: Banishing the Myth of Standard Written English." Thomas R. Watson Conference on Rhetoric and Composition, Louisville, Ky: October, 2010

"Narratives From the Gutters: The Comic Book as a Transgressive and Transformative Space." The 38th Annual Louisville Conference on Literature and Culture since 1900, Louisville, Ky: February 2010.

"Speech Craft or Crafty Speaking: The 'problem' of Rhetoric in the 2008 Election." The University of Tennessee at Chattanooga First Annual Graduate and Undergraduate Student Conference on Literature, Composition and Rhetoric, Chattanooga, Tenn.: March 28, 2009

"Forgetful Lovers: Imprisoned Minds and the Repetition of Trauma in Eternal Sunshine of the Spotless Mind and Memento" Kentucky Philological Association, Louisville, Ky: February 2008.

\section{Select Graduate Coursework}

Composition and Pedagogy

Teaching College Composition (Bronwyn Williams)

Responding to Student Writing (Min-Zhan Lu) 
Composition Theory and Practice (Min-Zhan Lu)

Research Methods in Composition (Joanna Wolfe)

Ethnographic Research Methods (Geoffrey Cross)

Politics of Language in the Teaching and Study of Composition (Bruce Horner)

\section{Rhetoric and Literature}

Life Writing as Social Practice (Min-Zhan Lu)

Creative Nonfiction: Practices \& Pedagogy (Bronwyn Williams)

Cultural Rhetorics and Writing (Annette Powell)

History of Rhetoric (Carol Mattingly)

$19^{\text {th }}$ Century American Poetry and Prose (Susan Ryan)

Narrative Theory (Debra Journet)

Experimental Poetics and / as Pedagogy (Alan Golding)

\section{References}

Dr. Bronwyn Williams: Director of University Writing Center, University of Louisville Email: Bronwyn.williams@louisville.edu Office Phone: (502)-852-2173

Dr. Joanna Wolfe: Director Global Communications Center, Carnegie Mellon University. Email: jowolfe@andrew.cmu.edu Office Phone: (412) 268-2850

Dr. Susan Ryan: Associate Professor of English, University of Louisville.

Email: sryan@louisville.edu Office Phone: (502) 852-5920 